\title{
Advanced Earthquake Monitoring System for U.S. Department of Veterans Affairs Medical Buildings-Instrumentation
}

By Erol Kalkan, Krishna Banga, Hasan S. Ulusoy, Jon Peter B. Fletcher, William S. Leith, Shahneam Reza, and Timothy Cheng

Open-File Report 2012-1241

U.S. Department of the Interior

U.S. Geological Survey 


\section{U.S. Department of the Interior \\ KEN SALAZAR, Secretary}

\section{U.S. Geological Survey \\ Marcia K. McNutt, Director}

U.S. Geological Survey, Reston, Virginia: 2012

For product and ordering information:

World Wide Web: http://www.usgs.gov/pubprod/

Telephone: 1-888-ASK-USGS

For more information on the USGS-the Federal source for science about the Earth, its natural and living resources, natural hazards, and the environment:

World Wide Web: http://www.usgs.gov/

Telephone: 1-888-ASK-USGS

Suggested citation:

Kalkan, E., Banga, K., Ulusoy, H.S., Fletcher, J.P.B, Leith, W.S., Reza, S., and Cheng, T., 2012, Advanced earthquake monitoring system for U.S. Department of Veterans Affairs medical buildings-instrumentation: U.S. Geological Survey Open-File Report 2012-1241, $143 p$.

Any use of trade, product, or firm names is for descriptive purposes only and does not imply endorsement by the U.S. Government.

Although this report is in the public domain, permission must be secured from the individual copyright owners to reproduce any copyrighted material contained within this report. 


\section{Contents}

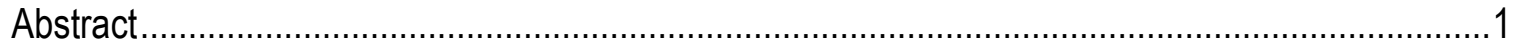

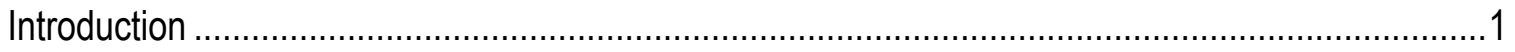

Selection of Hospital Buildings for Advanced Earthquake Monitoring .........................................2

Instrumentation Objectives...........................................................................................

Earthquake Monitoring Hardware and Installation....................................................................5

VA MEDICAL BUILDINGS ……...............................................................................

NSMP Station 8045-Anchorage, Alaska: New Hospital, Building No. B100 …….........................

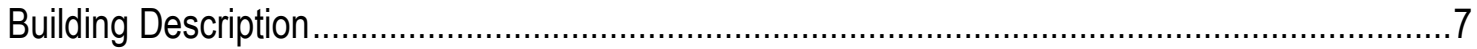

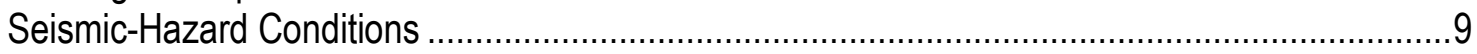

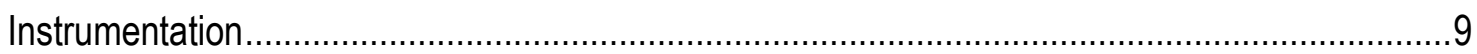

NSMP Station 1868-Palo Alto, California: Outpatient Clinic, Building No. 100 ...........................11

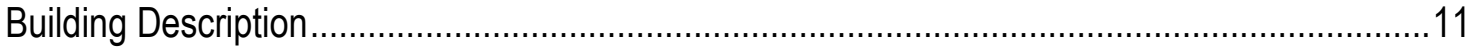

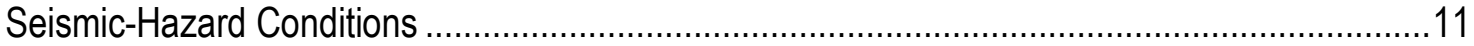

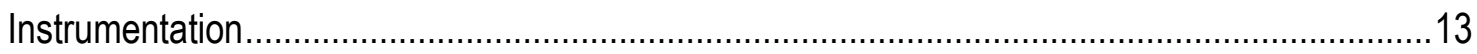

NSMP Station 1869—Palo Alto, California: Outpatient Clinic, Building No. 101 ..........................17

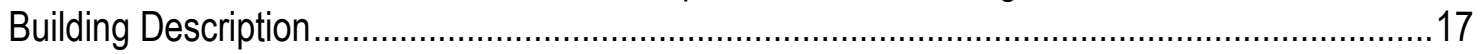

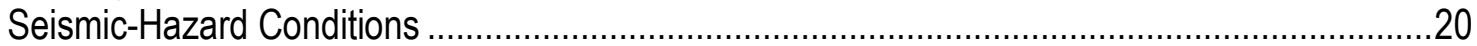

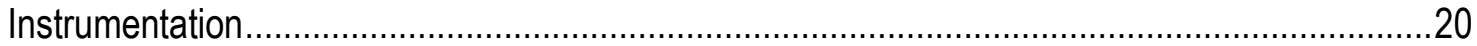

NSMP Station 1870-Menlo Park, California: Center Core Building, Building No. 334 .................22

Building Description....................................................................................................22

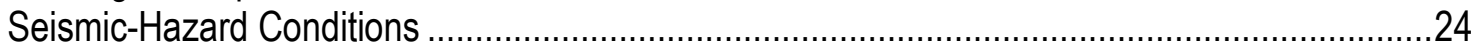

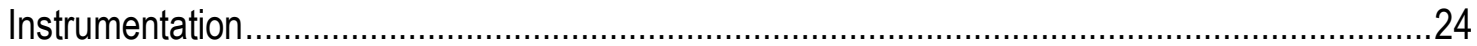

NSMP Station 1226-Livermore, California: Medical, Surgical and Neurological (MS and N),

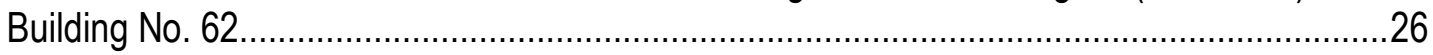

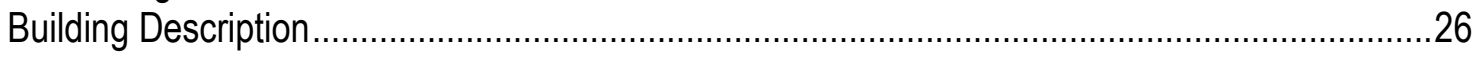

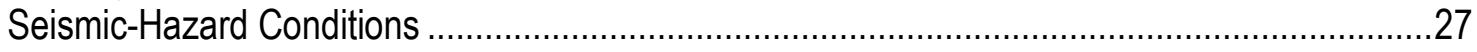

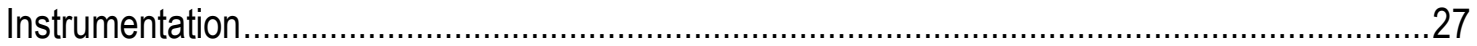

NSMP Station 1875-San Francisco, California: Ambulance Care/Clinical Support Building,

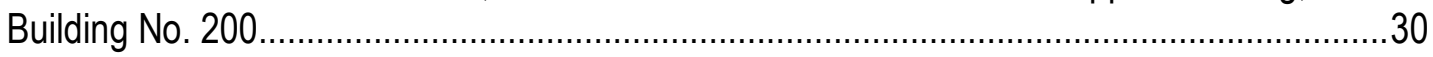

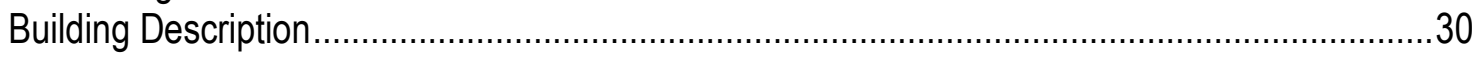

Seismic-Hazard and Soil Conditions ...............................................................................

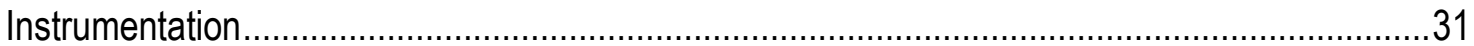

NSMP Station 5483-Los Angeles, California: Outpatient Clinic, Building No. 1 ..........................34

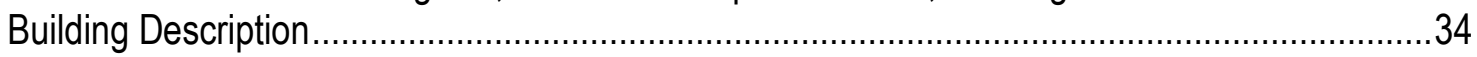

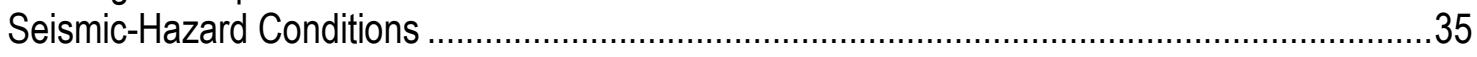

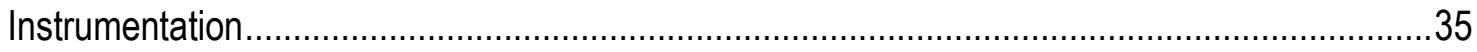

NSMP Station 5478-Sepulveda, California: Outpatient Clinical Care, Building No. 10 ................38

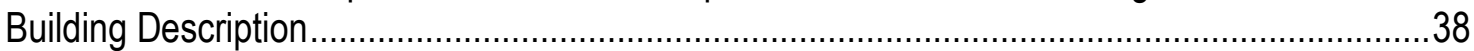

Seismic-Hazard Conditions ........................................................................................ 40

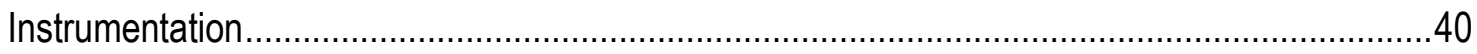

NSMP Station 5082-West Los Angeles, California: Main Hospital, Building No. 500..................42

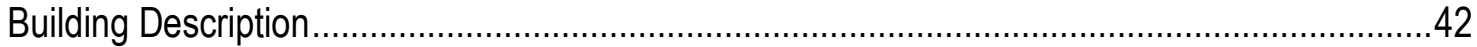

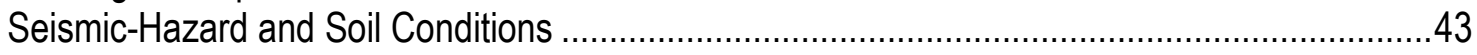

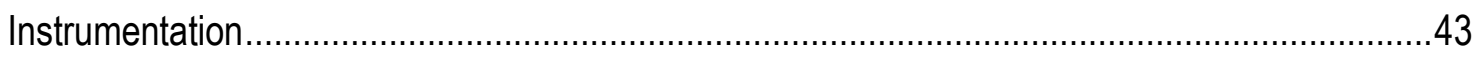

NSMP Station 5485-West Los Angeles, California: Research Lab., Building No. 114 „...............47 


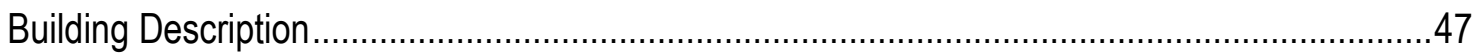

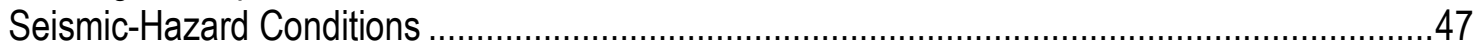

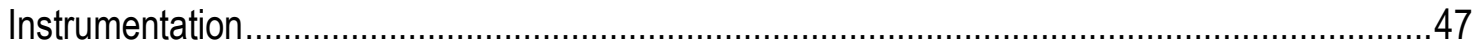

NSMP Station 5105-San Diego, California: Main Hospital, Building No. 1................................50

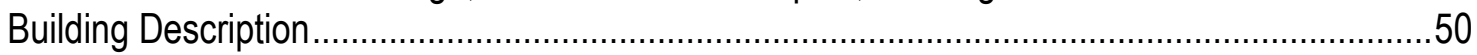

Seismic-Hazard and Soil Conditions ………….............................................................51

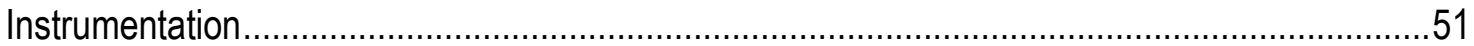

NSMP Station 7415-Marion, Illinois: Main Hospital, Building No. 1.........................................55

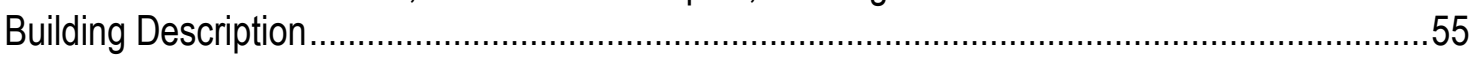

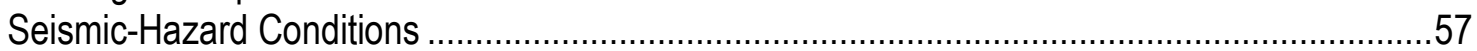

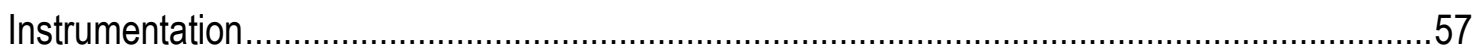

NSMP Station 7402-Poplar Bluff, Missouri: Medical Nursing PCC, Building No. 1 .....................60

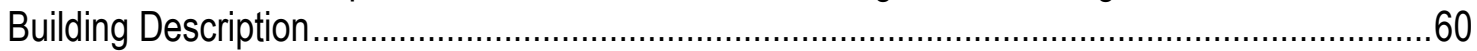

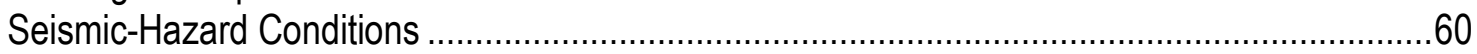

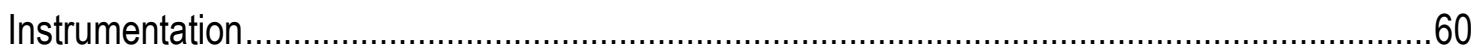

NSMP Station 7235-Fort Harrison, Montana: Main Hospital, Building No. 154 ..........................64

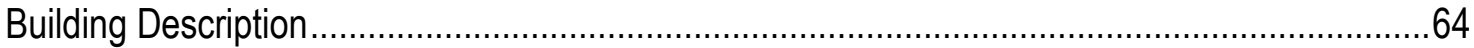

Seismic-Hazard and Soil Conditions ............................................................................67

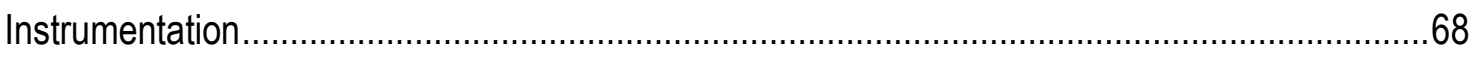

NSMP Station 2028-Reno, Nevada: New Bed Building/Clinic, Building No. 12 .........................71

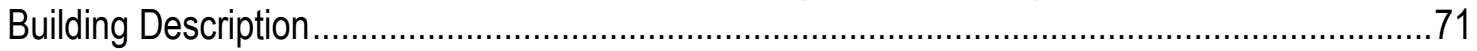

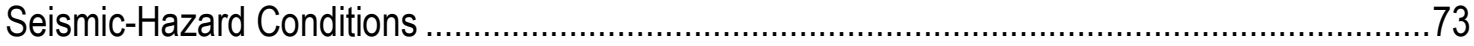

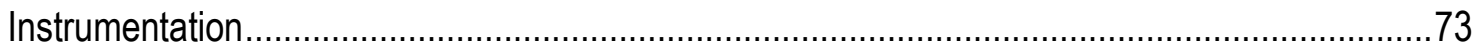

NSMP Station 3096-San Juan, Puerto Rico: Nursing, Building No. 10 ....................................76

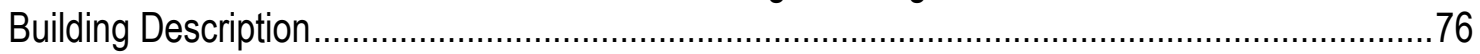

Seismic-Hazard Conditions ........................................................................................

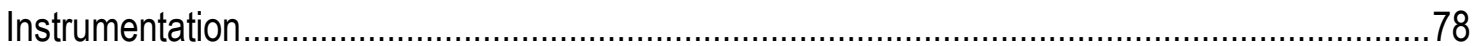

NSMP Station 3095-San Juan, Puerto Rico: New Bed Tower, Building No. B30 ………............80

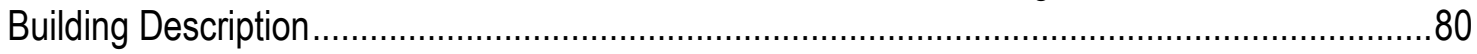

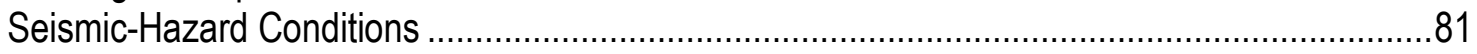

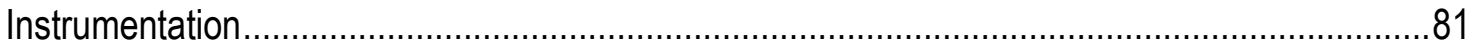

NSMP Station 7413-Oklahoma City, Oklahoma: Main Hospital, Building No. 1 .........................83

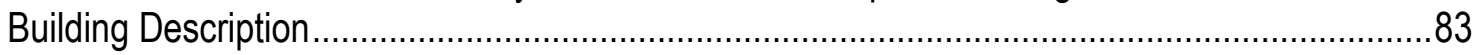

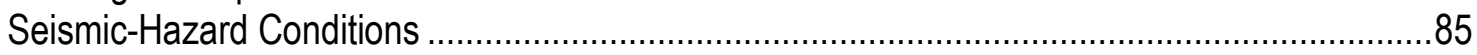

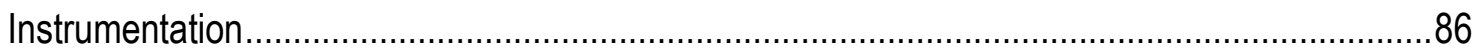

NSMP Station 7057-Roseburg, Oregon: Main Hospital, Building No. 1 ....................................90

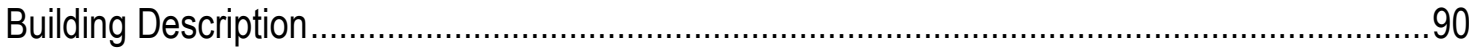

Seismic-Hazard and Soil Conditions ..............................................................................90

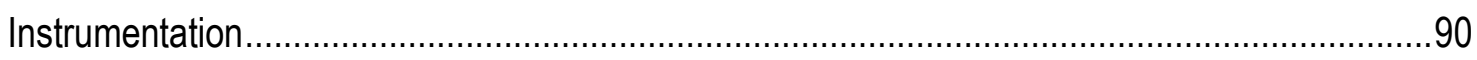

NSMP Station 7059—White City, Oregon: Primary Care Clinic, Building No. 201 ........................97

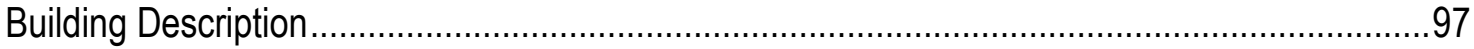

Seismic-Hazard Conditions .........................................................................................

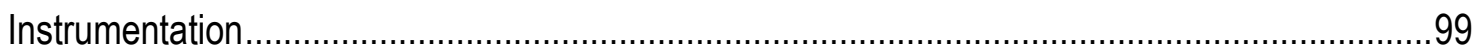

NSMP Station 2191-Portland, Oregon: Main Hospital, Building No. 100 ….............................101

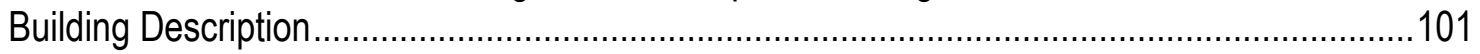

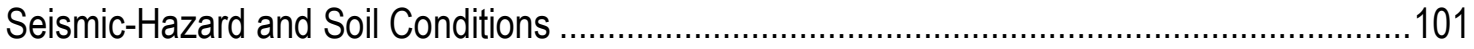

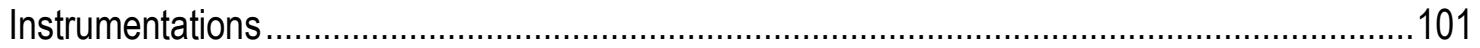


NSMP Station 2561-Charleston, South Carolina: Main Hospital, Building No. 1 ......................105

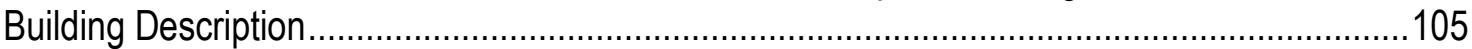

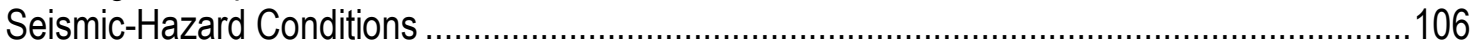

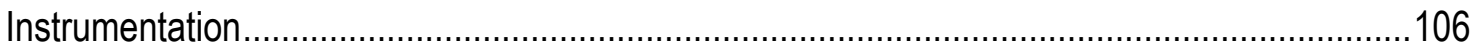

NSMP Station 7411-Memphis, Tennessee: Spinal-Chord Injury, Building No. 7 .....................110

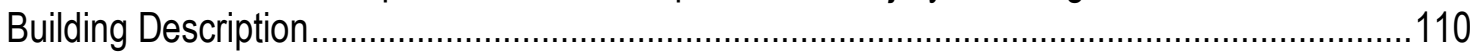

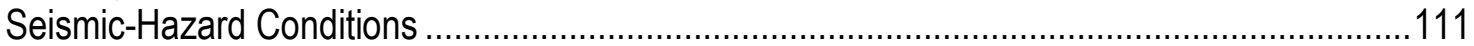

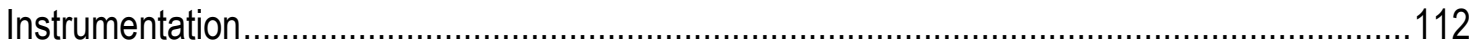

NSMP Station 7410-Memphis, Tennessee: Bed Tower, Building No. 1A ...............................115

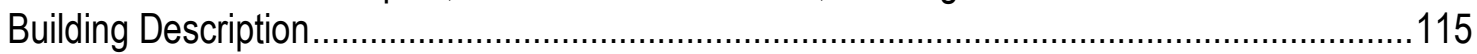

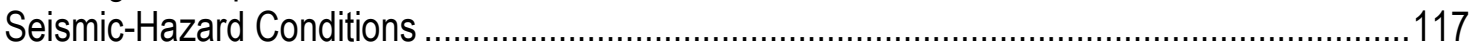

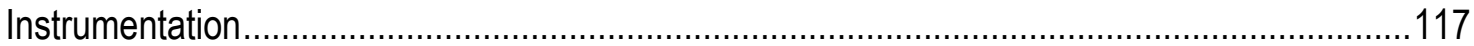

NSMP Station 7237-Salt Lake City, Utah: Main Hospital, Building No. 14.............................121

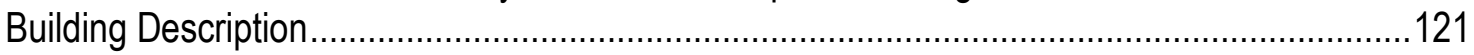

Seismic-Hazard and Soil Conditions .............................................................................121

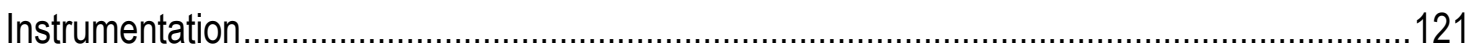

NSMP Station 7600-Richmond, Virginia: Main Hospital, Building No. 500 .............................125

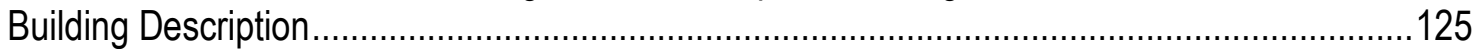

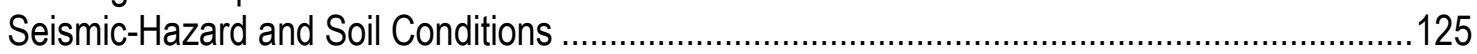

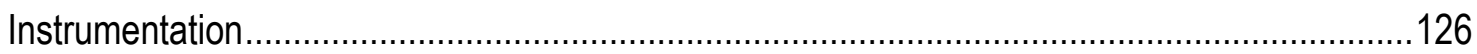

NSMP Station 2129-Seattle, Washington: Main Hospital Diagnosis and Treatment Wing,

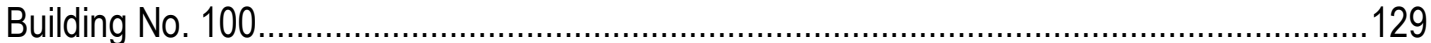

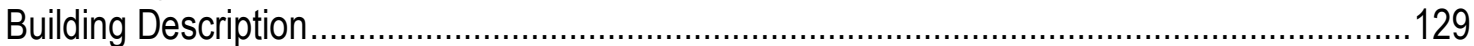

Seismic-Hazard and Soil Conditions ............................................................................131

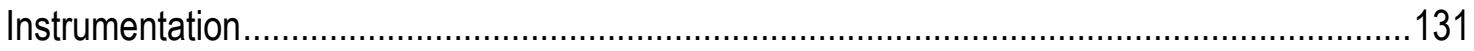

NSMP Station 7061-Vancouver, Washington: Barnes Rehabilitation Building, Building No.

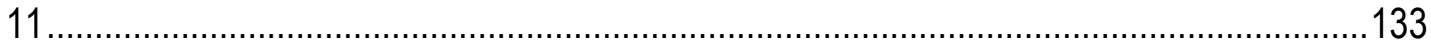

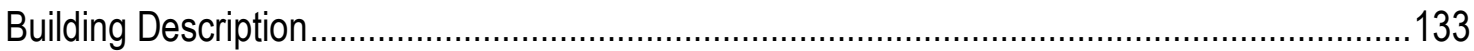

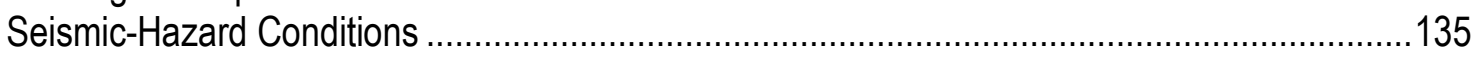

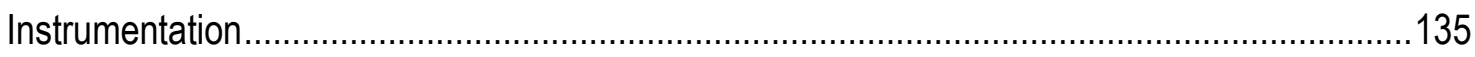

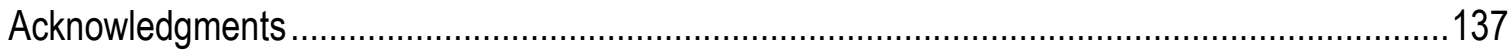

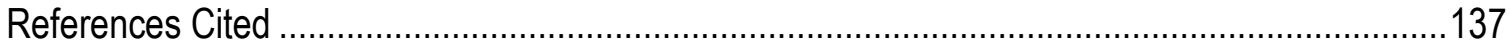

Appendix A: Hardware for Earthquake Monitoring ............................................................138

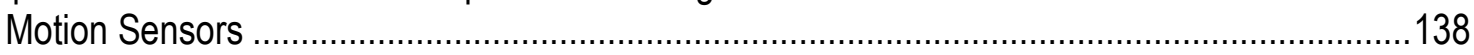

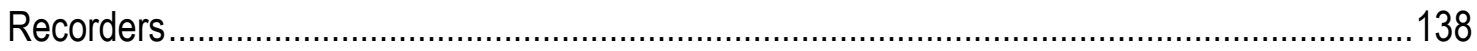

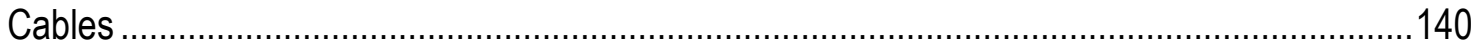

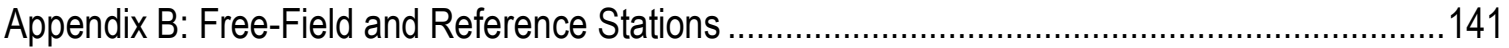

\section{Tables}

1. List of Veterans Affairs hospitals identified for use of an advanced earthquake monitoring system.

\section{Figures}

1. During the San Fernando, California, earthquake in February 1971, buildings 1 and 2 (older unreinforced masonry structures) of the Veterans Hospital collapsed and killed 49 people. 
2. Seismic hazard map of the conterminous United States, Alaska, and Puerto Rico, ...............3

3. Photograph of a typical free-field station in West Los Angeles Veterans Affairs Medical

Center, California.

4. Photograph of Building B100, Anchorage Veterans Affairs Medical Center, Alaska (areal view). ..............................................................................................................

5. Photograph of Building B100, Anchorage Veterans Affairs Medical Center, Alaska (looking north)

6. Photograph of Building B100, Anchorage Veterans Affairs Medical Center, Alaska (looking northeast).

7. Photograph of steel braces providing additional lateral stiffness in Building B100, Anchorage Veterans Affairs Medical Center, Alaska.

8. Diagram of sensor layout showing 21 sensors in Building B100 of the Anchorage Veterans Affairs Medical Center, Alaska.

9. Photograph of Building 100, Palo Alto Veterans Affairs Medical Center, California (front view). ..................................................................................................................

10. Photograph of Building 100, Palo Alto Veterans Affairs Medical Center, California (side view).

11. Photograph of Building 100, Palo Alto Veterans Affairs Medical Center, California

12. Photograph of Building 100, Palo Alto Veterans Affairs Medical Center, California (looking northwest).

13. Diagram of sensor layout showing a total of 24 sensors in Building 100 of the Palo Alto Veterans Affairs Medical Center, California (page 1 of 2; see also fig. 14).

14. Sensor layout showing a total of 24 sensors in Building 100 of the Palo Alto Veterans

Affairs Medical Center, California (page 2 of 2; see also fig. 13).

15. Photograph of Building 101, Palo Alto Veterans Affairs Medical Center, California (looking east).

16. Photograph of Building 101, Palo Alto Veterans Affairs Medical Center, California

17. Photograph of Building 101, Palo Alto Veterans Affairs Medical Center, California (looking southwest).

8. Photograph of Building 101, Palo Alto Veterans Affairs Medical Center, California (looking east).

19. Photograph showing 4-story high connecting structure between Building 100 and Building 101 Palo Alto Veterans Affairs Medical Center, California.

D. Diagram of sensor layout showing a total of 12 sensors in Building 101, Palo Alto Veterans Affairs Medical Center, California.

21. Photograph of Building 334, Menlo Park Veterans Affairs Medical Center, California (front view).

22. Photograph of Building 334, Menlo Park Veterans Affairs Medical Center, California (looking west).

23. Photograph of Building 334, Menlo Park Veterans Affairs Medical Center, California (looking north).

24. Diagram of sensor layout showing a total of 24 sensors in Building 334, Menlo Park Veterans Affairs Medical Center, California.

25. Photograph of Building 62, Livermore Veterans Affairs Medical Center, California (front view). 
26. Photograph of Building 62, Livermore Veterans Affairs Medical Center, California (back side of the building looking north).

27. Diagrams of sensor layout showing 24 sensors in of Building 62, Livermore Veterans Affairs Medical Center, California (page 1 of 2; see also fig. 28).

28. Diagrams of sensor layout showing 24 sensors in of Building 62 , Livermore Veterans Affairs Medical Center, California (page 2 of 2; see also fig. 27).

29. Photograph of free-field station (NSMP Station No. 1874) at Livermore Veterans Affairs Medical Center, California.....................................................................................30

30. Photograph of Building 200, San Francisco Veterans Affairs Medical Center, California........31

31. Diagram of sensor layout showing 16 sensors in the Building 200 of the San Francisco Veterans Affairs Medical Center, California.

32. Photograph of Building 1, Los Angeles Veterans Affairs Medical Center, California (side view).

33. Photograph of Building 1, Los Angeles Veterans Affairs Medical Center, California (looking east; back side view).

34. Diagrams of sensor layout showing 24 sensors in Building 1, Los Angeles Veterans Affairs Medical Center, California (page 1 of 2; see also fig. 35).

35. Diagrams of sensor layout showing 24 sensors in Building 1, Los Angeles Veterans Affairs Medical Center, California (page 1 of 2; see also fig. 35).

36. Photograph of Building 10, Sepulveda Veterans Affairs Medical Center, California (front view).

37. Photograph of Building 10, Sepulveda Veterans Affairs Medical Center, California (looking north).

38. Photograph of Building 10, Sepulveda Veterans Affairs Medical Center, California (side

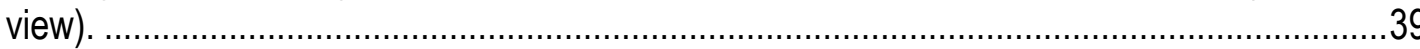

39. Photograph of Building 10, Sepulveda Veterans Affairs Medical Center, California (side view).

40. Diagram of sensor layout showing 24 sensors in Building 10 of the Sepulveda Veterans Affairs Medical Center, California.

41. Photograph of Building 500, West Los Angeles Veterans Affairs Medical Center, California (side view).

42. Photograph of Building 500, West Los Angeles Veterans Affairs Medical Center, California (looking northwest).

43. Diagrams of sensor layout showing 24 sensors in Building 500 of the West Los Angeles Veterans Affairs Medical Center, California (page 1 of 2; see also fig. 44).

44. Diagrams of sensor layout showing 24 sensors in Building 500 of the West Los Angeles Veterans Affairs Medical Center, California (page 2 of 2; see also fig. 43).

45. Photograph of Building 114, West Los Angeles Veterans Affairs Medical Center, California.

46. Photograph of Building 114, West Los Angeles Veterans Affairs Medical Center, California (looking southeast).

47. Diagram of sensor layout showing 10 sensors in Building 114 of the West Los Angeles Veterans Affairs Medical Center, California.

48. Photograph of Building 1, San Diego Veterans Affairs Medical Center, California (front view).

49. Diagrams of sensor layout showing 60 sensors in Building 1 of the San Diego Veterans Affairs Medical Center, California (page 1 of 3; see also figs. 50 and 51). 
50. Diagrams of sensor layout showing 60 sensors in Building 1 of the San Diego Veterans Affairs Medical Center, California (page 2 of 3; see also figs. 49 and 51).....

51. Diagrams of sensor layout showing 60 sensors in Building 1 of the San Diego Veterans Affairs Medical Center, California (page 3 of 3; see also figs. 49 and 50).....

52. Photograph of Building 1, Marion Veterans Affairs Medical Center, Illinois (front view)..........55

53. Photograph of Building 1, Marion Veterans Affairs Medical Center, Illinois (looking southwest)

54. Photograph of free-field site at the Marion Veterans Affairs Medical Center, Illinois 56

55. Diagrams of sensor layout showing 48 sensors in Building 1 of the Marion Veterans Affairs Medical Center, Illinois (page 1 of 2; see also fig. 56). 58

56. Diagrams of sensor layout showing 48 sensors in Building 1 of the Marion Veterans Affairs Medical Center, Illinois (page 2 of 2; see also fig. 55).

57. Photograph of Building 1, Poplar Bluff Veterans Affairs Medical Center, Missouri... 60

58. Diagrams of sensor layout showing 48 sensors in Building 1 of the Poplar Bluff Veterans Affairs Medical Center, Missouri (page 1 of 2; see also fig. 59).

59. Diagrams of sensor layout showing 48 sensors in Building 1 of the Poplar Bluff Veterans Affairs Medical Center, Missouri (page 2 of 2; see also fig. 58).

60. Photograph of Building 154, Fort Harrison Veterans affairs Medical Center, Montana. 65

61. Photograph of Building 154, Fort Harrison Veterans affairs Medical Center, Montana (looking northwest; front view).

62. Photograph of Building 154, Fort Harrison Veterans affairs Medical Center, Montana (looking south).

63. Photograph of Building 154, Fort Harrison Veterans affairs Medical Center, Montana (looking west).

64. Photograph of Building 154, Fort Harrison Veterans affairs Medical Center, Montana (looking southeast).

65. Photograph of Building 154, Fort Harrison Veterans affairs Medical Center, Montana (looking northwest).

66. Diagrams of sensor layout showing 24 sensors in Building 154 of the Fort Harrison Veterans Affairs Medical Center, Montana (page 1 of 2; see also fig. 67).

67. Diagrams of sensor layout showing 24 sensors in Building 154 of the Fort Harrison Veterans Affairs Medical Center, Montana (page 2 of 2; see also fig. 66)............................70

68. Photograph of Building 12, Reno Veterans Affairs Medical Center, Nevada (front view) ........71

69. Photograph of Building 12, Reno Veterans Affairs Medical Center, Nevada (looking northeast)

70. Photograph of Building 12, Reno Veterans Affairs Medical Center, Nevada (looking northwest).

71. Diagrams of sensor layout showing 36 sensors in Building 12 of the Reno Veterans Affairs Medical Center, Nevada (page 1 of 2; see also fig. 72).

72. Diagrams of sensor layout showing 36 sensors in Building 12 of the Reno Veterans Affairs Medical Center, Nevada (page 2 of 2; see also fig. 71).

73. Photograph of Building 10, San Juan Caribbean Veterans Affairs Medical Center, Puerto Rico (side view)

74. Photograph of Building 10, San Juan Caribbean Veterans Affairs Medical Center, Puerto Rico (front view) (U.S. Geological Survey photograph by NSMP).

75. Photograph of Building 10, San Juan Caribbean Veterans Affairs Medical Center, Puerto Rico (back side view). 
76. Diagram of sensor layout showing 12 sensors in Building 10 of the Photograph of Building 10, San Juan Caribbean Veterans Affairs Medical Center, Puerto Rico.

77. Photograph of Building 30, San Juan Caribbean Veterans Affairs Medical Center, Puerto Rico (front view).

78. Photograph of Building 30, San Juan Caribbean Veterans Affairs Medical Center, Puerto Rico (side view)

79. Diagram of sensor layout showing 24 sensors in Building B30 of the San Juan Caribbean Veterans Affairs Medical Center, Puerto Rico.

80. Photograph of the Building 1, Oklahoma City Veterans Affairs Medical Center, Oklahoma (back side view).

81. Photograph of the Building 1, Oklahoma City Veterans Affairs Medical Center, Oklahoma (front view).

82. Photograph of the Building 1, Oklahoma City Veterans Affairs Medical Center, Oklahoma (entrance).

83. Photograph of the Building 1, Oklahoma City Veterans Affairs Medical Center, Oklahoma (east side view)

84. Photograph of the Building 1, Oklahoma City Veterans Affairs Medical Center, Oklahoma (west side view).

85. Diagrams of sensor layout showing 96 sensors in Building 1 of the Oklahoma City Veterans Affairs Medical Center, Oklahoma (page 1 of 3; see also figs. 86 and 87).

86. Diagrams of sensor layout showing 96 sensors in Building 1 of the Oklahoma City Veterans Affairs Medical Center, Oklahoma (page 2 of 3 ; see also figs. 86 and 87).

87. Diagrams of sensor layout showing 96 sensors in Building 1 of the Oklahoma City Veterans Affairs Medical Center, Oklahoma (page 3 of 3; see also figs. 85 and 86).

88. Photograph of Building 1, Roseburg Veterans Affairs Medical Center, Oregon (front view).

89. Photograph of Building 1, Roseburg Veterans Affairs Medical Center, Oregon (looking west).

90. Photograph of typical floor slab, viewed from below, in Building 1, Roseburg Veterans Affairs Medical Center, Oregon.

91. Photograph of roof framing in Building 1, Roseburg Veterans Affairs Medical Center, Oregon.

92. Photograph of Building 1, Roseburg Veterans Affairs Medical Center, Oregon (looking north).

93. Photograph of reference station to measure ground shaking on Roseburg Veterans Affairs Medical Center, Oregon, away from Building 1

94. Diagrams of sensor layout showing 36 sensors in Building 1 of the Roseburg Veterans Affairs Medical Center, Oregon, (page 1 of 2; see also fig. 95).

95. Diagrams of sensor layout showing 36 sensors in Building 1 of the Roseburg Veterans Affairs Medical Center, Oregon, (page 2 of 2; see also fig. 94)

96. Photograph of Building 201, White City Veterans Affairs Medical Center, Oregon (front view).

97. Photograph of Building 201, White City Veterans Affairs Medical Center, Oregon (looking northeast)

98. Photograph of Building 201, White City Veterans Affairs Medical Center, Oregon (looking east) 
99. Diagram of sensor layout showing 11 sensors in Building 201 of the White City Veterans Affairs Medical Center, Oregon.

100. Photograph of Building 100, Portland Veterans Affairs Medical Center, Oregon (back side view).

101. Photographs of Building 100, Portland Veterans Affairs Medical Center, Oregon (side views).

102. Diagram of sensor layout showing 39 sensors in Building 100 of the Portland Veterans Affairs Medical Center, Oregon.

103. Photograph of Building 1, Charleston Veterans Affairs Medical Center, South Carolina (front view).

104. Photograph of Building 1, Charleston Veterans Affairs Medical Center, South Carolina (back side view).

105. Photograph of Building 1, Charleston Veterans Affairs Medical Center, South Carolina (side view).

106. Diagrams of sensor layout showing 48 sensors in Building 1 of the Charleston Veterans Affairs Medical Center, South Carolina (page 1 of 2; see also fig. 107). 108

107. Diagrams of sensor layout showing 48 sensors in Building 1 of the Charleston Veterans Affairs Medical Center, South Carolina (page 2 of 2; see also fig. 106).

108. Photograph of Building 7, Memphis Veterans Affairs Medical Center, Tennessee (entrance)

109. Photograph of Building 7, Memphis Veterans Affairs Medical Center, Tennessee (looking northwest).

110. Photograph of Building 7, Memphis Veterans Affairs Medical Center, Tennessee (looking west).

111. Diagrams of sensor layout showing 12 sensors in Building 7 of the Memphis Veterans Affairs Medical Center, Tennessee (page 1 of 2; see also fig. 112).

112. Diagrams of sensor layout showing 12 sensors in Building 7 of the Memphis Veterans Affairs Medical Center, Tennessee (page 2 of 2; see also fig. 111).

113. Photograph of Building $1 \mathrm{~A}$, Memphis Veterans Affairs Medical Center, Tennessee

114. Photograph of Building 1A, Memphis Veterans Affairs Medical Center, Tennessee (looking north)

115. Photograph of Building 1A, Memphis Veterans Affairs Medical Center, Tennessee (looking southeast).

116. Diagrams of sensor layout showing 24 sensors in Building $1 \mathrm{~A}$ of the Memphis Veterans Affairs Medical Center, Tennessee (page 1 of 3; see also figs. 117 and 118).

117. Diagrams of sensor layout showing 24 sensors in Building $1 \mathrm{~A}$ of the Memphis Veterans Affairs Medical Center, Tennessee (page 2 of 3; see also figs. 116 and 118).

118. Diagrams of sensor layout showing 24 sensors in Building $1 \mathrm{~A}$ of the Memphis Veterans Affairs Medical Center, Tennessee (page 3 of 3; see also figs. 116 and 117).

119. Photograph of Building 14, Salt Lake City Veterans Affairs Medical Center, Utah.

120. Diagrams of sensor layout showing 24 sensors in Building 14 of the Salt Lake City Veterans Affairs Medical Center, Utah (page 1 of 2; see also fig. 120).

121. Diagrams of sensor layout showing 24 sensors in Building 14 of the Salt Lake City Veterans Affairs Medical Center, Utah (page 2 of 2; see also fig. 120).

122. Photograph of Building 1, Richmond Veterans Affairs Medical Center, Virginia.

123. Diagram of the sensor layout showing 36 sensors in Building 500 of the Richmond Veterans Affairs Medical Center, Virginia (page 1 of 2; see also fig. 124). 
124. Diagram of the sensor layout showing 36 sensors in Building 500 of the Richmond Veterans Affairs Medical Center, Virginia (page 2 of 2; see also fig. 123).

125. Photograph of Building 100, Seattle Veterans Affairs Medical Center, Washington 130

126. Photograph of Building 100, Seattle Veterans Affairs Medical Center, Washington (back side view).

127. Diagram of sensor layout showing 27 sensors in Building 100 of the Seattle Veterans Affairs Medical Center, Washington

128. Photograph of Building 11, Vancouver Veterans Affairs Medical Center, Washington (entrance).

129. Photograph of Building 11, Vancouver Veterans Affairs Medical Center, Washington (looking west).

130. Photograph of Building 11, Vancouver Veterans Affairs Medical Center, Washington (looking east).

131. Diagram of sensor layout showing 24 sensors in Building 11 of the Vancouver Veterans Affairs Medical Center, Washington.

132. Photograph of uniaxial force-balance accelerometers installed on a mounting plate. 138

133. Photograph of 24-bit digital Internet Protocol (IP)-based recorder with batteries and charger installed within a National Electrical Manufacturers Association (NEMA) cabinet....139

134. Photograph of Global Positioning System (GPS) antenna installed at the roof level of a medical building for absolute timing.

135. Photographs of custom-made U.S. Geological Survey (USGS) cable used for connecting accelerometers to recorders.

136. Photograph of a typical free-field station where a triaxial accelerometer and a recorder are installed to measure ground motion at Veterans Affairs medical centers away from structures that are being seismically monitored.

137. Photograph of a typical reference station where a triaxial accelerometer and a recorder are installed to measure ground motion at Veterans Affairs medical centers away from structures that are being seismically monitored.

138. Foundation details for free-field ground-motion recording stations. 


\title{
Advanced Earthquake Monitoring System for U.S. Department of Veterans Affairs Medical Buildings-Instrumentation
}

\author{
By Erol Kalkan ${ }^{1}$, Krishna Banga ${ }^{2}$, Hasan S. Ulusoy ${ }^{3}$, Jon Peter B. Fletcher ${ }^{1}$, \\ William S. Leith ${ }^{4}$, Shahneam Reza', and Timothy Cheng ${ }^{1}$
}

\begin{abstract}
In collaboration with the U.S. Department of Veterans Affairs (VA), the National Strong Motion Project (NSMP; http://nsmp.wr.usgs.gov/) of the U.S. Geological Survey has been installing sophisticated seismic systems that will monitor the structural integrity of 28 VA hospital buildings located in seismically active regions of the conterminous United States, Alaska, and Puerto Rico during earthquake shaking. These advanced monitoring systems, which combine the use of sensitive accelerometers and real-time computer calculations, are designed to determine the structural health of each hospital building rapidly after an event, helping the VA to ensure the safety of patients and staff. This report presents the instrumentation component of this project by providing details of each hospital building, including a summary of its structural, geotechnical, and seismic hazard information, as well as instrumentation objectives and design. The structural-health monitoring component of the project, including data retrieval and processing, damage detection and localization, automated alerting system, and finally data dissemination, will be presented in a separate report.
\end{abstract}

\section{Introduction}

The 1971 magnitude 6.6 San Fernando Earthquake in Southern California resulted in collapse of several hospital buildings, including the older unreinforced masonry buildings at the San Fernando VA medical center (fig. 1). Following this earthquake, the VA established its Seismic Vulnerability Assessment Program to identify and strengthen VA medical facilities that needed to be brought up to acceptable seismic safety standards. An important component of this program is monitoring earthquake shaking in hospital buildings. Shortly after the 1971 earthquake, the U.S. Geological Survey (USGS) collaborated with the VA on installing analog accelerographs in $60 \mathrm{VA}$ hospital buildings across the country. These accelerographs were mostly placed on the base level of the buildings to record input ground motion to the building. Because these instruments recorded data on photographic film, it often took many days or even weeks after an earthquake to process and analyze the records. Later, in 2003, 45 of these seismic

\footnotetext{
${ }^{1}$ U.S. Geological Survey, Menlo Park, California

${ }^{2}$ U.S. Department of Veterans Affairs, Washington, D.C.

${ }^{3}$ Menlo Park, California

${ }^{4}$ U.S. Geological Survey, Reston, Virginia
} 
monitoring instruments were replaced by modern digital systems. Since 2008, 22 VA medical centers have been instrumented with sophisticated arrays of seismic motion sensors to better understand their response to strong ground shaking during earthquakes - instrumentation of six more hospital buildings is currently underway. Today, the USGS National Strong Motion Project (NSMP) works closely with the VA to monitor earthquake shaking in more than 70 of their medical centers ${ }^{5}$ in earthquake-prone regions across the conterminous United States, in Alaska, and in Puerto Rico. These monitored structures are part of a larger network of more than 250 structures instrumented under the USGS Advanced National Seismic System (ANSS), which is modernizing and expanding earthquake monitoring around the Nation to improve the overall understanding of earthquakes and their effects on the built environment. Data recorded by these instruments will enable improvement of building design to create more resilient and safer structures that can better protect people and resources.

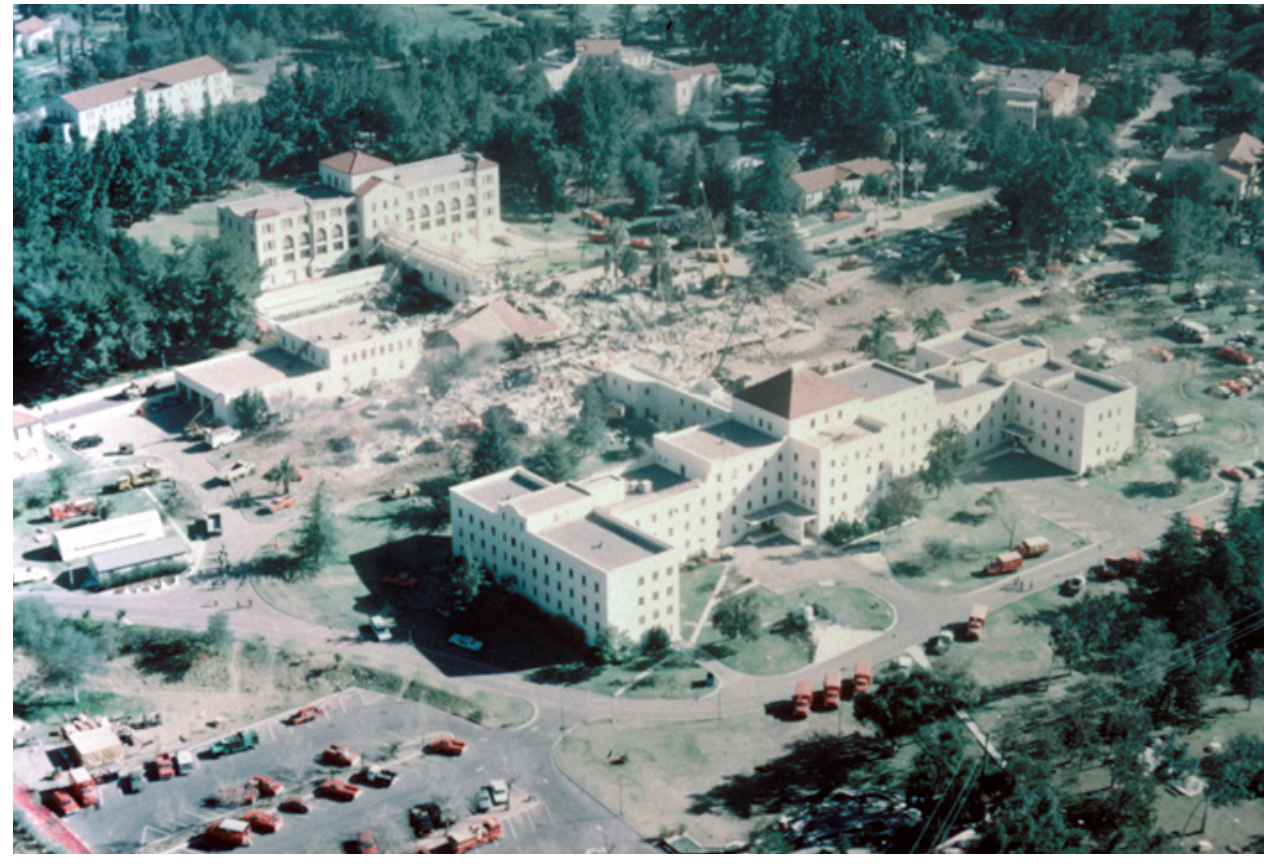

Figure 1. During the San Fernando, California, earthquake in February 1971, buildings 1 and 2 (older unreinforced masonry structures) of the Veterans Hospital collapsed and killed 49 people (U.S. Geological Survey Photographic Library: ID. Kachadoorian, R. 57ct).

\section{Selection of Hospital Buildings for Advanced Earthquake Monitoring}

An important goal of VA hospitals is to be able to continue to operate and to serve the patient community after a major earthquake. However, a building itself may have been damaged and, consequently, may pose a hazard to patients and staff. It is critical that hospital management have the tools and information necessary to make a rapid decision about whether to evacuate or not. Early assessment of the integrity of the hospital buildings affected by the earthquake is valuable in this decision making process. For resilience and sustainability of the Nation's hospitals, it is also necessary to assess the structural condition periodically to facilitate necessary repairs and retrofit measures.

\footnotetext{
${ }^{5}$ Locations of Veterans Affairs medical centers with instrumentation can be found at http://earthquake.usgs.gov/monitoring/buildings/.
} 
In response to these needs, the VA Seismic Vulnerability Assessment Program, together with the USGS NSMP, created a new initiative in 2008 to develop an advanced earthquake monitoring system for VA medical centers. This advanced system has two components-(1) instrumentation and (2) structural-health monitoring (SHM). The instrumentation component comprises a dense array of motion sensors, installed permanently at each and every floor of a building, and rapid data transmission and acquisition system. The SHM component consists of several data processing modules integrated into an open-source software package (OpenSHM) that automatically analyses a large amount of measured data to extract useful information for assessing the condition of a building before and after an earthquake (Kalkan and others 2012a,b; Ulusoy and others, 2012). Twenty-eight hospital buildings located in earthquake-prone regions across the country were identified by VA for advanced real-time structural-health monitoring with sophisticated systems of multiple seismic motion sensors and an on-site data analysis server. table 1 lists these 28 hospital buildings, and figure 2 shows their locations on the seismic hazard map of the United States. As shown, most of these medical buildings are located in very high and high seismic-hazard regions. These hospital buildings either did not have any instrumentation before or had only a seismic instrument at their base level.

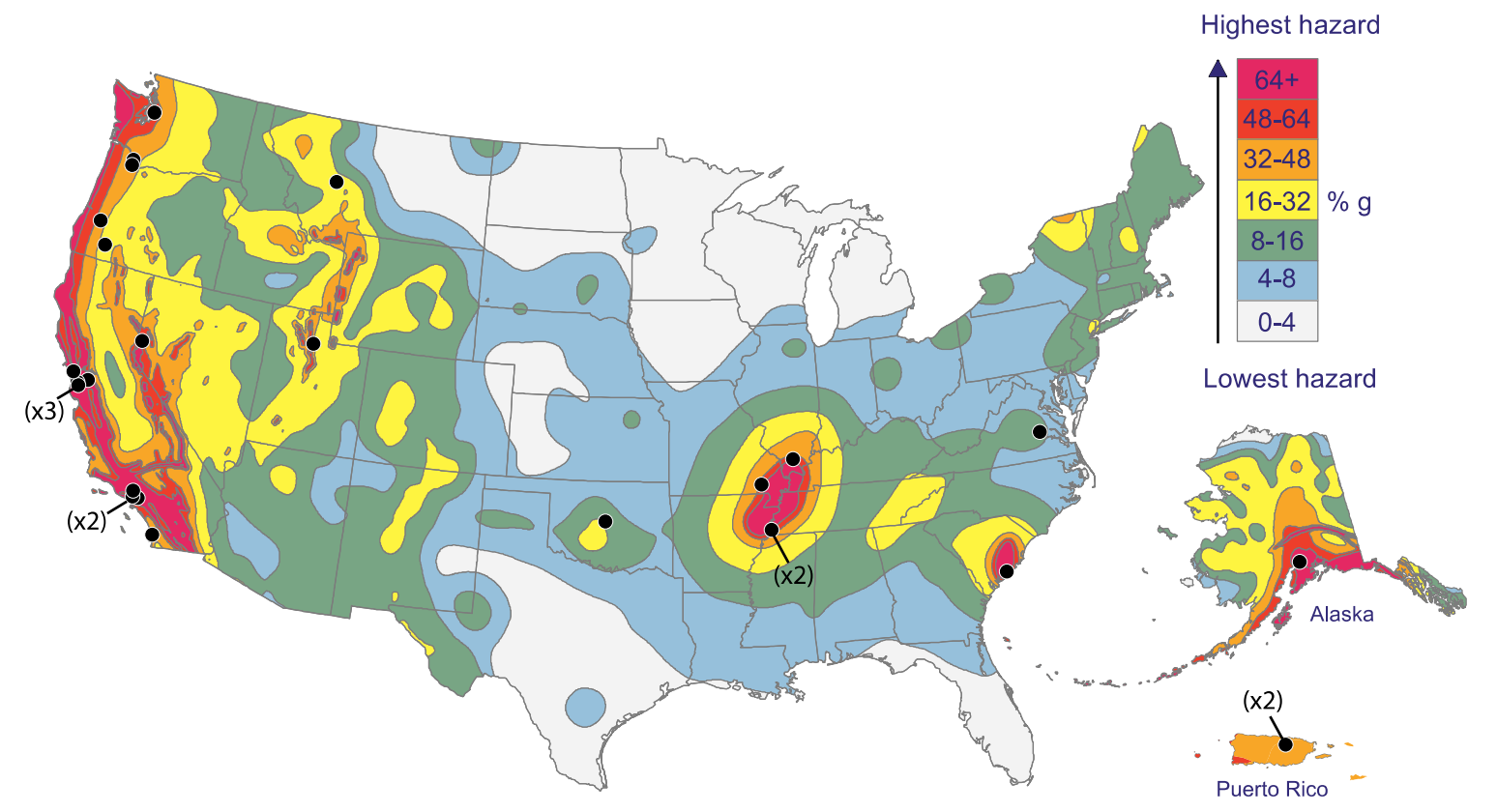

Figure 2. Seismic hazard map of the conterminous United States, Alaska, and Puerto Rico, showing the locations of 28 Veterans Affairs medical centers (black dots); "x" sign indicates multiple hospital buildings on campus for instrumentation; the seismic hazard map can be found at http://pubs. usgs.gov/fs/2008/3018/. Colors on this map show the levels of horizontal ground shaking that have a 2-in-100 chance of being exceeded in a 50-year period. Shaking is expressed as a percentage of $g$ ( $g$ is the acceleration of a falling object due to gravity).

\section{Instrumentation Objectives}

The number of sensors deployed in each medical building varies, depending on the floor area, the number of stories, and the number of blocks (or wings). For instance, the instrumentation design for the main hospital building at the VA medical center in San Diego, California, has 60 sensors (fig. 51). Locations for these sensors are strategically selected to be 
where the maximum response is expected, mostly at the edges of floors. Every story in each instrumented building has at least three seismic motion sensors oriented horizontally in two orthogonal directions to detect building motion along the reference east-west and north-south directions. Floor rotation (torsion) about the vertical axis can be computed from the recordings of sensors pointing in the same direction but located at different places on the same floor with an assumption of a rigid-floor diaphragm. Each building also has a triaxial sensor located on the ground floor, which records the input motions in three orthogonal directions (two horizontal and one vertical) at this level. Additional vertically oriented sensors at the same floor level allow the building's rocking motions to be computed. Vertical wave propagation can also be studied by using vertical sensors at the base and roof level of select hospital buildings. The instrumentation in the hospital buildings is sensitive enough to record a building's earthquake response due to small local earthquakes as well as to ambient vibrations.

The instrumentation within each medical building is designed to obtain:

- Health status of the building via system identification for rapid structural condition assessment,

- Swaying and twisting of the building,

- Inter-story drift at each floor level,

- Amount of time it takes for seismic waves to travel from the foundation to the roof, and

- How the frame of the building changed during the earthquake.

Other seismic motion sensors located away from the building record free-field ground shaking. These free-field or reference stations are generally located at twice the height of the nearest structure to eliminate structural interference to recorded data. A typical free-field station is shown in figure 3 for the West Los Angeles VA medical center, located roughly 660 feet (ft) away from the main hospital building. Motions recorded at the free-field site and at ground level of the instrumented building help to quantify the wave-propagation and soil-structure interaction. Such free-field data is also useful for development of ground-motion prediction equations (for example, Boore and others, 1997) and quantification of site transfer functions. Free-field motion also provides input for USGS ShakeMaps, maps that depict ground motion and shaking intensity after significant earthquakes, and USGS ShakeCast, an application for automating ShakeMap delivery to the VA for facilitating notification of shaking levels at VA facilities. Data from the free-field station may also be used for earthquake early warning systems, which are currently under development. Details of free-field and reference stations are given in appendix B.

Recorded data from the instrumented VA hospitals will be available to the VA engineering staff through a dedicated Web site (which is currently under development as part of the ongoing project) and also through the Center for Engineering Strong Motion Data (CESMD) at http://www.strongmotioncenter.org/. The CESMD is a cooperative center established by the USGS and the California Geological Survey (CGS) to integrate and disseminate earthquake strong-motion data from the California Strong Motion Instrumentation Program, the NSMP, and the ANSS. The CESMD provides raw and processed strong-motion data for earthquake engineering applications. 


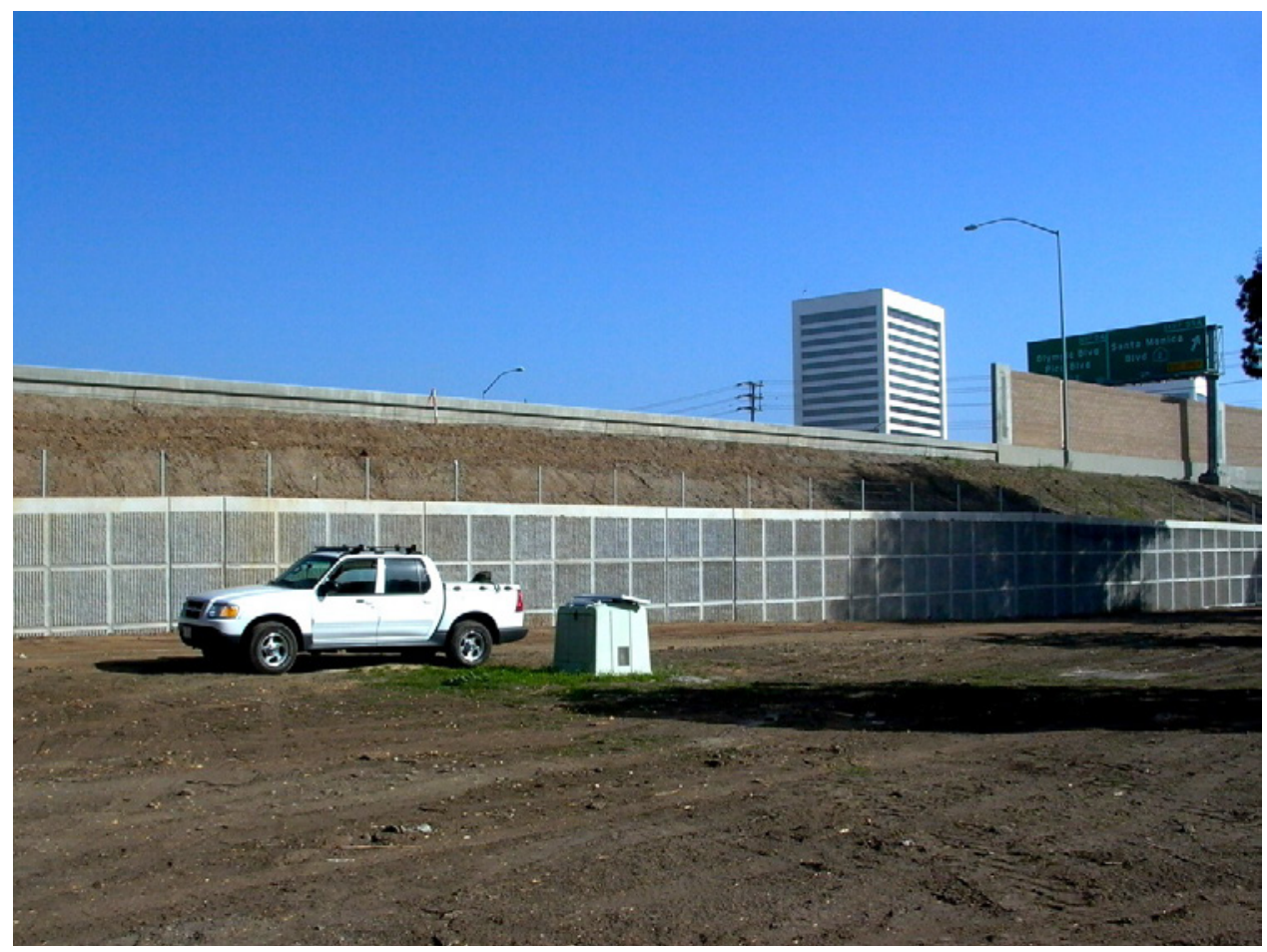

Figure 3. Photograph of a typical free-field station in West Los Angeles Veterans Affairs Medical Center, California (U.S. Geological Survey photograph).

\section{Earthquake Monitoring Hardware and Installation}

To identify the optimum list of hardware to be used for instrumentation of medical buildings, equipment from different vendors were considered in terms of data requirements, quality, durability and cost. Appendix A describes technical details of sensors, cables, and recorders used. The equipment is installed in the medical building according to the following steps:

1. Structural and architectural drawings and geology reports (if available) are obtained from VA.

2. Instrumentation design showing approximate locations for the sensor and central recorder is prepared by a USGS structural engineer.

3. A USGS structural engineer and technicians meet with the VA engineers and staff on site to review instrumentation design and determine exact sensor locations, cable routes, and the location of the free-field (or reference) site on the medical campus.

4. The USGS structural engineer and technician meet with the electrical contractor for cabling work and inspect the entire structure and free-field (or reference) site. The cabling routes, location of central recorder, and sensor locations are checked once again with the contractor.

5. An initial calibration of hardware is conducted in the NSMP Menlo Park or Pasadena offices. The calibrated system is installed in the structure with appropriate test procedures, including a static tilt sensitivity test for each sensor and determination of 
direction of motion for upward trace deflection on the record by a team of USGS technicians.

Remote testing of the installed system is conducted by analyzing ambient vibration data through a system identification approach. This approach provides elastic dynamic properties of the building, including its fundamental modes, mode shapes, and modal damping values. The results are used to verify that the system, including the data logger and all sensors, is fully functional.

Table 1. List of Veterans Affairs hospitals identified for use of an advanced earthquake monitoring system.

[Seismic Hazard: VH, very high; H, high, ML, moderately low. -, no data. AK, Arkansas; CA, California; IL, Illinois; MO, Missouri; MT, Montana; NV, Nevada; PR, Puerto Rico; OK, Oklahoma; OR, Oregon; SC, South Carolina; TN, Tennessee]

\begin{tabular}{|c|c|c|c|c|c|c|c|c|}
\hline \multirow{2}{*}{ State } & \multirow{2}{*}{$\begin{array}{l}\text { Medical Center } \\
\text { Location }\end{array}$} & \multirow{2}{*}{$\begin{array}{l}\text { Building } \\
\text { Number }\end{array}$} & \multirow{2}{*}{ Building Name } & \multicolumn{2}{|c|}{ Number of Stories } & \multirow{2}{*}{$\begin{array}{l}\text { Seismic } \\
\text { Hazard }\end{array}$} & \multicolumn{2}{|c|}{ Number of Sensors } \\
\hline & & & & $\begin{array}{l}\text { Below } \\
\text { Ground }\end{array}$ & $\begin{array}{l}\text { Above } \\
\text { Ground }\end{array}$ & & $\begin{array}{c}\text { In } \\
\text { structure }\end{array}$ & $\begin{array}{c}\text { Ground } \\
\text { level }\end{array}$ \\
\hline AK & Anchorage & $\mathrm{B} 100$ & New Hospital Building & - & 2 & $\mathrm{VH}$ & 21 & 3 \\
\hline CA & Palo Alto & 100 & Outpatient Clinic & 1 & 4 & $\mathrm{VH}$ & 24 & \multirow{2}{*}{3} \\
\hline CA & Palo Alto & 101 & Outpatient Clinic & 1 & 4 & VH & 12 & \\
\hline CA & Menlo Park & 334 & Center Core Building & 1 & 3 & VH & 24 & 3 \\
\hline CA & Livermore & 62 & MS and $\mathrm{N}$ & 1 & 6 & VH & 24 & 3 \\
\hline CA & San Francisco & 200 & $\begin{array}{l}\text { AmbCare/Clinical } \\
\text { Support }\end{array}$ & 1 & 4 & VH & 16 & 3 \\
\hline CA & Los Angeles & 1 & Out Patient Clinic & 1 & 6 & $\mathrm{VH}$ & 24 & 3 \\
\hline CA & Sepulveda & 10 & $\begin{array}{l}\text { Outpatient Clinical } \\
\text { Care }\end{array}$ & - & 3 & VH & 24 & 3 \\
\hline CA & West Los Angeles & 114 & Research Lab & 1 & 4 & VH & 12 & 3 \\
\hline CA & West Los Angeles & 500 & Main Hospital & 1 & 7 & VH & 24 & 3 \\
\hline CA & San Diego & 1 & Main Hospital & 1 & 6 & $\mathrm{VH}$ & 60 & 3 \\
\hline IL & Marion & 1 & Main Hospital & 1 & 4 & $\mathrm{H}$ & 48 & 3 \\
\hline MO & Poplar Bluff & 1 & $\begin{array}{l}\text { Medical / Nursing / } \\
\text { PCC }\end{array}$ & - & 7 & $\mathrm{H}$ & 48 & 3 \\
\hline MT & Fort Harrison & 154 & Main Hospital & - & 6 & $\mathrm{H}$ & 24 & 3 \\
\hline NV & Reno & 12 & $\begin{array}{l}\text { New Bed } \\
\text { Building/Clinic }\end{array}$ & - & 6 & VH & 36 & 3 \\
\hline PR & San Juan & 10 & Nursing Building & - & 2 & $\mathrm{H}$ & 12 & 3 \\
\hline PR & San Juan & B30 & New Bed Tower & 1 & 6 & $\mathrm{H}$ & 24 & 3 \\
\hline OK & Oklahoma City & 1 & Main Hospital & 1 & 11 & $\mathrm{ML}$ & 60 & 3 \\
\hline OR & Roseburg & 1 & Main Hospital & - & 5 & VH & 36 & 3 \\
\hline OR & White City & 201 & Primary Care Clinic & - & 2 & $\mathrm{H}$ & 12 & - \\
\hline OR & Portland & 100 & Main Hospital & 2 & 9 & $\mathrm{H}$ & 39 & - \\
\hline SC & Charleston & 1 & Main Hospital & - & 5 & VH & 48 & 3 \\
\hline TN & Memphis & 7 & Spinal Chord Injury & - & 3 & VH & 12 & $?$ \\
\hline TN & Memphis & $1 \mathrm{~A}$ & Bed Tower & - & 3 & VH & 24 & 6 \\
\hline UT & Salt Lake City & 14 & Main Hospital & 1 & 4 & VH & 24 & 3 \\
\hline VA & Richmond & 500 & Main Hospital & 1 & 5 & $\mathrm{ML}$ & 36 & 3 \\
\hline WA & Seattle & $\begin{array}{c}100 \mathrm{D} \text { and } \\
\mathrm{T}\end{array}$ & $\begin{array}{l}\text { Main Hosp. Diag. and } \\
\text { Treatment Wing }\end{array}$ & 1 & 7 & $\mathrm{VH}$ & 27 & 3 \\
\hline WA & Vancouver & 11 & $\begin{array}{l}\text { Barnes Rehab } \\
\text { Building }\end{array}$ & - & 3 & $\mathrm{H}$ & 24 & 3 \\
\hline
\end{tabular}




\section{VA Medical Buildings}

Twenty-eight VA hospital buildings selected for seismic monitoring are described in the following sections. These buildings are listed below in alphabetical order given in table 1 .

\section{NSMP Station 8045-Anchorage, Alaska: New Hospital, Building No. B100}

\section{Building Description}

Building B100 at the medical center in Anchorage, Alaska, is part of the Alaska VA Healthcare System (http://www.alaska.va.gov/). This two-story steel building is approximately 188,000 square feet ( $\mathrm{ft}^{2}$ ) (fig. 4 through fig. 6). It was designed in 2007 and completed in 2010. The building has an irregular plan shape with three wings located in the east, north, and the southwest. These wings have dimensions of 99 by $240 \mathrm{ft}, 240$ by $90 \mathrm{ft}$, and 300 by $90 \mathrm{ft}$, respectively. A seismic joint separates the southwest wing from other wings. The first story is $14.5 \mathrm{ft}$ tall and the second story is $14 \mathrm{ft}$ tall. There is a small penthouse located on the roof that is approximately $12 \mathrm{ft}$ tall. The base of the structure is supported by a 4-inch-thick concrete slab on grade. The second floor is supported by a composite slab made up of 2.5 inches of concrete fill over decking reinforcement. The roof is composed of a similar composite slab as the second floor, but there is 3 inches of concrete fill. The building's lateral-force resisting system consists of steel braced moment resisting frames (fig. 7). The steel columns that support the building rest on isolated spread footings. These details were obtained from the structural and architectural drawings provided by the VA.

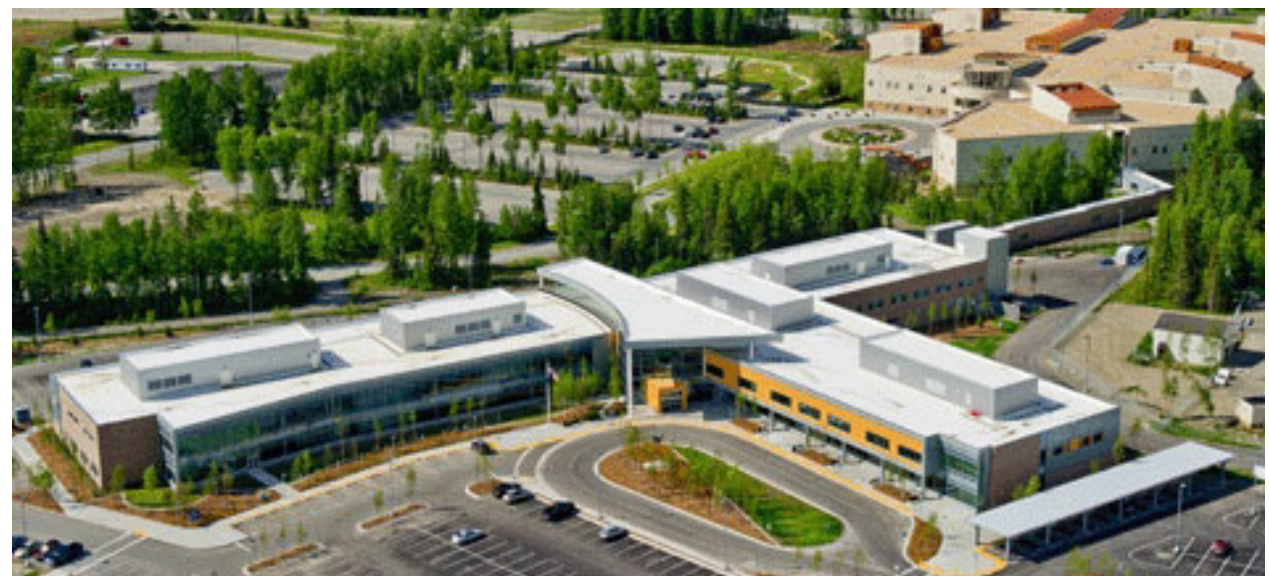

Figure 4. Photograph of Building B100, Anchorage Veterans Affairs Medical Center, Alaska (aerial view) (U.S. Department of Veterans Affairs photograph). 


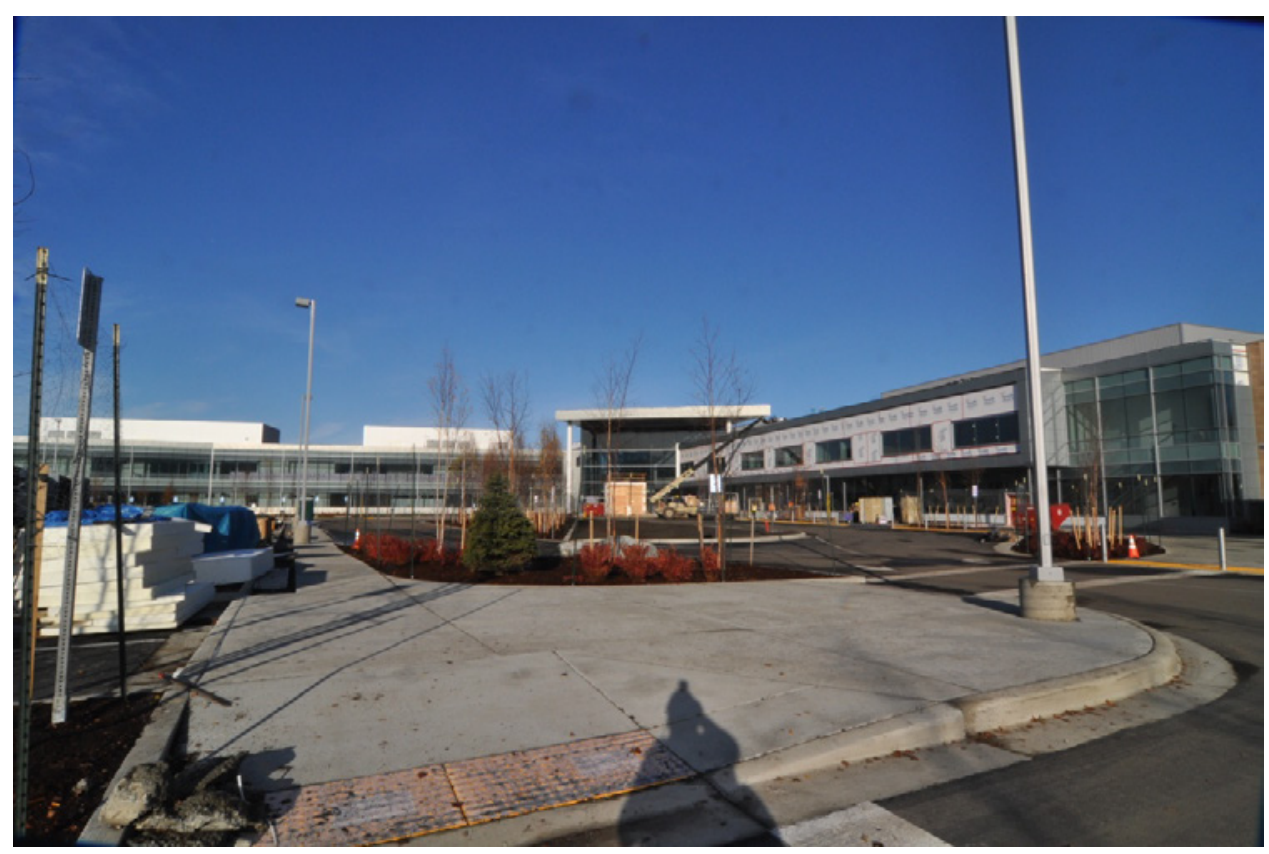

Figure 5. Photograph of Building B100, Anchorage Veterans Affairs Medical Center, Alaska (looking north) (U.S. Geological Survey photograph).

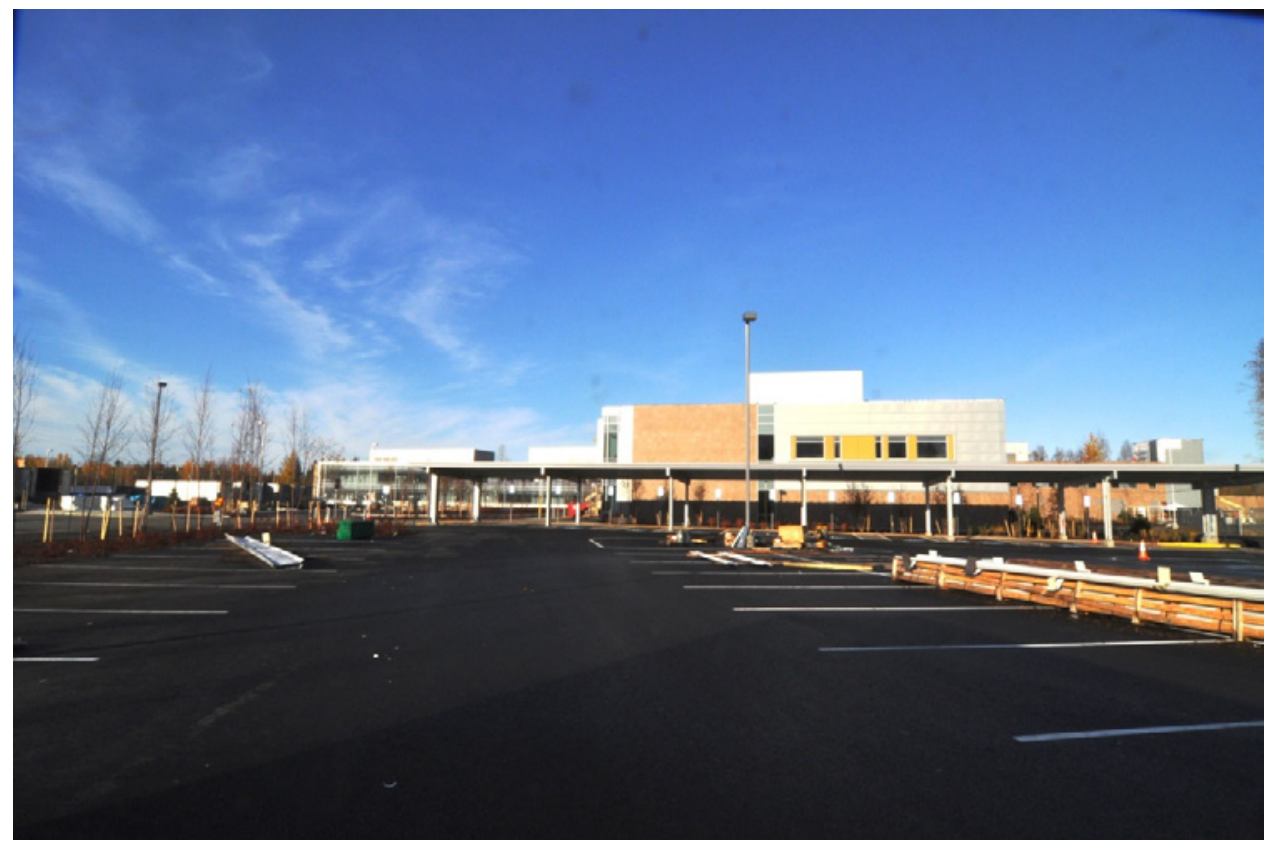

Figure 6. Photograph of Building B100, Anchorage Veterans Affairs Medical Center, Alaska (looking northeast) (U.S. Geological Survey photograph). 


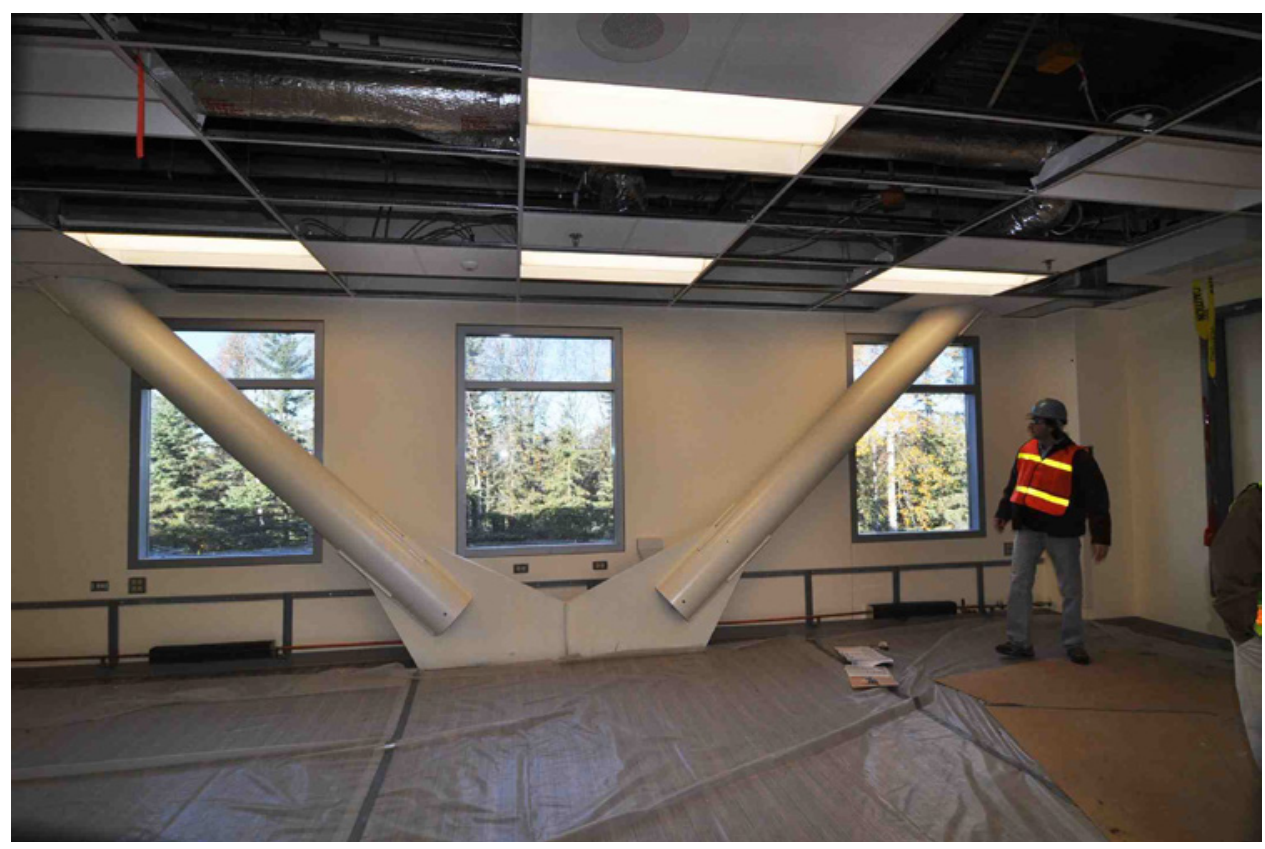

Figure 7. Photograph of steel braces providing additional lateral stiffness in Building B100, Anchorage Veterans Affairs Medical Center, Alaska (U.S. Geological Survey photograph).

\section{Seismic-Hazard Conditions}

The building is located in an area of very high seismic hazard. The short-period spectral acceleration, $\mathrm{S}_{\mathrm{S}}$, using the current 2003 National Earthquake Hazard Reduction Program (NEHRP) recommended provisions for seismic regulations of new buildings and other structures ${ }^{6}$, is 1.51 times the acceleration due to gravity $(g)$. The long-period spectral acceleration, $\mathrm{S}_{1}$, is $0.56 \mathrm{~g}$.

\section{Instrumentation}

A total of 21 accelerometers are deployed in the building to obtain its lateral and torsional motion as well as inter-story drifts (fig. 8) during an earthquake. A triaxial accelerometer (channels 1 through 3 ) is placed on first floor ground level to measure the three components of input ground motion. Nine accelerometers oriented parallel to the building sides (channels 4 through 12) are placed on the first-floor ceiling to measure the lateral motion of each wing. Another nine accelerometers (channels 13 through 21) are placed on the second-floor ceiling to monitor the roof diaphragm's lateral motion. The floor relative displacements can be computed from accelerometers located at the same corner of the building on the same vertical axis. Also, the relative motions of the wings can be computed using sensors on the same floor pointing the same direction (for example, channels 14 and 15; 19 and 20). The building's accelerometers are complemented by a three-component seismic accelerometer located at a free-field site (NSMP Station No. 8046), approximately $156 \mathrm{ft}$ away from the building, to monitor ground shaking without interference from the building's earthquake response.

\footnotetext{
${ }^{6}$ Seismic hazard map values were obtained from http://earthquake.usgs.gov/hazards/designmaps/.
} 
U.S. Department of Veterans Affairs

Anchorage, AK - Steel Moment Frame, Two-Story Hospital Building

Building No: B100

NSMP Station No: 8045

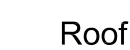

2nd Floor

1st Floor

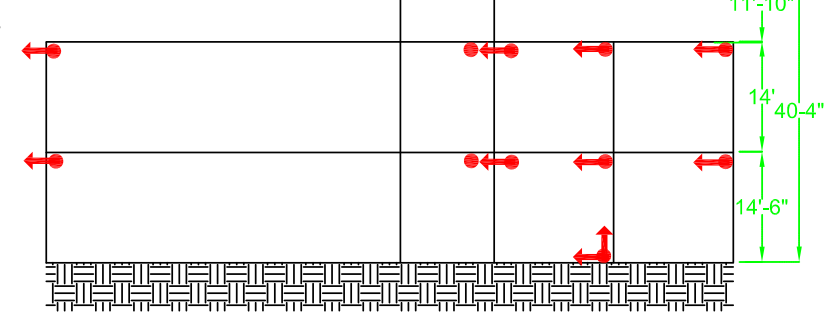

Elevation View Looking Reference West
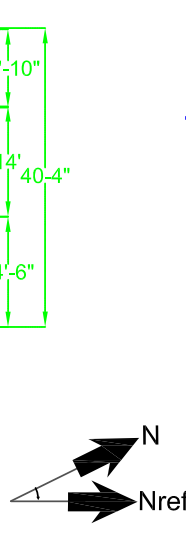

Nref

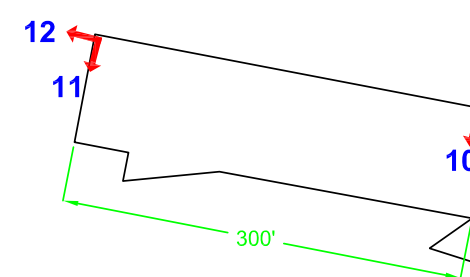

Structure Reference Orientation: $10^{\circ}$

Revision Number: 10

Revised on 10/11/2012

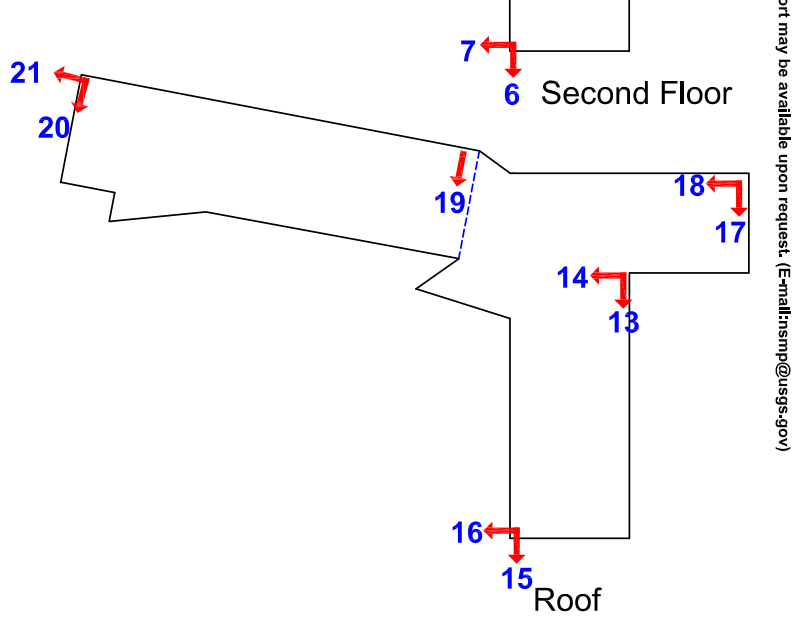

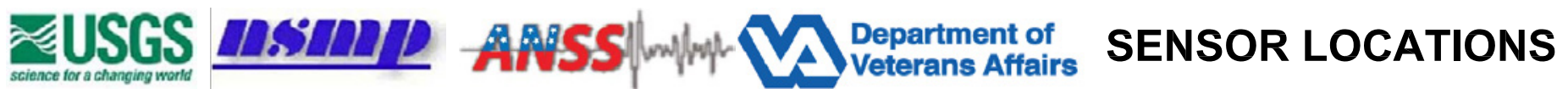

Figure 8. Diagram of sensor layout showing 21 sensors in Building B100 of the Anchorage Veterans Affairs Medical Center, Alaska (circle denotes a sensor oriented outward; for example sensor 1 in first floor plan is oriented in vertical direction). 


\section{NSMP Station 1868-Palo Alto, California: Outpatient Clinic, Building No. 100}

\section{Building Description}

Building 100, the main hospital building of the VA Palo Alto Health Care System (http://www.paloalto.va.gov/), is located in Palo Alto, California. This four-story structure with a partial basement is approximately $341,300 \mathrm{ft}^{2}$ (fig. 9 through fig. 12). It has not been significantly modified since it was built in 1994. The building has an irregular plan shape, in which the main part of the building is square with dimensions of 286 by $286 \mathrm{ft}$. There is a courtyard near the center of the building. The building also has two wings adjoining the main section of the structure in south and the west directions. The wings have symmetrical plans with dimensions of 104 by $130 \mathrm{ft}$. The typical floor height is $16 \mathrm{ft}$. The building's lateral-force resisting system consists of moment-resisting steel frames with chevron braces.

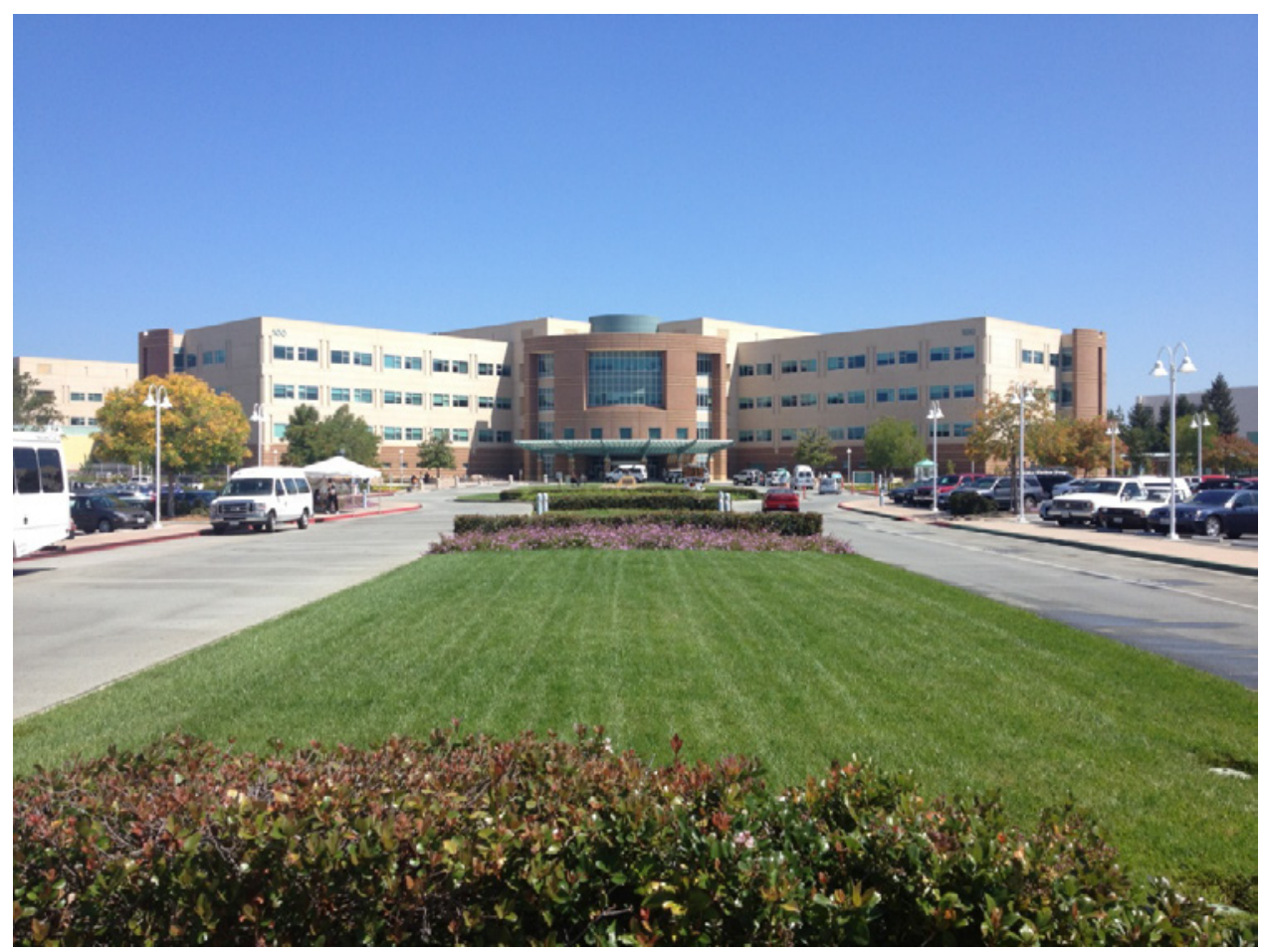

Figure 9. Photograph of Building 100, Palo Alto Veterans Affairs Medical Center, California (front view) (U.S. Geological Survey photograph).

\section{Seismic-Hazard Conditions}

The building is located in an area of very high seismic hazard. The short-period spectral acceleration, $\mathrm{S}_{\mathrm{S}}$, using the current NEHRP recommended provisions for seismic regulations of new buildings and other structures, is $1.98 \mathrm{~g}$. The long-period spectral acceleration, $\mathrm{S}_{1}$, is $0.80 \mathrm{~g}$. 


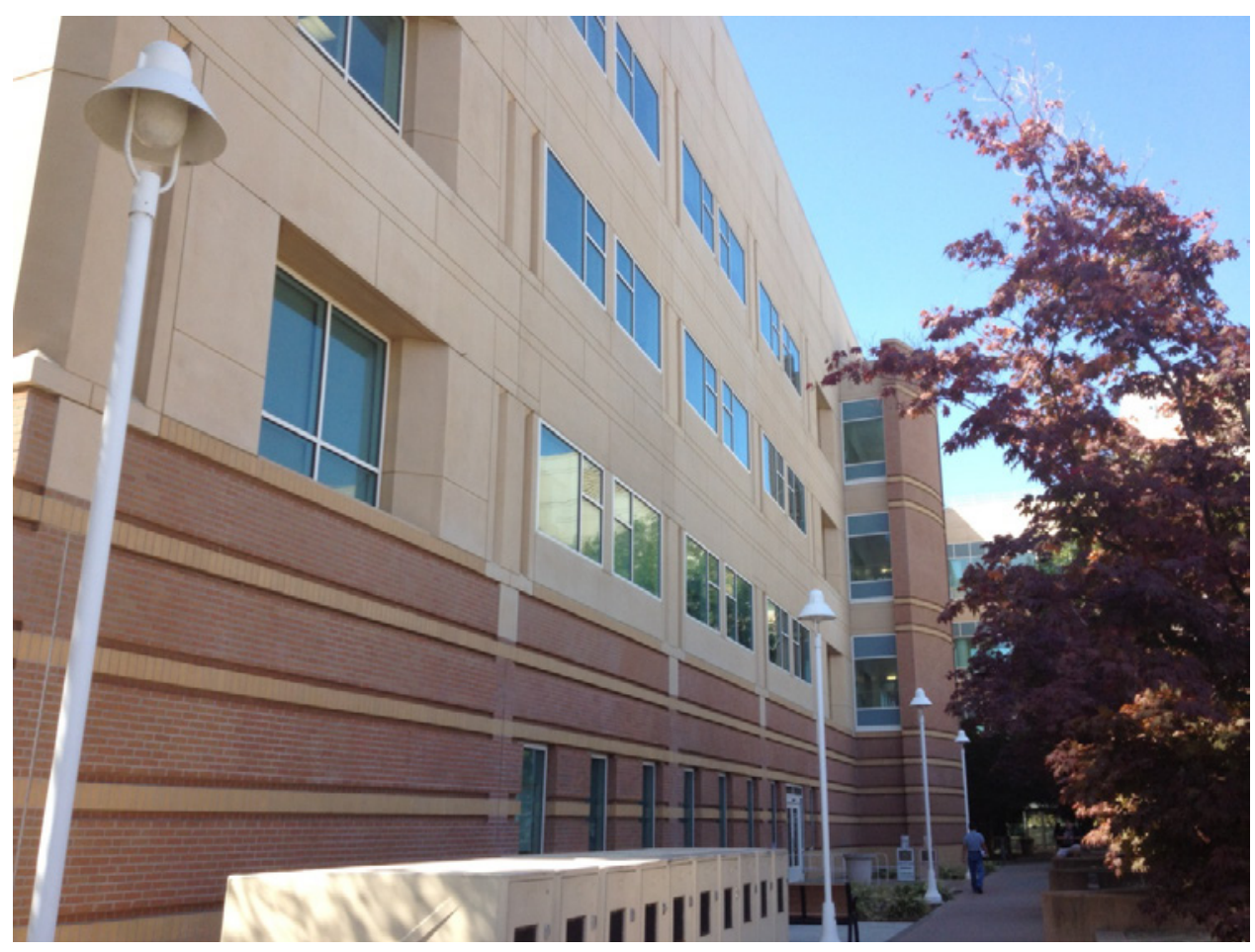

Figure 10. Photograph of Building 100, Palo Alto Veterans Affairs Medical Center, California (side view) (U.S. Geological Survey photograph).

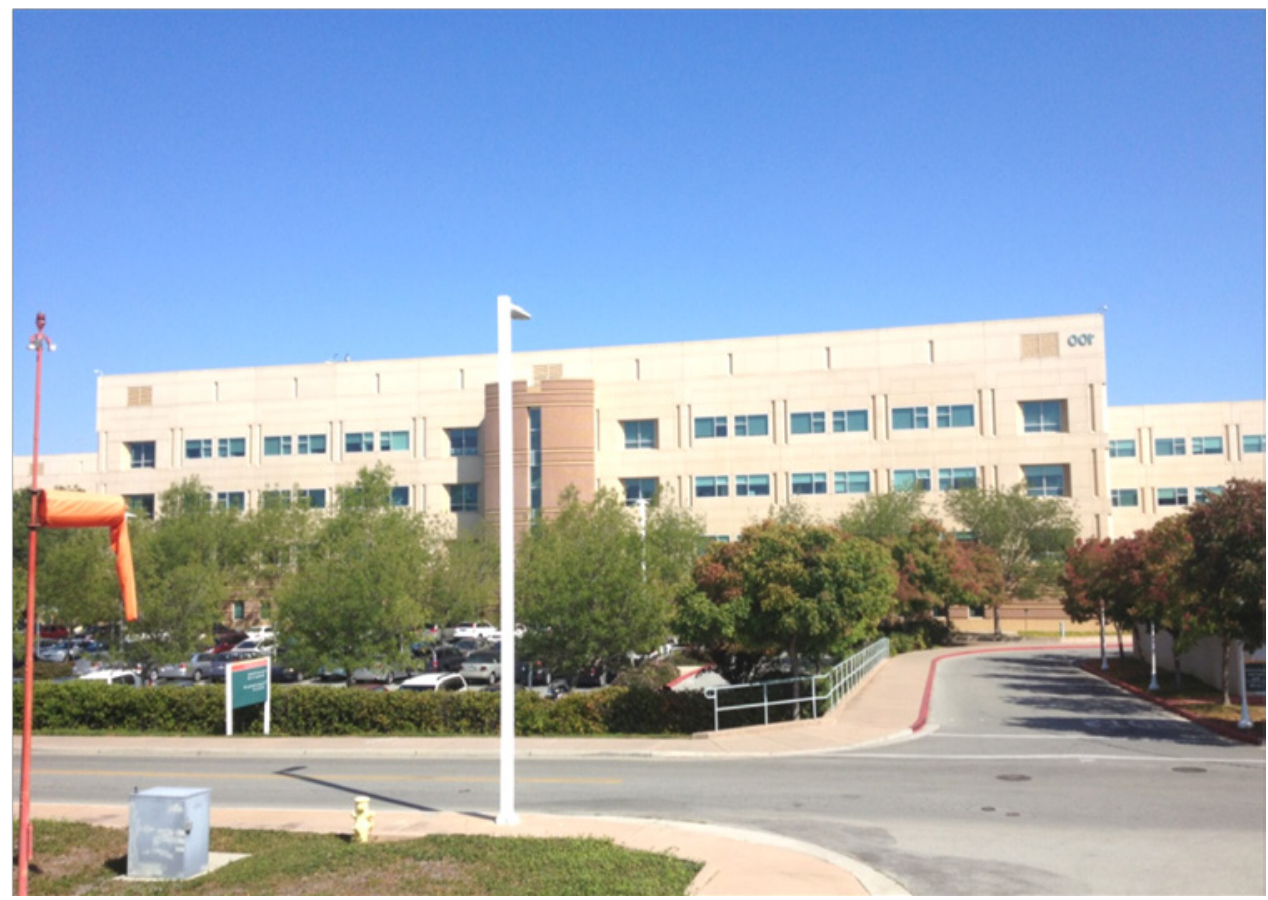

Figure 11. Photograph of Building 100, Palo Alto Veterans Affairs Medical Center, California (looking southwest) (U.S. Geological Survey photograph). 


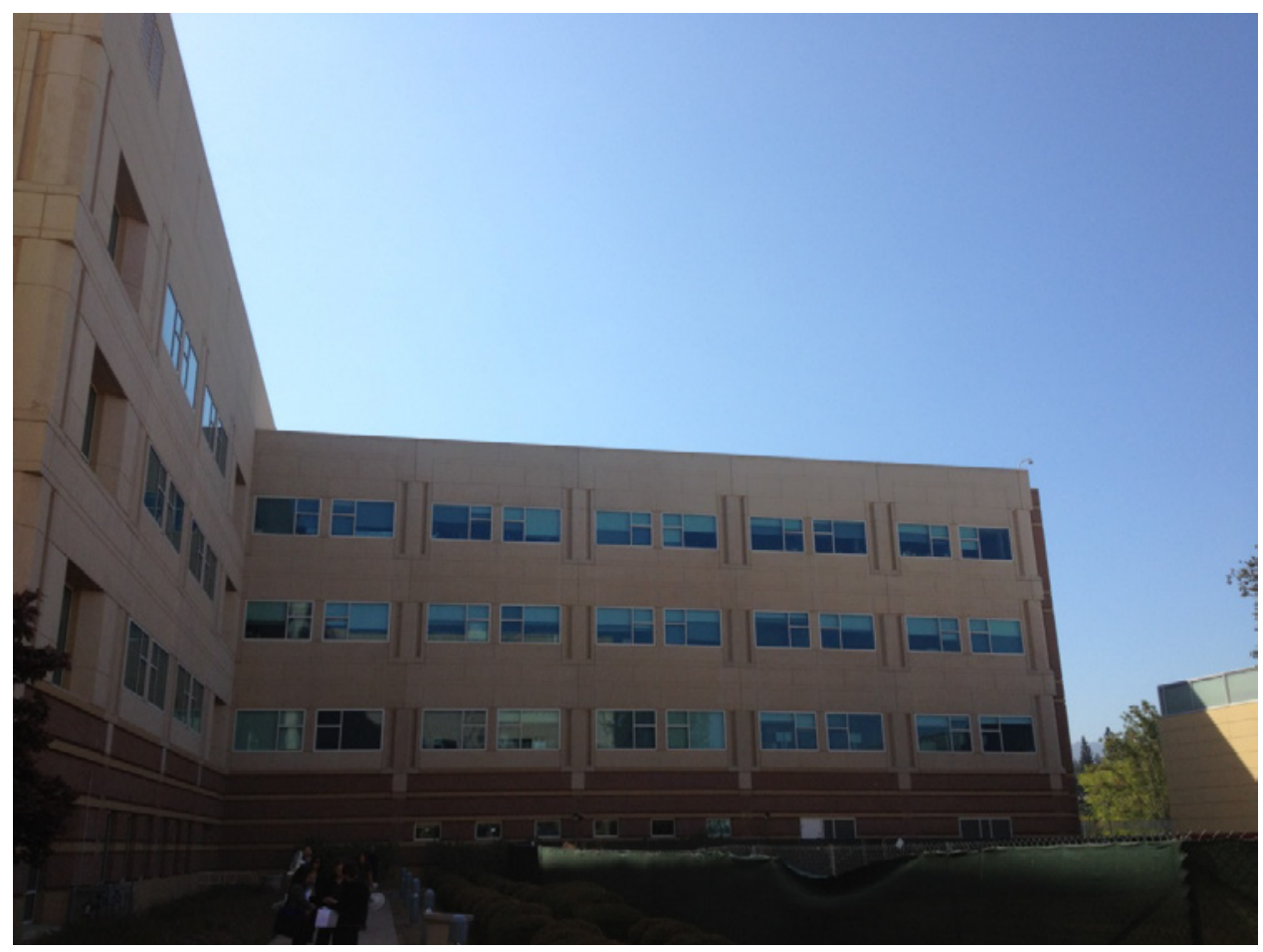

Figure 12. Photograph of Building 100, Palo Alto Veterans Affairs Medical Center, California (looking northwest) (U.S. Geological Survey photograph).

\section{Instrumentation}

A total of 24 accelerometers are deployed in the building to measure its earthquake response (fig. 13 and fig. 14). Every floor is instrumented by at least four acceloremeters. A triaxial accelerometer (channels 1 through 3) is placed on the basement. Because the basement is partial and does not cover the building's entire footprint, two additional accelerometers (channels 6 and 7) are also located on the part of the first-floor slab sitting on the ground to measure the horizontal and vertical input motions at this level. These sensors together with the triaxial sensors at the basement will measure the input ground motion to the building. Two accelerometers (channels 4 and 5) are mounted on the basement ceiling to measure the first-floor slab lateral movement. To measure the second-floor lateral motion in reference east-west and north-south directions, four accelerometers (channels 8 through 11) are placed on the first-floor ceiling. The floor torsional motions and diaphragm rigidity can be computed using accelerometers pointing the same direction on the same level (for example channels 8 and 11 or channels 9 and 10). Four accelerometers (channels 12 through 15) are placed on the second-floor ceiling, and four accelerometers (channels 16 through 19) are mounted on the third-floor ceiling to obtain the third and fourth floor's lateral and torsional motions, respectively. Another five accelerometers (channels 20 through 24) are placed on the fourth-floor ceiling to measure the lateral motion of the roof diaphragm. Relative motion of the west wing as compared to the main building can be obtained by differentiating data from channels 22 and 23 at the roof level (fig. 13 and fig. 14). The inter-story drift can also be computed from likewise oriented accelerometers on the same vertical axes (for example, channels 1, 5, 9, 13, 17, and 21 for the east-west direction and channels $6,11,14,18$, and 22 for the north-south direction). 
The building's sensor array is complemented by a three-component accelerometer located at a free-field site (NSMP Station No. 1872), approximately $330 \mathrm{ft}$ away from the building, to monitor ground shaking without interference from the building's earthquake response. 
U.S. Department of Veterans Affairs

Palo Alto, CA - Steel Moment Frame, Four-Story Hospital Building

Building No: 100

NSMP Station No: 1868
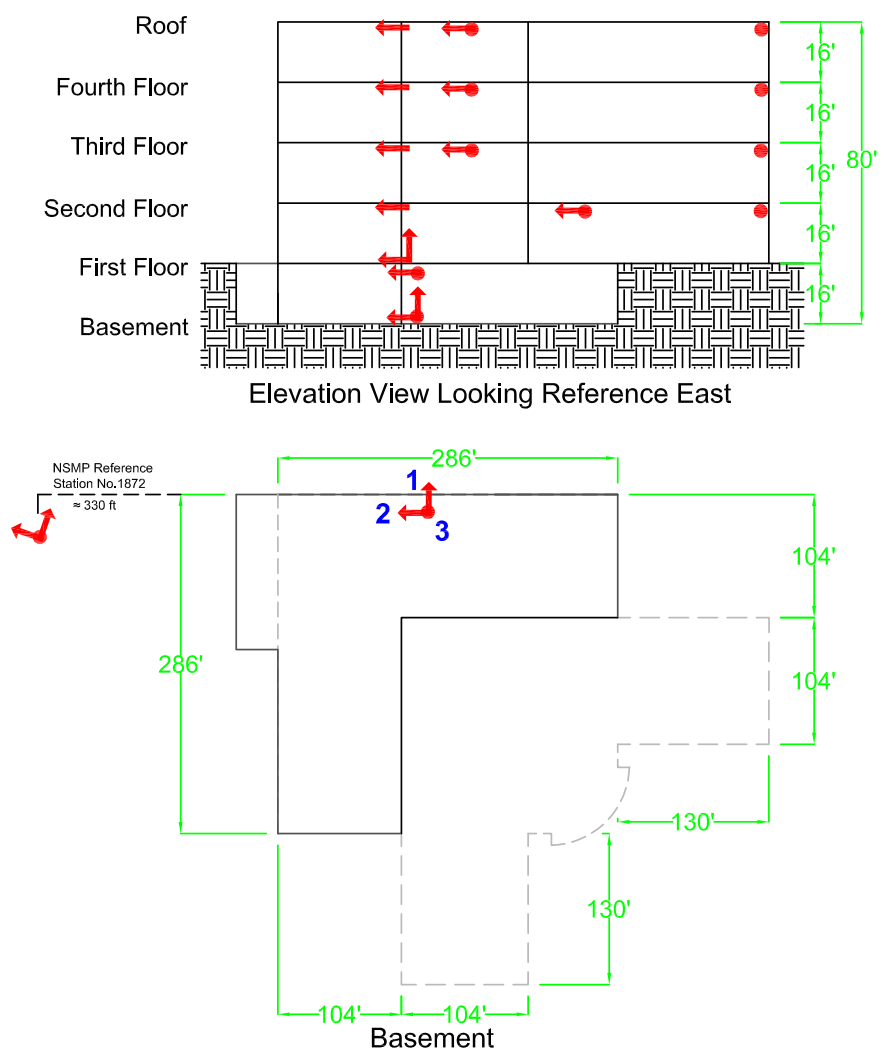

Revision Number: 9

Revised on 10/10/2012

Page 1 of 2

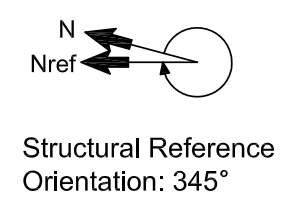

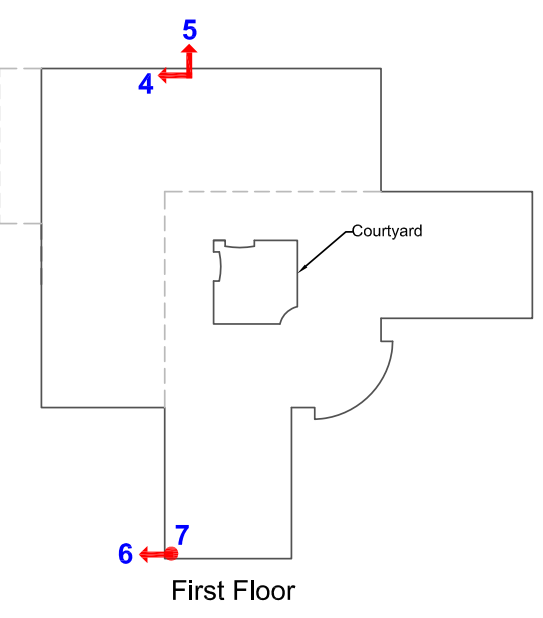

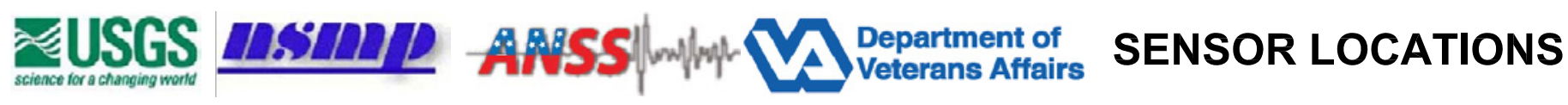

Figure 13. Diagram of sensor layout showing a total of 24 sensors in Building 100 of the Palo Alto Veterans Affairs Medical Center, California (page

1 of 2 ; see also fig. 14). 


\section{U.S. Department of Veterans Affairs}

Palo Alto, CA - Steel Moment Frame, Four-Story Hospital Building

Building No: 100

NSMP Station No: 1868
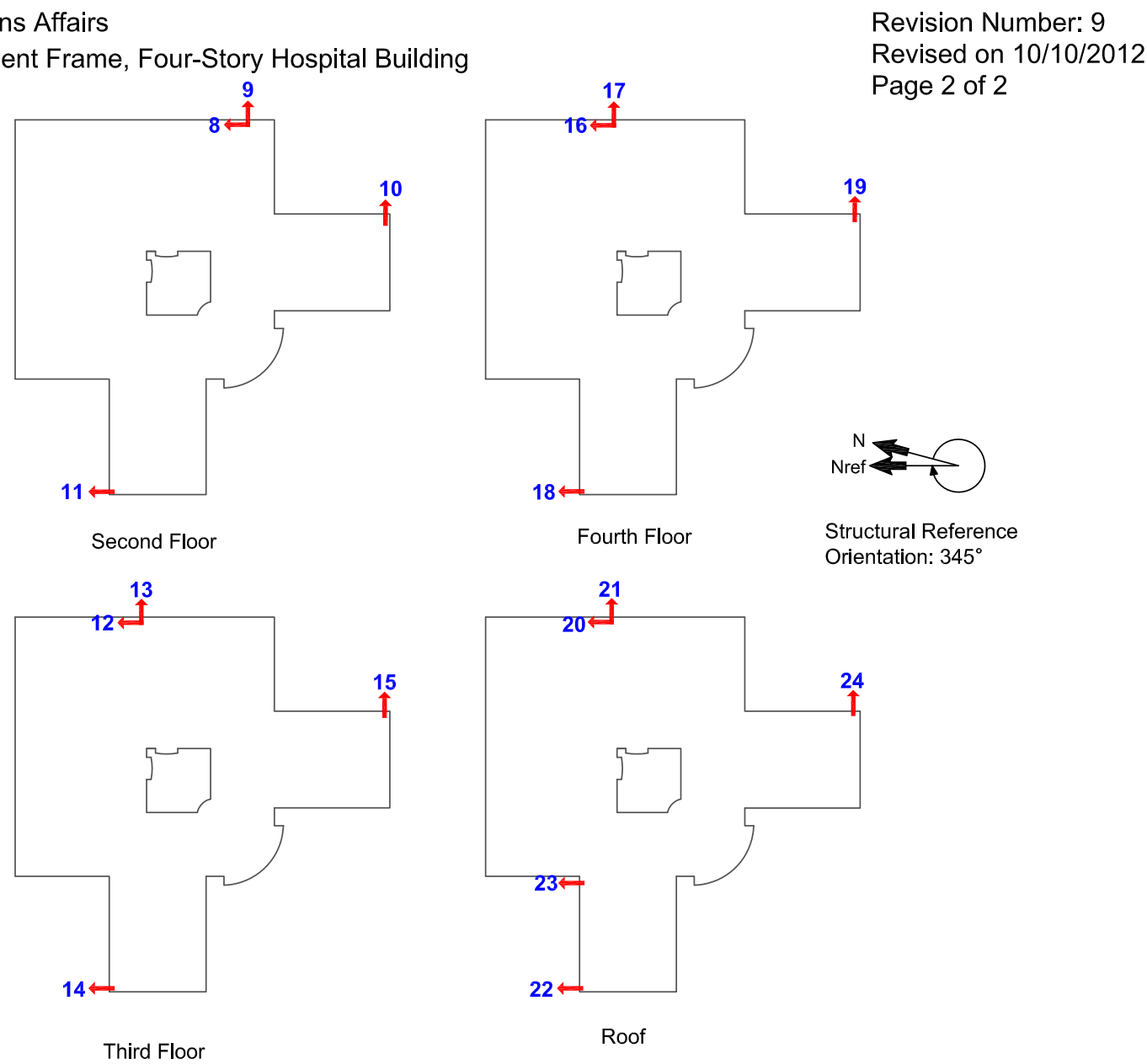

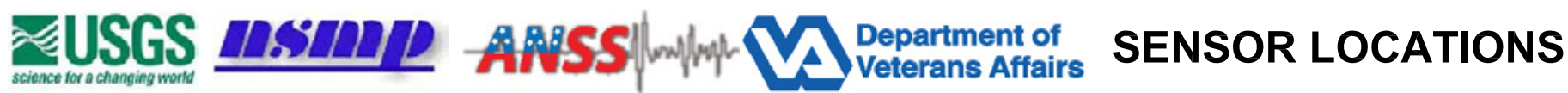

Figure 14. Sensor layout showing a total of 24 sensors in Building 100 of the Palo Alto Veterans Affairs Medical Center, California (page 2 of 2; see also fig. 13). 


\section{NSMP Station 1869—Palo Alto, California: Outpatient Clinic, Building No. 101}

\section{Building Description}

Building 101, located in Palo Alto, California, is part of the VA Palo Alto Health Care System (http://www.paloalto.va.gov). This 4-story structure is approximately $110,700 \mathrm{ft}^{2}$ (fig. 15 through fig. 18). The building has not been heavily renovated since its initial design in 1994. The structural system of the building is composed of steel moment-resisting frames and concrete slabs. The building's base shape at ground level is a square with the southwest quarter removed, and an extended, circular protrusion at the northeast and southwest directions. The stories above the first floor are similar except without the circular protrusion continuing to the roof of the structure. Story heights are typically $16 \mathrm{ft}$, with a total height of $80 \mathrm{ft}$ above the ground. The building has a concrete mat foundation. Building 101 is connected to Building 100 at all floor levels, separated by seismic joints (fig. 19).

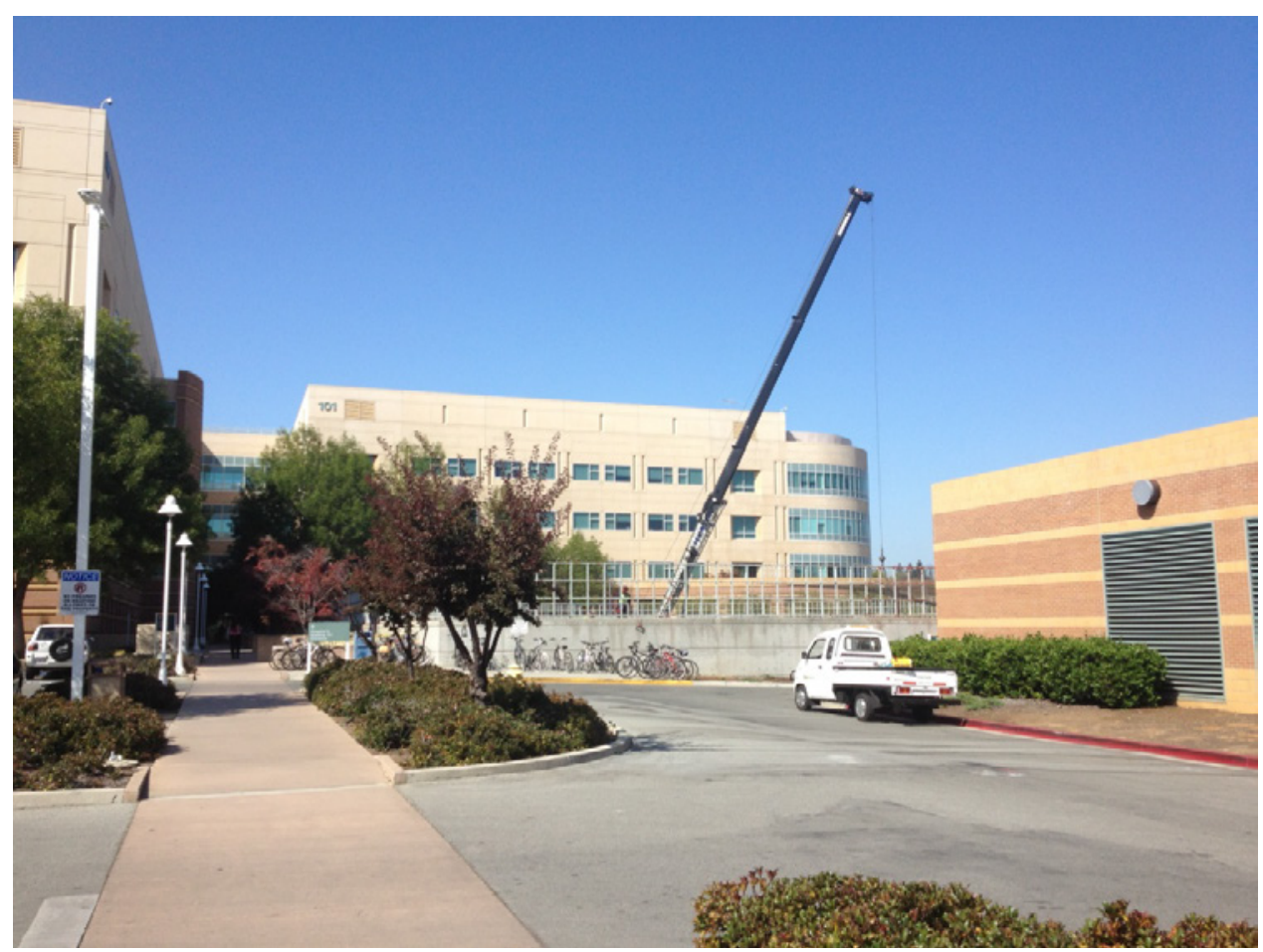

Figure 15. Photograph of Building 101, Palo Alto Veterans Affairs Medical Center, California (looking east)

(U.S. Geological Survey photograph). 


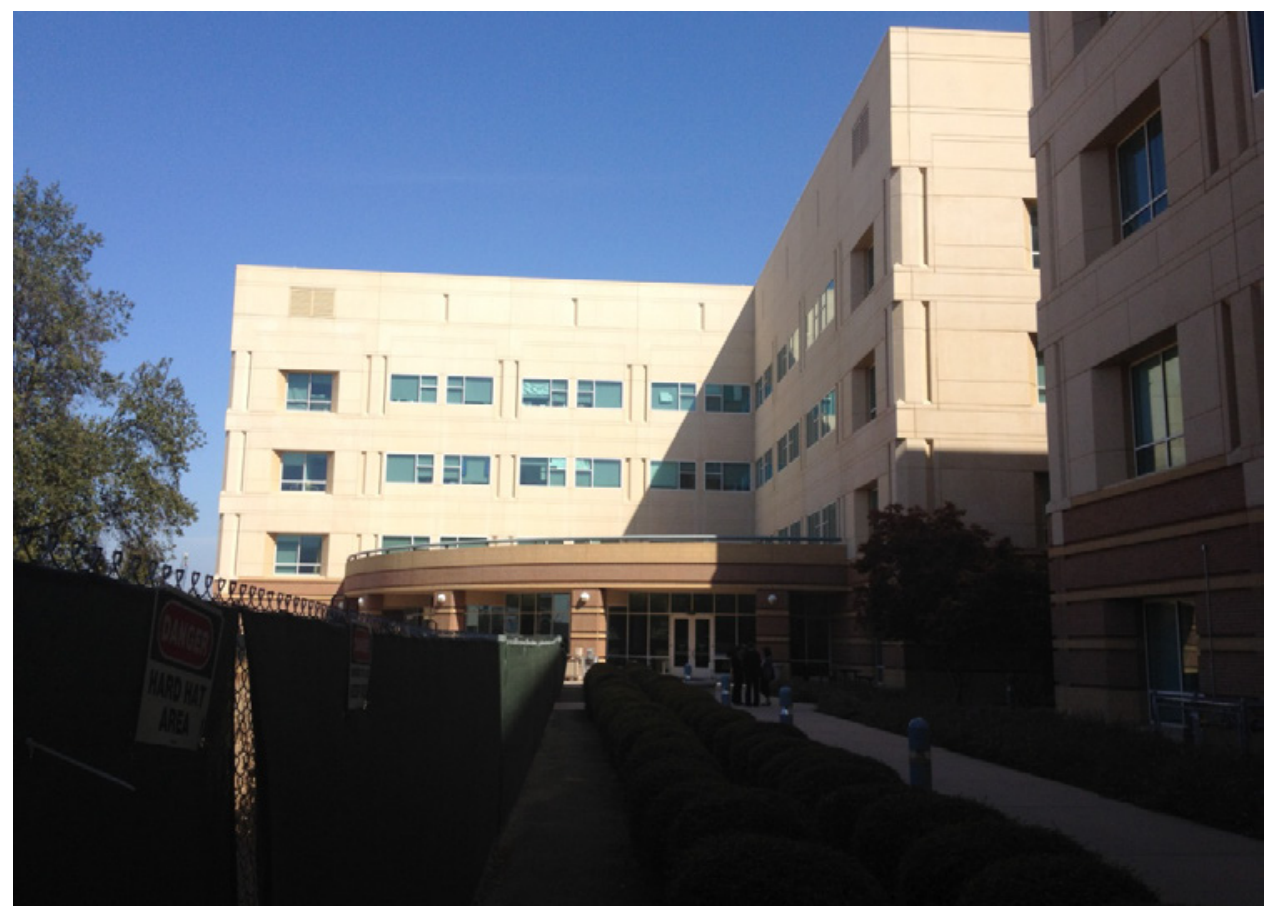

Figure 16. Photograph of Building 101, Palo Alto Veterans Affairs Medical Center, California (looking northeast) (U.S. Geological Survey photograph).

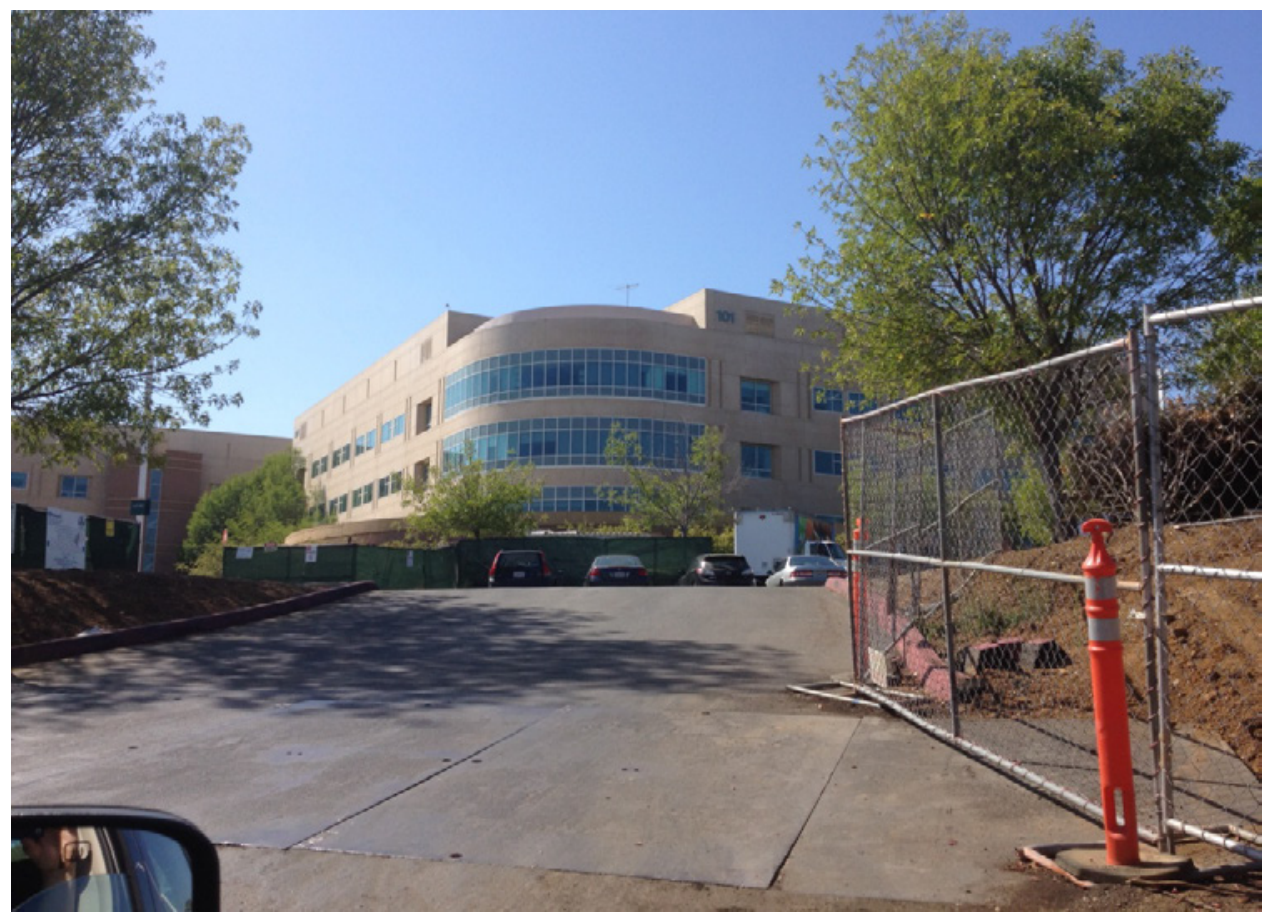

Figure 17. Photograph of Building 101, Palo Alto Veterans Affairs Medical Center, California (looking southwest) (U.S. Geological Survey photograph). 


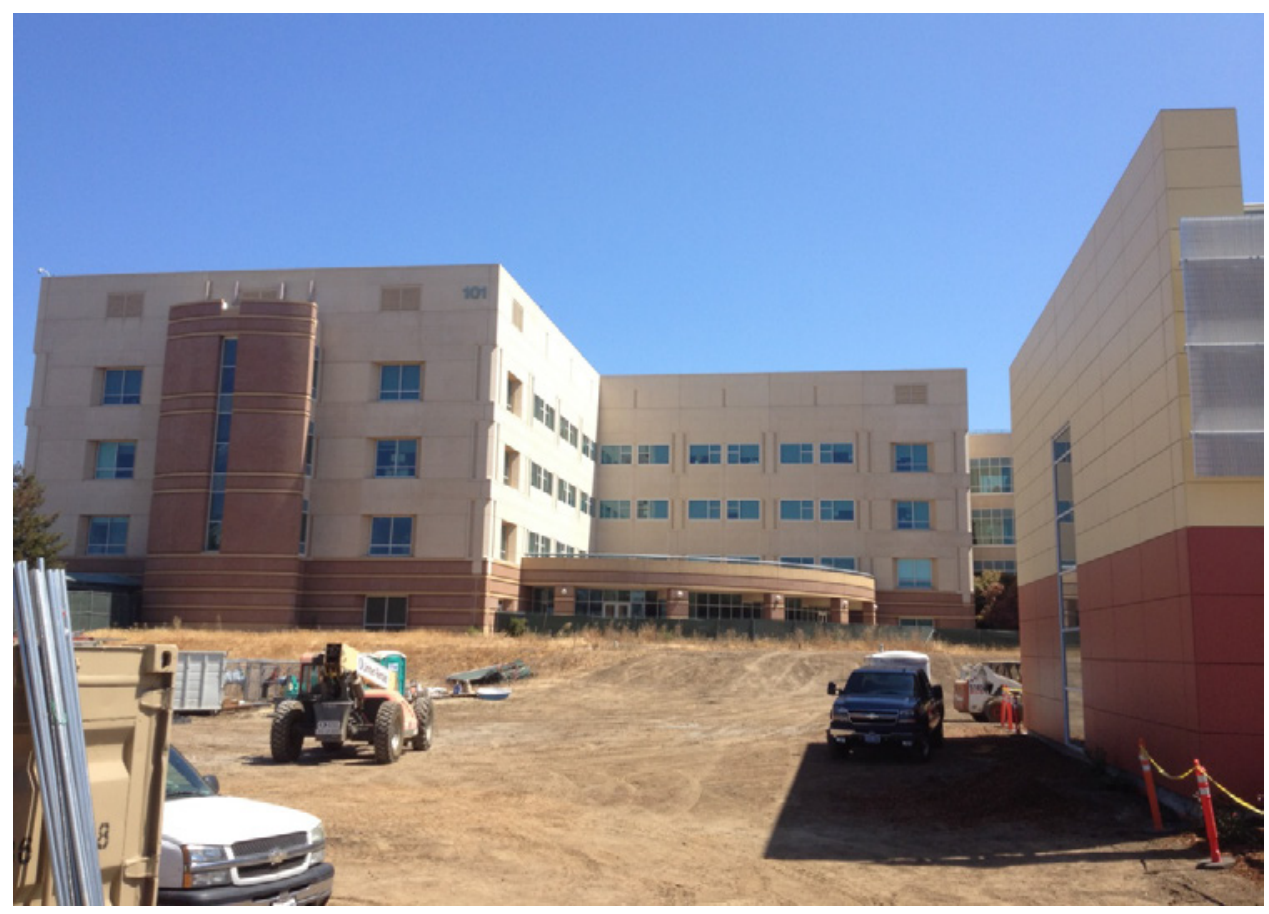

Figure 18. Photograph of Building 101, Palo Alto Veterans Affairs Medical Center, California (looking east) (U.S. Geological Survey photograph).

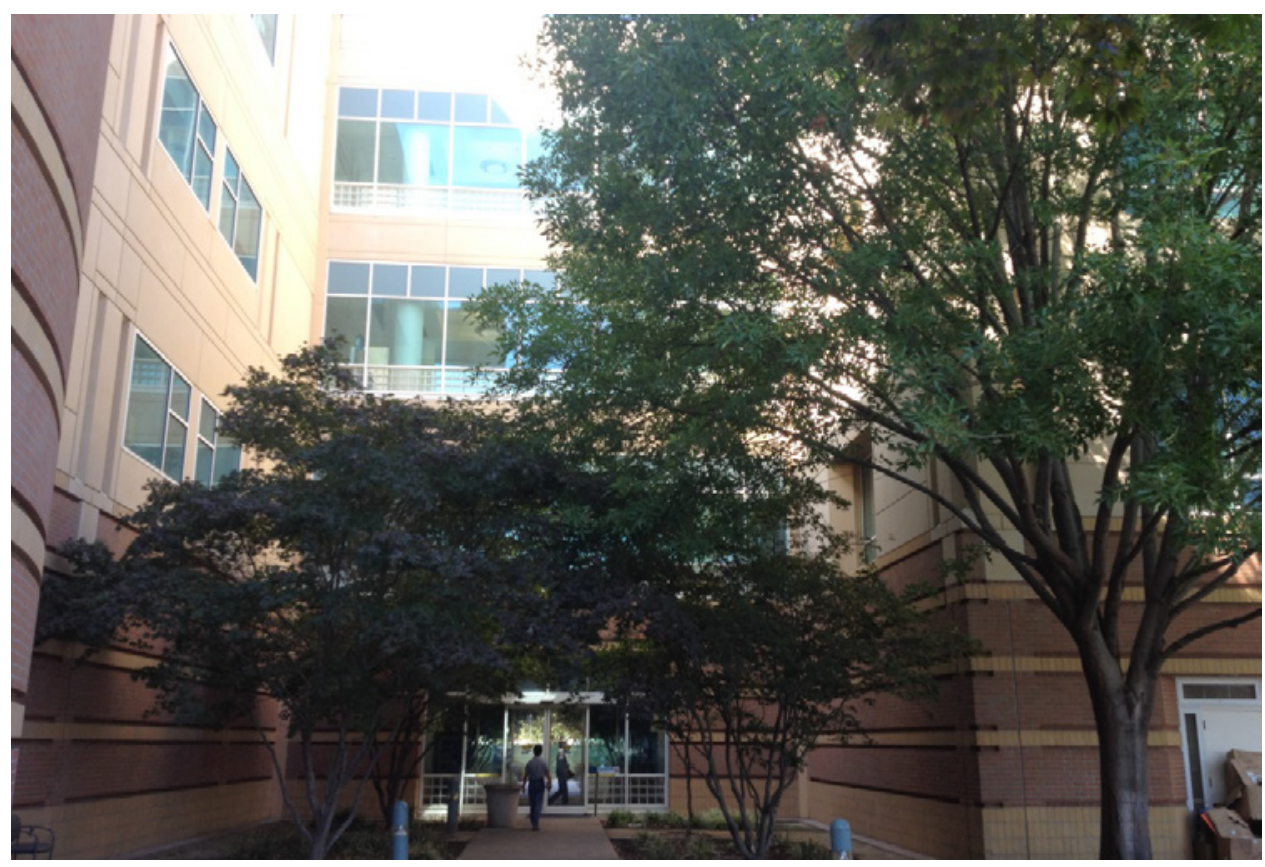

Figure 19. Photograph showing 4-story high connecting structure between Building 100 and Building 101 Palo Alto Veterans Affairs Medical Center, California (U.S. Geological Survey photograph). 


\section{Seismic-Hazard Conditions}

Building 101 is located in an area of very high seismic hazard. The short-period spectral acceleration, $\mathrm{S}_{\mathrm{S}}$, using the current NEHRP recommended provisions for seismic regulations of new buildings and other structures, is $1.98 \mathrm{~g}$. The long-period spectral acceleration, $\mathrm{S}_{1}$, is $0.80 \mathrm{~g}$.

\section{Instrumentation}

A total of 12 accelerometers are deployed in the building at four levels to measure its lateral motion in the reference east-west and north-south directions (fig. 20). Three accelerometers (channels 25 through 27) are placed on the ground-floor ceiling to monitor the first-floor lateral motions. Nine accelerometers (channels 28 through 36) are distributed on the ceilings of the first, second, and third floors to measure floor lateral motions and compute floor torsional motions. The accelerometers are placed at the same corner of the building so that the inter-story drift computations in reference east-west and north-south direction can be performed along the same vertical axis (for example, channels 27, 30, 33, and 36 for the north-south direction drifts). Because the recorder for sensors deployed in Building 101 is located in Building 100, the sensor numbers start from 25. The first 24 channels of the recorder are dedicated to motion sensors in Building 100. The building's channels will be presented separately during the post-processing of recorded data.

The building's accelerometers are complemented by a three-component seismic accelerometer located at a free-field site (NSMP Station No. 1872), approximately $330 \mathrm{ft}$ away from the building to monitor ground shaking without interference from the building's earthquake response. 
U.S. Department of Veterans Affairs

Palo Alto, CA- Steel Moment Frame, Four Story Hospital Building Building No: 101

NSMP Station No: 1869
Revision Number: 8

Revised on $10 / 10 / 2012$
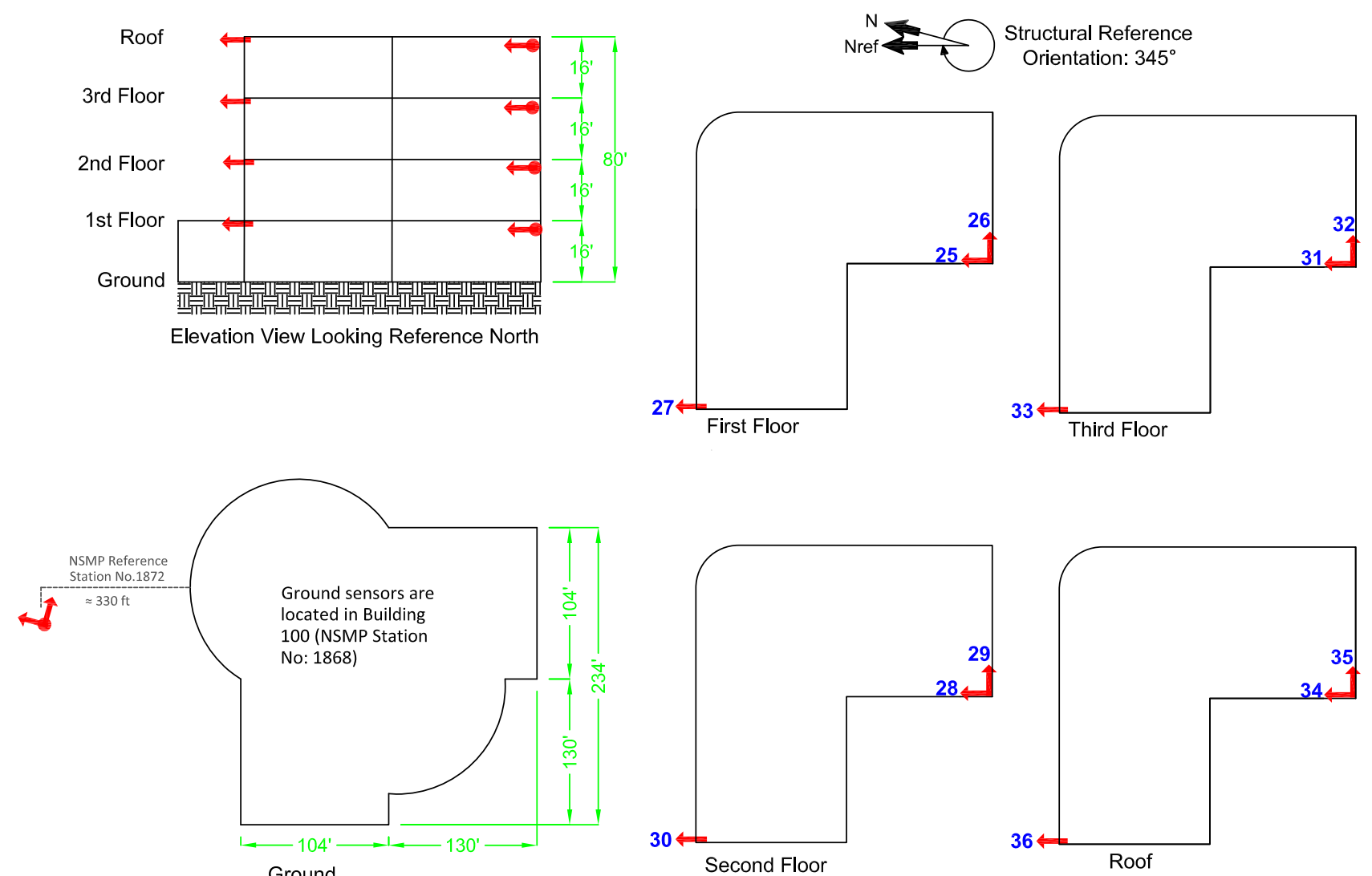

\section{₹USGS}

Figure 20. Diagram of sensor layout showing a total of 12 sensors in Building 101, Palo Alto Veterans Affairs Medical Center, California. 


\section{NSMP Station 1870-Menlo Park, California: Center Core Building, Building No. 334}

\section{Building Description}

Building 334 located in Menlo Park, California, is part of the VA Palo Alto Health Care System (http://www.paloalto.va.gov). This building (fig. 21 through fig. 23) has not been significantly modified since it was built in 1998. This steel braced moment-resisting frame building, approximately $153,100 \mathrm{ft}^{2}$, has an irregular shape as it is composed of three different blocks divided by two seismic joints. The building also has a courtyard located on the north side. This building has two stories located above ground and a basement level. Typical floor and roof construction is composed of composite slabs made from 1.5-inch metal decking with 8 inches of lightweight concrete. The composite slab is supported by steel columns. The buildings lateral force resisting system consists of steel moment-resisting frames. The columns supporting this building are resting on isolated spread footings.

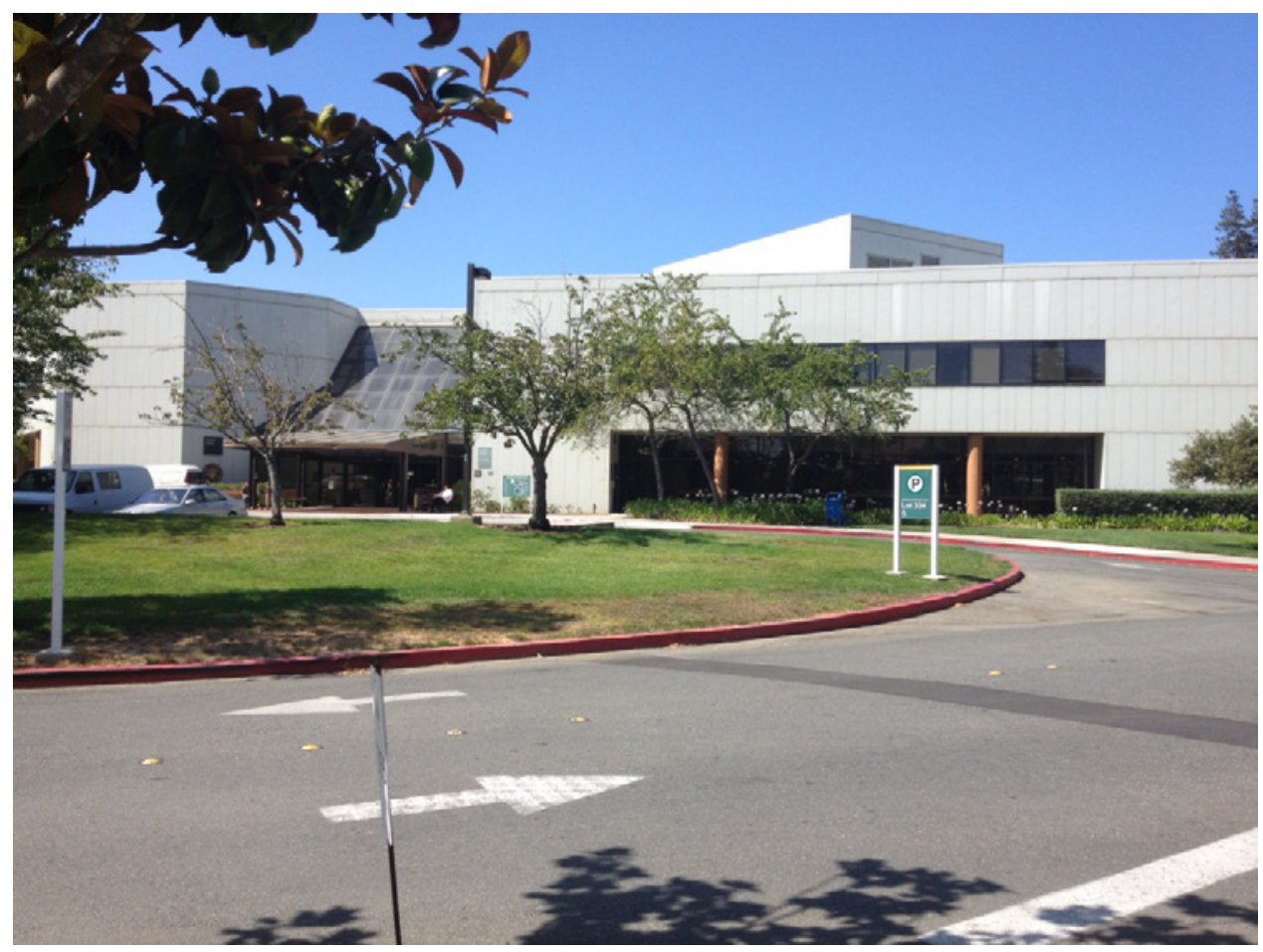

Figure 21. Photograph of Building 334, Menlo Park Veterans Affairs Medical Center, California (front view) (U.S. Geological Survey photograph). 


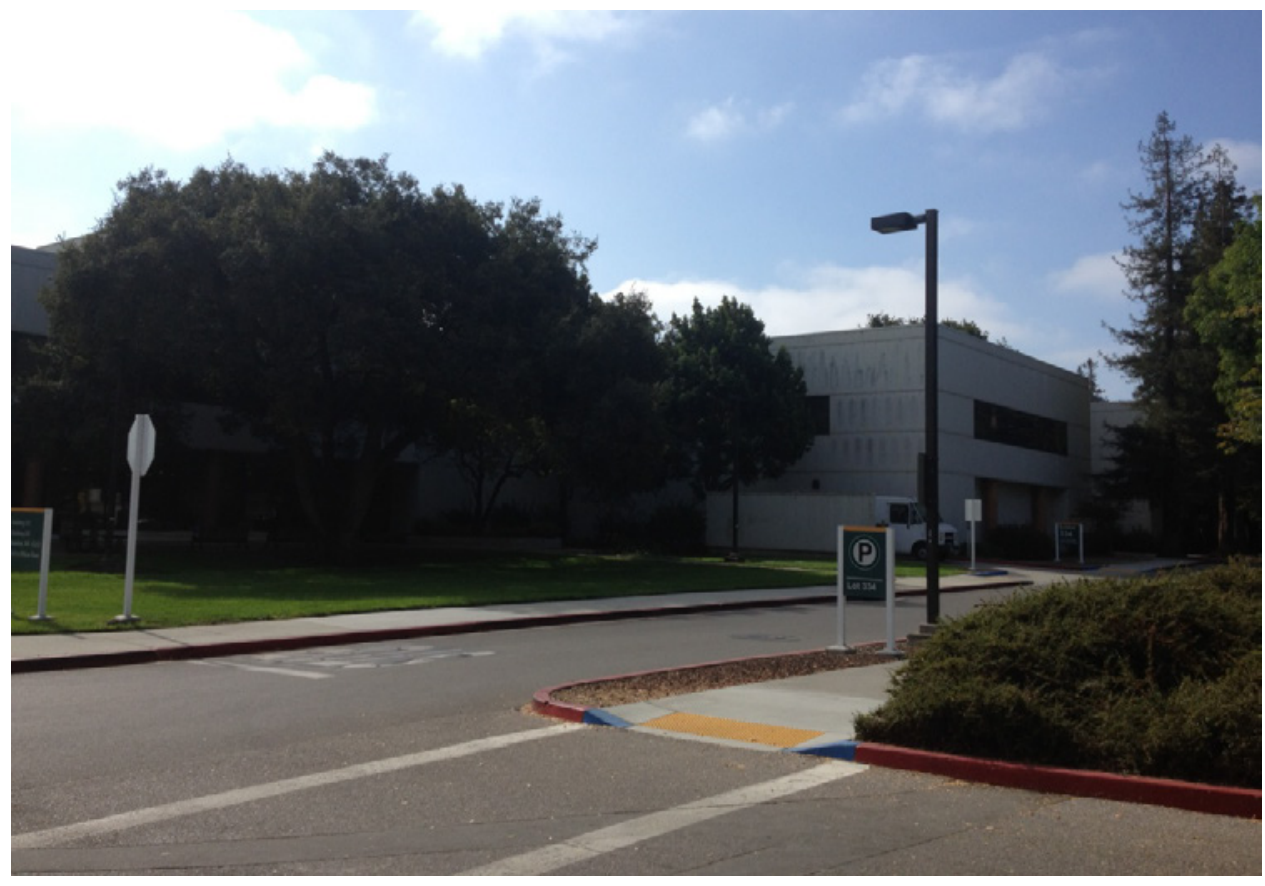

Figure 22. Photograph of Building 334, Menlo Park Veterans Affairs Medical Center, California (looking west) (U.S. Geological Survey photograph).

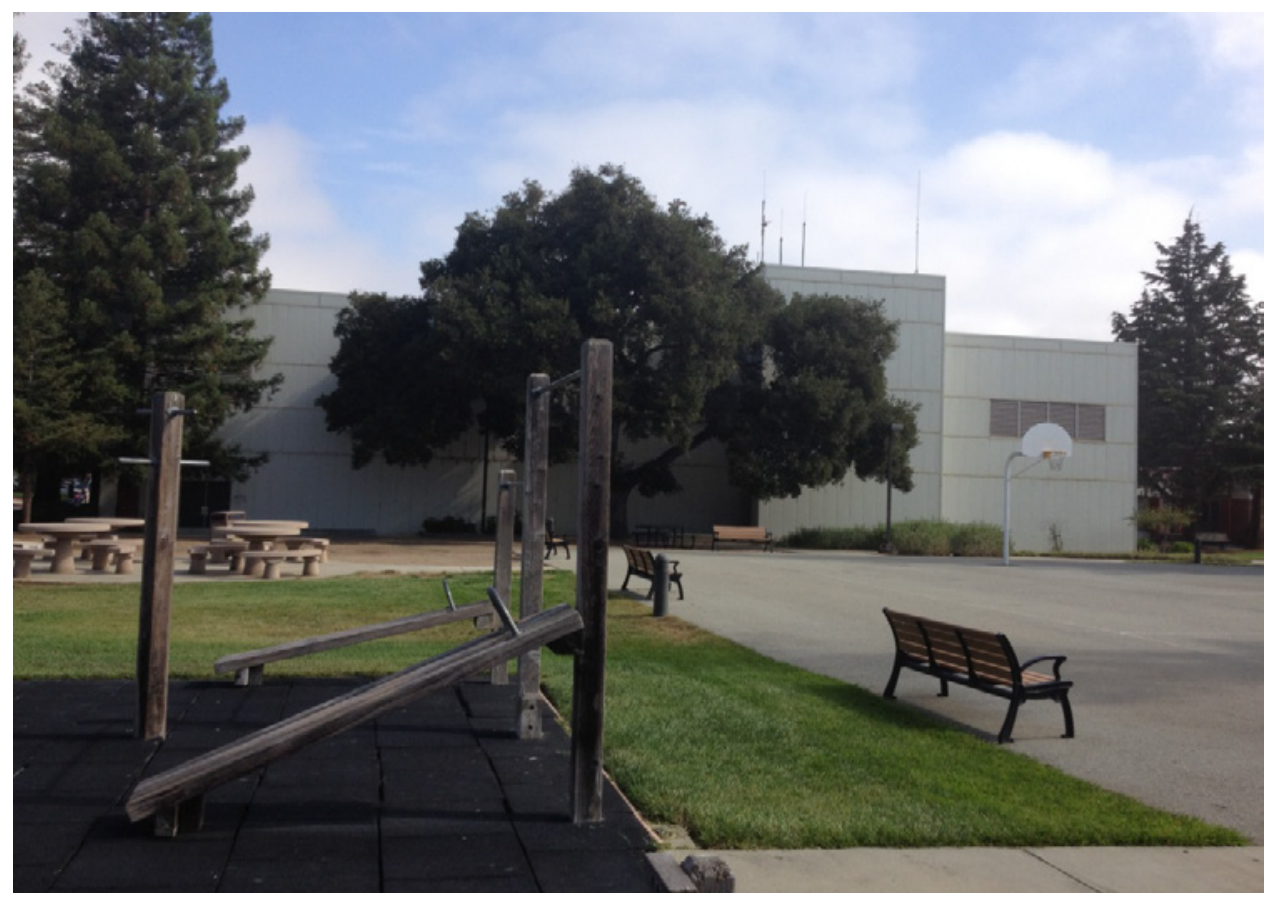

Figure 23. Photograph of Building 334, Menlo Park Veterans Affairs Medical Center, California (looking north) (U.S. Geological Survey photograph). 


\section{Seismic-Hazard Conditions}

The building is located in an area of very high seismic hazard. The short-period spectral acceleration, $\mathrm{S}_{\mathrm{S}}$, using the current NEHRP recommended provisions for seismic regulations of new buildings and other structures, is $1.50 \mathrm{~g}$. The long-period spectral acceleration, $\mathrm{S}_{1}$, is $0.69 \mathrm{~g}$.

\section{Instrumentation}

The building is split into three blocks by two seismic joints. A total of 21 accelerometers are deployed in the building at critical locations to capture translational and torsional motions of each block at each floor level (fig. 24). A triaxial accelerometer (channels 1 through 3) is placed on the basement level to measure the three components of input ground motion. Four accelerometers (channels 4 through 7) are placed on the first floor to measure the lateral floor motions of the side blocks in the reference east-west and north-south directions. Likewise, four accelerometers (channels 8 through 13) are placed on the first-floor ceiling level to monitor the second-floor lateral motion and compute floor torsional motion. Another seven accelerometers (channels 15 through 21) are placed on the second-floor ceiling level to measure the roof lateral motion along the reference directions, and to compute diaphragm torsional response.

The building accelerometers are complemented by a three-component seismic accelerometer located at a reference site (NSMP Station No. 1871), approximately $300 \mathrm{ft}$ away from the building, to monitor ground shaking without interference from the building's earthquake response. 
U.S. Department of Veterans Affairs

Menlo Park, CA - Steel Moment Frame, Two-Story Hospital Building

Building No: 334

NSMP Station No: 1870

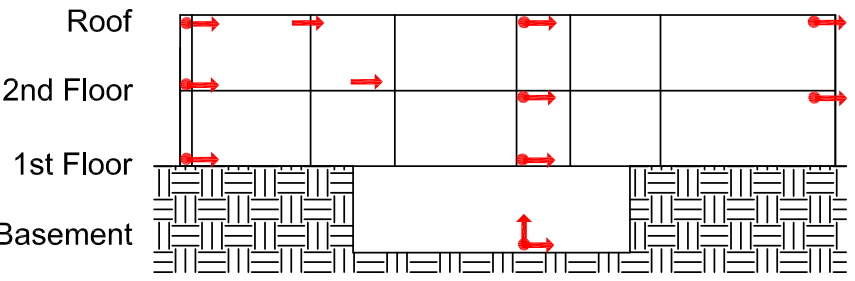

Elevation View Looking Reference West

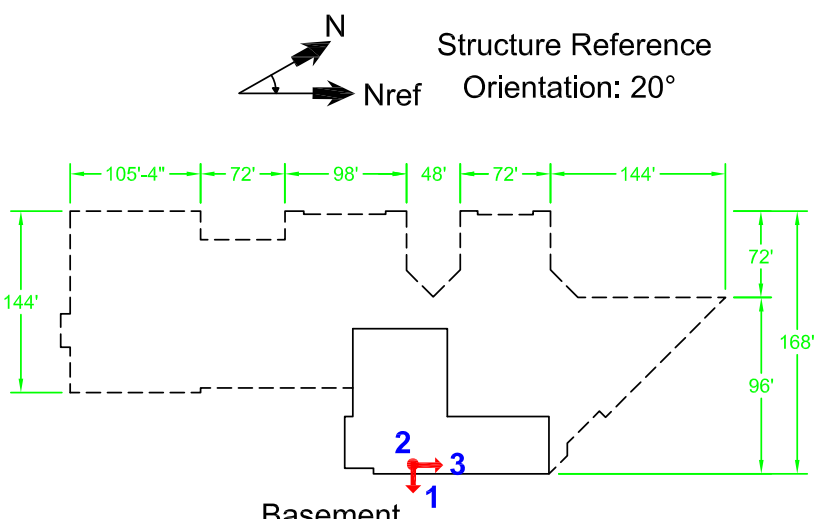

Basement
NSMP Reference Station No.187

Station No.1871

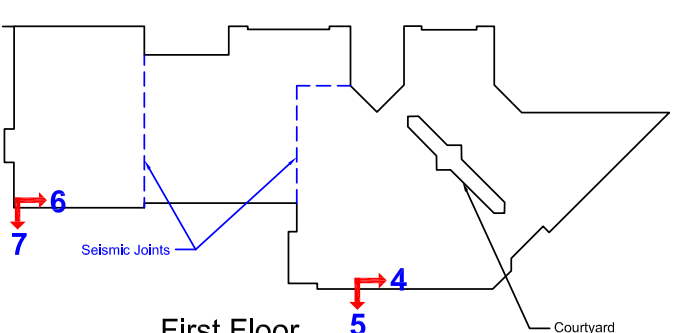

First Floor

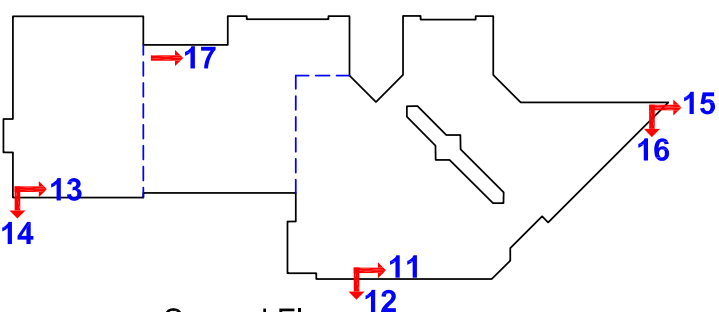

Second Floor

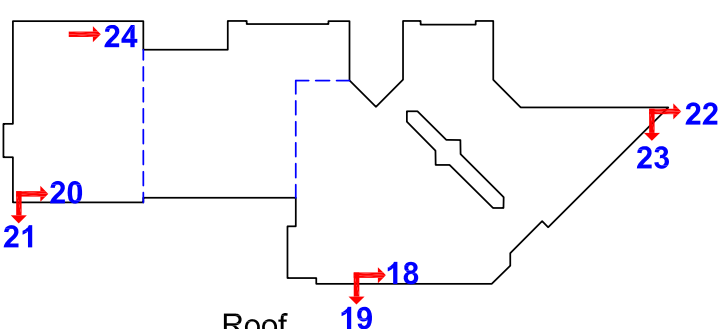

Revision Number: 13

Revised on $10 / 10 / 2012$

\section{ZUSGS IDSTIDL ARSS|}

Figure 24. Diagram of sensor layout showing a total of 24 sensors in Building 334, Menlo Park Veterans Affairs Medical Center, California. 


\section{NSMP Station 1226-Livermore, California: Medical, Surgical and Neurological (MS and N), Building No. 62}

\section{Building Description}

Building 62 located in Livermore, California, is part of the VA Palo Alto Health Care System (http://www.paloalto.va.gov). This six-story, reinforced-concrete structure has approximately 74,200 $\mathrm{ft}^{2}$ (fig. 25 and fig. 26). No seismic retrofitting has been done since it was built in 1948. The building has a rectangular plan with a center protrusion in the southern direction. The base dimensions of the rectangular plan measure 286 by $49 \mathrm{ft}$. There is a centrally located mechanical penthouse above the core at the roof, next to the elevator shaft. The walls are comprised of cast-in-place concrete slabs supported by concrete beams and girders and concrete shear walls. The foundation is composed of isolated spread footings below the columns and continuous footings under the shear walls.

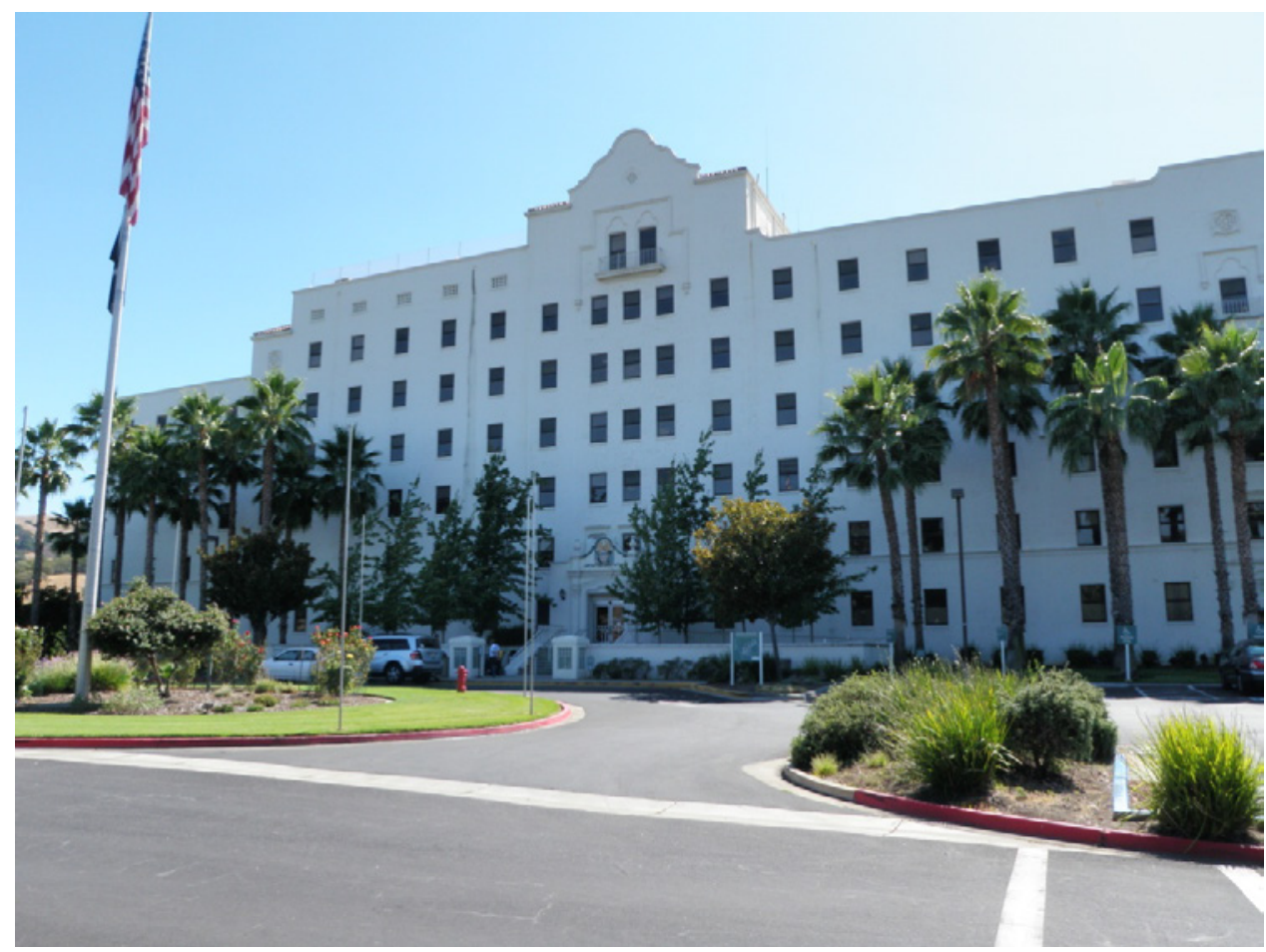

Figure 25. Photograph of Building 62, Livermore Veterans Affairs Medical Center, California (front view) (U.S. Geological Survey photograph). 


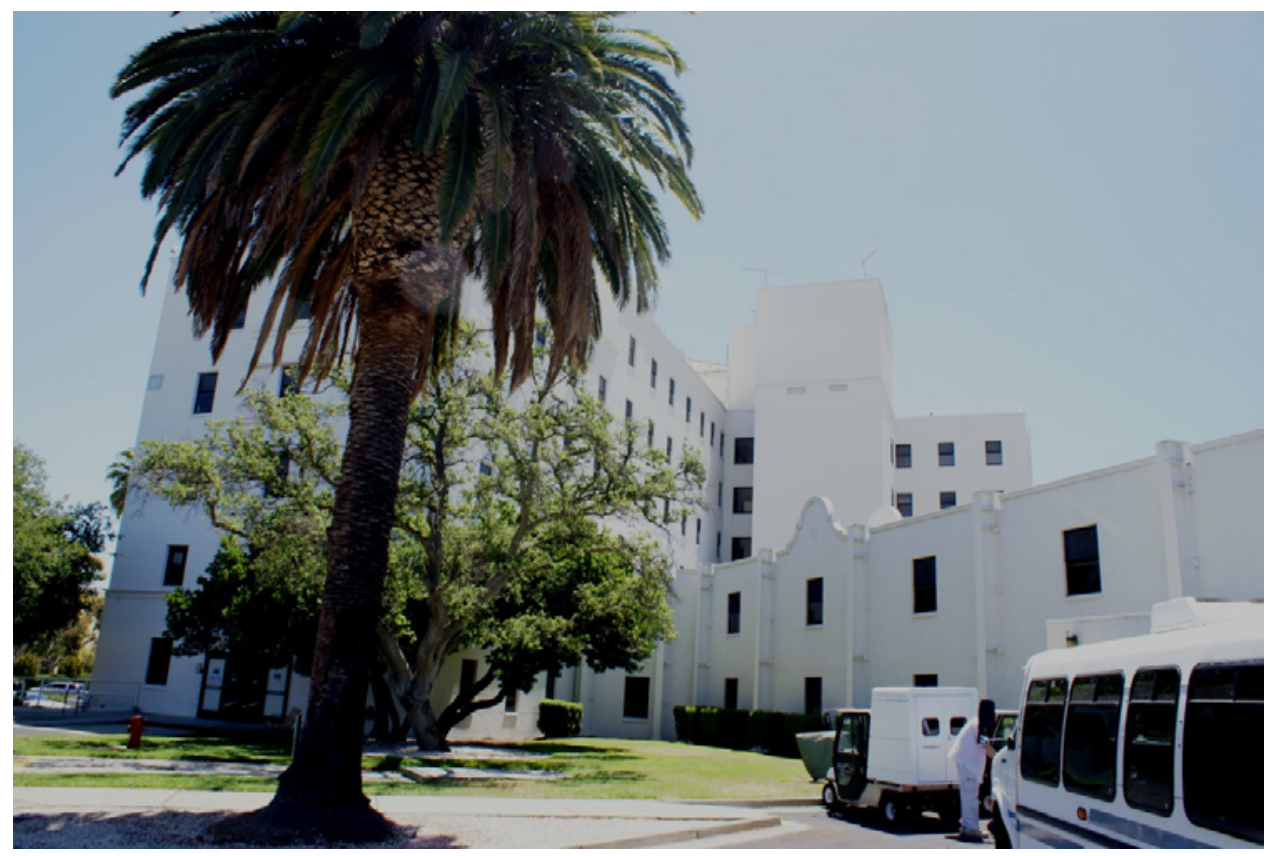

Figure 26. Photograph of Building 62, Livermore Veterans Affairs Medical Center, California (back side of the building looking north) (U.S. Geological Survey photograph).

\section{Seismic-Hazard Conditions}

The building is located in an area of very high seismic hazard. The short-period spectral acceleration, $\mathrm{S}_{\mathrm{S}}$, using the current NEHRP recommended provisions for seismic regulations of new buildings and other structures, is $1.50 \mathrm{~g}$. The long-period spectral acceleration, $\mathrm{S}_{1}$, is $0.60 \mathrm{~g}$.

\section{Instrumentation}

A total of 21 accelerometers are deployed in Building 62 to measure its lateral response at each floor level (fig. 27 and fig. 28). A triaxial accelerometer (channels 1 through 3 ) is placed in the basement to measure ground shaking in three orthogonal directions as input motion to the building. Two accelerometers (channels 4 and 5) are placed on the ceiling of the basement floor to measure the lateral motion of the first floor in the reference east-west and north-south direction. Similarly, two accelerometers (channels 6 and 7) are placed on the first-floor ceiling to measure second-floor lateral motion. The second-floor and the third-floor ceilings are similarly instrumented with three accelerometers each (channels 8 through 13). Four accelerometers (channels 14 through 17) are placed on the fourth-floor ceiling level. The fifth-floor ceiling is monitored by three accelerometers (channels 18 through 20). Another four accelerometers (channels 21 through 24) are placed on the sixth-floor ceiling to measure the lateral floor motion of the roof in two orthogonal directions. For example for the fifth floor, the floor torsional motion can be computed using data either from channel 14 and 15 or from channel 16 and 17 . Throughout the building, a rigid diaphragm behavior is expected to occur due to a thick concrete slab.

As shown in figure 29, the building accelerometers are complemented by a threecomponent seismic accelerometer located at a free-field site (NSMP Station No. 1874), approximately $300 \mathrm{ft}$ away from the building to monitor ground shaking without interference from the building's earthquake response. 
U.S. Department of Veterans Affairs

Livermore, CA - Reinforced Concrete, Six-Story Hospital Building

Building No: 62

NSMP Station No: 1226
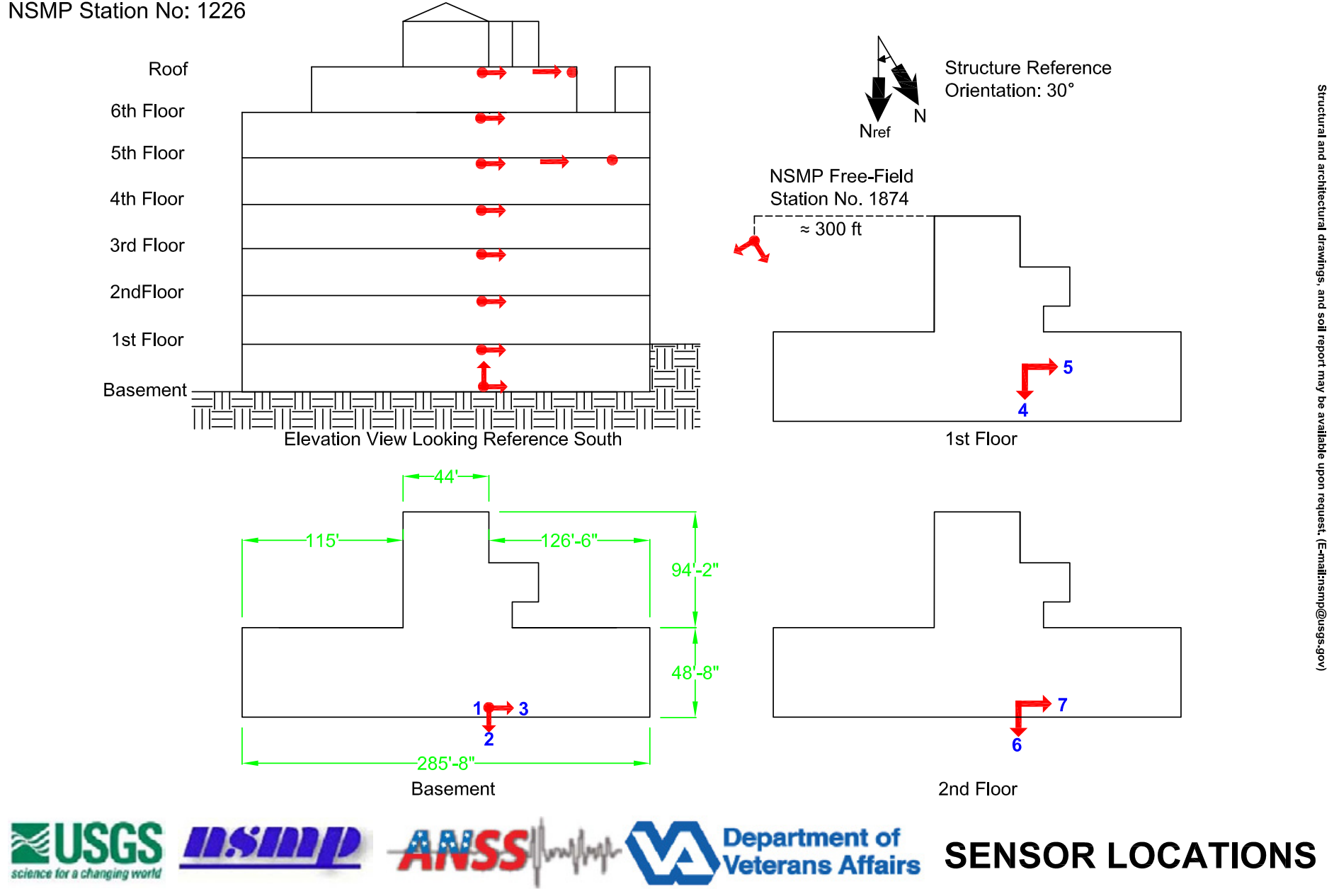

Revision Number: 8

Revised on 10/10/2012

Page 1 of 2

Figure 27. Diagrams of sensor layout showing 24 sensors in of Building 62, Livermore Veterans Affairs Medical Center, California (page 1 of 2; see also fig. 28). 
U.S. Department of Veterans Affairs

Livermore, CA - Reinforced Concrete, Six-Story Hospital Building

Building No: 62

NSMP Station No: 1226

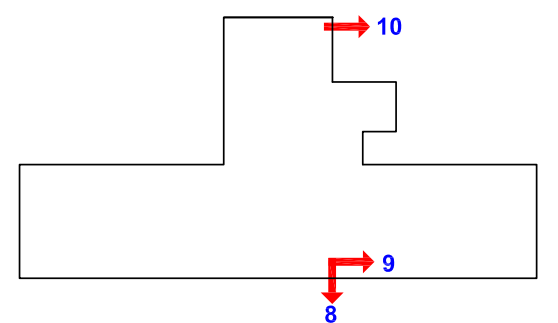

3rd Floor

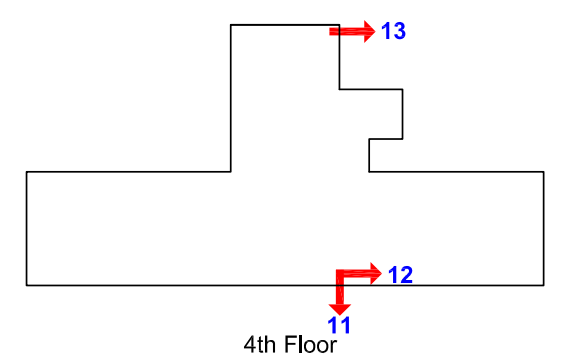

4th Floor
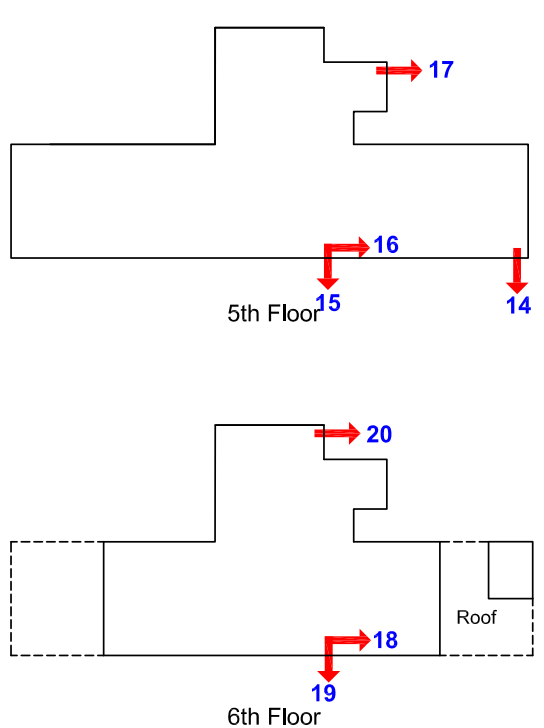

6th Floor
Revision Number: 8

Revised on 10/10/2012

Page 2 of 2
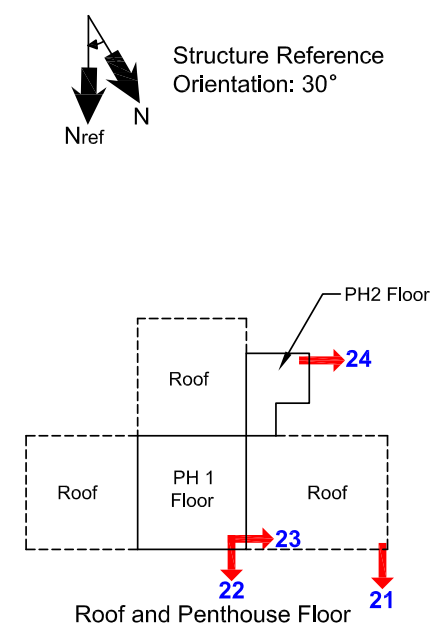

\section{ZUSGS IDSTIDL ARSS|}

Figure 28. Diagrams of sensor layout showing 24 sensors in of Building 62, Livermore Veterans Affairs Medical Center, California (page 2 of 2; see also fig. 27). 


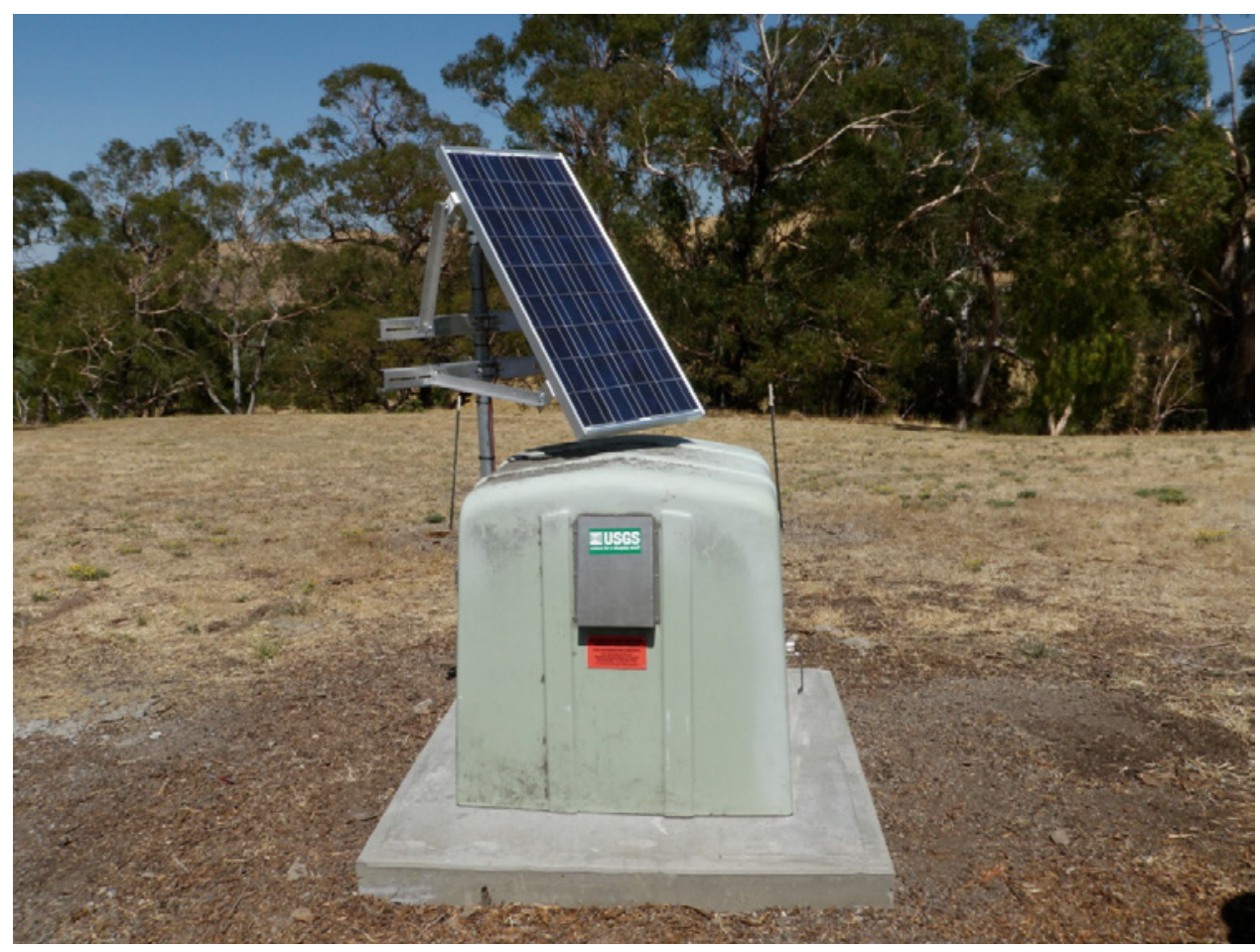

Figure 29. Photograph of free-field station (NSMP Station No. 1874) at Livermore Veterans Affairs Medical Center, California (U.S. Geological Survey photograph).

\section{NSMP Station 1875-San Francisco, California: Ambulance Care/Clinical Support Building, Building No. 200}

\section{Building Description}

Building 200 is located in San Francisco, California, is part of the VA San Francisco Medical Center (http://www.sanfrancisco.va.gov). This four-story reinforced concrete structure, built in 1962, has approximately $155,509 \mathrm{ft}^{2}$ (fig. 30). The building is composed of two adjoining rectangular sections, the first being 241 by $103 \mathrm{ft}$, and the second being 102 by $110 \mathrm{ft}$. Story heights for the first floor through the fourth floor are typically $12 \mathrm{ft}$. The basement level is $14 \mathrm{ft} 4$ inches below the ground level. Typical floor and roof construction consists of composite slabs supported by concrete columns. The basement is a concrete slab on grade, and the foundation of the building consists of shallow isolated footings. The building's lateral-force resisting system consists of reinforced concrete frames and shear walls. 


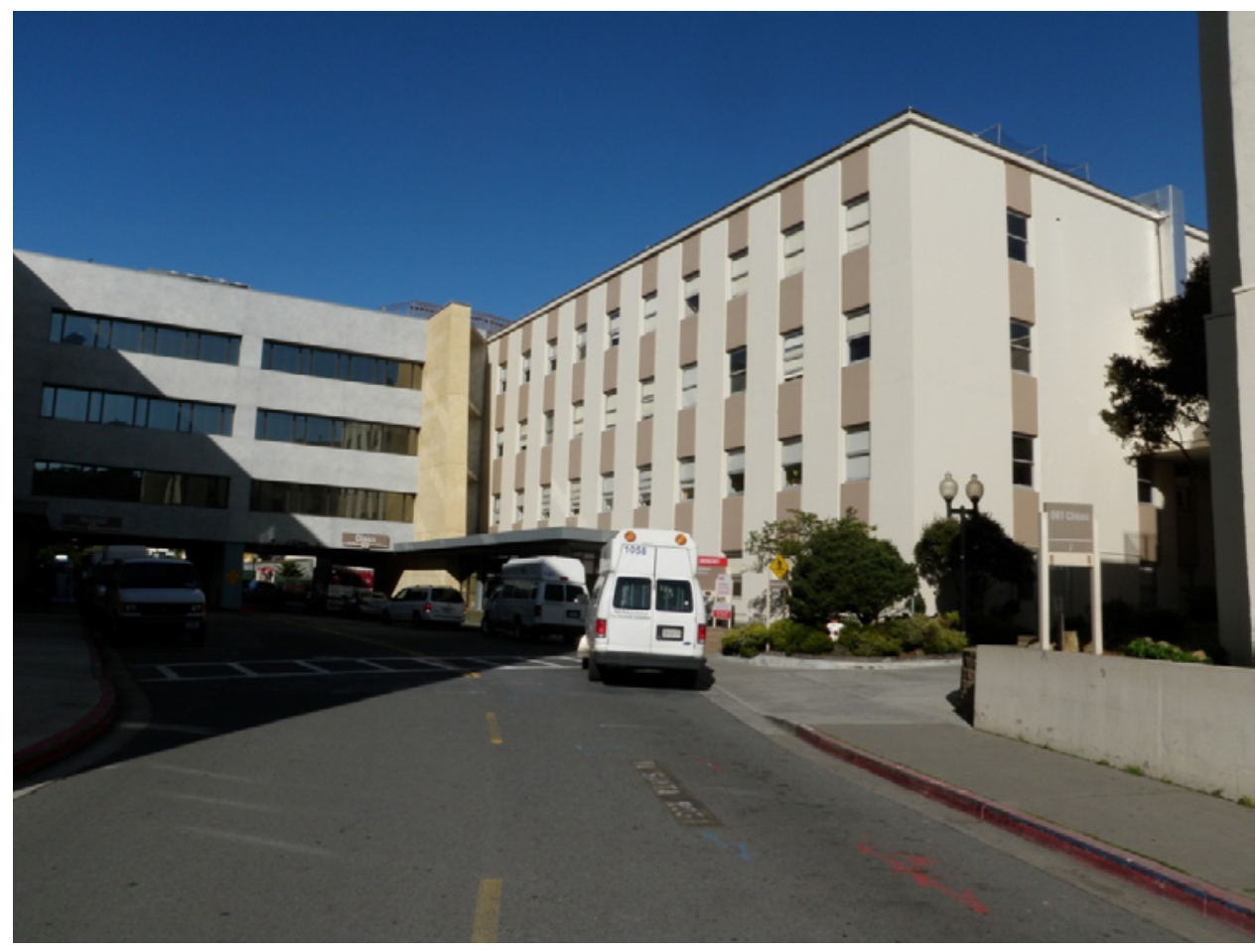

Figure 30. Photograph of Building 200, San Francisco Veterans Affairs Medical Center, California (U.S. Geological Survey photograph).

\section{Seismic-Hazard and Soil Conditions}

Data obtained from geologic maps suggests that the site is underlain by intensely sheared rocks of the Franciscan Formation. This site also borders sites with deposits of Quaternary-age dune sand and weathered Franciscan bedrock. The dune sand is made up of clean, fine to medium grained sand that is underlain by weathered Franciscan bedrock. Bore holes and laboratory tests suggest that the site has a stratigraphy that consists of five to seven feet of medium-dense sand fill that is underlain by medium stiff sandy clay. The sandy clay is underlain by sandstone and claystone bedrock. Groundwater was discovered at approximately $13 \mathrm{ft}$ below ground level.

The building is located in an area of very high seismic hazard. The short-period spectral acceleration, $\mathrm{S}_{\mathrm{S}}$, using the current NEHRP recommended provisions for seismic regulations of new buildings and other structures, is $1.83 \mathrm{~g}$. The long-period spectral acceleration, $\mathrm{S}_{1}$, is $0.95 \mathrm{~g}$.

\section{Instrumentation}

A total of 16 accelerometers are deployed in the building (fig. 31). The three components of ground motion are measured by a triaxial accelerometer (channels 1 through 3 ) placed on the slab of the basement. Two accelerometers (channels 4 and 5) are placed on the basement-floor ceiling to measure lateral motion of the first floor in two orthogonal directions. Three accelerometers (channels 6 through 8) are placed on the first-floor ceiling to measure secondfloor lateral motion in the reference east-west and north-south direction. The floor torsional motion can be computed from channel 6 and 8. Similarly, three accelerometers (channels 9 through 11) are placed on the second-floor ceiling and three accelerometers (channels 12 through 
14) are placed on the third-floor ceiling to measure respective floor lateral motions of the third and fourth floor in two orthogonal directions. The fourth-floor ceiling (roof) is monitored by two accelerometers (channels 15 and 16). Because of the physical constraints, no more than two accelerometers were deployed to monitor the roof motion.

The building accelerometers are complemented by a three-component seismic accelerometer located at a reference site (NSMP Station No. 1876), approximately $330 \mathrm{ft}$ away from the building, to monitor ground shaking without interference from the building's earthquake response. 
U.S. Department of Veterans Affairs

San Francisco, CA - Reinforced Concrete, Four-Story Hospital Building

Building No: 200

NSMP Station No: 1875

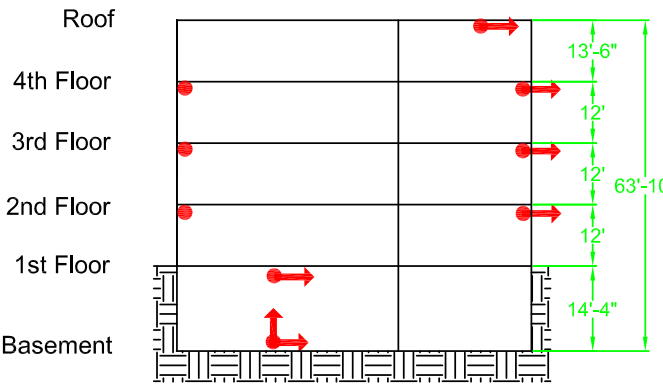

Elevation View Looking Reference North

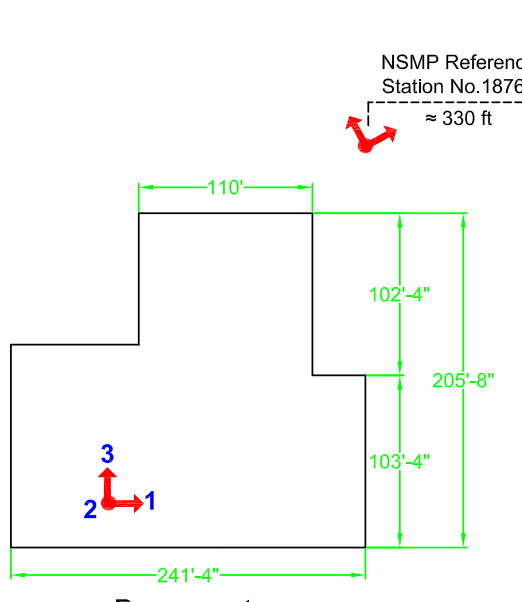

Basement
N Nref

A Structure Reference Orientation: $5^{\circ}$

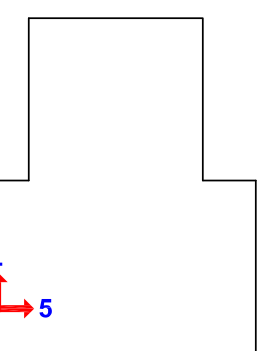

First Floor

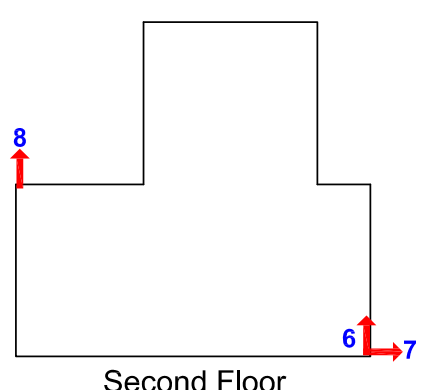

Second Floor
Revision Number: 12

Revised on 10/10/2012

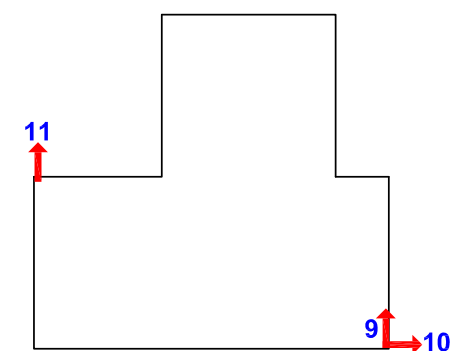

Third Floor

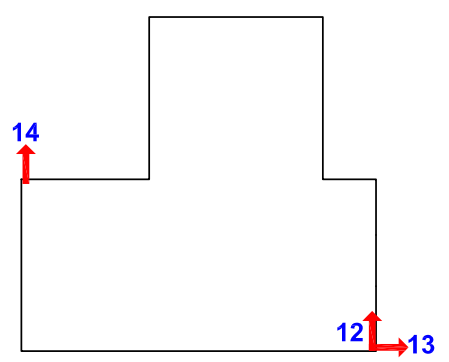

Fourth Floor

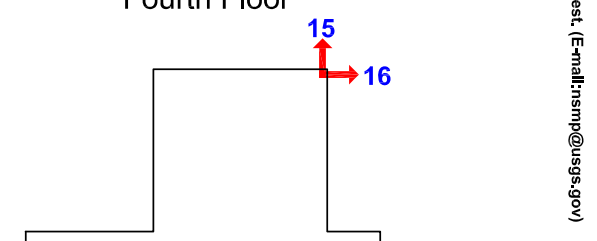

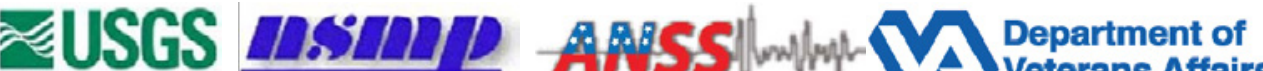

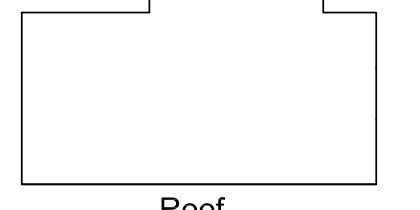

Figure 31. Diagram of sensor layout showing 16 sensors in the Building 200 of the San Francisco Veterans Affairs Medical Center, California. 


\section{NSMP Station 5483-Los Angeles, California: Outpatient Clinic, Building No. 1}

\section{Building Description}

Building 1, located in Los Angeles, California, is part of the VA Greater Los Angeles Healthcare System (http://www.losangeles.va.gov). This five-story structure with two underground parking levels has approximately $201,395 \mathrm{ft}^{2}$ (fig. 32 and fig. 33). It has an irregular plan shape and several offsets in vertical directions. The typical story height is $15 \mathrm{ft}$, although the underground parking levels have heights from higher than $13.5 \mathrm{ft}$ to lower than $10.5 \mathrm{ft}$. The structure's foundation is composed mainly of spread footings to support both exterior and interior columns. Some of the spread footings are isolated, whereas others are combined. The vertical load carrying system and lateral-force resisiting systems both consist of reinforced concrete walls and steel frames.

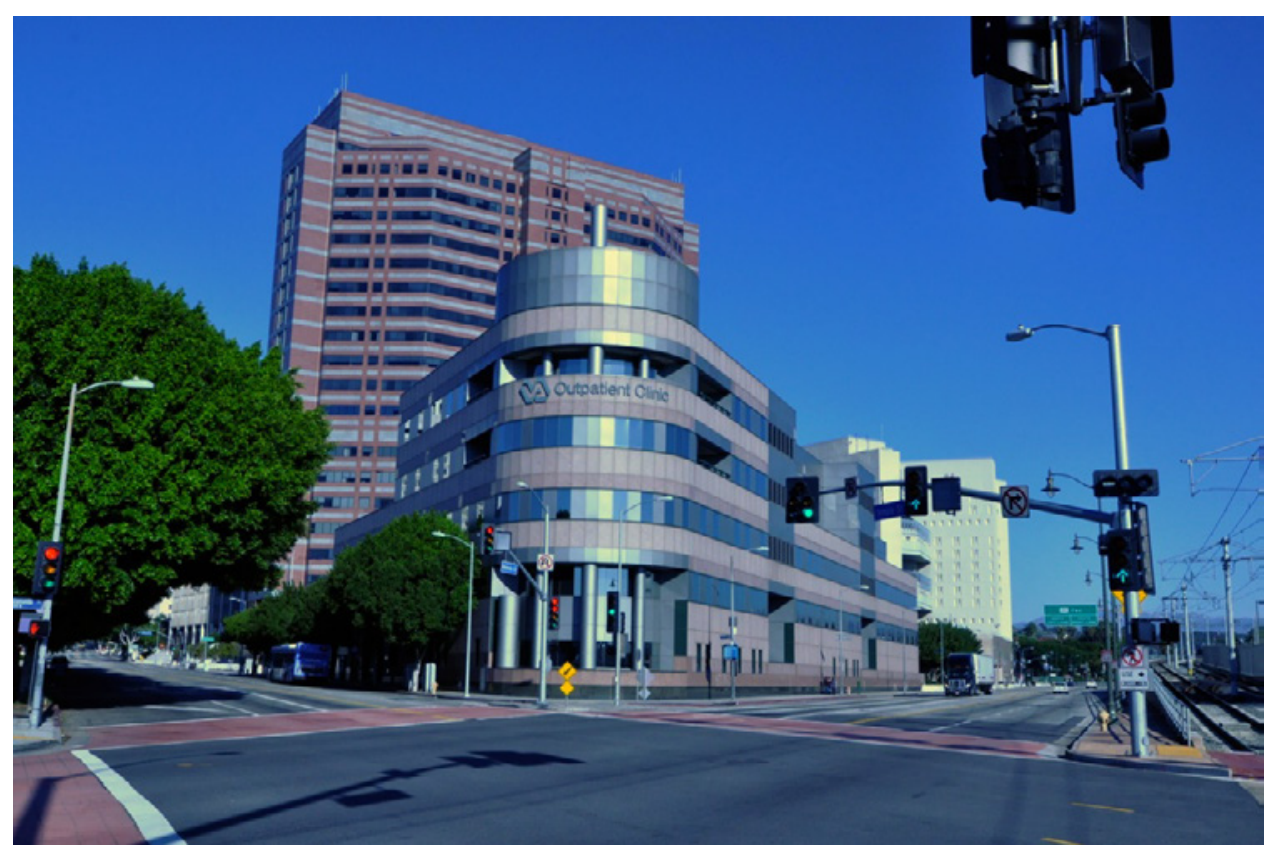

Figure 32. Photograph of Building 1, Los Angeles Veterans Affairs Medical Center, California (side view) (U.S. Geological Survey photograph). 


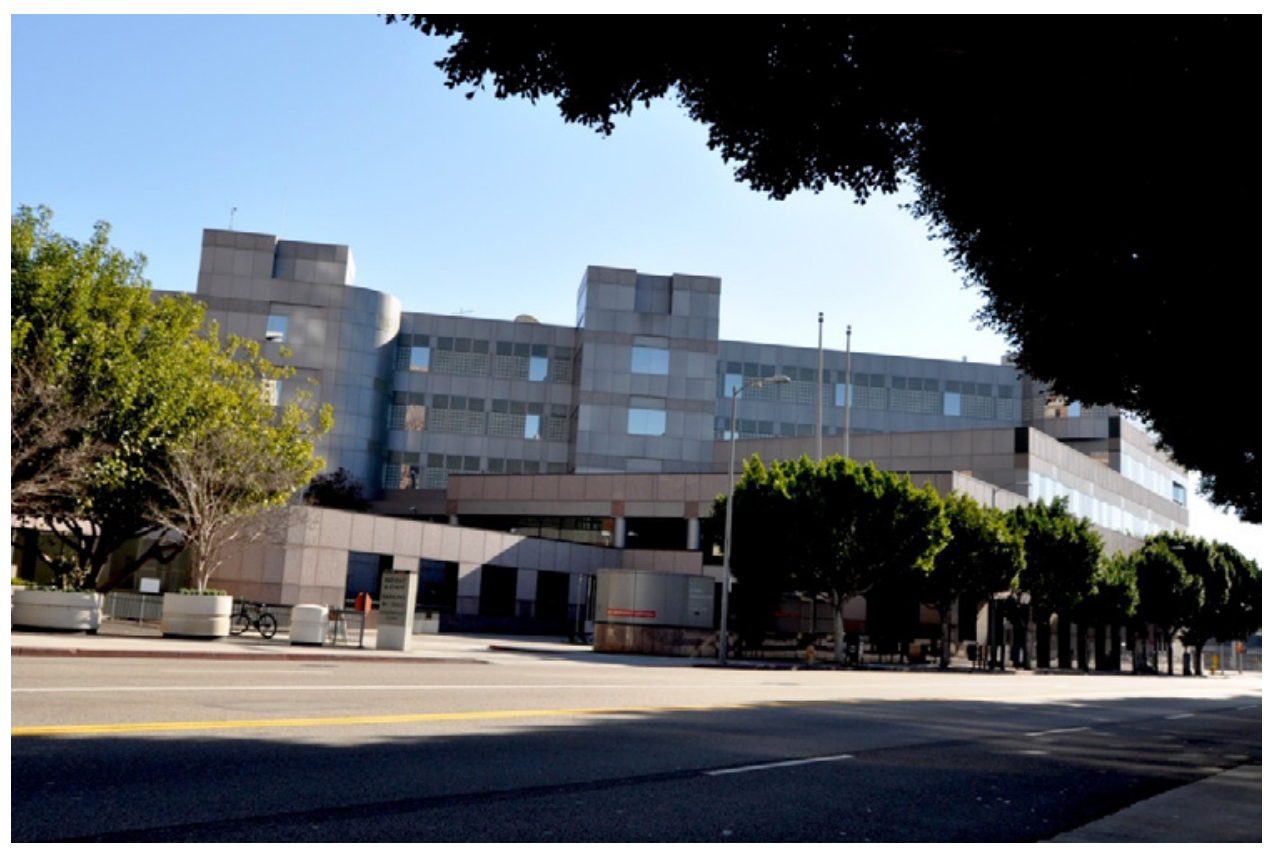

Figure 33. Photograph of Building 1, Los Angeles Veterans Affairs Medical Center, California (looking east; back side view) (U.S. Geological Survey photograph).

\section{Seismic-Hazard Conditions}

The building is located in an area of very high seismic hazard. The short-period spectral acceleration, $\mathrm{S}_{\mathrm{S}}$, using current NEHRP recommended provisions for seismic regulations of new buildings and other structures, is $2.18 \mathrm{~g}$. The long-period spectral acceleration, $\mathrm{S}_{1}$, is $0.73 \mathrm{~g}$.

\section{Instrumentation}

A total of 24 accelerometers are deployed in the building to measure its lateral response in the reference east-west and north-south directions (fig. 34 and fig. 35). A triaxial accelerometer (channels 1, 4, and 5) is placed on the ground of the parking level 2 to measure the three components input to ground motion. Another two accelerometers oriented vertically (channels 2 and 3) are also placed on the parking level 2. The rocking motion of the building can be computed from channels 1, 2, and 3. Two accelerometers (channels 6 and 7) are placed on the ceiling of parking level 2. Another two accelerometers (channels 8 and 9) are placed on the ceiling of parking level 1 to measure slab lateral motions in two orthogonal directions. Fifteen accelerometers (channels 10 through 24) are evenly distributed on the ceilings of the first, second, third, fourth, and fifth floors to monitor their motion in two horizontal directions. The accelerometers are located at the same corners of the building so that inter-story drifts can be computed from likewise oriented accelerometers along the same vertical axes. Because the building has an irregular plan, same direction oriented sensors at each floor level will help to compute torsional motion of each floor.

The building's accelerometers are complemented by a three-component seismic accelerometer located at a free-field site (NSMP Station No. 5484), approximately $655 \mathrm{ft}$ away from the building to monitor ground shaking without interference from the building's earthquake response. 
U.S. Department of Veterans Affairs

Los Angeles, CA - Reinforced Concrete, Five Story Hospital Building

Building No: 1

NSMP Station No: 5483

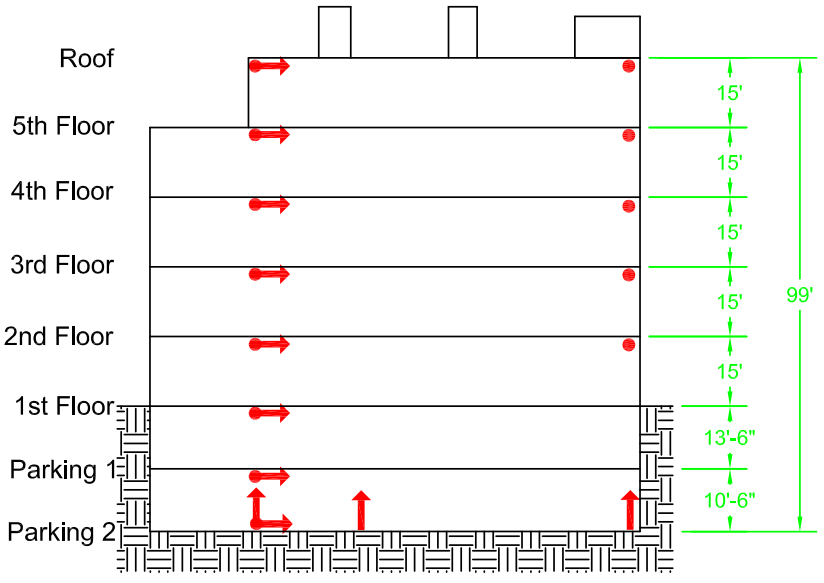

Elevation View Looking Reference West
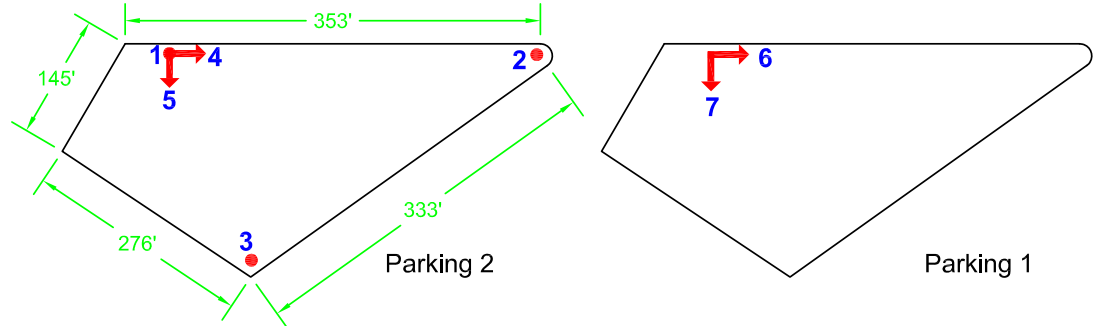

Parking 1

Revision Number: 10

Revised on 10/10/2012

Page 1 of 2
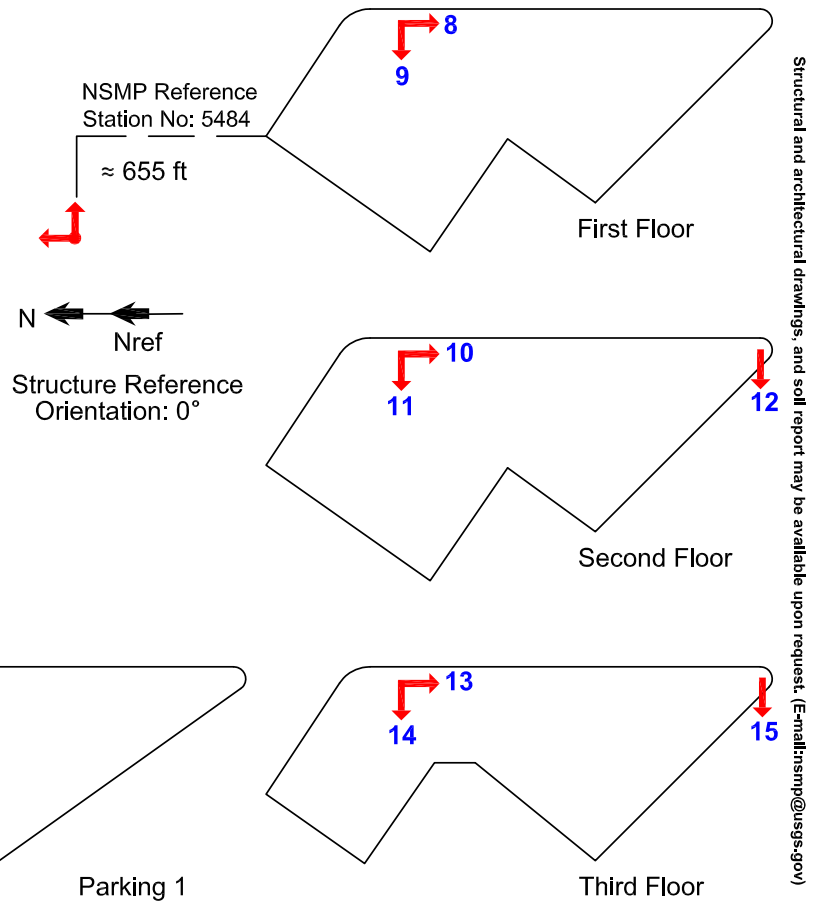

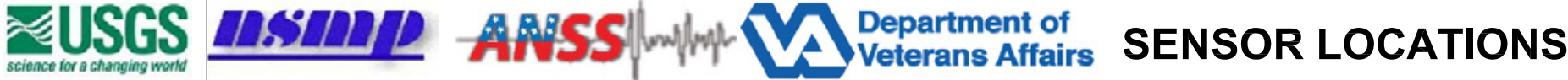

Figure 34. Diagrams of sensor layout showing 24 sensors in Building 1, Los Angeles Veterans Affairs Medical Center, California (page 1 of 2; see also fig. 35). 
U.S. Department of Veterans Affairs

Los Angeles, CA - Reinforced Concrete, Five Story Hospital Building

Building No:

NSMP Station No: 5483
Revision Number: 10

Revised on 10/10/2012

Page 2 of 2

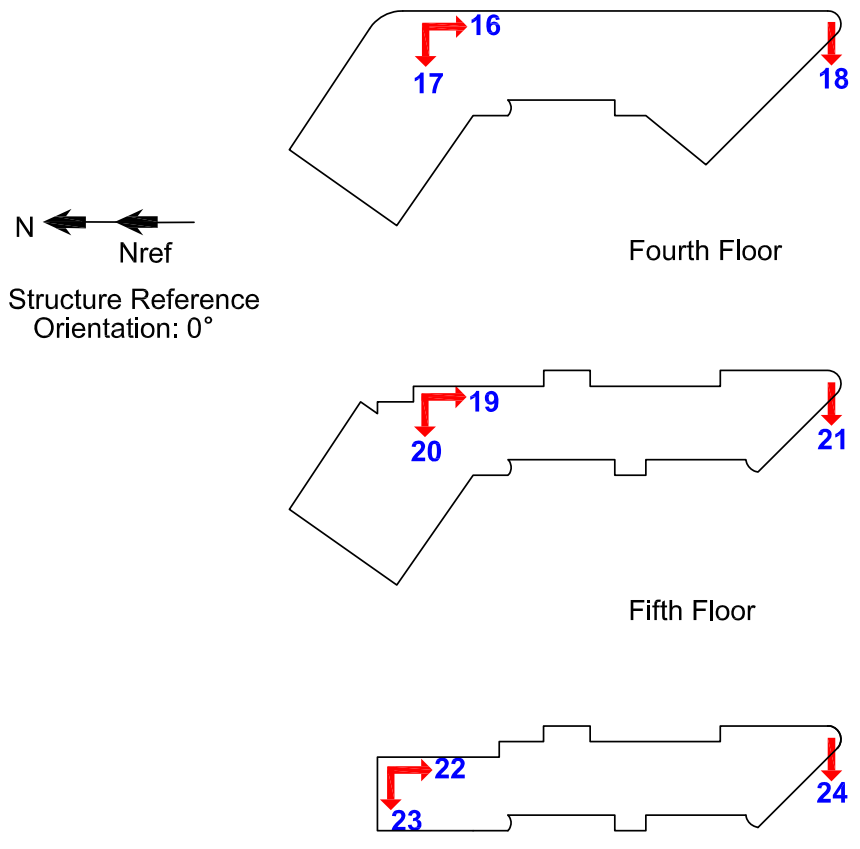

Roof

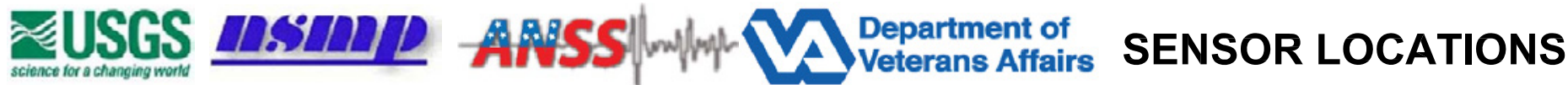

Figure 35. Diagrams of sensor layout showing 24 sensors in Building 1, Los Angeles Veterans Affairs Medical Center, California (page 2 of 2; see also fig. 34). 


\section{NSMP Station 5478-Sepulveda, California: Outpatient Clinical Care, Building No. 10}

\section{Building Description}

Building 10 is located in Sepulveda, California, is part of the VA Greater Los Angeles Healthcare System (http://www.losangeles.va.gov). The building is approximately 101,223 $\mathrm{ft}^{2}$ (fig. 36 through fig. 39). It was originally built in 1952 and later retrofitted in 1998. This building is irregularly shaped with the main wing at 451 by $42 \mathrm{ft}$. The typical story height for this three-story structure is $11.5 \mathrm{ft}$. Typical floor and roof construction consists of composite slabs supported by steel frames. The columns rest on isolated spread footings. The buildings lateralforce resisting system consists of reinforced concrete frames.

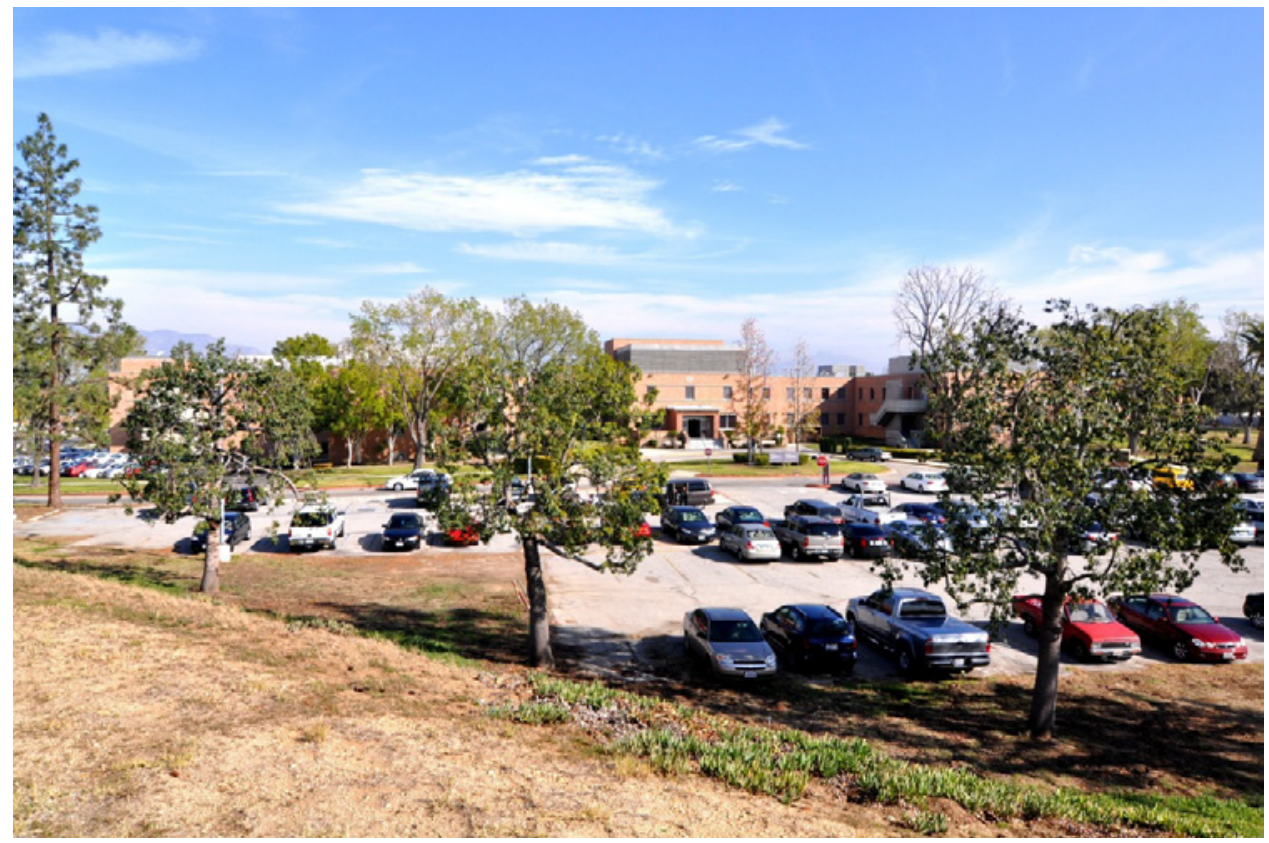

Figure 36. Photograph of Building 10, Sepulveda Veterans Affairs Medical Center, California (front view) (U.S. Geological Survey photograph). 


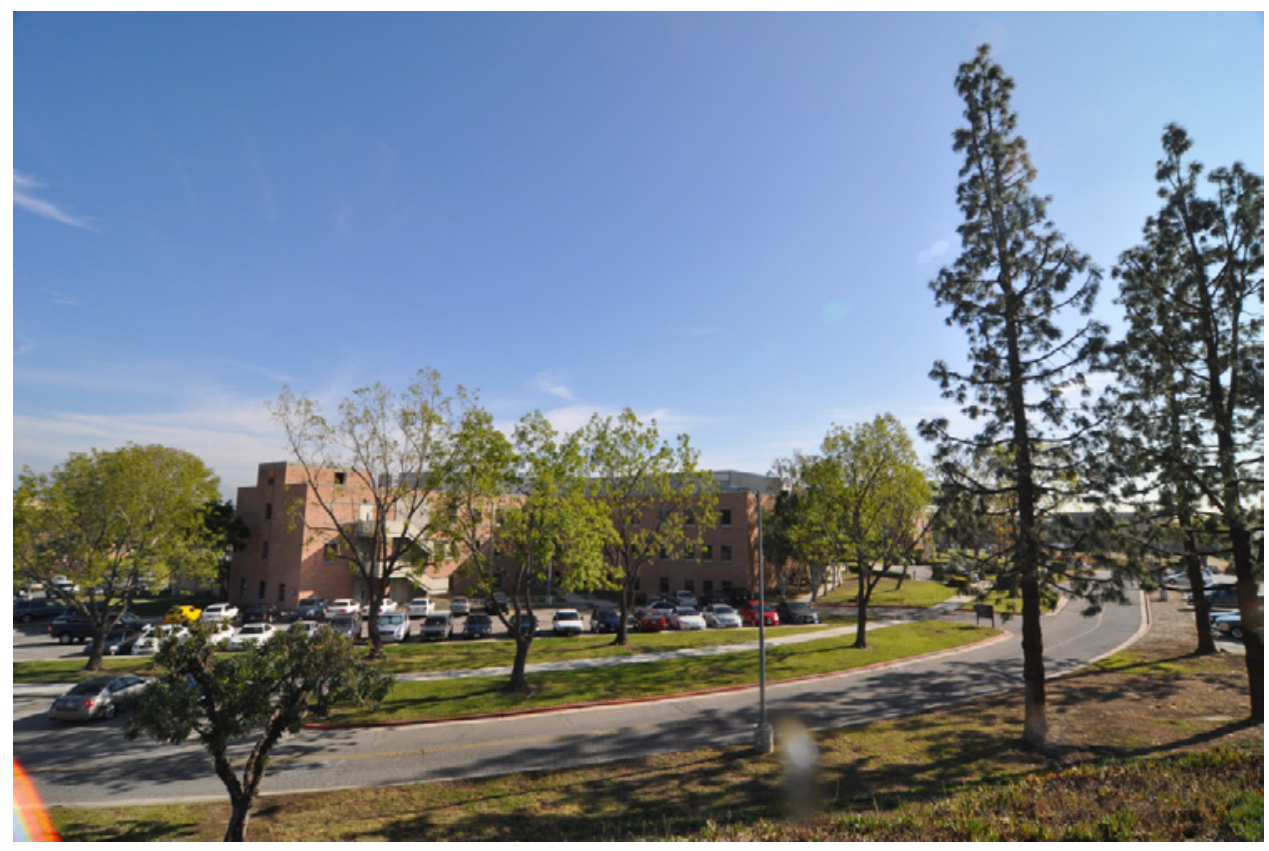

Figure 37. Photograph of Building 10, Sepulveda Veterans Affairs Medical Center, California (looking north) (U.S. Geological Survey photograph).

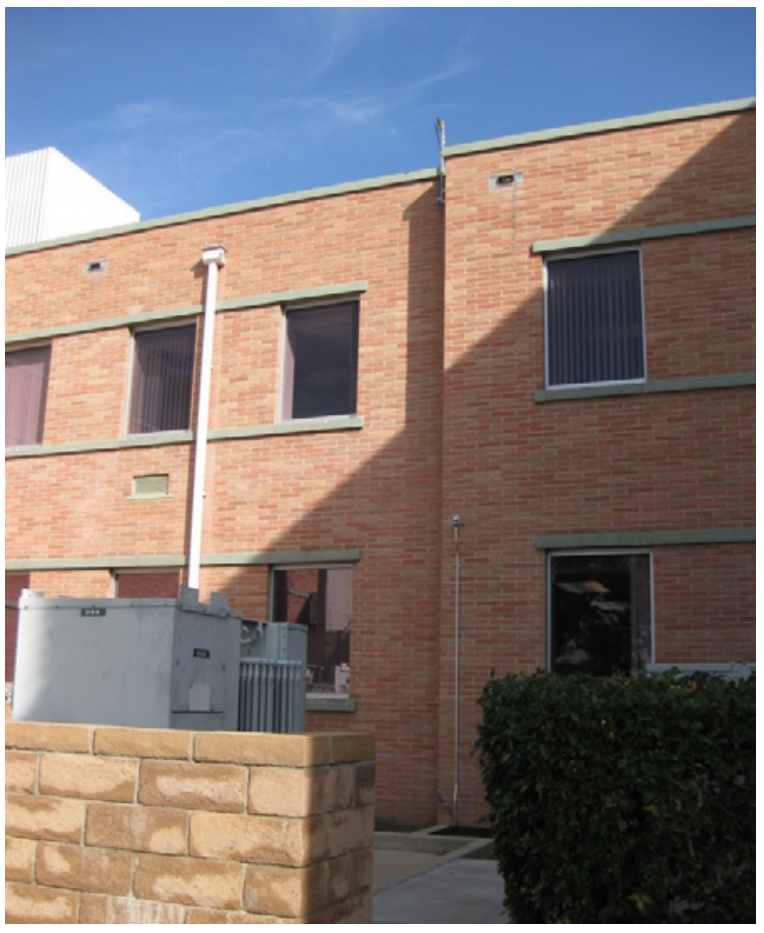

Figure 38. Photograph of Building 10, Sepulveda Veterans Affairs Medical Center, California (side view) (U.S. Geological Survey photograph). 


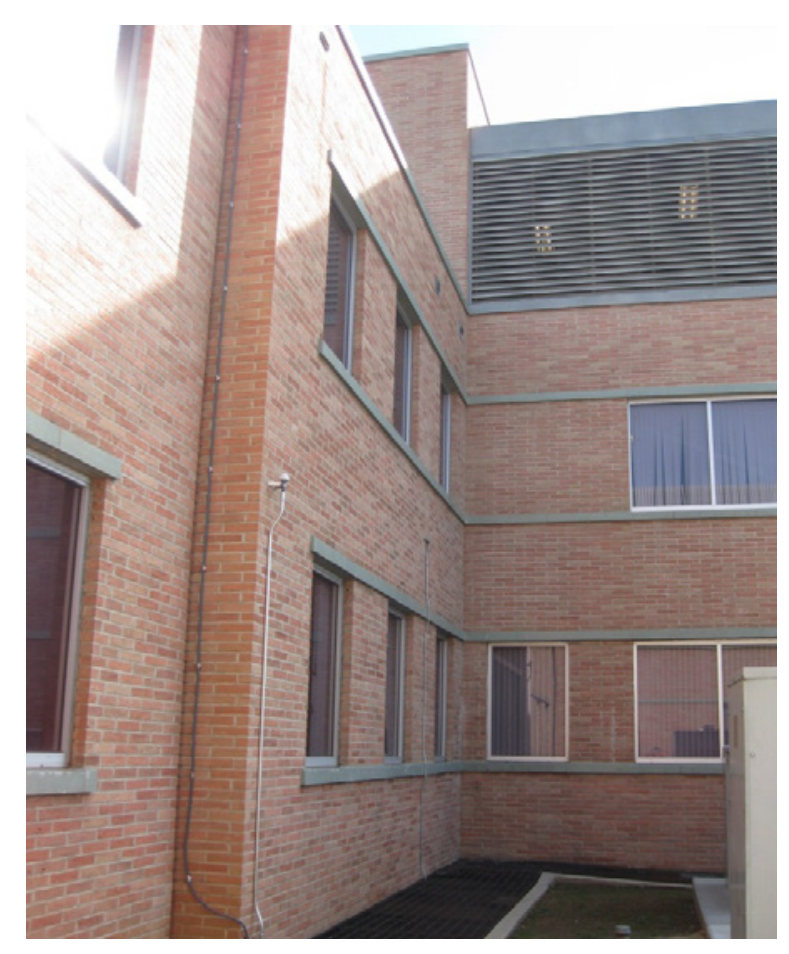

Figure 39. Photograph of Building 10, Sepulveda Veterans Affairs Medical Center, California (side view) (U.S. Geological Survey photograph).

\section{Seismic-Hazard Conditions}

The building is located in an area of very high seismic hazard. The short-period spectral acceleration, $\mathrm{S}_{\mathrm{S}}$, using the current NEHRP recommended provisions for seismic regulations of new buildings and other structures, is $2.10 \mathrm{~g}$. The long-period spectral acceleration, $\mathrm{S}_{1}$, is $0.74 \mathrm{~g}$.

\section{Instrumentation}

A total of 24 accelerometers are deployed in the building at four different levels (fig. 40). A triaxial accelerometer (channels 1 through 3 ) is placed on the ground floor to measure the input ground motion. A vertically oriented accelerometer (channel 4) is also placed on the ground floor so that the rocking motion of the building around the reference east-west axis can be obtained. Two accelerometers (channels 5 and 6 ) are placed on the ground floor to measure the spatial variation of input ground motion due to the lengthy wings of the structure. Eighteen accelerometers (channels 7 through 24) are distributed on ceilings of the ground, first, and second floors to measure lateral floor motion along the reference east-west and north-south directions, and compute torsional response of each floor. Channels 18 and 24 are oriented in the same direction to compute floor diaphragm flexibility. The response of the wings as opposed to the response of the main structure will be computed by comparing channels 7 and 8 with channels 10 and 11 for the first floor and for other floors by using the corresponding channels on similar vertical axes.

The building's accelerometers are complemented by a three-component seismic accelerometer located at a reference site (NSMP Station No. 637), approximately 1,150 ft away from the building to monitor ground shaking without interference from the building's earthquake response. 
U.S. Department of Veterans Affairs

Sepulveda, CA - Steel Moment Frame, Three-Story Hospital Building

Building No: 10

NSMP Station No: 5478

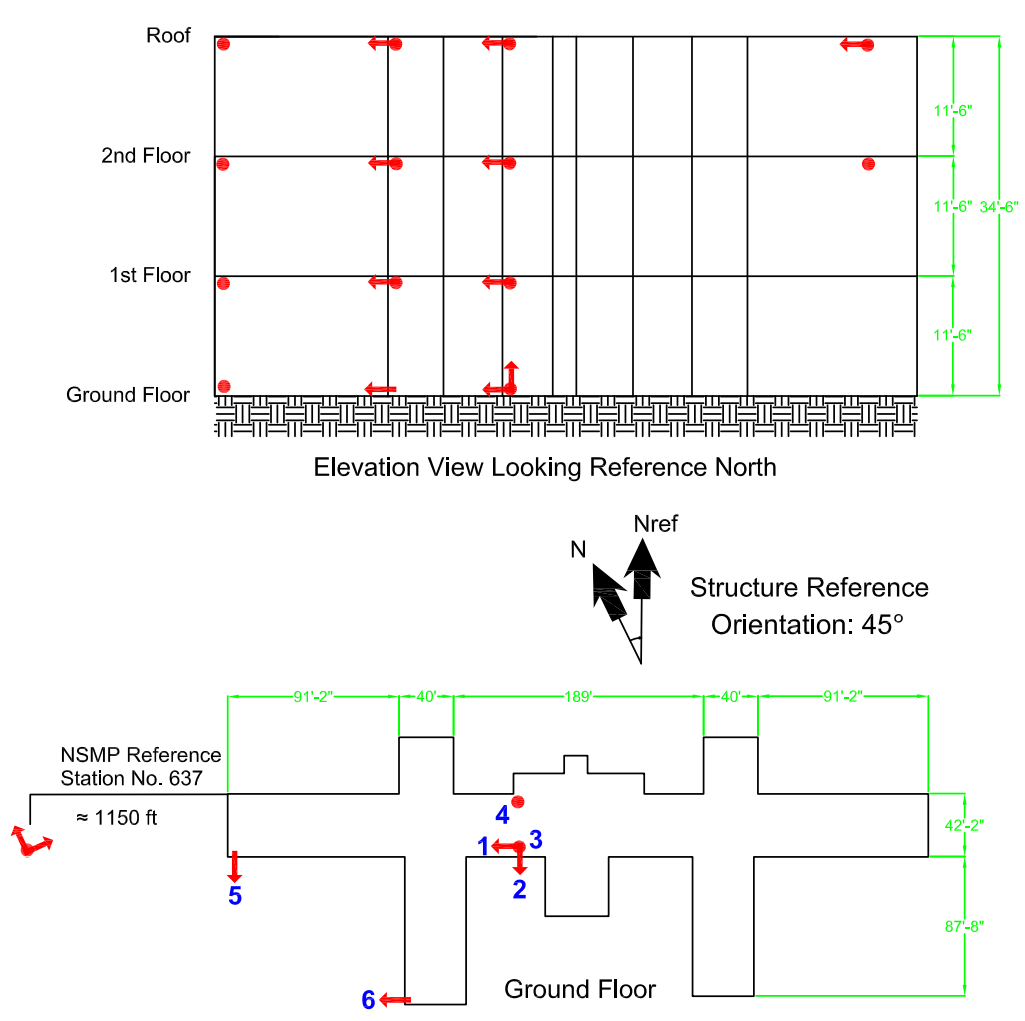

Revision Number: 7

Revised on 10/10/2012
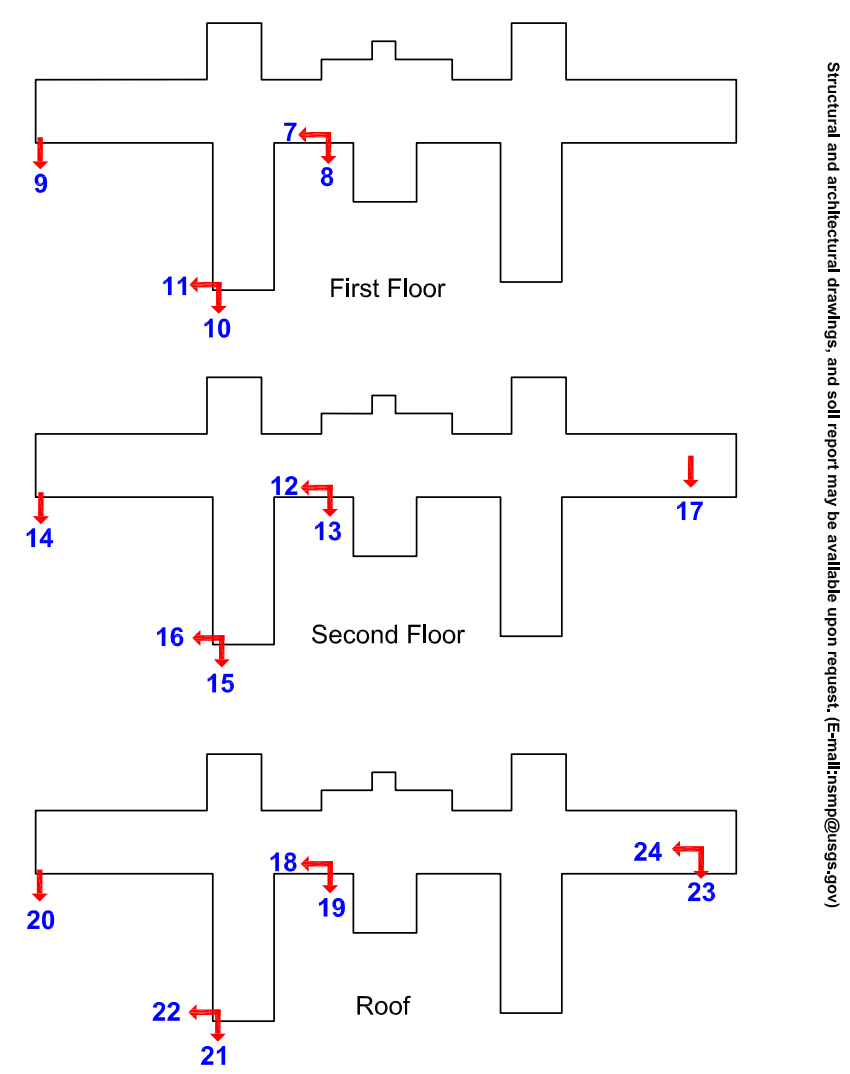

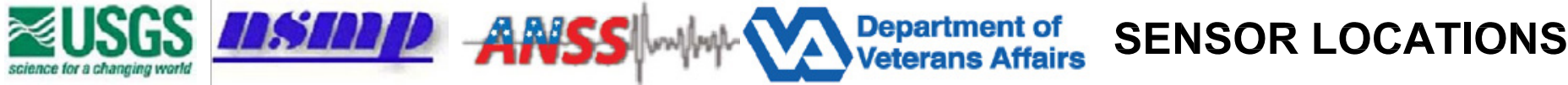

Figure 40. Diagram of sensor layout showing 24 sensors in Building 10 of the Sepulveda Veterans Affairs Medical Center, California. 


\section{NSMP Station 5082-West Los Angeles, California: Main Hospital, Building No. 500}

\section{Building Description}

Building 500 located in West Los Angeles, California, is part of the VA Greater Los Angeles Healthcare System (http://www.losangeles.va.gov). The building, built in 1976, is a sixstory structure of approximately $937,000 \mathrm{ft}^{2}$ (fig. 41 and fig. 42 ). It serves as the main hospital on the VA medical campus. This steel-frame building has a square plan on the lowest two stories and a cruciform plan above the second floor, with an overall width of $457 \mathrm{ft}$ in each direction. It has an isolated central core above the second floor, connected by enclosed bridges to the main sections of the building. Story heights are typically $17 \mathrm{ft} 3$ inches with an unfinished basement approximately $10 \mathrm{ft}$ below the ground floor. There is a partial full-height basement under the center of the building and a centrally located mechanical penthouse above the core at the roof. Typical floor and roof construction consists of composite slabs supported by steel trusses and steel columns. The bottom chords of the trusses form an interstitial space with steel catwalks installed to provide access to the numerous mechanical systems located above the ceiling of each floor. The basement floor is a concrete slab on grade, and the foundations are concrete pile caps with drilled concrete piers. The perimeter walls below the first floor are reinforced concrete.

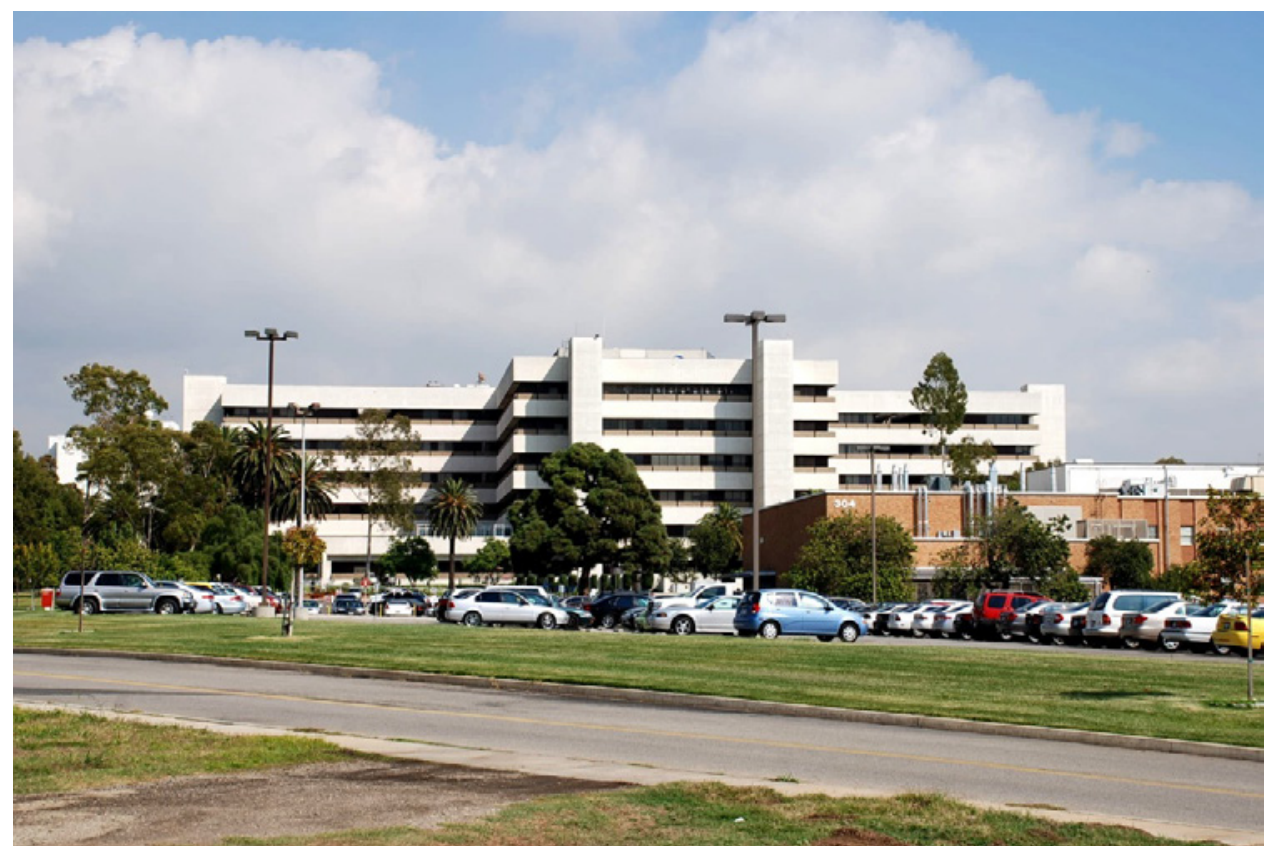

Figure 41. Photograph of Building 500, West Los Angeles Veterans Affairs Medical Center, California (side view) (U.S. Geological Survey photograph). 


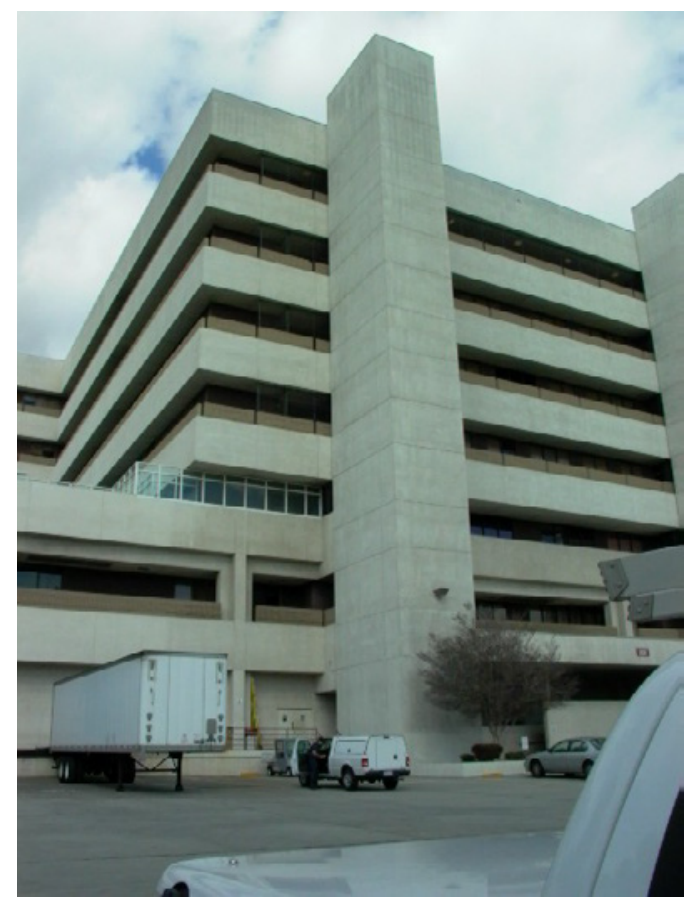

Figure 42. Photograph of Building 500, West Los Angeles Veterans Affairs Medical Center, California (looking northwest) (U.S. Geological Survey photograph).

The building's lateral force resisting system consists of steel braced frames. Each wing of the cruciform floor plan has four groups of three braced frames as well as two groups of three frames around the stairwells at the exterior end of each wing. Each pile cap has a large number of drilled piers. A single large pile cap as much as $10 \mathrm{ft}$ thick supports each group of braced frames. The concrete walls below the first floor at the perimeter transfer some of the lateral load to the foundation. The floor and roof diaphragms are concrete slabs on metal decks that typically span between steel collectors located along the lines of braced frames.

\section{Seismic-Hazard and Soil Conditions}

The building is located on a fairly level site. The exterior grade slopes slightly so that it is at the first-floor level on the north side and at the ground-floor level on the south side. The buildings are founded on relatively soft soils of varying depths.

The building is located in an area of very high seismic hazard. The short-period spectral acceleration, $\mathrm{S}_{\mathrm{S}}$, using the current NEHRP recommended provisions for seismic regulations of new buildings and other structures, is $1.89 \mathrm{~g}$. The long-period spectral acceleration, $\mathrm{S}_{1}$, is $0.64 \mathrm{~g}$.

\section{Instrumentation}

A total of 24 accelerometers are deployed in the building at different floor levels to measure floor lateral motions in two orthogonal directions (fig. 43 and fig. 44). A triaxial accelerometer (channels 3 through 5), together with vertically oriented accelerometers (channels 1 and 2), is placed on the basement to measure ground motion input to the building. The recordings of the three vertically oriented accelerometers also provide the rocking motions of the building around the reference east-west and north-south axes. Another accelerometer (channel 6) is placed on the basement-floor ceiling level to monitor first-floor slab motion. Eighteen 
accelerometers (channels 7 through 24) are evenly distributed on the ceiling of the upper floors to measure floor lateral motion. The floor torsional motion can be computed from likewise oriented accelerometers on the same floor (for example, channels 22 and 24 will be used to compute roof torsional motion)

The building accelerometers are complemented by two sets of three-component seismic accelerometers located at free-field sites (NSMP Station No. 5082), approximately 655 and $1,560 \mathrm{ft}$ away from the building, to monitor ground shaking without interference from building's earthquake response. 
U.S. Department of Veterans Affairs

West Los Angeles, CA - Steel Moment Frame, Six Story Hospital Building

Building No: 500

NSMP Station No: 5082
Revision Number: 10

Revised on 10/10/2012

Page 1 of 2

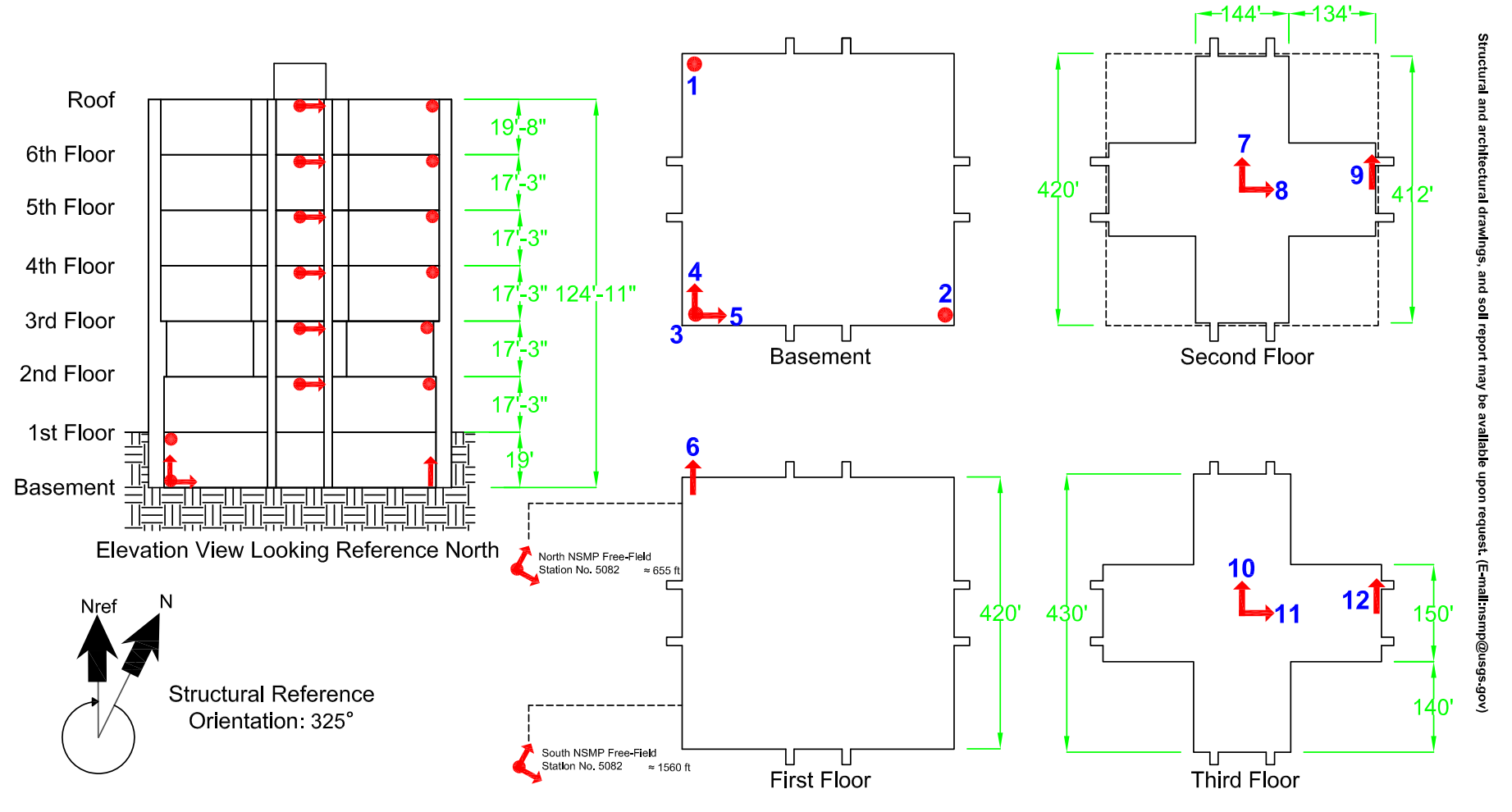

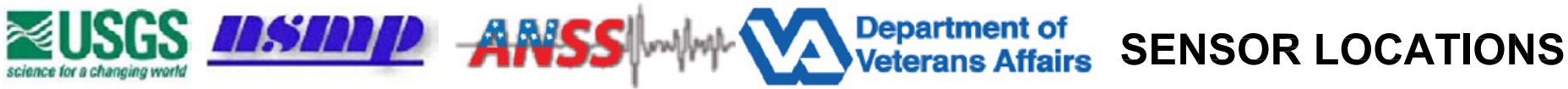

Figure 43. Diagrams of sensor layout showing 24 sensors in Building 500 of the West Los Angeles Veterans Affairs Medical Center, California (page 1 of 2; see also fig. 44). 
U.S. Department of Veterans Affairs

West Los Angeles, CA - Steel Moment Frame, Six Story Hospital Building

Building No: 500

NSMP Station No: 5082
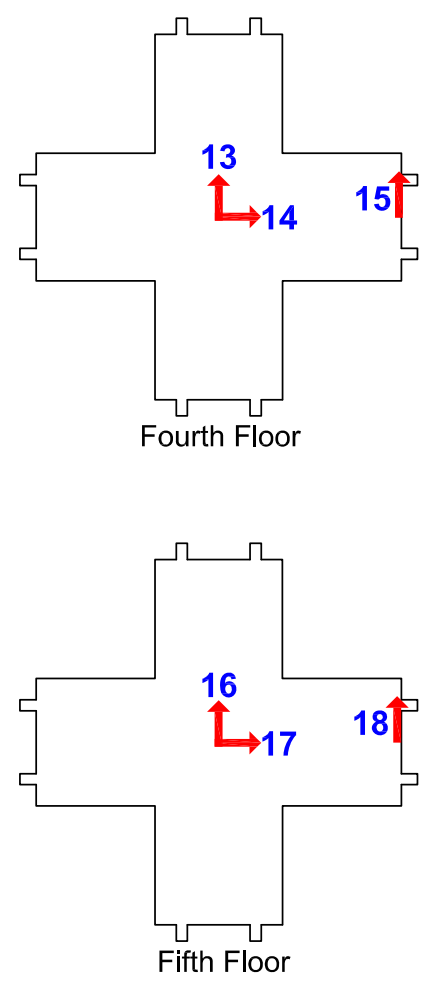

Revision Number: 10

Revised on 10/10/2012

Page 2 of 2

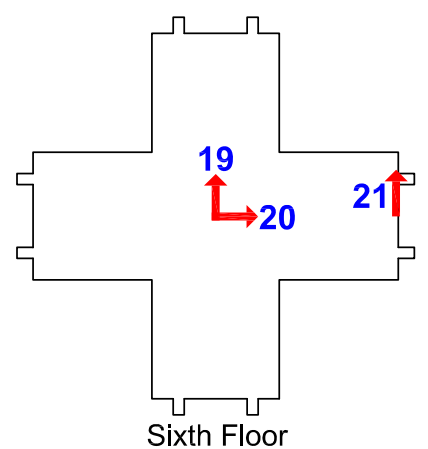

Structural Reference Orientation: $325^{\circ}$

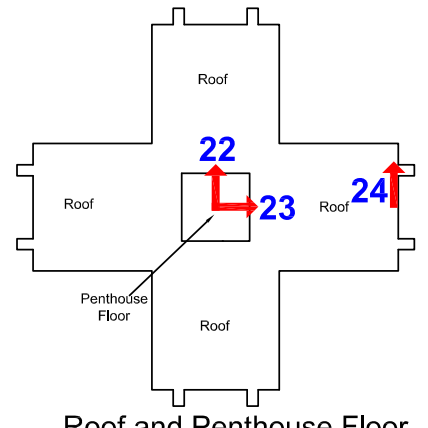

Roof and Penthouse Floo

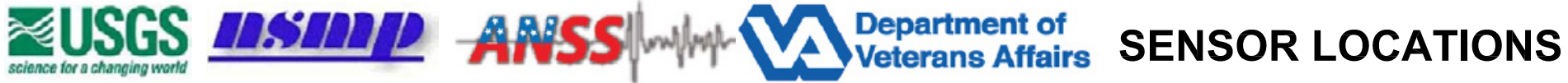

Figure 44. Diagrams of sensor layout showing 24 sensors in Building 500 of the West Los Angeles Veterans Affairs Medical Center, California (page 2 of 2; see also fig. 43). 


\section{NSMP Station 5485-West Los Angeles, California: Research Lab., Building No. 114}

\section{Building Description}

Building 114 located in West Los Angeles, California, is part of the VA Greater Los Angeles Healthcare System (http://www.losangeles.va.gov). This building is a four-story reinforced concrete and masonry structure that is approximately 69,921 $\mathrm{ft}^{2}$ (fig. 45 and fig. 46). It was designed and built in 1944 and serves as the research facility on the VA medical campus. No seismic retrofitting has been done since it was built in 1944. Its lateral- and vertical-force resisting system consists of reinforced concrete frames and shear walls. The building rests on isolated reinforced concrete footings.

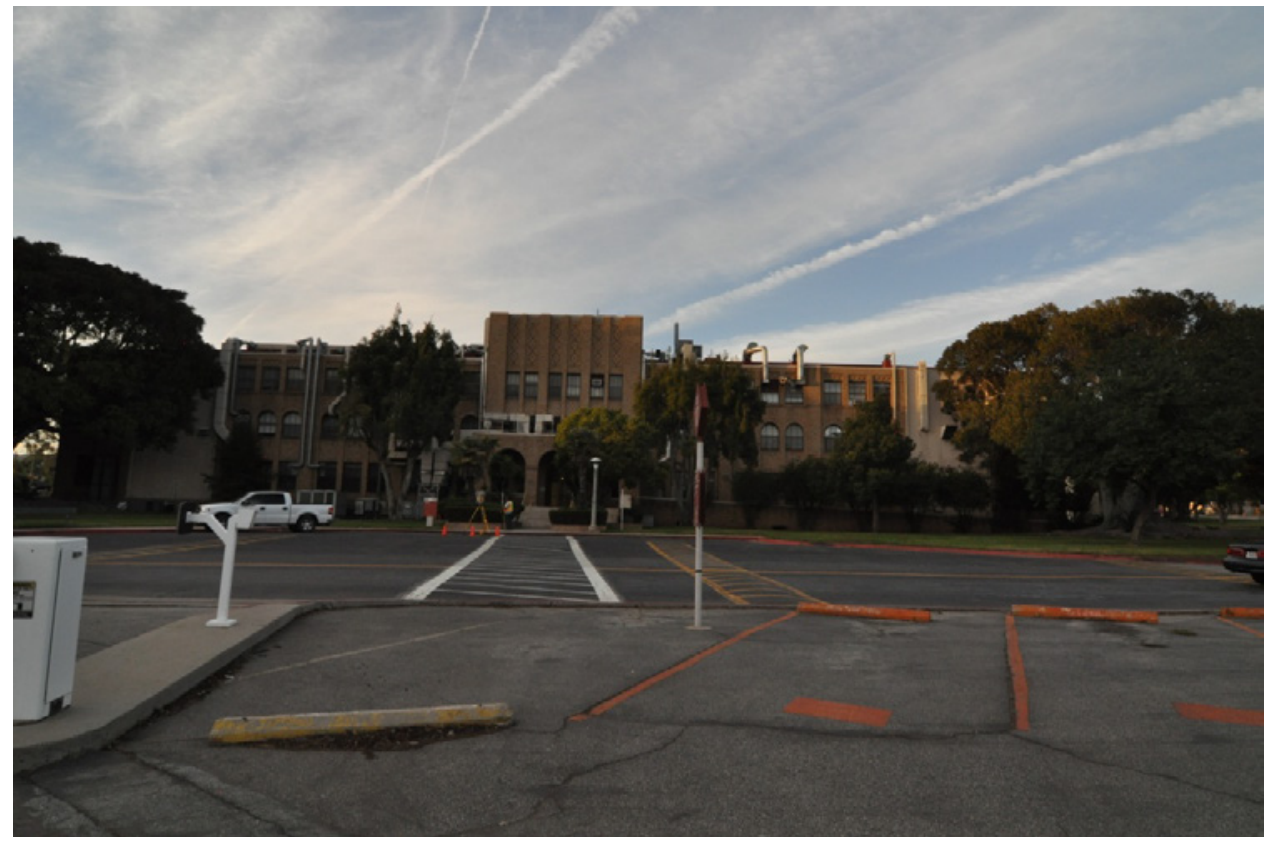

Figure 45. Photograph of Building 114, West Los Angeles Veterans Affairs Medical Center, California (U.S. Geological Survey photograph).

\section{Seismic-Hazard Conditions}

The building is located in an area of very high seismic hazard. The short-period spectral acceleration, $S_{\mathrm{S}}$, using the current NEHRP recommended provisions for seismic regulations of new buildings and other structures, is $1.84 \mathrm{~g}$. The long-period spectral acceleration, $S_{1}$, is $0.63 \mathrm{~g}$.

\section{Instrumentation}

A total of 10 accelerometers are deployed in the building (fig. 47). Channels 1 through 3 are placed on the basement to record input ground motion. Five accelerometers (channels 4, 5, 7, 8 , and 10) oriented in the reference north-south axis (the weak direction of the building) are placed on the ceilings of the ground, first, second, and third floors to measure floor lateral motion. Two accelerometers (channels 6 and 9) oriented in the reference east-west axis are 
placed on the ceilings of the first and third floors to measure the floor motion in the strong direction.

The building accelerometers are complemented by the three-component seismic accelerometer located at a free-field site (NSMP Station No. 5082), approximately 2,380 ft away from the building, to monitor ground shaking without interference from the earthquake response of the building.

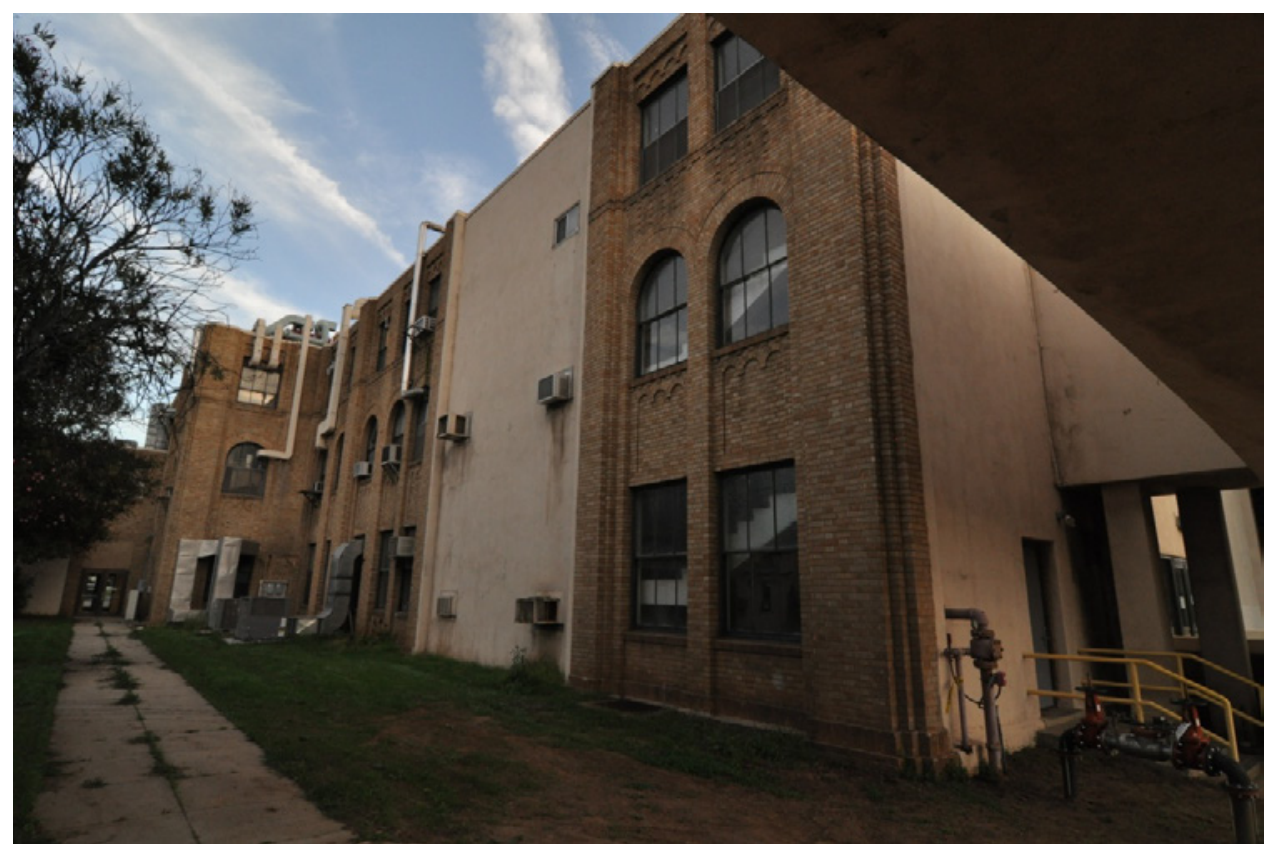

Figure 46. Photograph of Building 114, West Los Angeles Veterans Affairs Medical Center, California (looking southeast) (U.S. Geological Survey photograph). 
U.S. Department of Veterans Affairs

Building No: 114

NSMP Station No: 5485

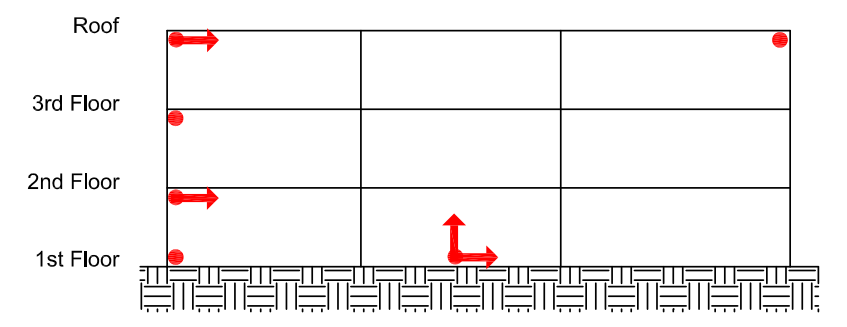

Elevation View Looking Reference North
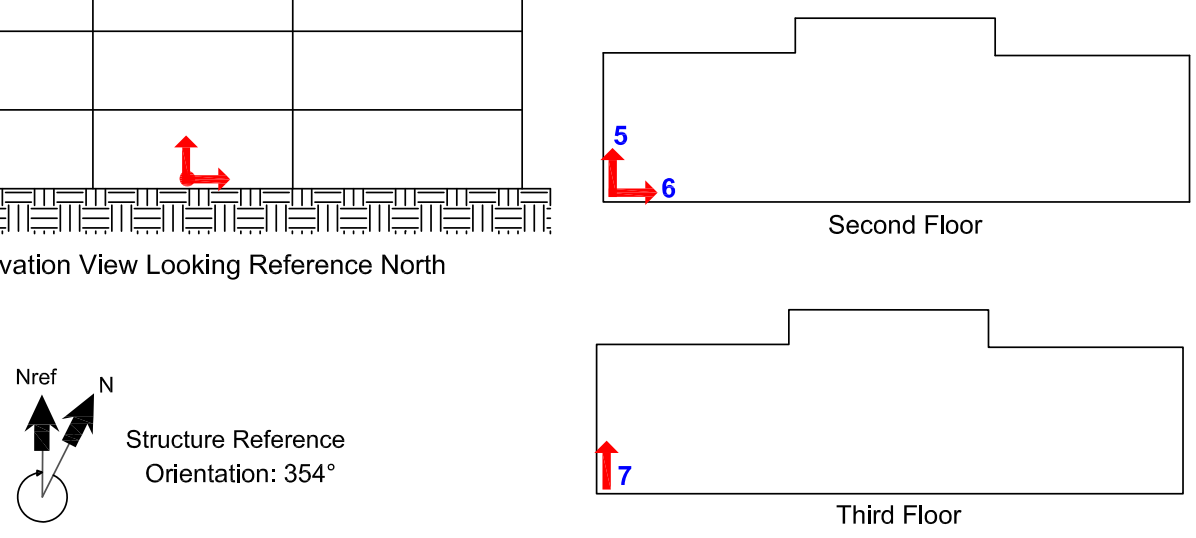

Second Floor

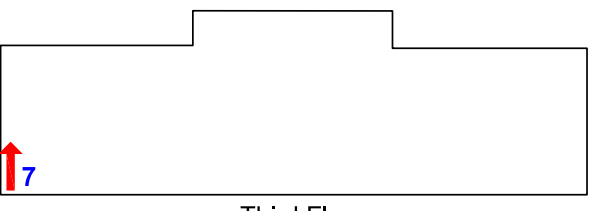

Third Floor

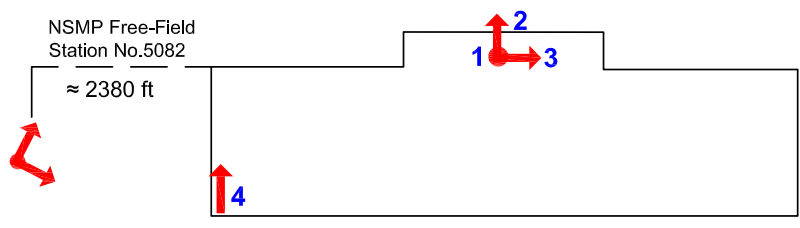

First Floor

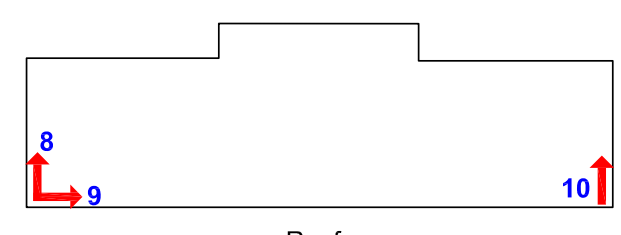

Roof

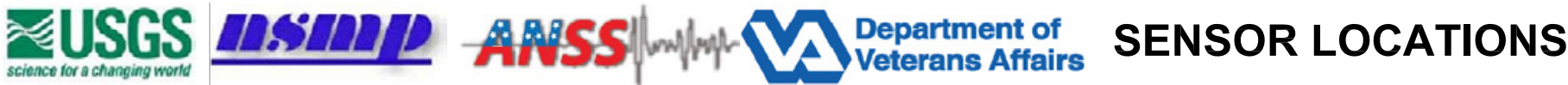

Figure 47. Diagram of sensor layout showing 10 sensors in Building 114 of the West Los Angeles Veterans Affairs Medical Center, California. 


\section{NSMP Station 5105-San Diego, California: Main Hospital, Building No. 1}

\section{Building Description}

Building 1, located in San Diego, California, is the main hospital building in VA San Diego Healthcare System (http://www.sandiego.va.gov). This 125-foot tall, steel-braced frame building was constructed in 1972 and has six-stories with a basement. Its total area is approximately $854,900 \mathrm{ft}^{2}$, with a typical floor area of approximately $106,000 \mathrm{ft}^{2}$ (fig. 48).

The building plan comprises four wings and a central core. Each wing is $158 \mathrm{ft}$ wide and $149 \mathrm{ft}$ long projecting from the central core as shown in figure 48. The floor height of the interstitial floors is approximately $17 \mathrm{ft}$. The first story is $450 \mathrm{ft}$ square in plan extending entirely to the ends of the wings, which results in a vertical irregularity due to the large increase of floor area relative to the levels above. The sloping site results in a partial basement level below the northern three wings, which is approximately $19 \mathrm{ft}$ in height.

The structural system for a typical floor consists of 5-inch thick cast-in-place concrete slabs supported by steel trusses spaced at approximately 12 to $14 \mathrm{ft}$. The trusses span transversely across each of the wings, cantilevering approximately $27 \mathrm{ft}$ at the ends, and are supported by truss girders at the braced frame column lines. The truss girders span to steel wideflange columns. The second and first floors are approximately $450 \mathrm{ft}$ square in plan.

The second-floor framing consists of long-span steel trusses similar to the typical floors above. However, the first floor system consists of a 5-inch thick cast-in-place concrete slab supported by typical steel wide-flange beams and columns. The foundations are concrete spread footings at the interior columns and concrete mat foundations supporting the steel-braced frames located approximately $5 \mathrm{ft}$ below grade.

The lateral-force resisting system for the building above the first floor uses the reinforced concrete floors as horizontal diaphragms spanning to tall, slender steel-braced frames. The top chord members of the truss girders have been detailed as collector elements in the line of the longitudinal braced frames in each wing. There are eight symmetrically located braced frames per wing in each orthogonal direction for the typical floor levels and are shown in figure 48 . The braced frames are $125 \mathrm{ft}$ tall and 12 to $19 \mathrm{ft}$ wide. The braced frames fall within three different configurations and have been designated as brace No. 1, 2, or 3. There are eight brace-1 frames in the transverse directions and four each of brace- 2 and brace- 3 frames in the longitudinal direction in each wing.

The lateral-force resisting system below the first floor level consists of a reinforced concrete diaphragm spanning concrete perimeter shear walls. The braced frames from the upper floor levels are continuous through the first floor. However, no special collectors were provided at the first floor to distribute the lateral force from the braced frames to the stiffer perimeter wall elements below the first-floor level.

The building's lateral stiffness is mainly provided by eight seismic towers located around the building and rigidly attached to slabs at each floor above ground. 


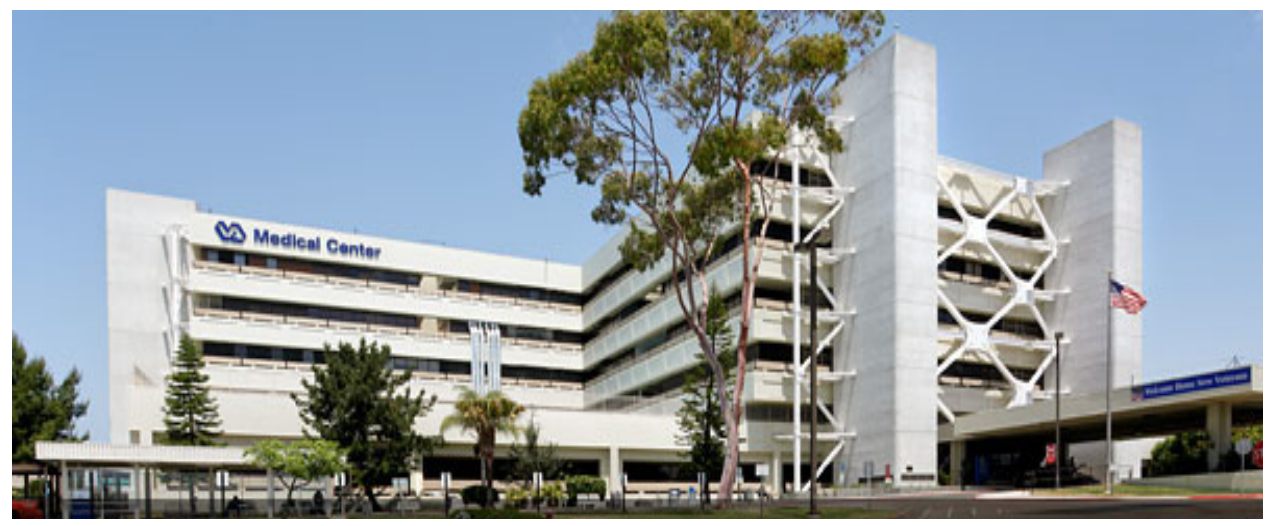

Figure 48. Photograph of Building 1, San Diego Veterans Affairs Medical Center, California (front view) (U.S. Department of Veterans Affairs photograph).

\section{Seismic-Hazard and Soil Conditions}

The building sits on the north face of a sloping site. A site-specific geotechnical report dated June 17, 1996, by Geotechnical Exploration, Inc., describes the soils observed at the site as medium dense, silty, fine to medium sand fill over dense, silty sand/sandy silt, siltstone, and sandstone formational soils.

The building is located in an area of very high seismic hazard. The short-period spectral acceleration, $\mathrm{S}_{\mathrm{S}}$, using the current NEHRP recommended provisions for seismic regulations of new buildings and other structures, is $1.56 \mathrm{~g}$. The long-period spectral acceleration, $\mathrm{S}_{1}$, is $0.60 \mathrm{~g}$.

\section{Instrumentation}

A total of 60 accelerometers are placed at eight levels in the building to measure its response to ground motion (fig. 49 through fig. 51). A triaxial accelerometer (channels 1 through 3 ) and two vertically oriented accelerometers (channels 4 and 5) are placed at the corner of the basement to measure input ground motion. The rocking motions of the building can be obtained from vertically oriented accelerometers (channels 1, 4, and 5). A triaxial accelerometer (channels 6 to 8 ) and three accelerometers (channels 9 through 11) are placed on the first-floor ground level. Accelerometers are placed on the upper floor edges and centers to measure the response of the wings and core of the building. Two triaxial accelerometers (channels 52 through 53 and channels 56 through 58) are also mounted on the core at the sixth-floor ceiling level; the vertically oriented sensors here will provide measurements of the rocking motion of the superstructure, as well as of the flexural response of the core.

The building's accelerometers are also complemented by three-component seismic accelerometers located at a reference site (NSMP Station No. 5440) distant from the building to monitor ground shaking without interference from the response of the building. 
U.S. Department of Veterans Affairs

San Diego, CA - Steel Moment Frame, Six-Story Hospital Building Building No: 1

NSMP Station No: 5105
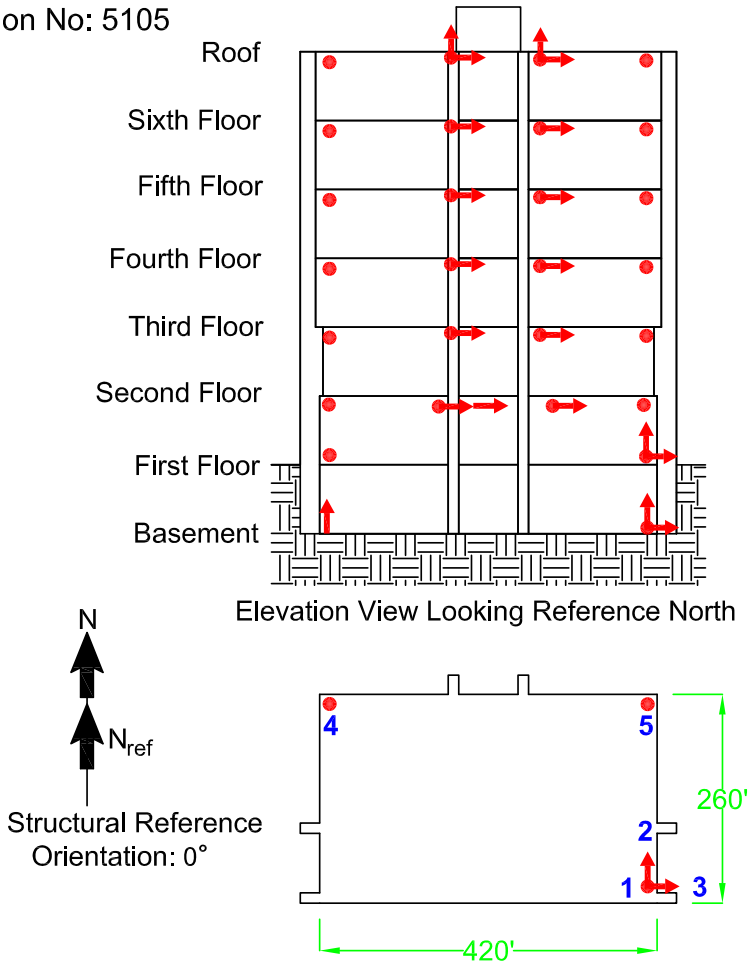

Basement
Revision Number: 7

Revised on 10/10/2012

Page 1 of 2

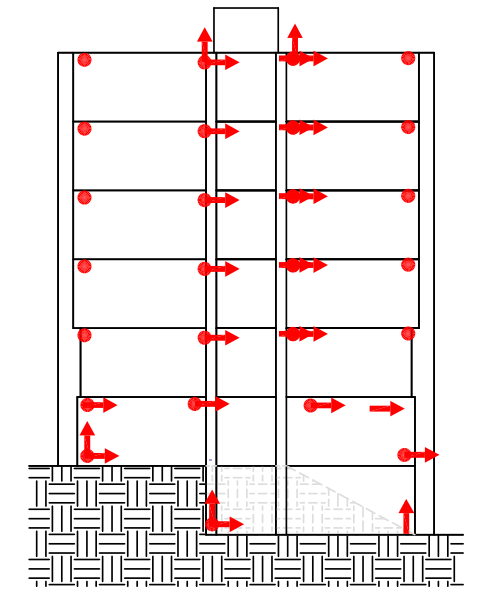

Elevation View Looking Reference West

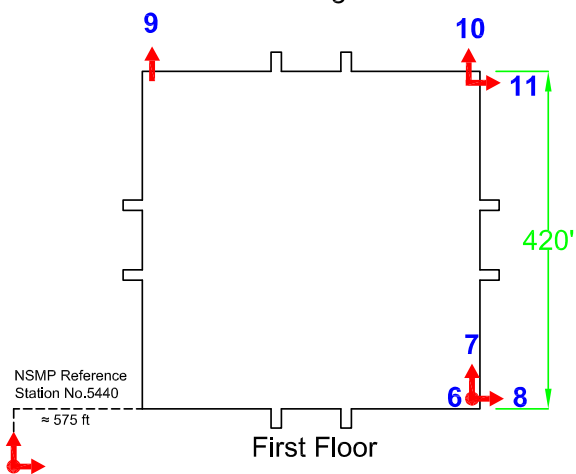

\section{₹USGS}

Figure 49. Diagrams of sensor layout showing 60 sensors in Building 1 of the San Diego Veterans Affairs Medical Center, California (page 1 of 3; see also figs. 50 and 51). 
U.S. Department of Veterans Affairs

San Diego, CA - Steel Moment Frame, Six-Story Hospital Building Building No: 1

NSMP Station No: $5105+144^{\prime}-{ }^{-134 '-}$
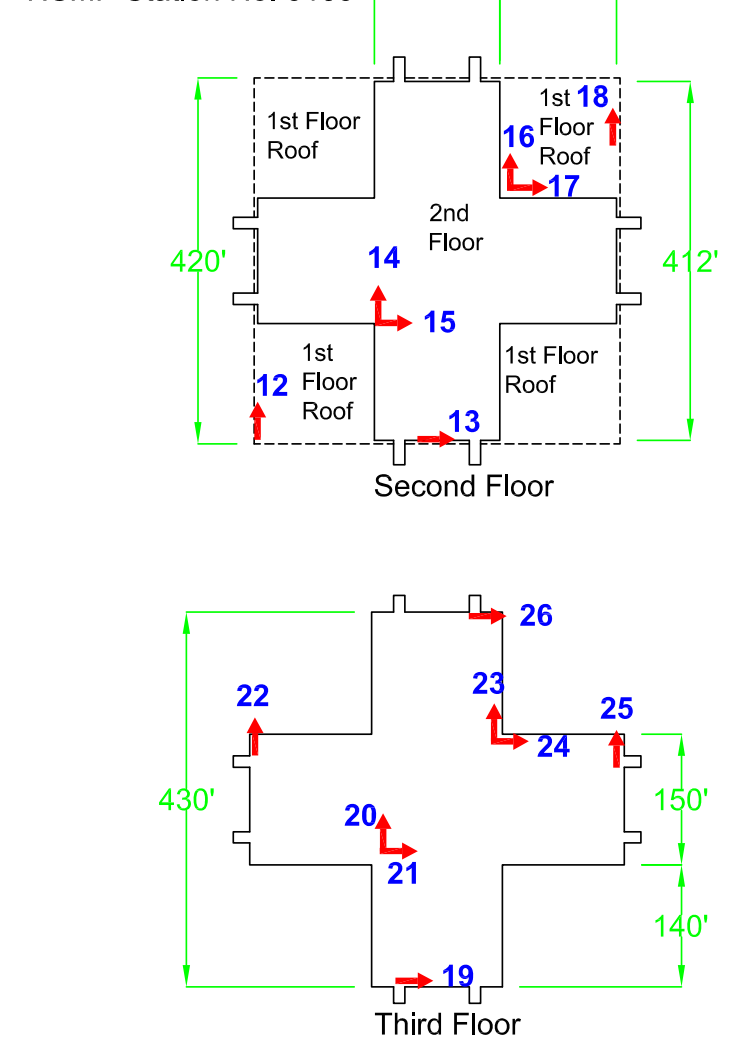

Revision Number: 7

Revised on $10 / 10 / 2012$

Page 2 of 2
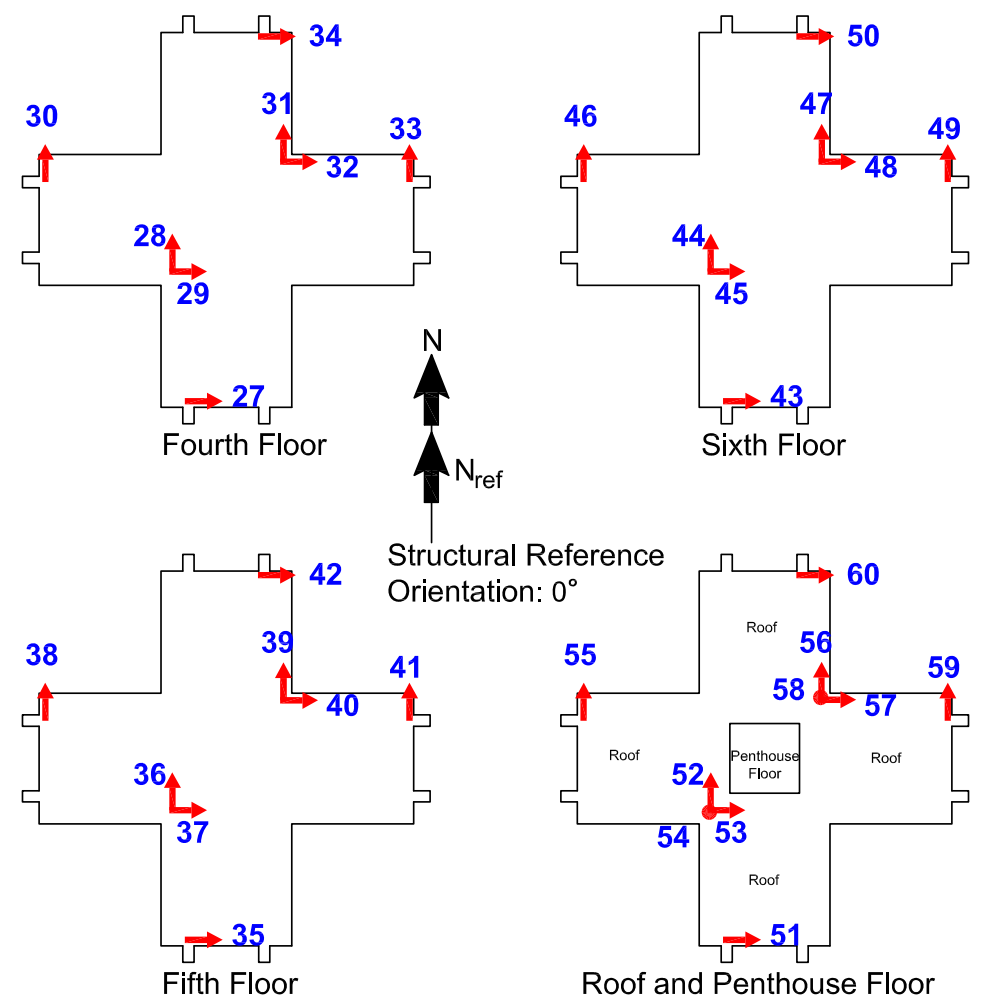

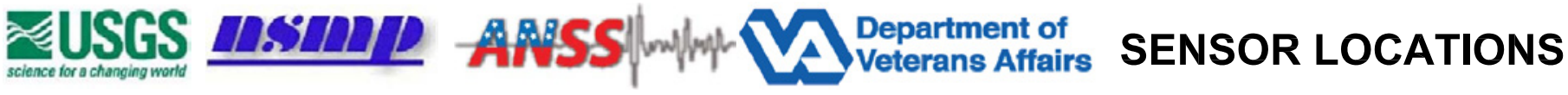

Figure 50. Diagrams of sensor layout showing 60 sensors in Building 1 of the San Diego Veterans Affairs Medical Center, California (page 2 of 3 ; see also figs. 49 and 51$)$. 
U S. Department of Veterans Affairs

San Diego, CA - Steel Moment Frame, Six-Story Hospital Building

Building No: 1

NSMP Station No: 5105

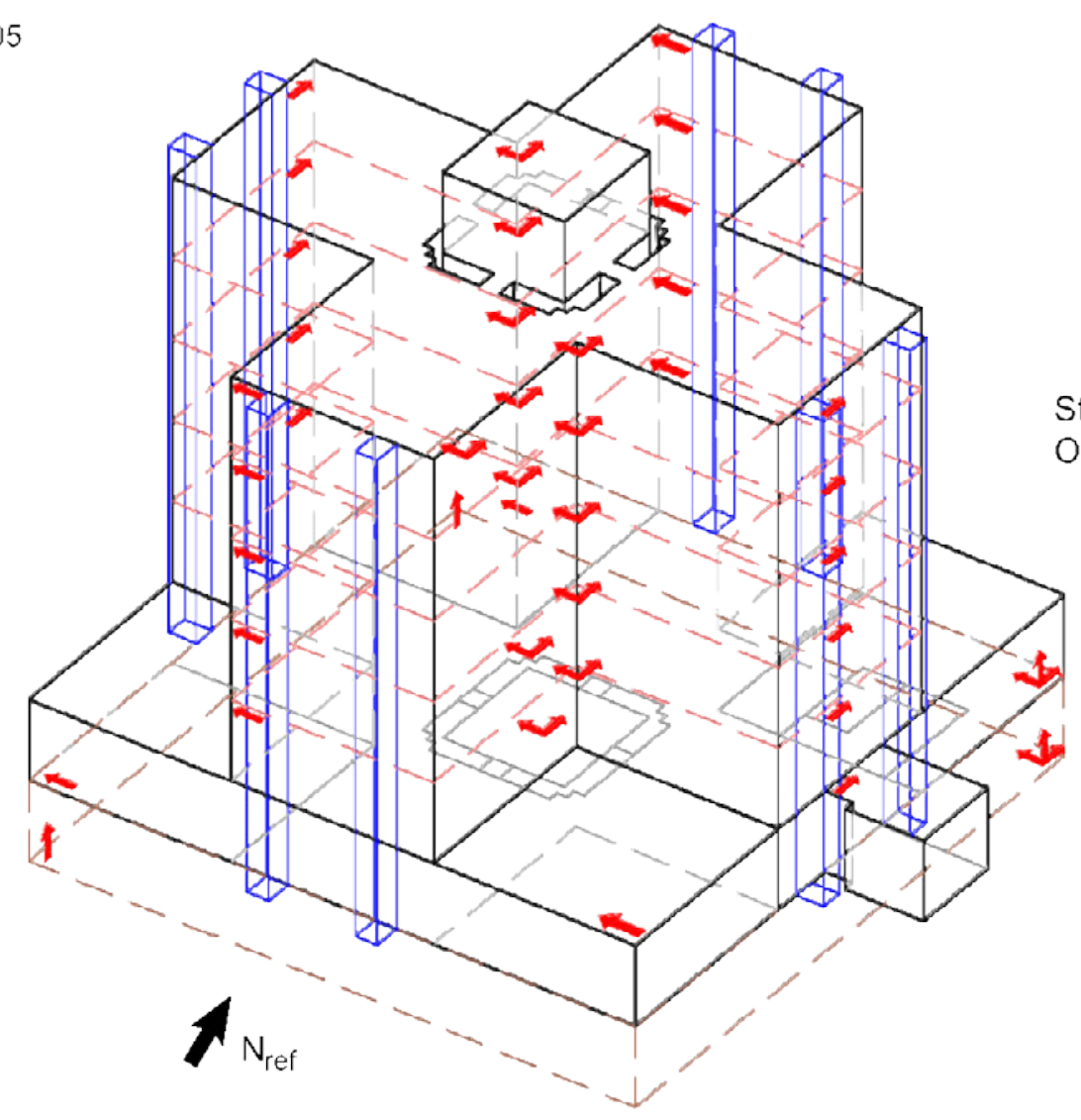

Revision Number: 8

Revised on 10/16/2012

Page 3 of 3

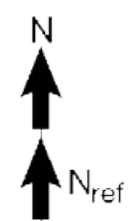

Structural Reference Orientation: $0^{\circ}$

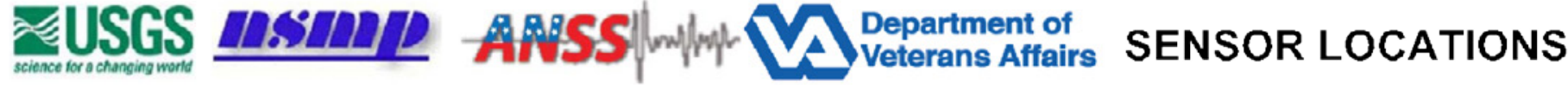

Figure 51. Diagrams of sensor layout showing 60 sensors in Building 1 of the San Diego Veterans Affairs Medical Center, California (page 3 of 3; see also figs. 49 and 50$)$. 


\section{NSMP Station 7415-Marion, Illinois: Main Hospital, Building No. 1}

\section{Building Description}

Building 1 at the Marion VA Medical Center (http://www.marion.va.gov) in Marion, Illinois, is approximately $81,750 \mathrm{ft}^{2}$ (fig. 52 through fig. 54). This reinforced concrete building was built in 1940, and underwent corrections to fix its seismic deficiencies in 1988. The building has an irregular plan shape with two wings on east and west sides of the central core and a protrusion in the middle of the building. The east and west wings are both separated from the central core by seismic joints. The east and west wings are symmetrical and have dimensions of $140 \mathrm{ft} 10$ inches by $38 \mathrm{ft} 6$ inches. This building is four stories high and has a single basement level. The basement is $12 \mathrm{ft}$ below ground level. The first floor is $12 \mathrm{ft} 4$ inches tall. The second and third floors are both $11 \mathrm{ft} 6$ inches tall. The fourth floor is $13 \mathrm{ft} 10$ inches tall. The building also has a penthouse that is $12 \mathrm{ft} 9$ inches tall. Typical floor and roof construction consists of composite reinforced concrete slabs supported by concrete columns. The basement floor is a concrete slab on grade, and the building is supported by isolated spread footings. The building lateral stiffness is mainly provided by two seismic towers located at the front of the building and rigidly attached to slabs at each floor above ground. The two wings also had shear walls added as part of the seismic correction.

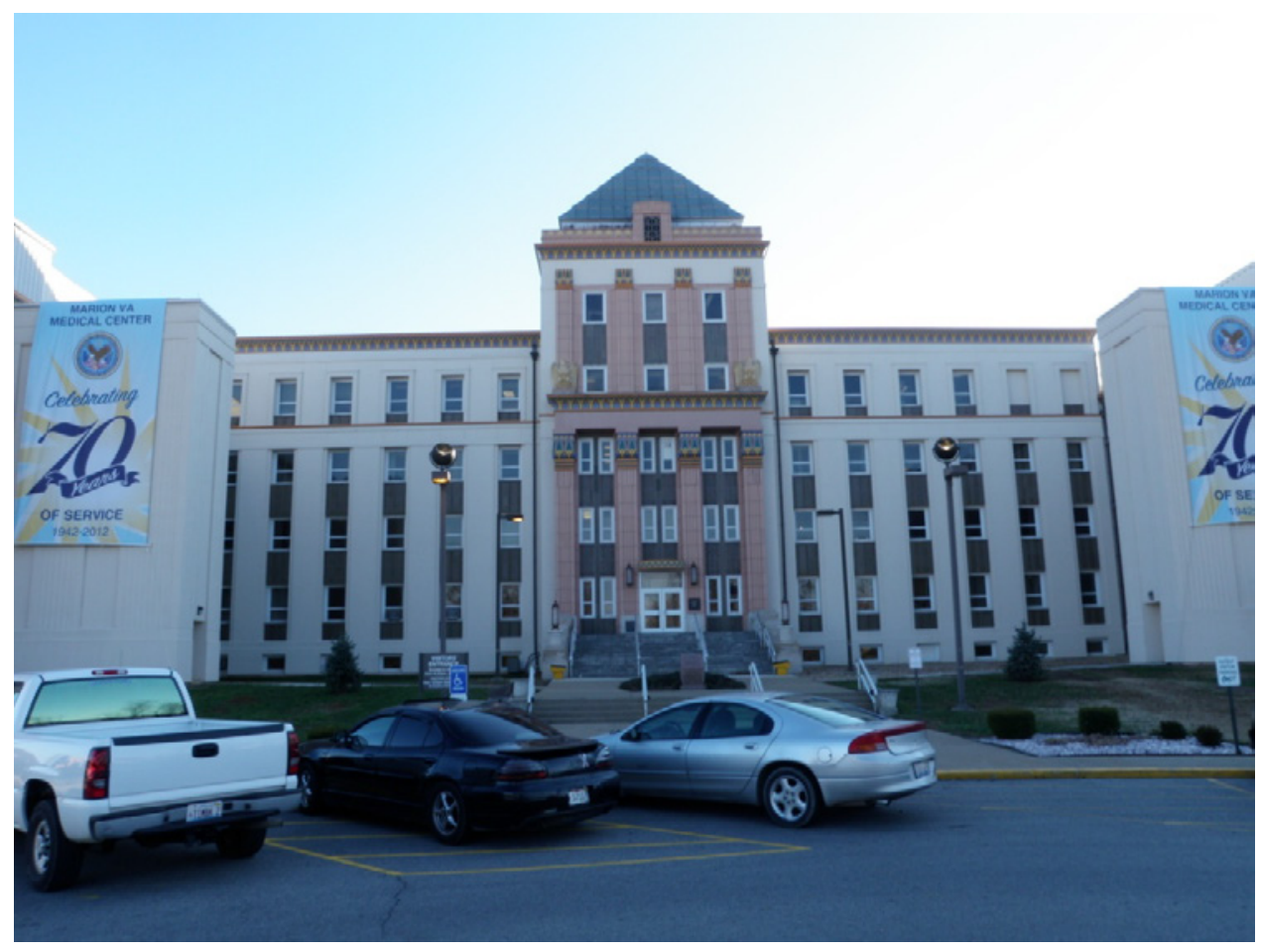

Figure 52. Photograph of Building 1, Marion Veterans Affairs Medical Center, Illinois (front view) (U.S. Geological Survey photograph). 


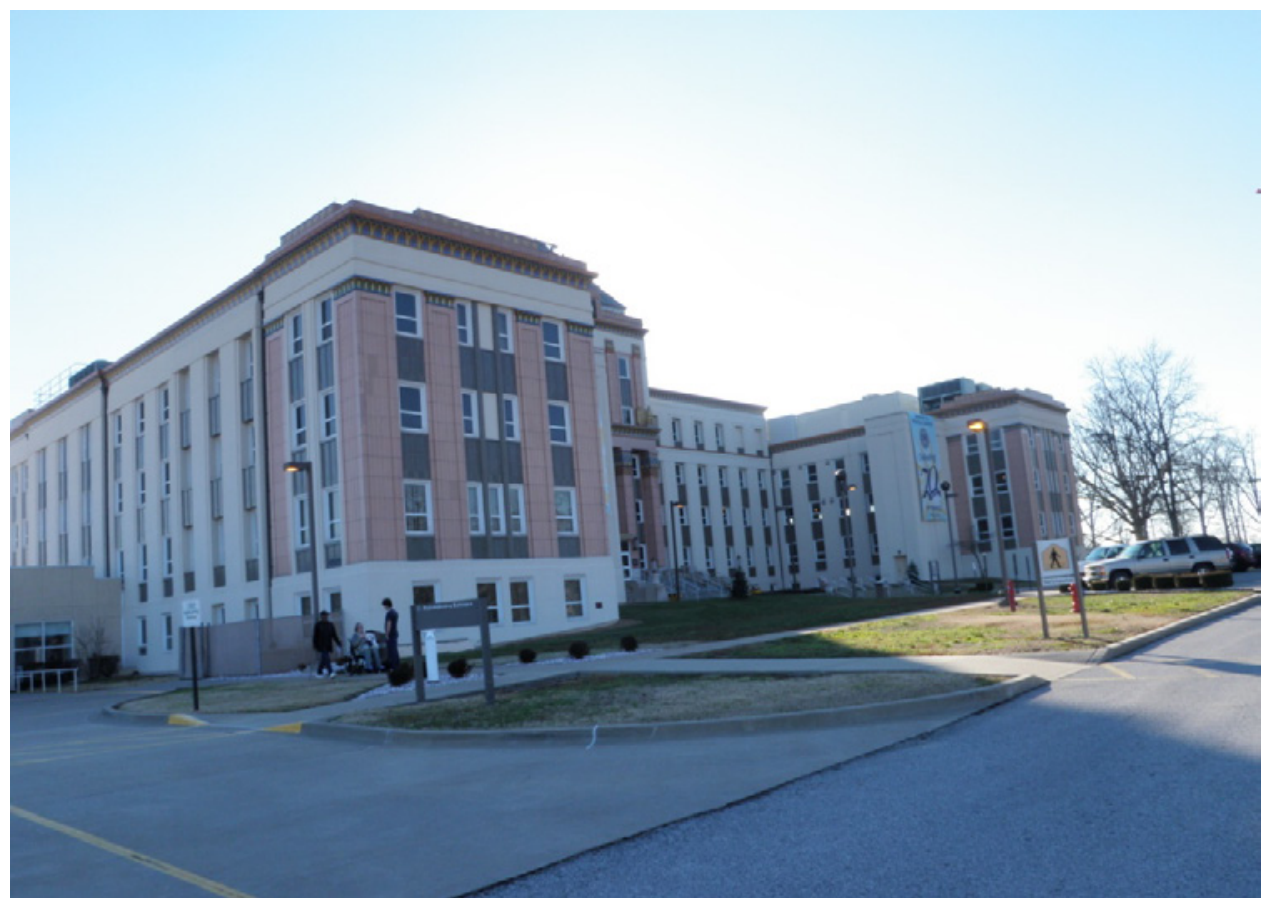

Figure 53. Photograph of Building 1, Marion Veterans Affairs Medical Center, Illinois (looking southwest) (U.S. Geological Survey photograph).

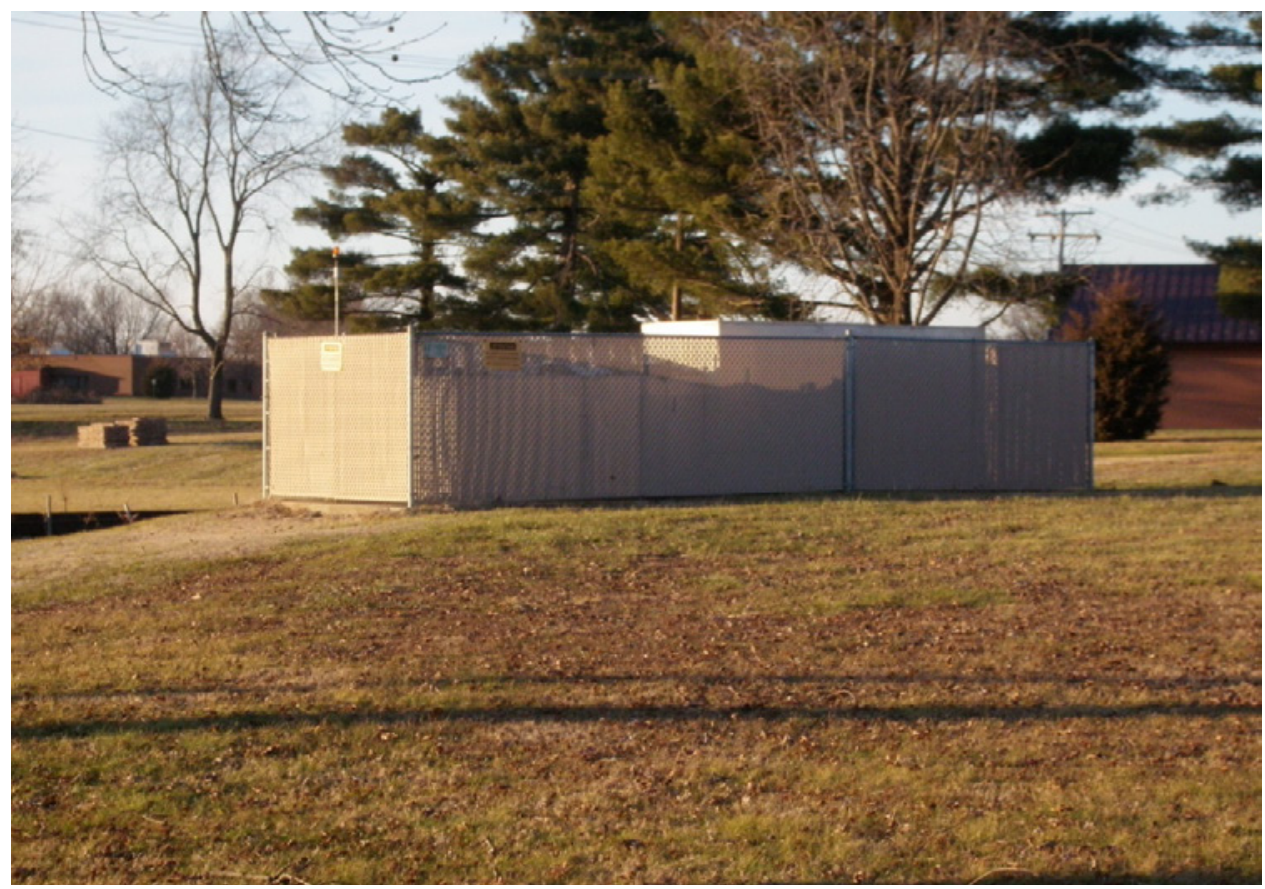

Figure 54. Photograph of free-field site at the Marion Veterans Affairs Medical Center, Illinois (U.S. Geological Survey photograph). 


\section{Seismic-Hazard Conditions}

The building is located in an area of high seismic hazard. The short-period spectral acceleration, $\mathrm{S}_{\mathrm{S}}$, using the current NEHRP recommended provisions for seismic regulations of new buildings and other structures, is $1.12 \mathrm{~g}$. The long-period spectral acceleration, $\mathrm{S}_{1}$, is $0.31 \mathrm{~g}$.

\section{Instrumentation}

A total of 48 accelerometers are deployed in the building to measure its lateral motion along the reference east-west and north-south directions (fig. 55 and fig. 56). A triaxial accelerometer (channels 3 through 5) is placed on the basement to measure the three components of input ground motion. Two vertically oriented accelerometers (channels 1 and 2) are also placed on the basement. The rocking motion of the building can be obtained from the vertically oriented accelerometers. Nineteen accelerometers are placed at different floor levels in the middle block to measure its lateral motions and compute its torsional motions. The side blocks are instrumented likewise; each has twelve accelerometers to measure lateral and torsional response. The relative floor displacement for each block can also be computed from the accelerometer located at the same corner of the building along the same vertical axis.

As shown in figure 54, the building's accelerometers are complemented by a threecomponent seismic accelerometer located at a free-field site (NSMP Station No. 7415), approximately 2,625 ft away from the building, to monitor ground shaking without interference from the earthquake response of the building. 
U.S. Department of Veterans Affairs

Marion, IL - Reinforced Concrete, Four-Story Hospital Building

Building No: 1

NSMP Station No: 7415

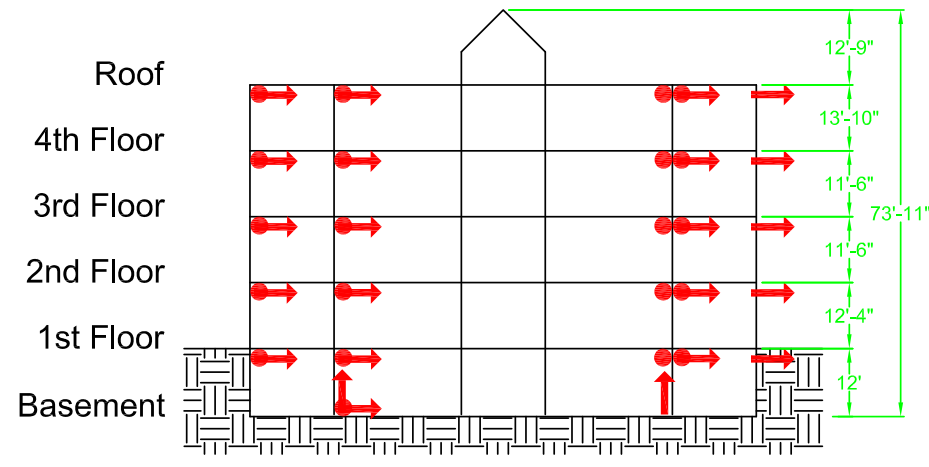

Elevation View Looking Reference North

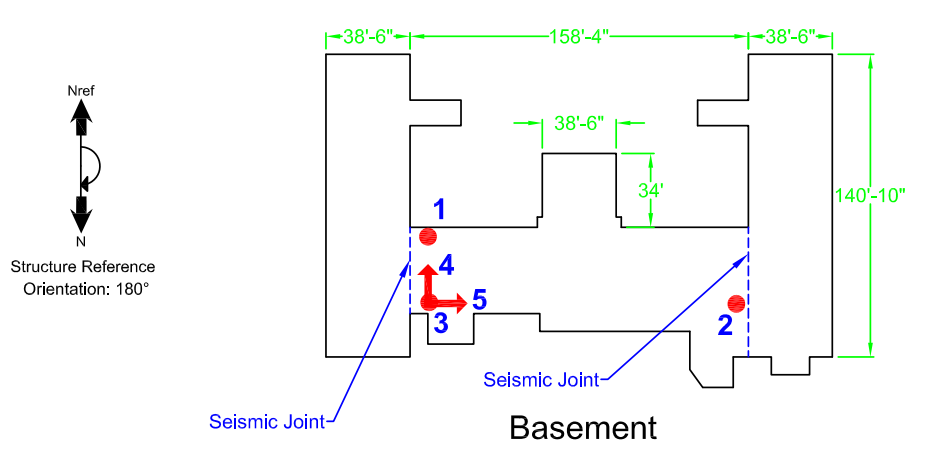

Revision Number: 3

Revised on 10/11/2012

Page 1 of 2

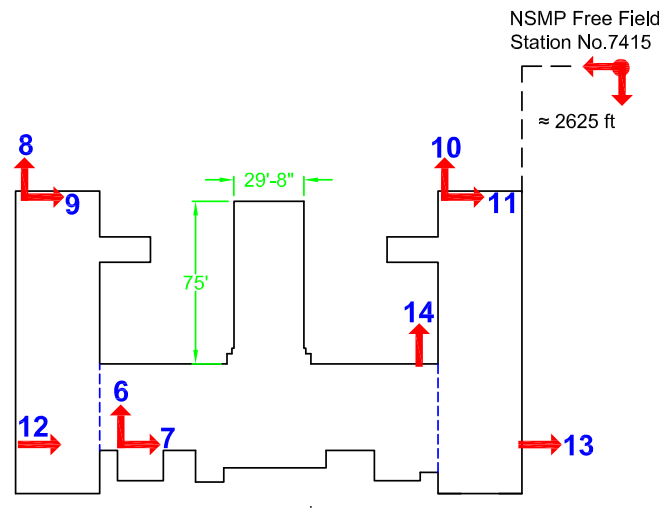

First Floor

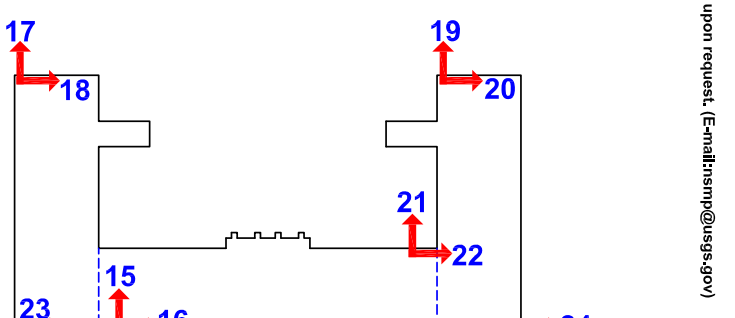

Second Floor

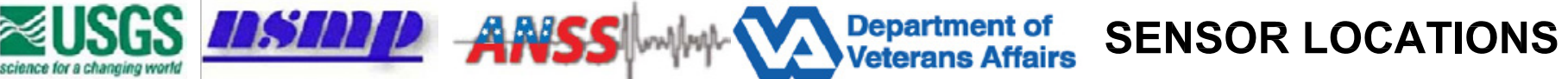

Figure 55. Diagrams of sensor layout showing 48 sensors in Building 1 of the Marion Veterans Affairs Medical Center, Illinois (page 1 of 2; see also fig. 56). 
U.S. Department of Veterans Affairs

Marion, IL - Reinforced Concrete, Four-Story Hospital Building

Building No: 1

NSMP Station No: 7415

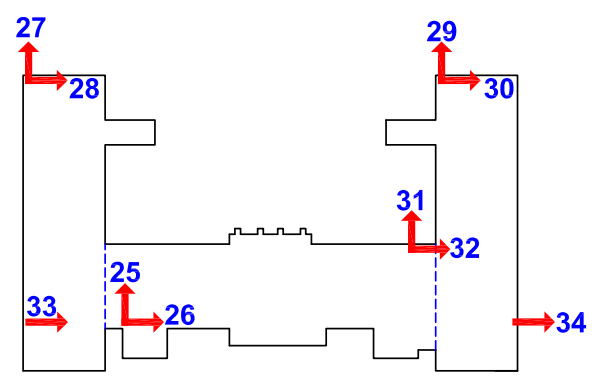

Third Floor

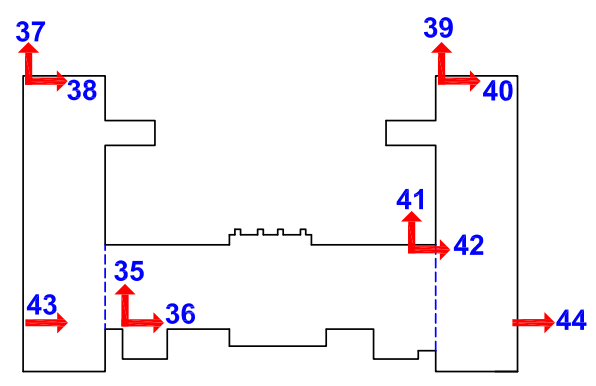

Fourth Floor

Revision Number: 3

Revised on 10/11/2012

Page 2 of 2

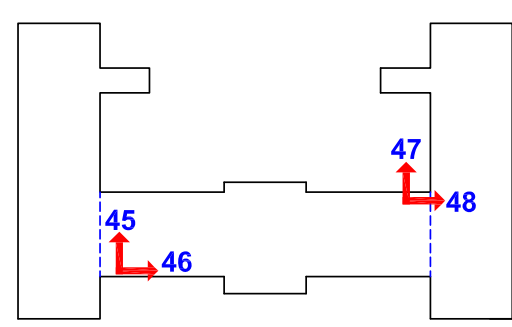

Roof

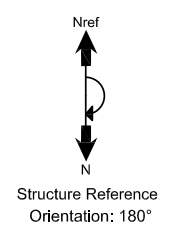

\section{ZUSGS IISTIDD ARSS/min/mh VA Department of SENSOR LOCATIONS}

Figure 56. Diagrams of sensor layout showing 48 sensors in Building 1 of the Marion Veterans Affairs Medical Center, Illinois (page 2 of 2; see also fig. 55). 


\section{NSMP Station 7402-Poplar Bluff, Missouri: Medical Nursing PCC, Building No. 1}

\section{Building Description}

Building 1 at the John J Pershing VA Medical Center (http://www.poplarbluff.va.gov/) in Poplar Bluff, Missouri, is approximately $137,718 \mathrm{ft}^{2}$ and has six floors. This structure was retrofitted in 1982 (fig. 57). It is a reinforced concrete structure with masonry façade. The building is comprised of six different wings - a central wing, northwest wing, northeast wing, southwest wing, southeast wing, and a north wing. This building has two seismic joints separating the north wing from the central wing on the east and west sides. The building's floor and roof construction consists of a composite reinforced concrete slab supported by reinforced concrete columns. The perimeter of the walls along the ground floor is a mixture of concrete walls. The building's lateral and vertical force resisting system consists of reinforced concrete frames and shear walls.

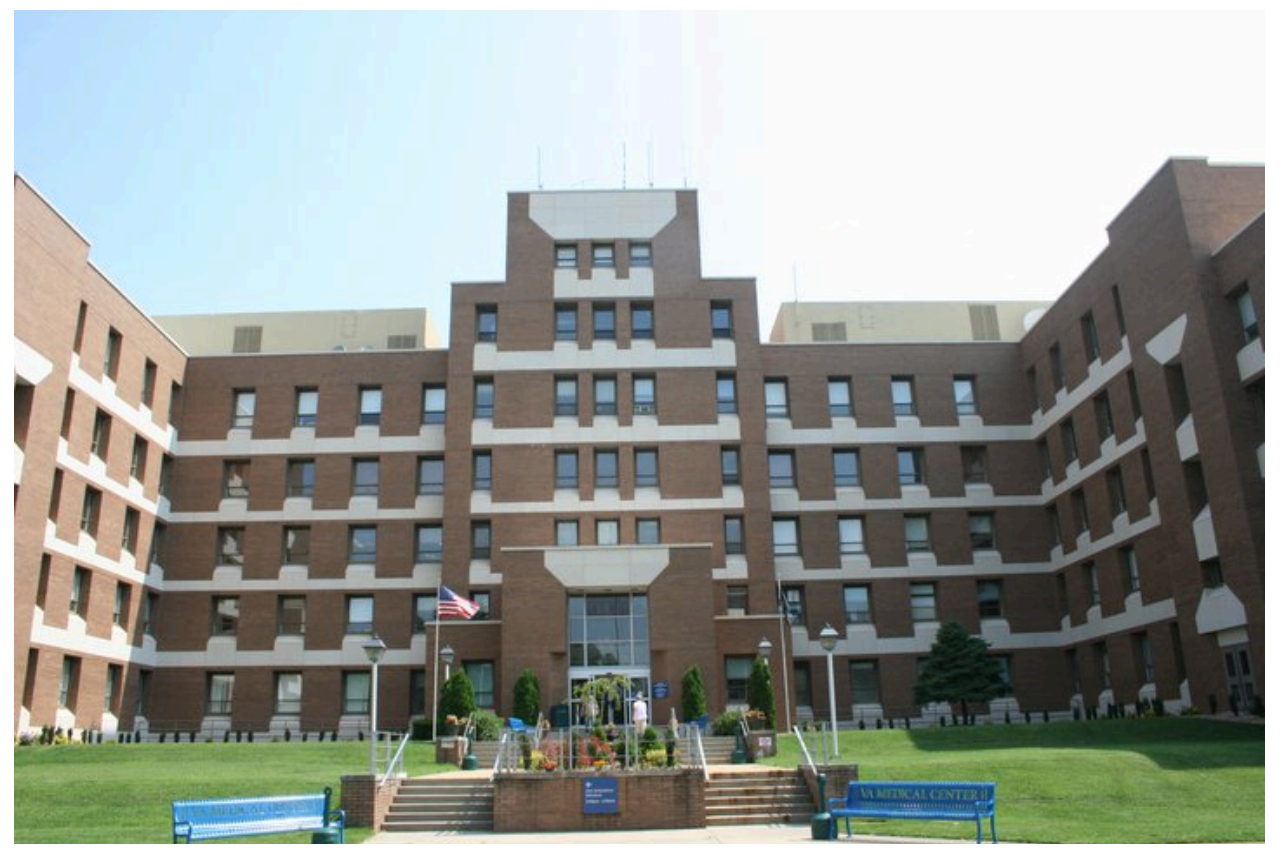

Figure 57. Photograph of Building 1, Poplar Bluff Veterans Affairs Medical Center, Missouri (U.S. Geological Survey photograph).

\section{Seismic-Hazard Conditions}

The building is located in an area of high seismic hazard. The short-period spectral acceleration, $\mathrm{S}_{\mathrm{S}}$, using the current NEHRP recommended provisions for seismic regulations of new buildings and other structures, is $1.10 \mathrm{~g}$. The long-period spectral acceleration, $\mathrm{S}_{1}$, is $0.30 \mathrm{~g}$.

\section{Instrumentation}

A total of 48 accelerometers are placed in the building at different levels and locations to measure the significant response of the building during an earthquake (fig. 58 and fig. 59). The accelerometers are placed in the critical corners of the building so that both the lateral and torsional responses can be measured and computed. A triaxial accelerometer (channels 1 through 
3 ) is placed on the ground-floor level to measure the three components of input ground motion. Forty-five accelerometers (channels 4 through 48) are distributed at six different floor levels to measure floor lateral motion along the reference east-west and north-south directions. Torsional motion of floors can be obtained from two likewise oriented accelerometers on the same floor. Floor relative displacements can also be computed from the recordings of the accelerometers located at the same vertical axis at three corners of the building.

The building accelerometers are complemented by a three-component seismic accelerometer located at a reference site (NSMP Station No. 7402), approximately $230 \mathrm{ft}$ away from the building, to monitor ground shaking without interference from the response of the building. 
U.S. Department of Veterans Affairs

Poplar Bluff, MO - Reinforced Concrete, Six-Story Hospital Building

Building No: 1

NSMP Station No: 7402

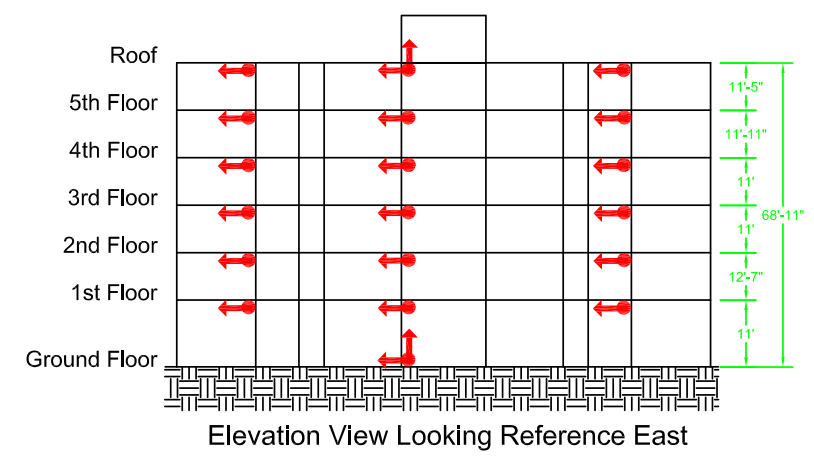

NSMP Reference Site
Station No.7402

Station No.7402

4
Revision Number: 4

Revised on $10 / 11 / 2012$

Page 1 of 2
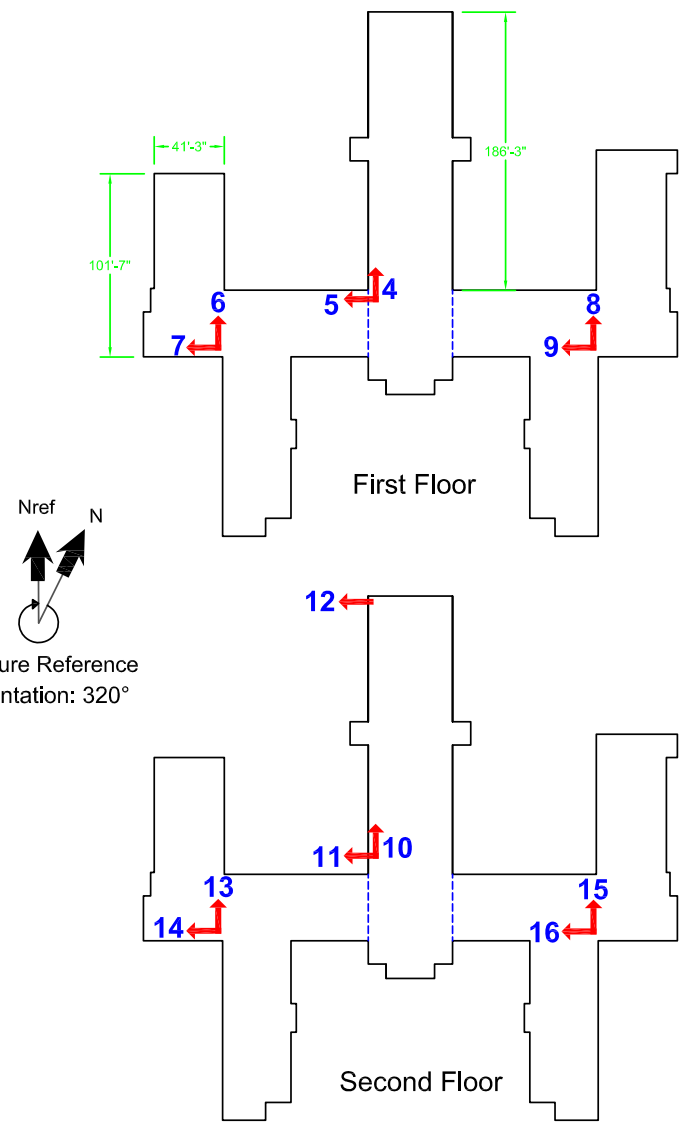

Structure Reference Orientation: $320^{\circ}$

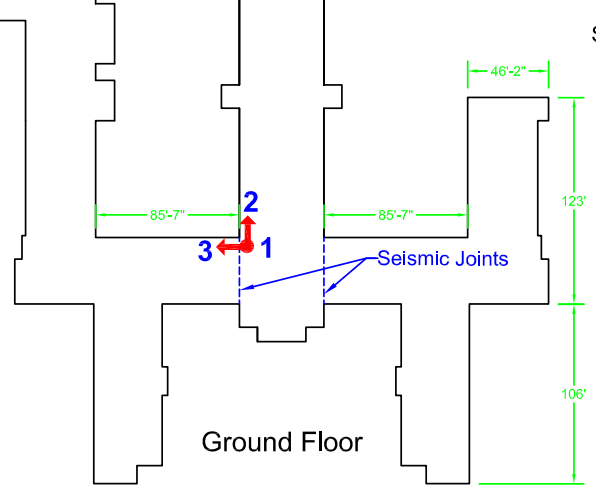

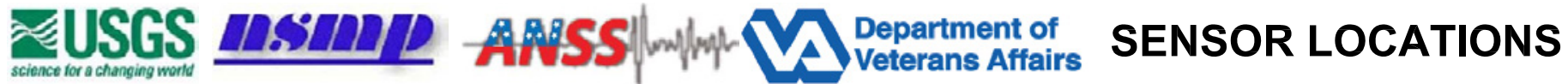

Figure 58. Diagrams of sensor layout showing 48 sensors in Building 1 of the Poplar Bluff Veterans Affairs Medical Center, Missouri (page 1 of 2; see also fig. 59). 
U.S. Department of Veterans Affairs

Poplar Bluff, MO - Reinforced Concrete, Six-Story Hospital Building

Building No: 1

NSMP Station No: 7402
Revision Number: 4

Revised on 10/11/2012

Page 2 of 2
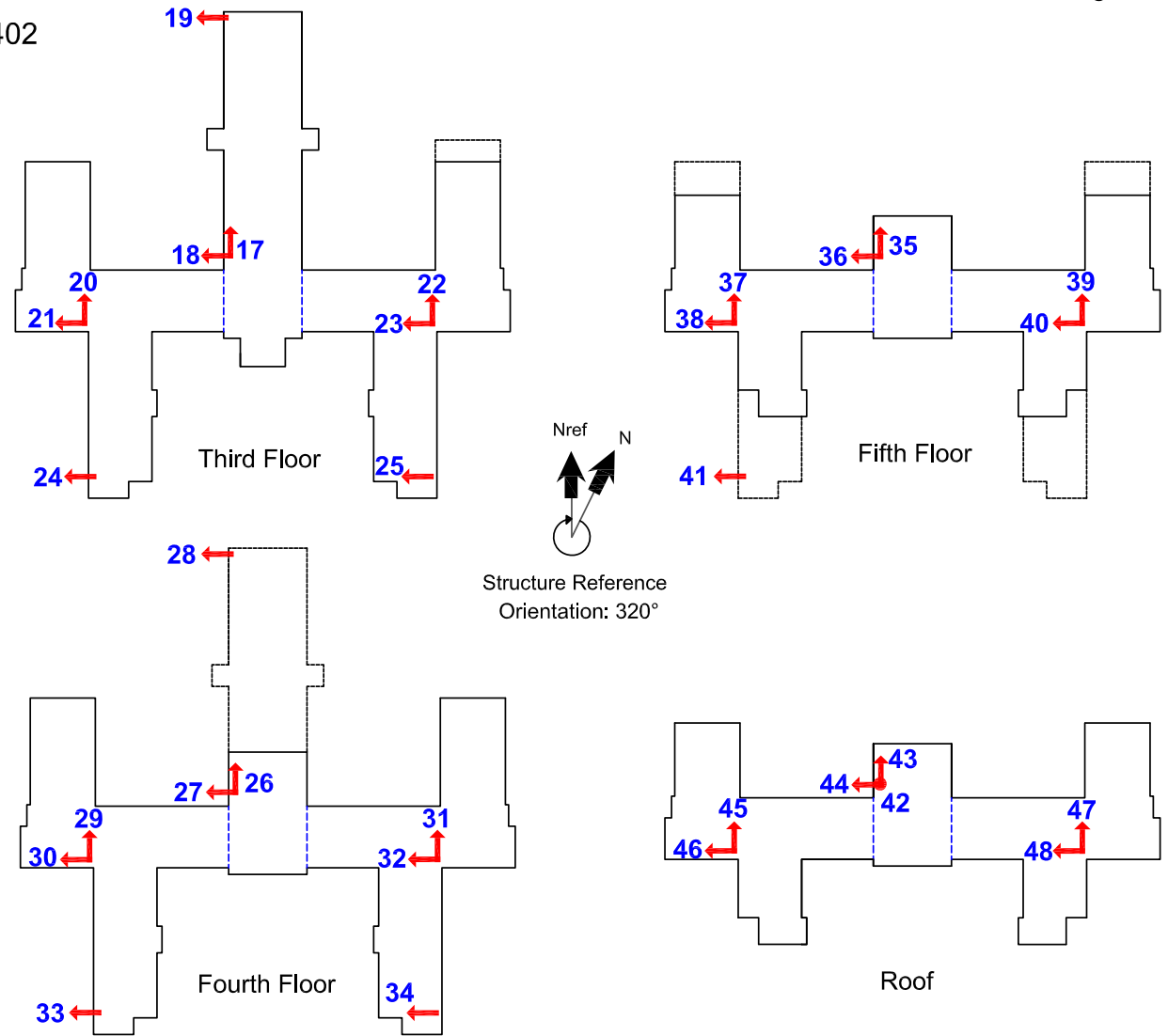

Structure Reference Orientation: $320^{\circ}$

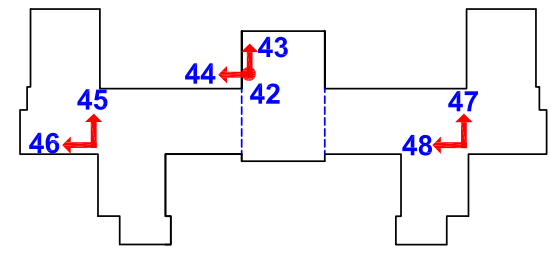

Roof

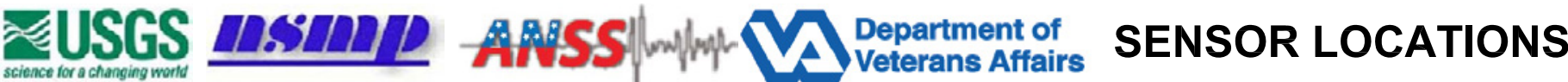

Figure 59. Diagrams of sensor layout showing 48 sensors in Building 1 of the Poplar Bluff Veterans Affairs Medical Center, Missouri (page 2 of 2; see also fig. 58). 


\section{NSMP Station 7235—Fort Harrison, Montana: Main Hospital, Building No. 154}

\section{Building Description}

Building 154 located at the Department of Veterans Affairs medical center campus in Fort Harrison, Montana, is the main hospital building as part of the VA Montana Health Care System (http://www.montana.va.gov/). The original structure, built in 1963, had additions in 1980, 1987, and 1995 (fig. 60 through fig. 65). The main part of Building 154 is a four-story structure with a full crawl-space basement and partial penthouse. The original Building 154 also includes a one-story structure to the north of the main hospital that is separated from the hospital by a 6-inch expansion joint. A connection corridor to the east was built during the original construction to link Building 154 with Buildings 150 and 141. The corridor is separated from the main structure by a 2 -inch expansion joint. In 1980, a one-story addition with a full basement was added to expand the existing pharmacy at the southeast corner. This addition is separated from the original construction by a 2 -inch expansion joint. In 1987, a one-story warehouse addition with a full, unfinished basement was added to the west of the west wing. This addition is separated from the main building except in the north-south direction. In 1995, a two-story addition with a full, unfinished basement was constructed to the south to expand the surgical and diagnostic imaging area of the hospital. This addition was rigidly connected at each level to the main part of hospital. The total gross square footage is approximately $132,381 \mathrm{ft}^{2}$. The building is the main hospital at the campus.

The original construction of Building 154 is a reinforced concrete frame building with reinforced concrete masonry unit infill walls. The main part of the building is cruciform in plan with overall plan dimensions of approximately 230 by $262 \mathrm{ft}$. The east wing of the building steps in at the second and third levels. The north wing also steps in at the second level. A 25 by $82 \mathrm{ft}$ mechanical penthouse extends up past the roof level at the northeast corner. The one-story structure to the north is L shaped with overall plan dimensions of approximately 88 by $88 \mathrm{ft}$. The pharmacy addition has overall plan dimensions of 116 by $64 \mathrm{ft}$. The warehouse addition has overall plan dimensions of 109 by $69 \mathrm{ft}$. The surgical and diagnostic imaging expansion measures approximately 110 by $60 \mathrm{ft}$. Building $154 \mathrm{~A}$, a one-story addition with a full basement, was added in 1976 immediately adjacent to Building 154 at the northeast corner. The typical story height is approximately $11 \mathrm{ft} 9$ inches with the unfinished basement level at $7 \mathrm{ft} 7$ inches below the first floor, and the penthouse roof is approximately $13 \mathrm{ft} 6$ inches above the main roof level.

The roofs and typical floors consist of 3-inch concrete-pan joist slabs that are supported on reinforced concrete beams and columns at both the interior and exterior of the building. Except at roof areas, an additional $1 \mathrm{ft} 1 / 2$ inch concrete topping slab is found at the floor levels. The perimeter concrete beams also support the concrete masonry infill walls. The interior and exterior concrete columns are founded on concrete spread footings. The basement is composed of reinforced concrete retaining walls cast between the perimeter columns. The retaining walls are supported by their own continuous footing or by a grade beam spanning between column footings. The basement floor consists of a 6 -inch concrete slab on grade at the mechanical area and an earth floor elsewhere. 


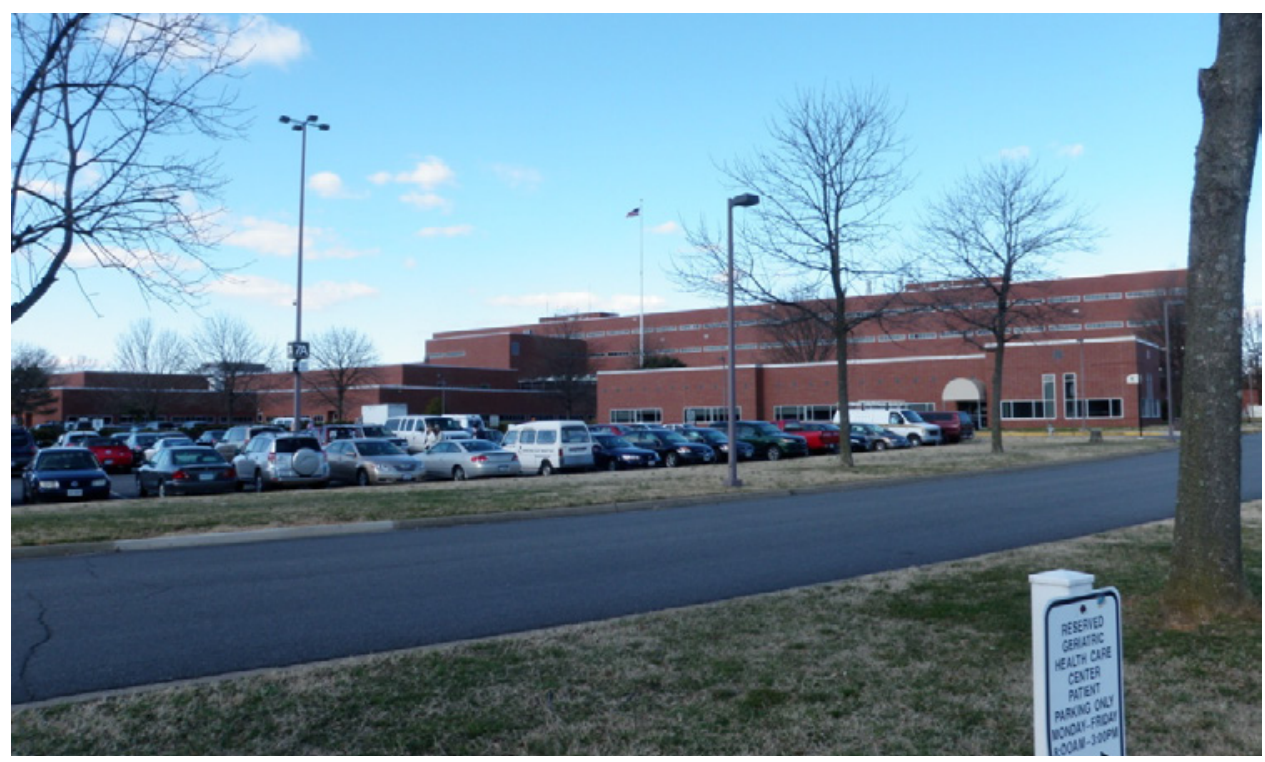

Figure 60. Photograph of Building 154, Fort Harrison Veterans affairs Medical Center, Montana (U.S. Geological Survey photograph).

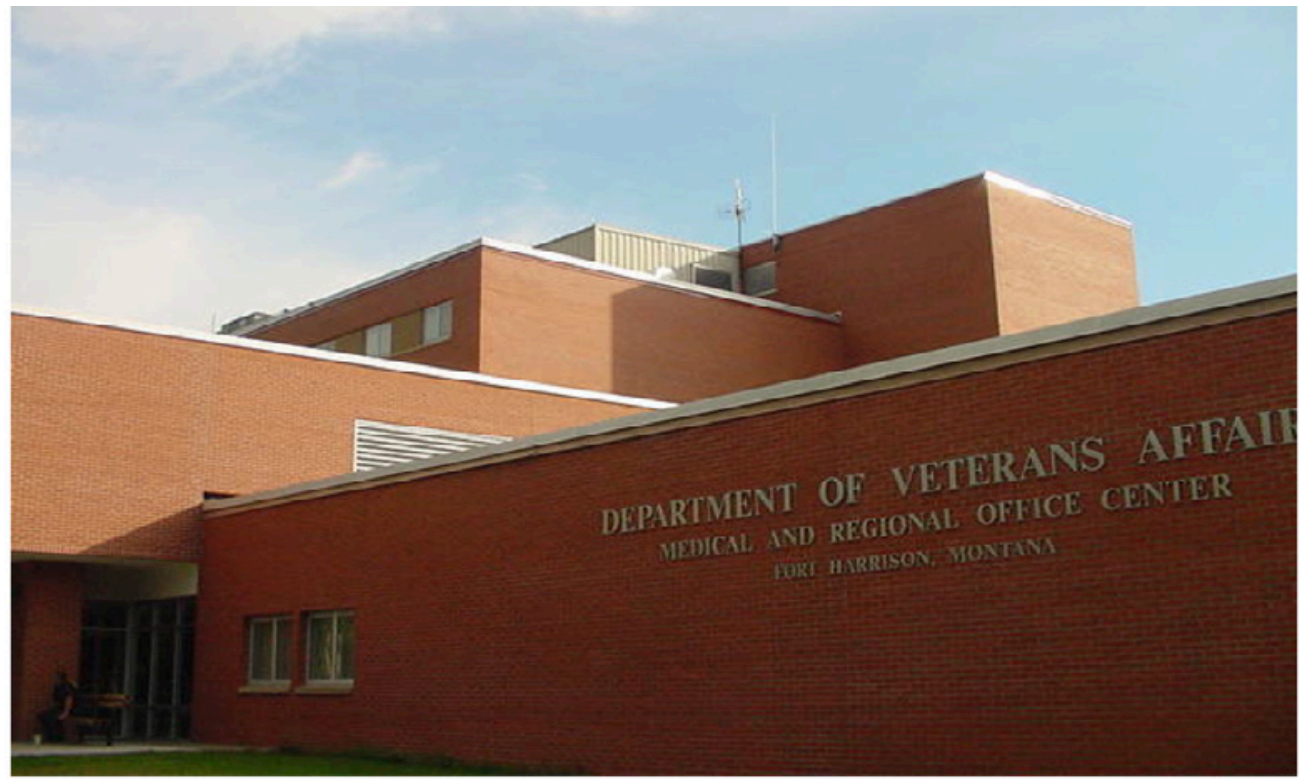

Figure 61. Photograph of Building 154, Fort Harrison Veterans affairs Medical Center, Montana (looking northwest; front view) (U.S. Geological Survey photograph). 


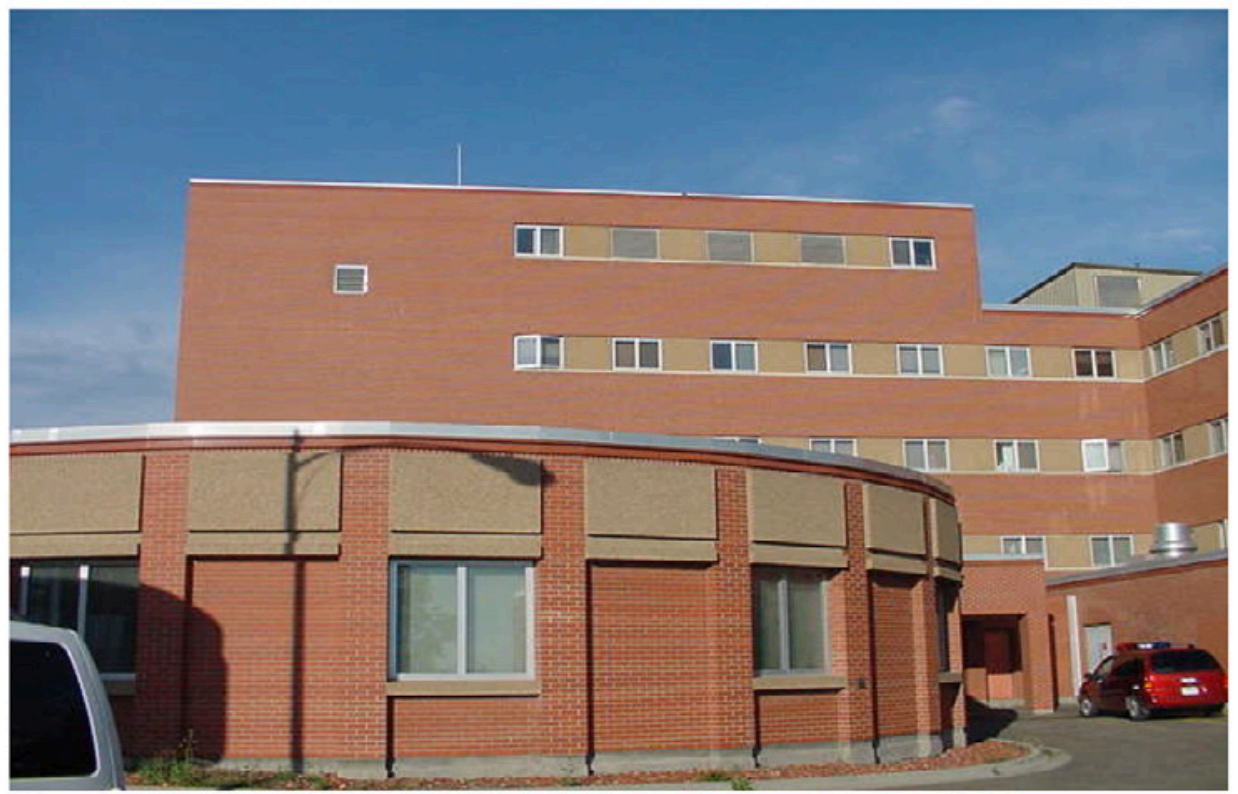

Figure 62. Photograph of Building 154, Fort Harrison Veterans affairs Medical Center, Montana (looking south) (U.S. Geological Survey photograph).

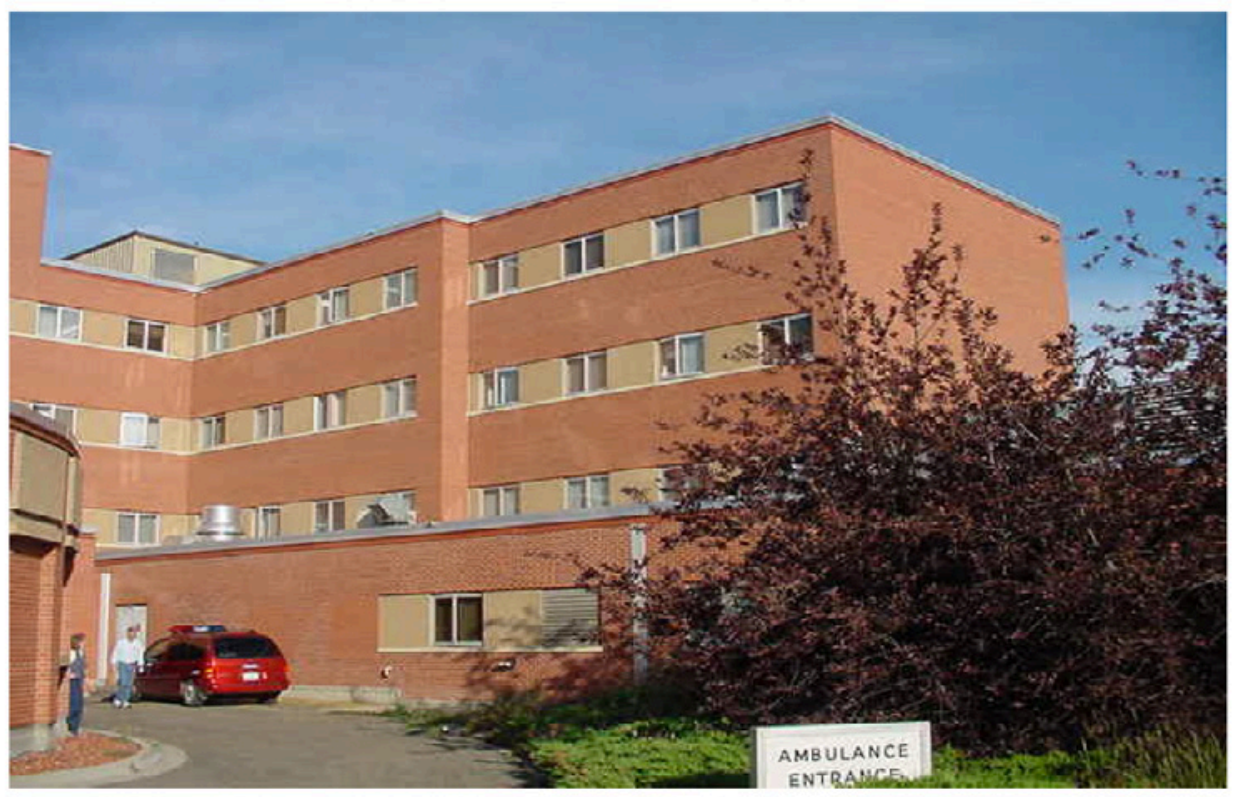

Figure 63. Photograph of Building 154, Fort Harrison Veterans affairs Medical Center, Montana (looking west) (U.S. Geological Survey photograph). 


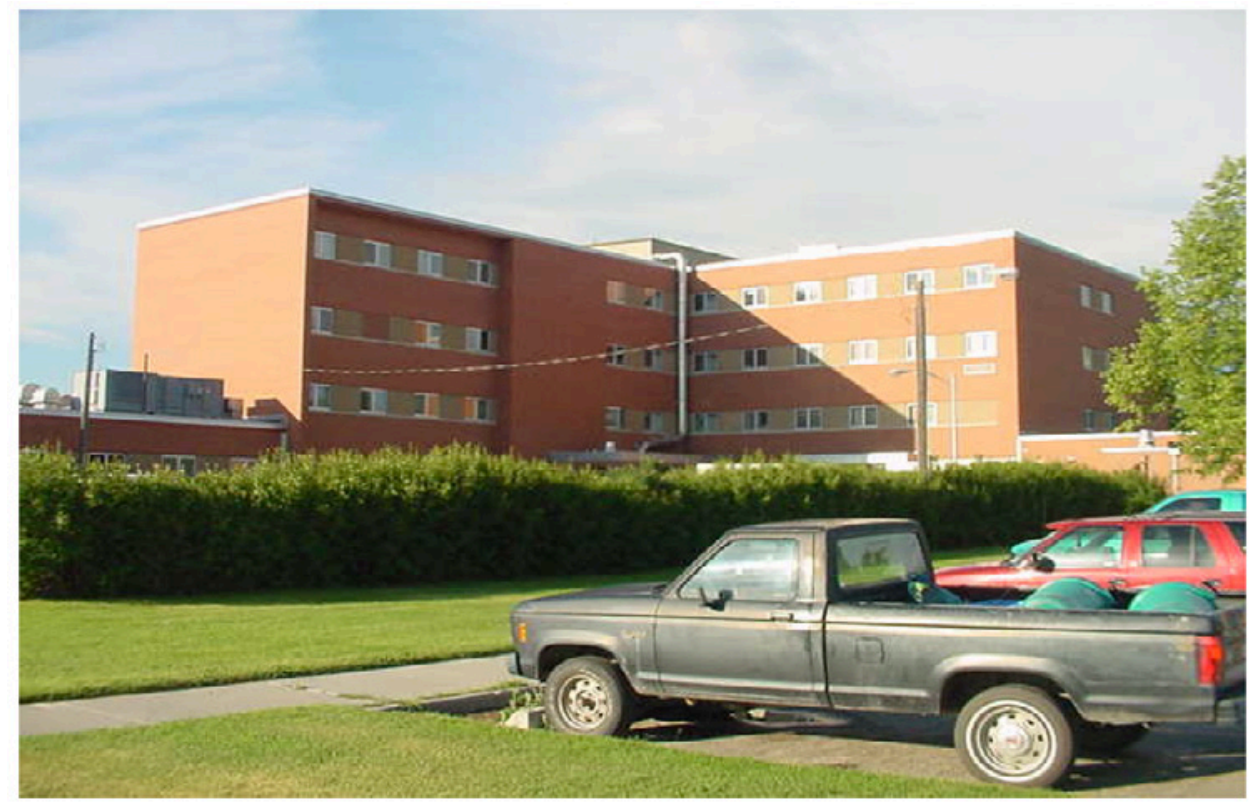

Figure 64. Photograph of Building 154, Fort Harrison Veterans affairs Medical Center, Montana (looking southeast) (U.S. Geological Survey photograph).

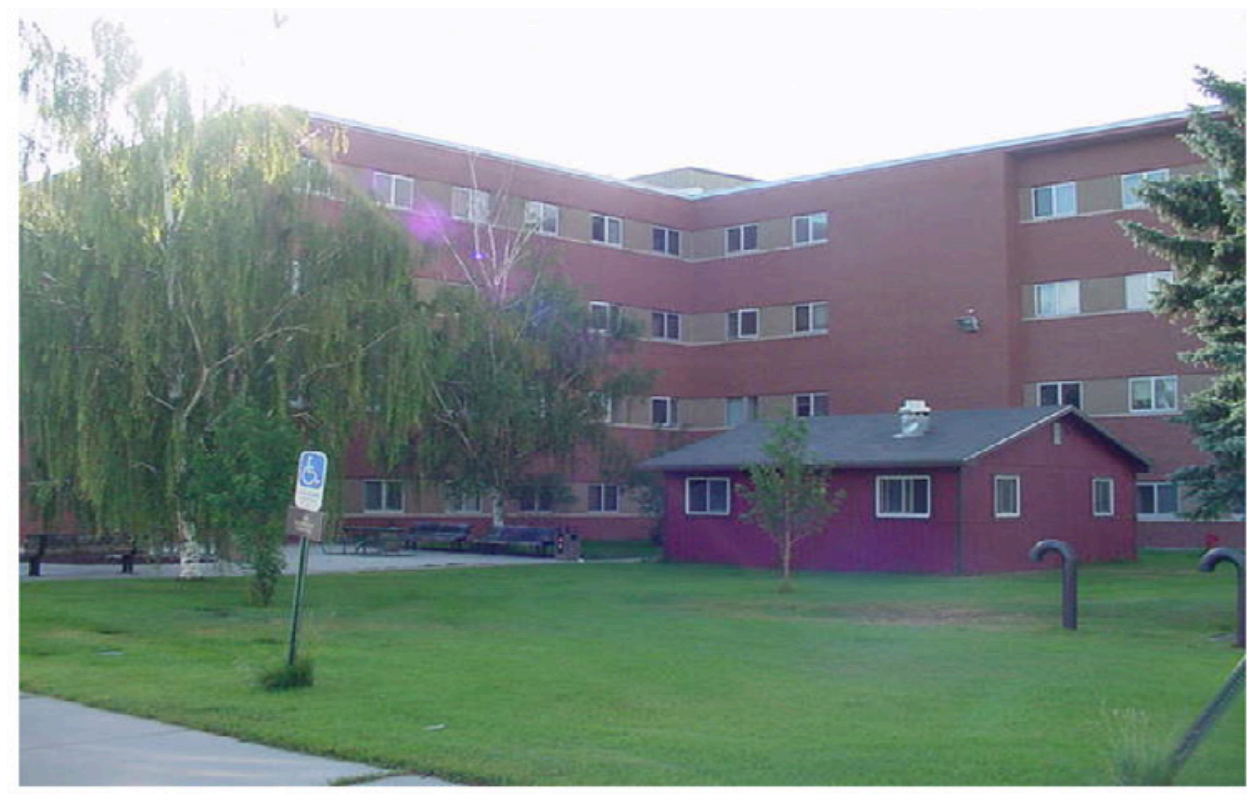

Figure 65. Photograph of Building 154, Fort Harrison Veterans affairs Medical Center, Montana (looking northwest) (U.S. Geological Survey photograph).

\section{Seismic-Hazard and Soil Conditions}

The building is located on a level site with the first floor at the level of the exterior grade. The building is founded on relatively soft soils of varying depths.

The building is located in an area of high seismic hazard. The short-period spectral acceleration, $\mathrm{S}_{\mathrm{S}}$, using the current NEHRP recommended provisions for seismic regulations of new buildings and other structures is $0.68 \mathrm{~g}$. The long-period spectral acceleration, $\mathrm{S}_{1}$, is $0.20 \mathrm{~g}$. 


\section{Instrumentation}

A total of 24 accelerometers are deployed in the building to measure its response to ground motion (fig. 66 and fig. 67). A triaxial accelerometer (channels 1 through 3) is placed on the basement to measure the input ground motion. Two accelerometers (channels 4 and 5) are placed on the ceiling of the basement to monitor first-floor diaphragm motion in two orthogonal directions. Four accelerometers (channels 6 through 9) are placed on the ceiling of the first floor to measure floor lateral motion of the second floor. Another 15 accelerometers (channels 10 through 23) are distributed on the ceiling of the second, third, and fourth floors. The accelerometers are placed at the same corner of the building at each level so that the relative floor displacements, and thus inter-story drifts, can be obtained. Floor torsional motion can be obtained from any pair of two likewise oriented accelerometers located on the same floor. Channels 13, 18, and 23 together with channels 10, 15, and 20 will be used to compute the relative motion of the west wing with respect to the main structure.

The building accelerometers are complemented by a three-component accelerometer located at a reference site (NSMP Station No. 7238), approximately $330 \mathrm{ft}$ away from the building, to monitor ground shaking without interference from the building's earthquake response. 
U.S. Department of Veterans Affairs

Fort Harrison, MT - Steel Moment Frame, Four-Story Hospital Building

Building No: 154

NSMP Station No: 7235

Basement

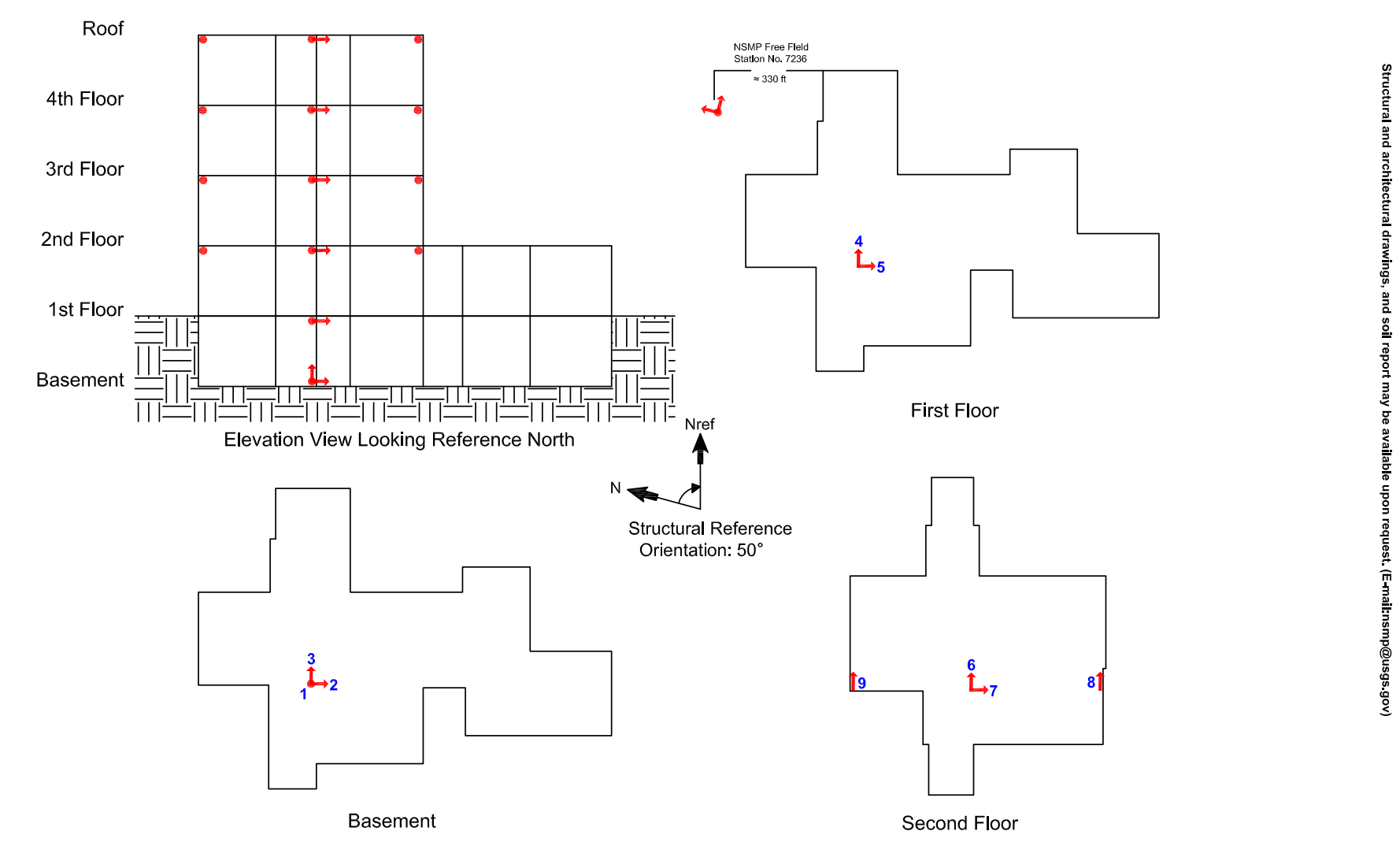

Revision Number: 2

Revised on $9 / 18 / 2012$

Page 1 of 2

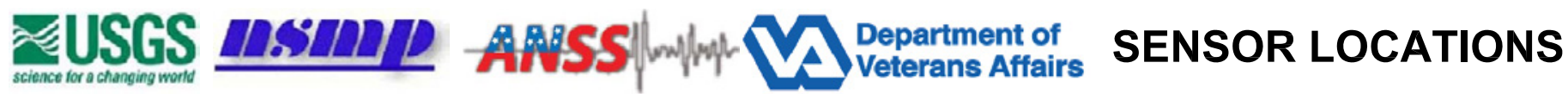

Figure 66. Diagrams of sensor layout showing 24 sensors in Building 154 of the Fort Harrison Veterans Affairs Medical Center, Montana (page 1 of 2; see also fig. 67). 
U.S. Department of Veterans Affairs

Fort Harrison, MT - Steel Moment Frame, Four-Story Hospital Building

Building No: 154

NSMP Station No: 7235

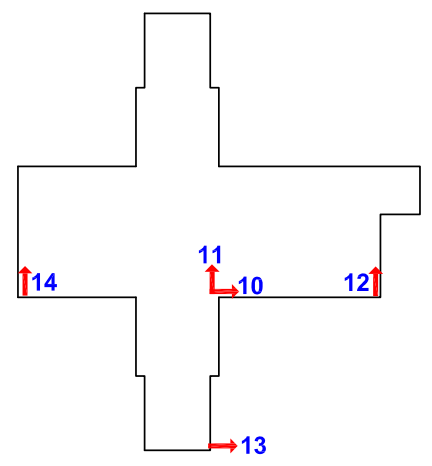

Third Floor
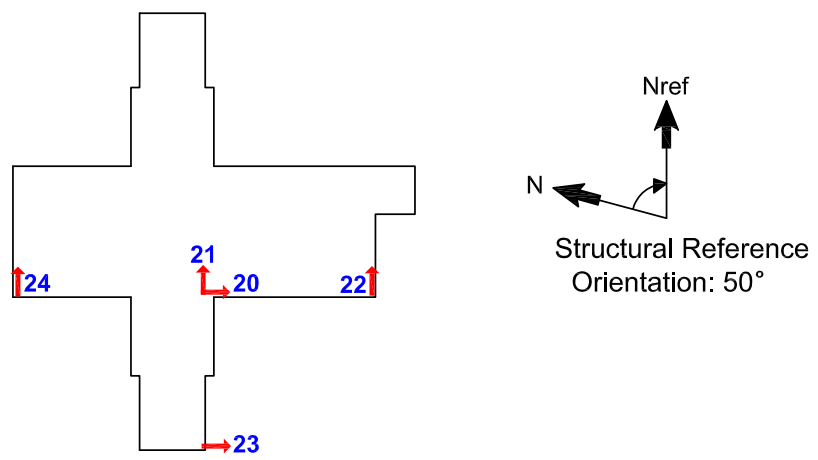

Roof
Revision Number: 2

Revised on $9 / 18 / 2012$

Page 2 of 2

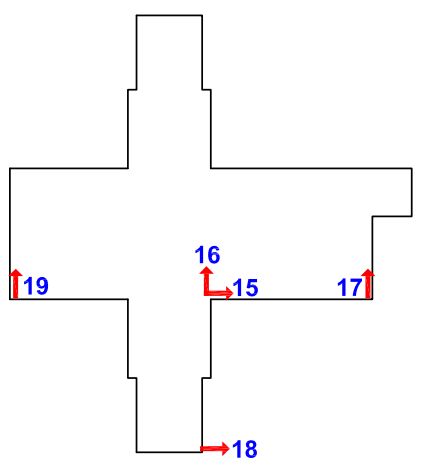

Fourth Floor

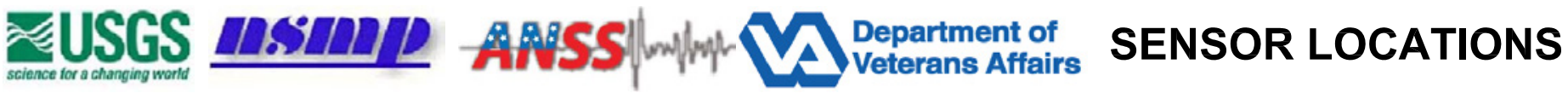

Figure 67. Diagrams of sensor layout showing 24 sensors in Building 154 of the Fort Harrison Veterans Affairs Medical Center, Montana (page 2 of 2; see also fig. 66). 


\section{NSMP Station 2028-Reno, Nevada: New Bed Building/Clinic, Building No. 12}

\section{Building Description}

Building 12 of the VA Sierra Nevada Health Care System (http://www.reno.va.gov/) in Reno, Nevada, is a six-story steel structure of approximately $109,143 \mathrm{ft}^{2}$ (fig. 68 through fig. 70). The structure was initially designed in 1995 , and there have been no major modifications since it was built. The building has an irregular shape with rough base dimensions of 200 by $90 \mathrm{ft}$ with a jagged perimeter on the ground level. Because of its irregular plan, it is very susceptible to torsion. The story heights are typically $15 \mathrm{ft}$ with the exception of the ground and first floor being $12 \mathrm{ft}$. There is a section of the ground floor with an atrium. The lateral- and vertical-force resisting systems consists of steel moment resisting frames. The columns are supported by isolated spread footings.

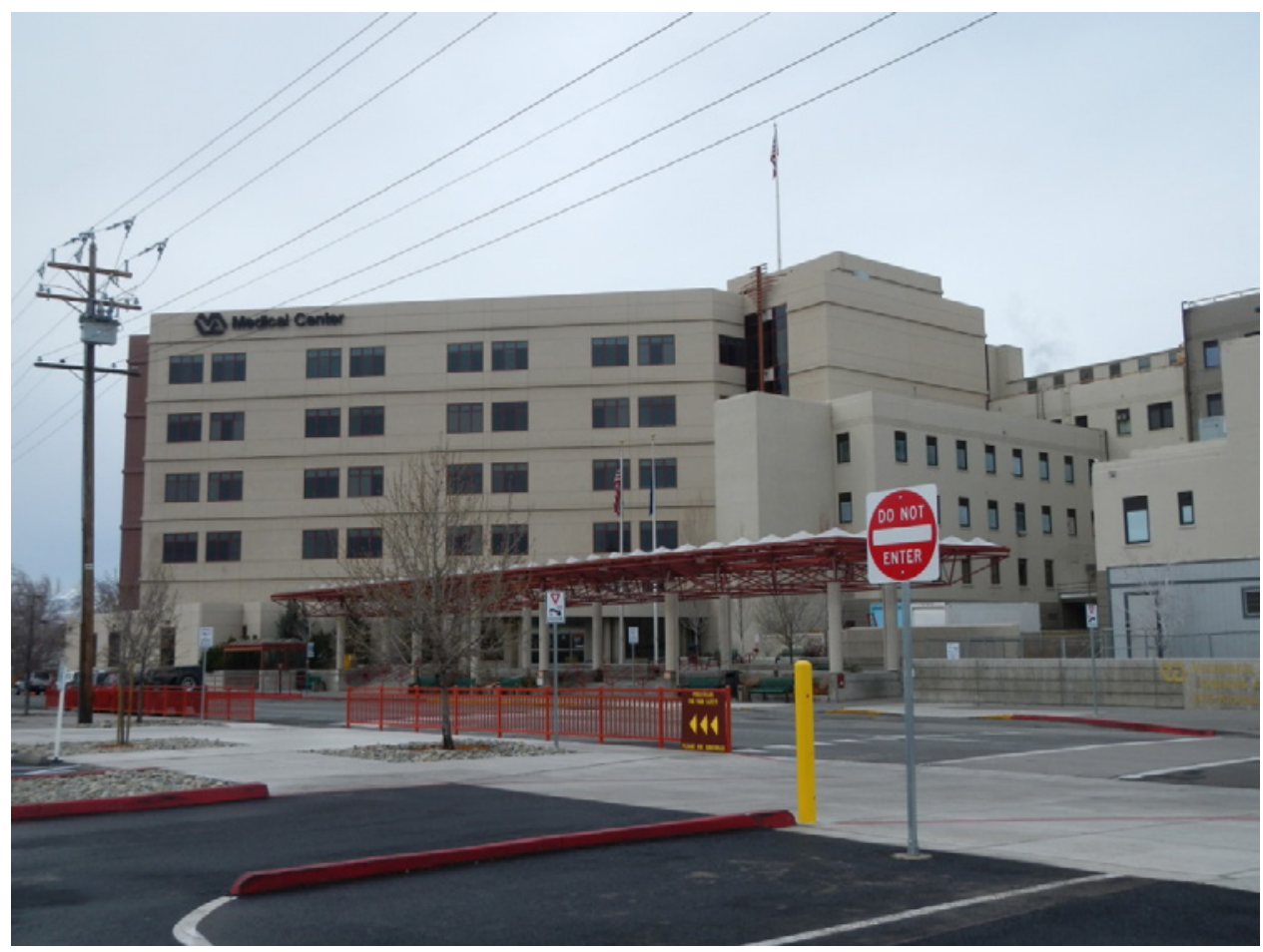

Figure 68. Photograph of Building 12, Reno Veterans Affairs Medical Center, Nevada (front view) (U.S. Geological Survey photograph). 


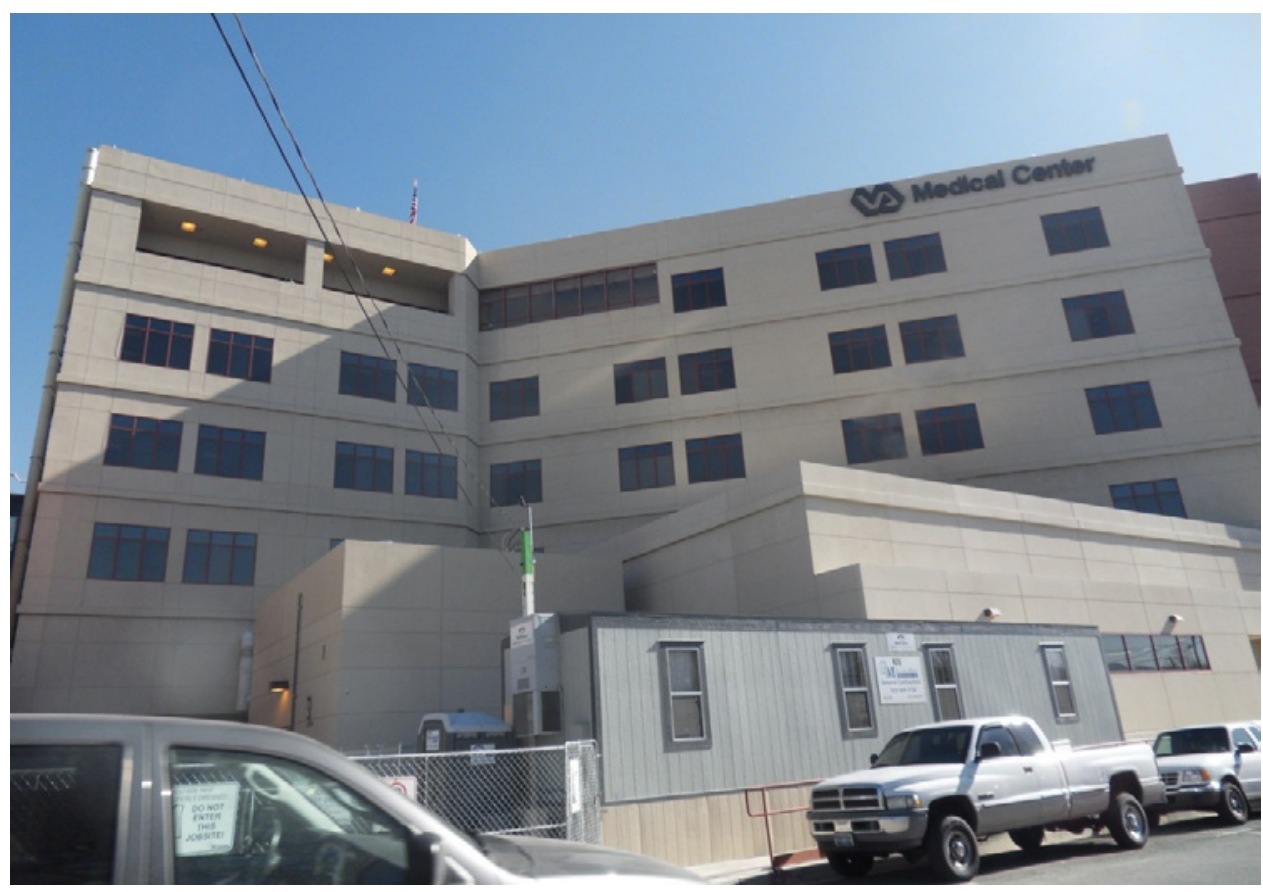

Figure 69. Photograph of Building 12, Reno Veterans Affairs Medical Center, Nevada (looking northeast) (U.S. Geological Survey photograph).

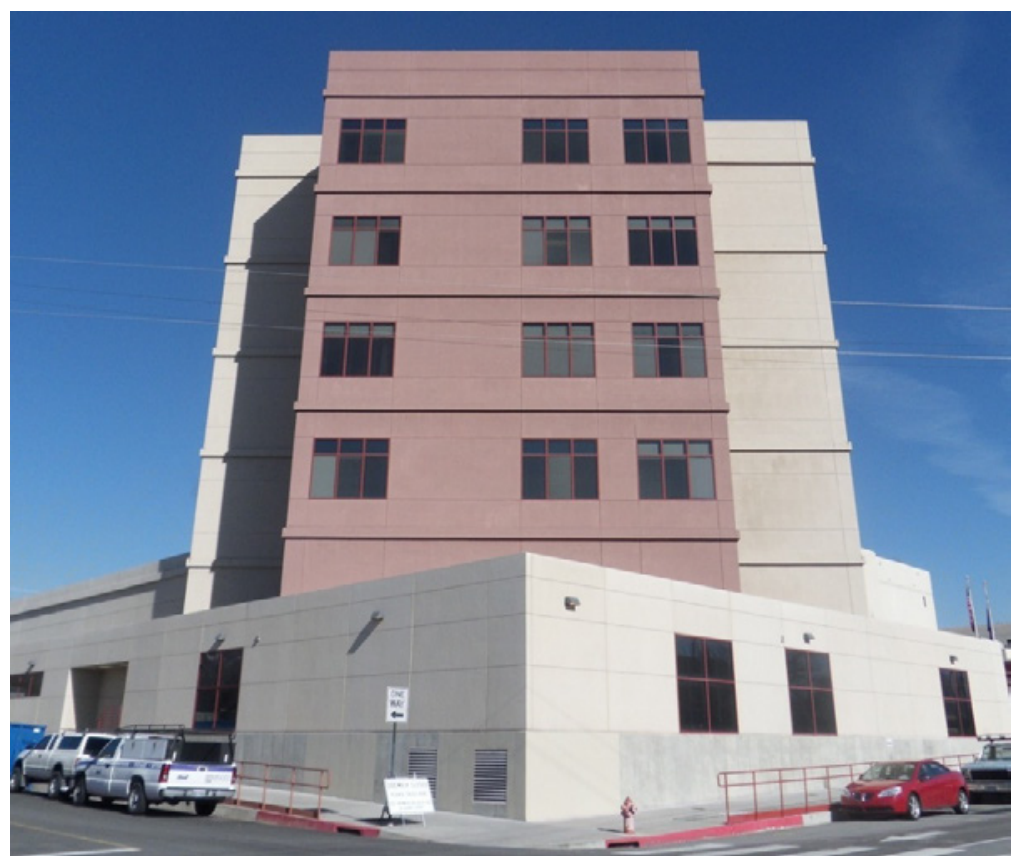

Figure 70. Photograph of Building 12, Reno Veterans Affairs Medical Center, Nevada (looking northwest) (U.S. Geological Survey photograph). 


\section{Seismic-Hazard Conditions}

The building is located in an area of high seismic hazard. The short-period spectral acceleration, $\mathrm{S}_{\mathrm{S}}$, using the current NEHRP recommended provisions for seismic regulations of new buildings and other structures, is $1.50 \mathrm{~g}$. The long-period spectral acceleration, $\mathrm{S}_{1}$, is $0.60 \mathrm{~g}$.

\section{Instrumentation}

This steel building has an unsymmetrical plan; therefore, significant torsion is expected to occur under strong ground shaking. To capture the building's lateral, vertical and torsional response, 36 accelerometers are distributed strategically in the building (fig. 71 and fig. 72). At the ground level, a triaxial accelerometer (channels 1 through 3 ) is used to record base-level ground shaking in two horizontal and a vertical direction. Four accelerometers (channels 4 through 7) are located at the first-floor level to measure the building's response in two horizontal directions and compute floor torsional motion. The higher floors are instrumented likewise. The floor relative displacements can be computed from the recordings of the accelerometers located at the same corner of the building at different levels.

The building accelerometers are complemented by a three-component seismic accelerometer located at a free-field site (NSMP Station No. 2029), approximately $720 \mathrm{ft}$ away from the building, to monitor ground shaking without interference from the response of the building. 
U.S. Department of Veterans Affairs

Reno, NV - Steel Moment Frame, Six-Story Hospital Building

Building No: 12

NSMP Station No: 2028

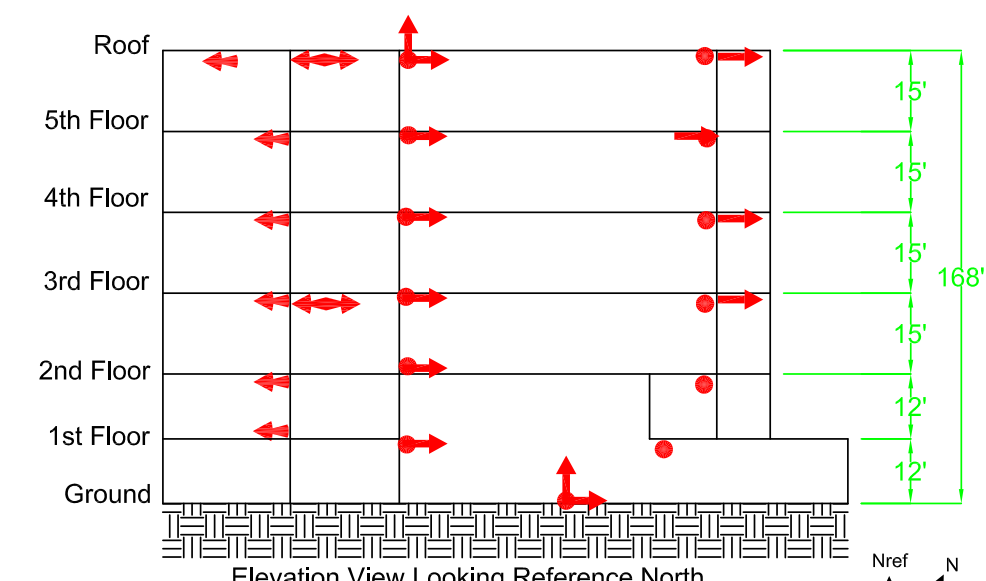

Elevation View Looking Reference North

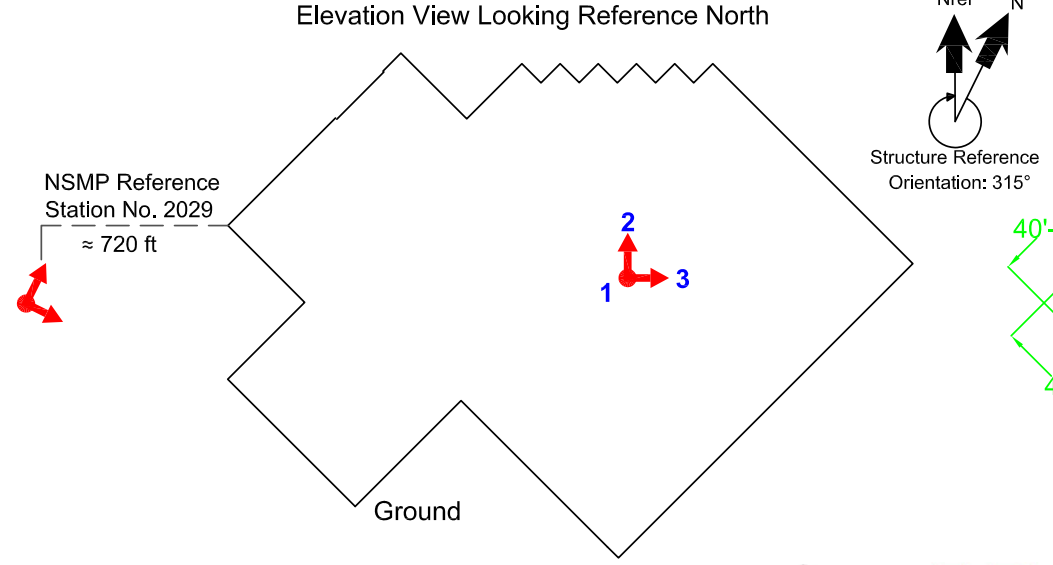

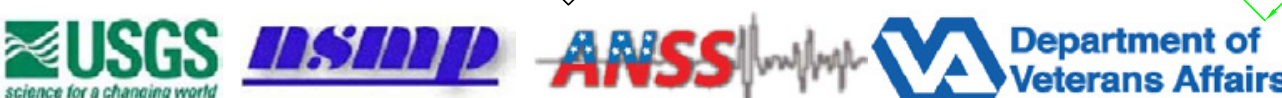

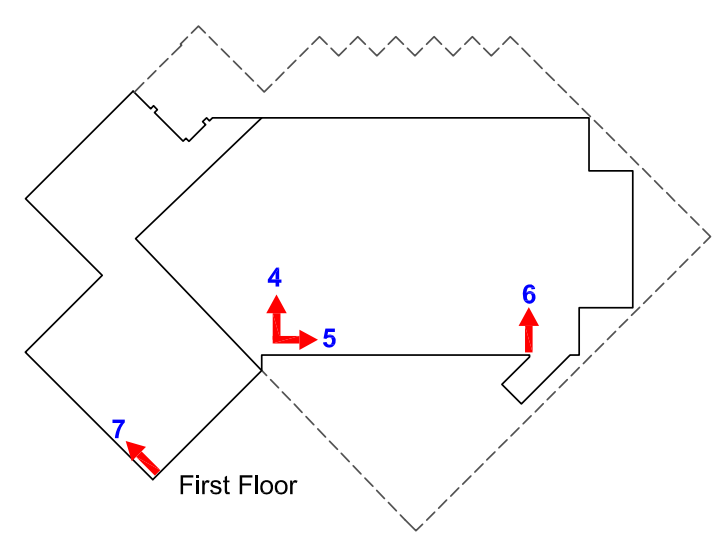

Revised on 10/10/2012

Page 1 of 2

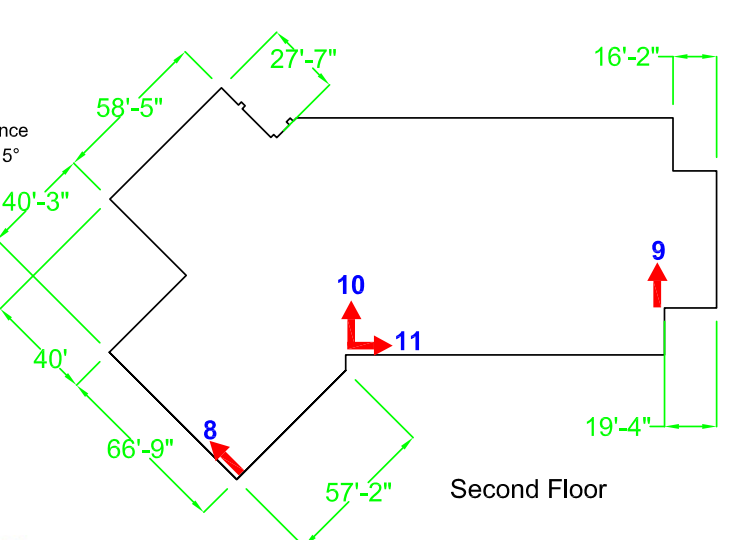

SENSOR LOCATIONS

Figure 71. Diagrams of sensor layout showing 36 sensors in Building 12 of the Reno Veterans Affairs Medical Center, Nevada (page 1 of 2; see also fig. 72). 
U.S. Department of Veterans Affairs

Reno, NV - Steel Moment Frame, Six-Story Hospital Building

Building No: 12

NSMP Station No: 2028
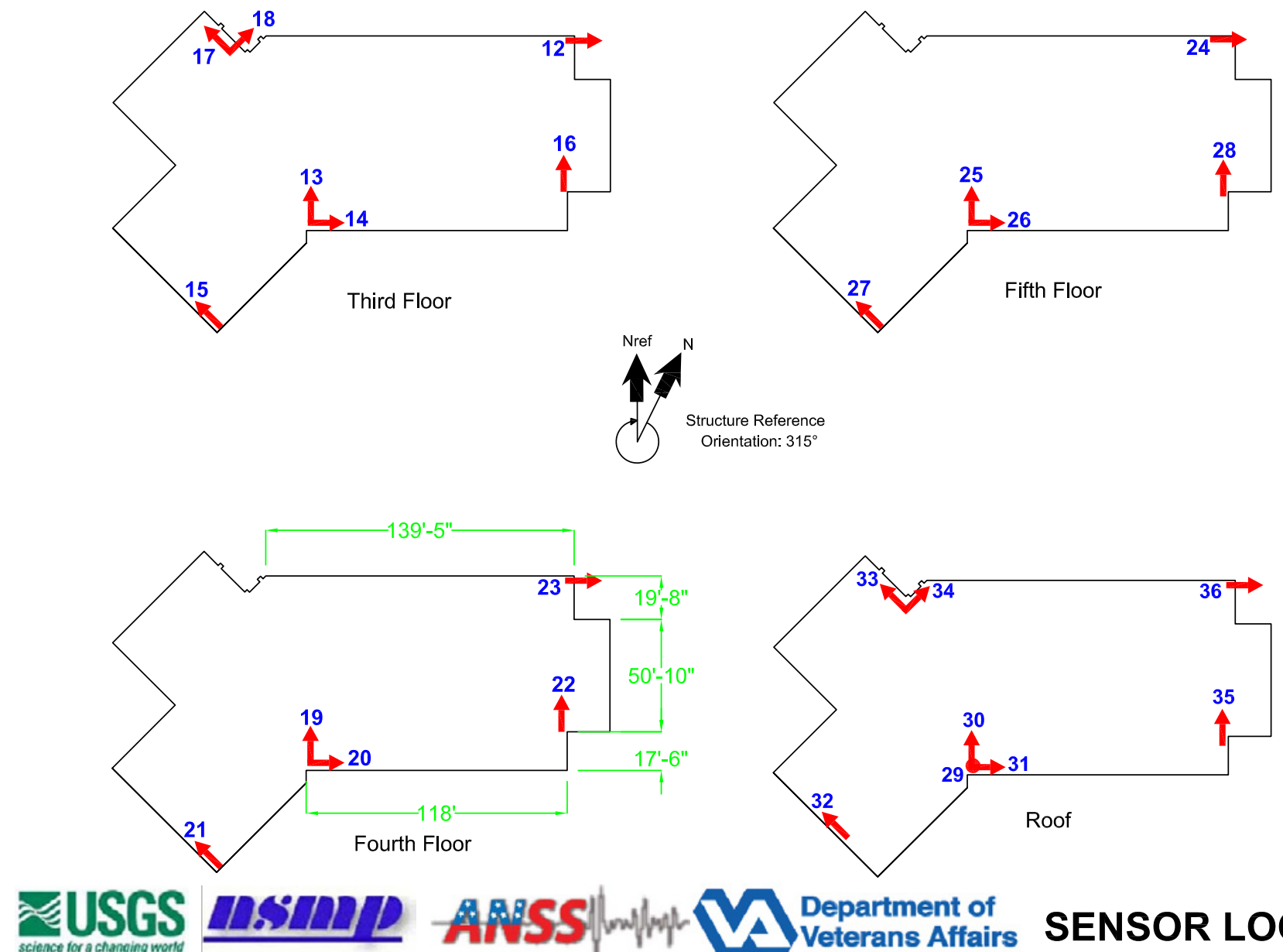

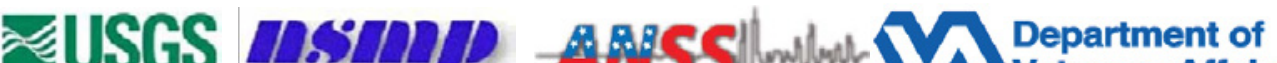
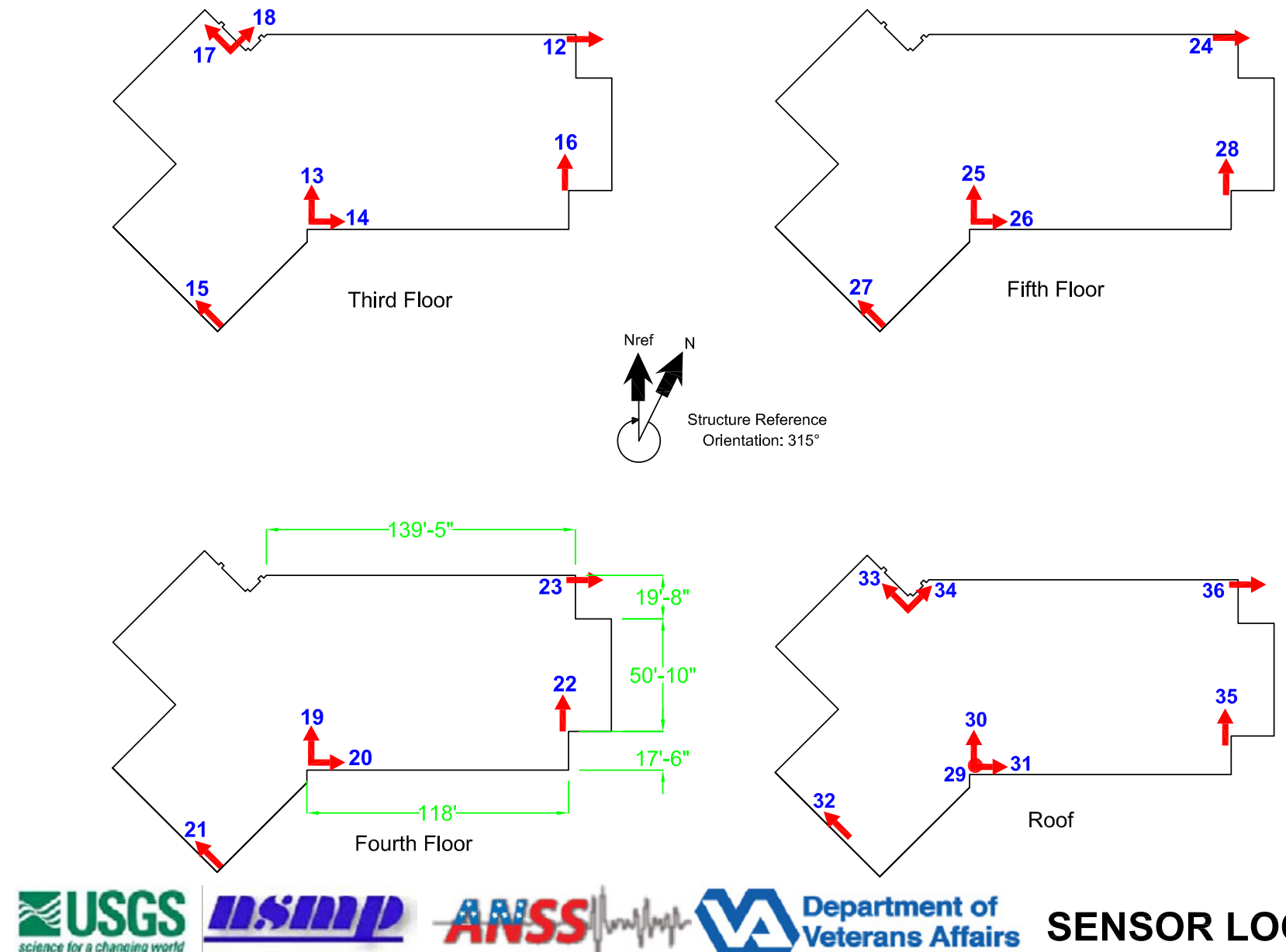

Revision Number: 10

Revised on $10 / 10 / 2012$

Page 2 of 2

SENSOR LOCATIONS

Figure 72. Diagrams of sensor layout showing 36 sensors in Building 12 of the Reno Veterans Affairs Medical Center, Nevada (page 2 of 2; see also fig. 71). 


\section{NSMP Station 3096-San Juan, Puerto Rico: Nursing, Building No. 10}

\section{Building Description}

Building 10 at the VA Caribbean Healthcare System (http://www.caribbean.va.gov/) in San Juan, Puerto Rico, is a two-story reinforced concrete structure (fig. 73 through fig. 75) covering approximately $63,900 \mathrm{ft}^{2}$. It serves as the nursing home and blind rehabilitation center. The structure has irregular plan shape with number of wings. The building was designed in 1986, and has not been modified since then. The typical story height of each floor is $14 \mathrm{ft} 6$ inches. Both the lateral- and vertical-force resisting systems consist of reinforced concrete frames and walls. The columns are supported by a foundation of isolated pile caps on piles.

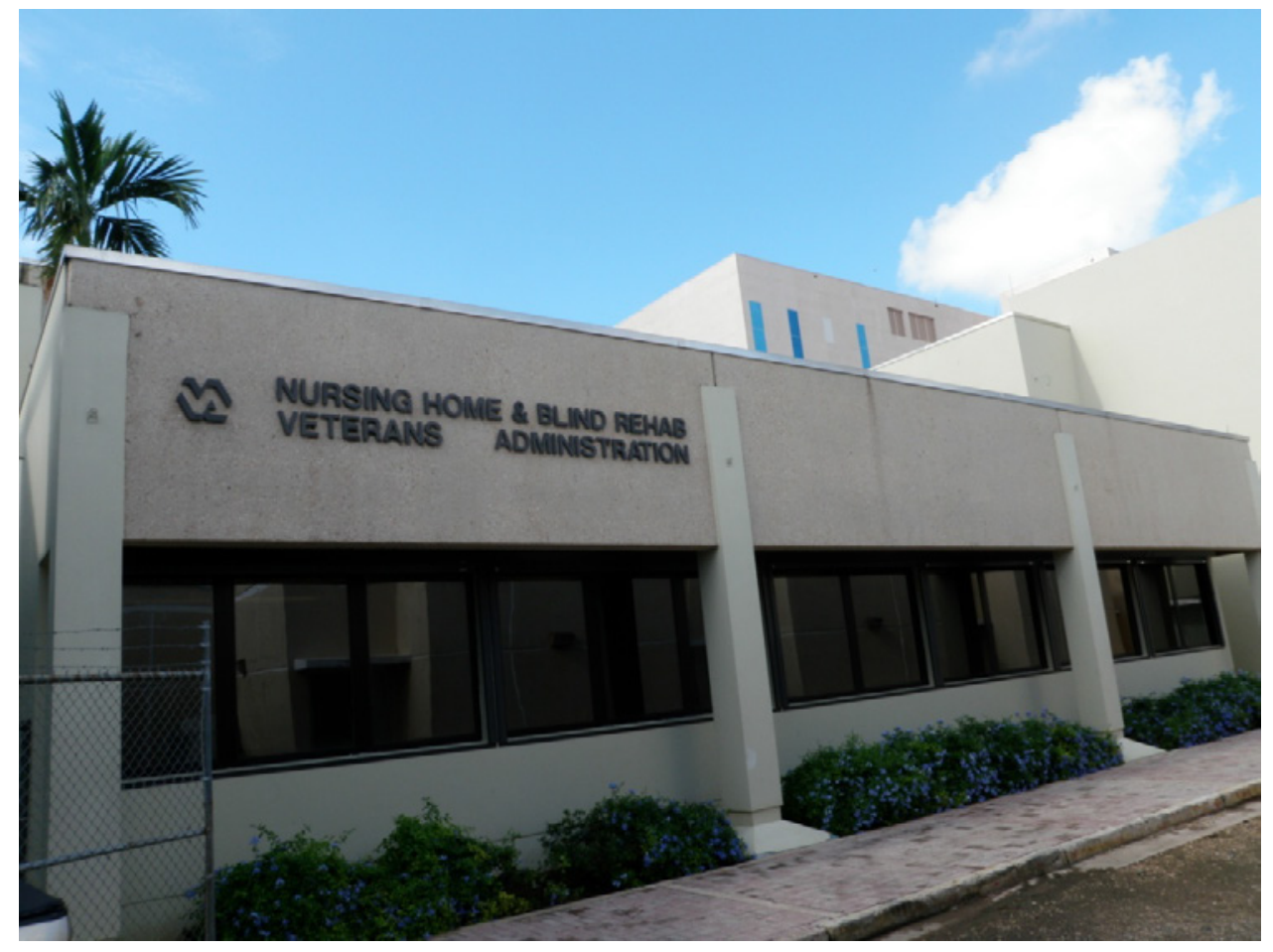

Figure 73. Photograph of Building 10, San Juan Caribbean Veterans Affairs Medical Center, Puerto Rico (side view) (U.S. Geological Survey photograph). 


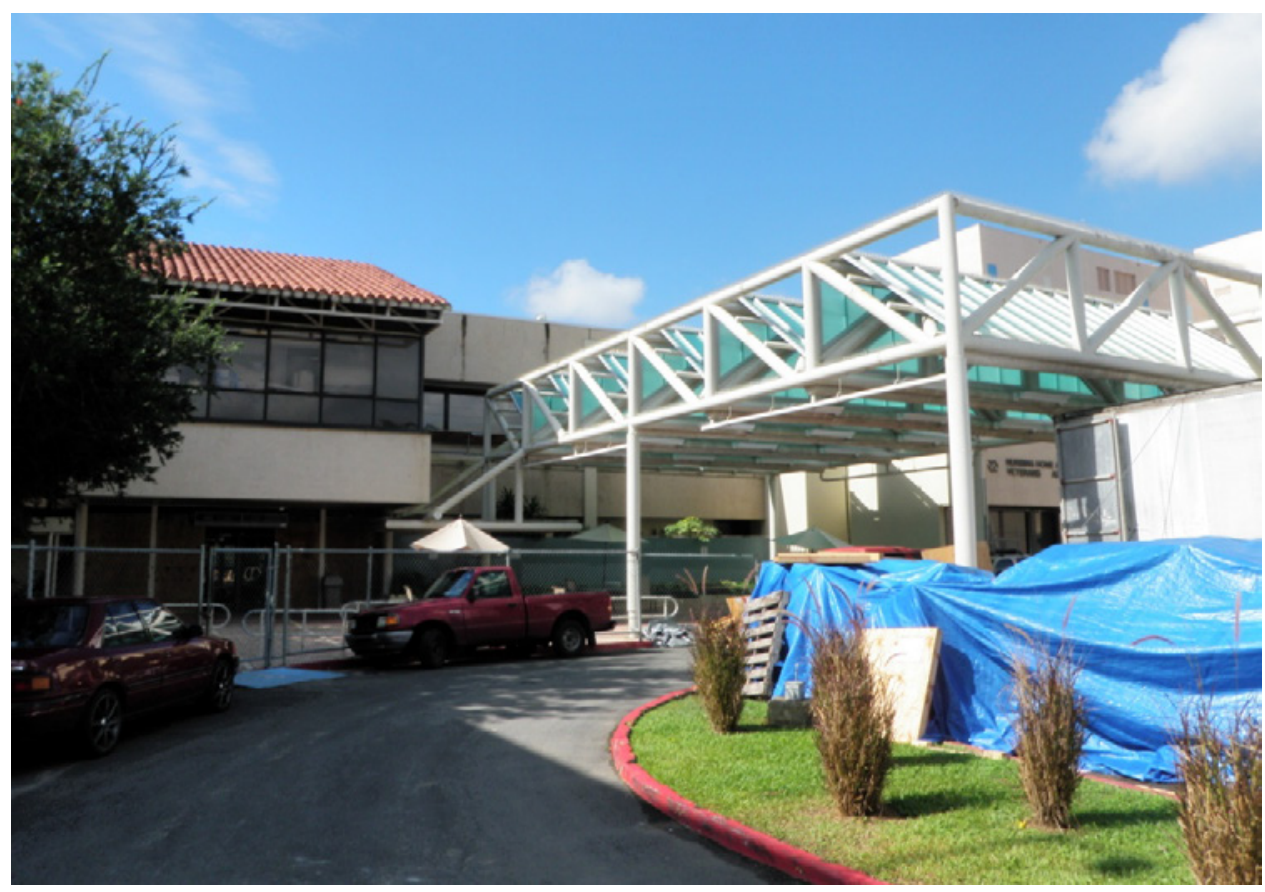

Figure 74. Photograph of Building 10, San Juan Caribbean Veterans Affairs Medical Center, Puerto Rico (front view) (U.S. Geological Survey photograph by NSMP).
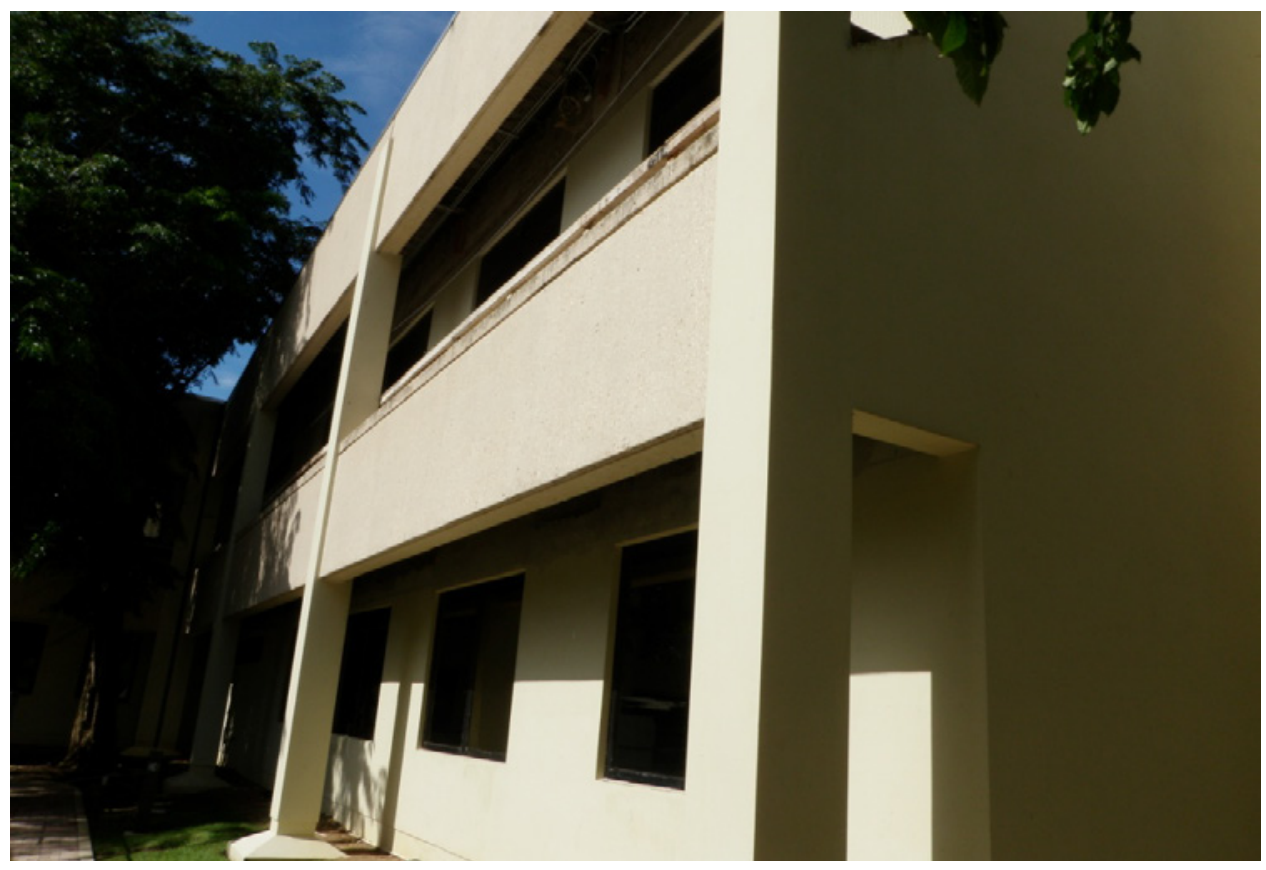

Figure 75. Photograph of Building 10, San Juan Caribbean Veterans Affairs Medical Center, Puerto Rico (back side view) (U.S. Geological Survey photograph). 


\section{Seismic-Hazard Conditions}

The building is located in an area of high seismic hazard. The short-period spectral acceleration, $\mathrm{S}_{\mathrm{S}}$, using the current NEHRP recommended provisions for seismic regulations of new buildings and other structures, is $0.87 \mathrm{~g}$. The long-period spectral acceleration, $\mathrm{S}_{1}$, is $0.29 \mathrm{~g}$.

\section{Instrumentation}

The building has two stories and a T-shape plan with three wings. To monitor translational and torsional responses of all three wings during a strong shaking, 12 accelerometers are located strategically throughout the building (fig. 76). A triaxial accelerometer (channels 1 through 3 ) is placed on the first-floor ground level. Four accelerometers (channels 4 through 7) are placed on the first-floor ceiling level to monitor second-floor diaphragm motion. Another five accelerometers (channels 8 through 12) are placed on the second-floor ceiling level to measure floor lateral and torsional motions of the roof.

The building accelerometers are complemented by a three-component seismic accelerometer located at a reference site (NSMP Station No. 3090), approximately $740 \mathrm{ft}$ away from the building, to monitor ground shaking without interference from the earthquake response of the building. 
U.S. Department of Veterans Affairs

San Juan, Puerto Rico - Reinforced Concrete, Two-Story Hospital Building

Building No: 10

NSMP Station No: 3096
Revision Number: 6

Revised on 10/10/2012

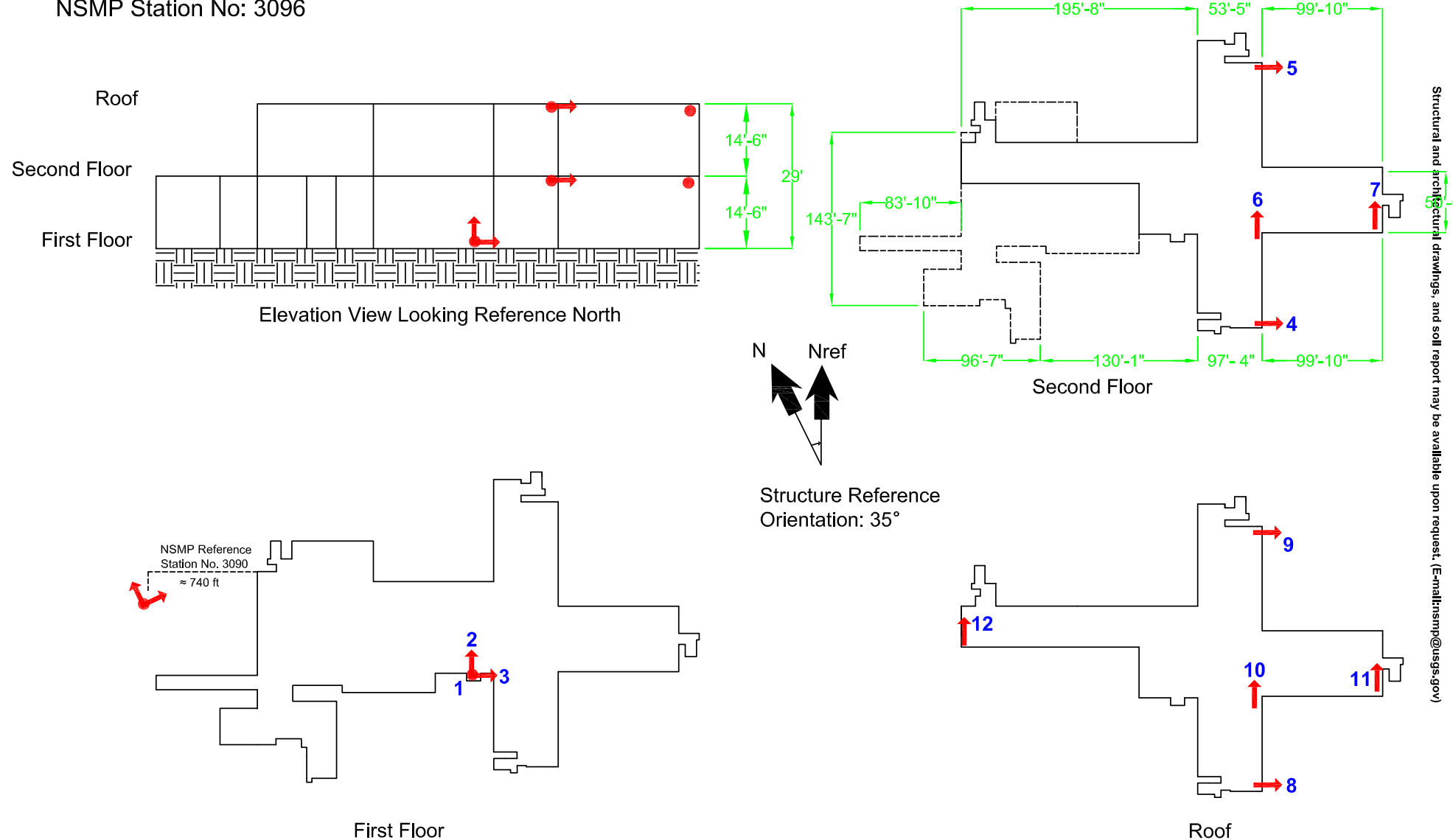

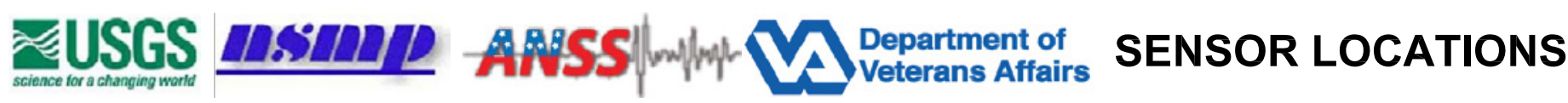

Figure 76. Diagram of sensor layout showing 12 sensors in Building 10 of the Photograph of Building 10, San Juan Caribbean Veterans Affairs Medical Center, Puerto Rico. 


\section{NSMP Station 3095-San Juan, Puerto Rico: New Bed Tower, Building No. B30}

\section{Building Description}

Building B30 in at the VA Caribbean Healthcare System (http://www.caribbean.va.gov/) in San Juan, Puerto Rico, was completed in 2011 and serves as a new bed tower. This reinforced concrete structure has a primarly rectangular shape with base dimensions of 285 by $105 \mathrm{ft}$. There is a small protrusion outward at the center of the northern side of the building and an offset of about $35 \mathrm{ft}$ nearly halfway across its long span (fig. 77 and fig. 78). This structure has been measured to be approximately $230,000 \mathrm{ft}^{2}$ and also has a basement below ground level in addition to the six stories above ground. The typical story height is $14 \mathrm{ft}$. Both the vertical- and lateral-force resisting systems consist of reinforced concrete moment resisting frames and shear walls. The foundation uses isolated spread footings to support the columns and shear walls.

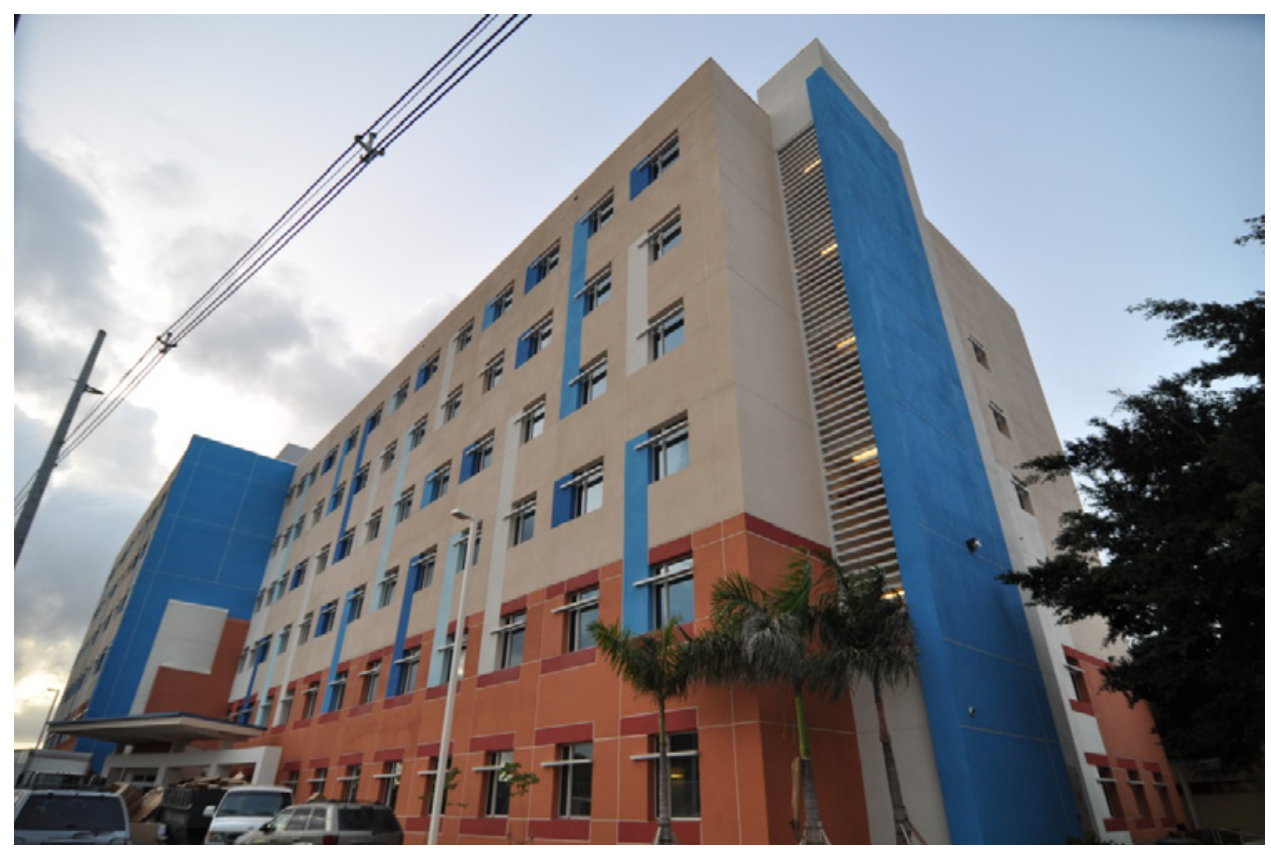

Figure 77. Photograph of Building 30, San Juan Caribbean Veterans Affairs Medical Center, Puerto Rico (front view) (U.S. Geological Survey photograph). 


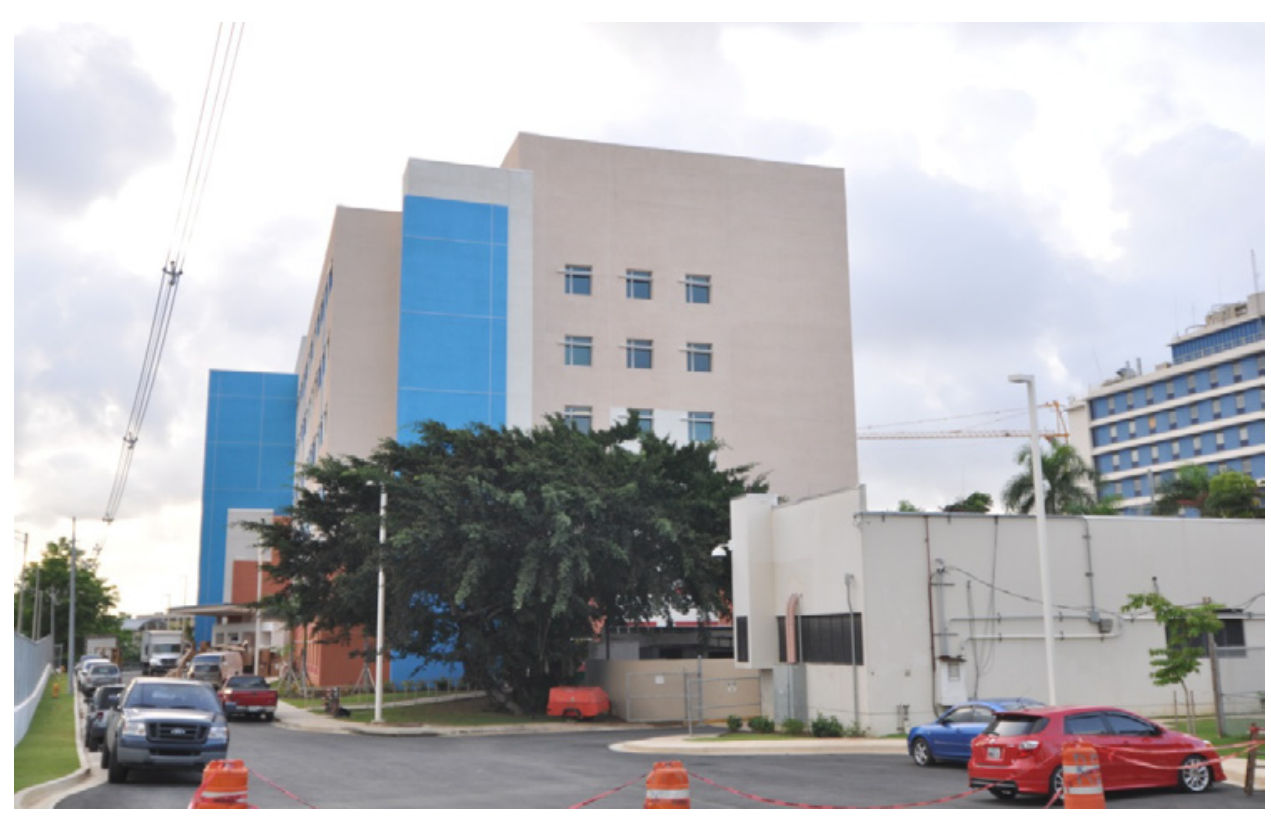

Figure 78. Photograph of Building 30 , San Juan Caribbean Veterans Affairs Medical Center, Puerto Rico (side view) (U.S. Geological Survey photograph).

\section{Seismic-Hazard Conditions}

The building is located in an area of high seismic hazard. The short-period spectral acceleration, $\mathrm{S}_{\mathrm{S}}$, using the current NEHRP recommended provisions for seismic regulations of new buildings and other structures, is $0.87 \mathrm{~g}$. The long-period spectral acceleration, $\mathrm{S}_{1}$, is $0.29 \mathrm{~g}$.

\section{Instrumentation}

The building B30 has six stories and a basement. A total of 24 accelerometers are deployed at eight levels in the building (fig. 79). A triaxial accelerometer is placed on the basement slab to measure the three component of input ground motion. Two accelerometers (channels 4 and 5) are placed on the ceiling of the basement to monitor first-floor diaphragm motions. Fifteen accelerometers (channels 6 through 20) are evenly distributed on the ceilings of the first floor through the fifth floor to measure floor lateral motion in the reference east-west and north-south directions. Floor torsional motions can be obtained from likewise oriented accelerometers on the same floor. The sixth floor ceiling is instrumented with four accelerometers (channels 21 through 24). Floor relative displacements, thus inter-story drifts, can be computed from the recordings of the accelerometers placed on each floor level at the reference south-east corner of the building.

The building accelerometers are complemented by a three-component seismic accelerometer located at a reference site (NSMP Station No. 3090), approximately $590 \mathrm{ft}$ from the building, to monitor ground shaking without interference from the earthquake response of the building. 
U.S. Department of Veterans Affairs

San Juan, PR - Reinforced Concrete, Six-Story Hospital Building

Building No: B30

NSMP Station No: 3095
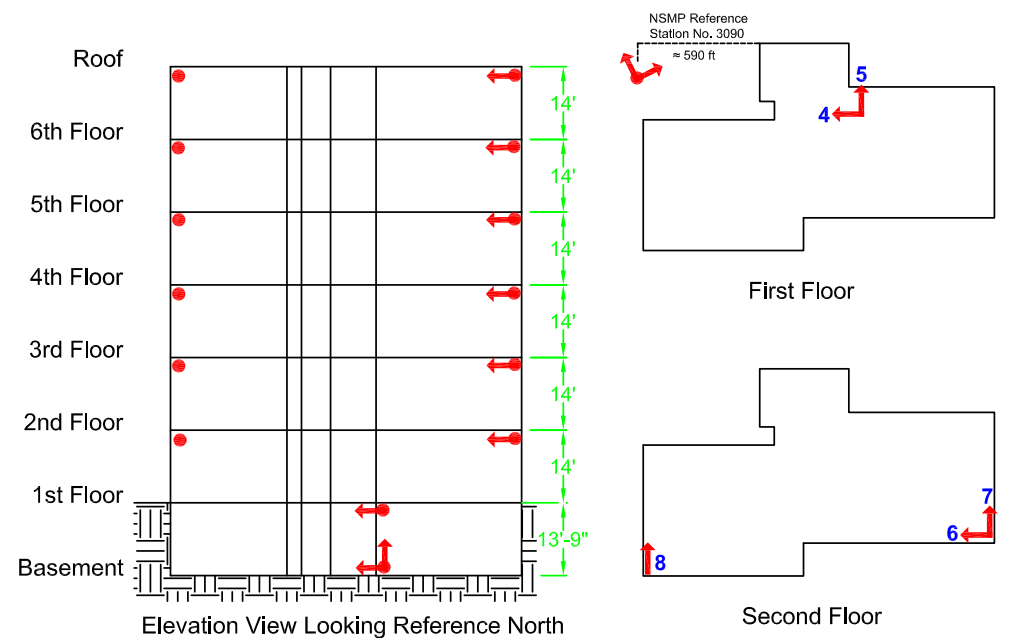

First Floor
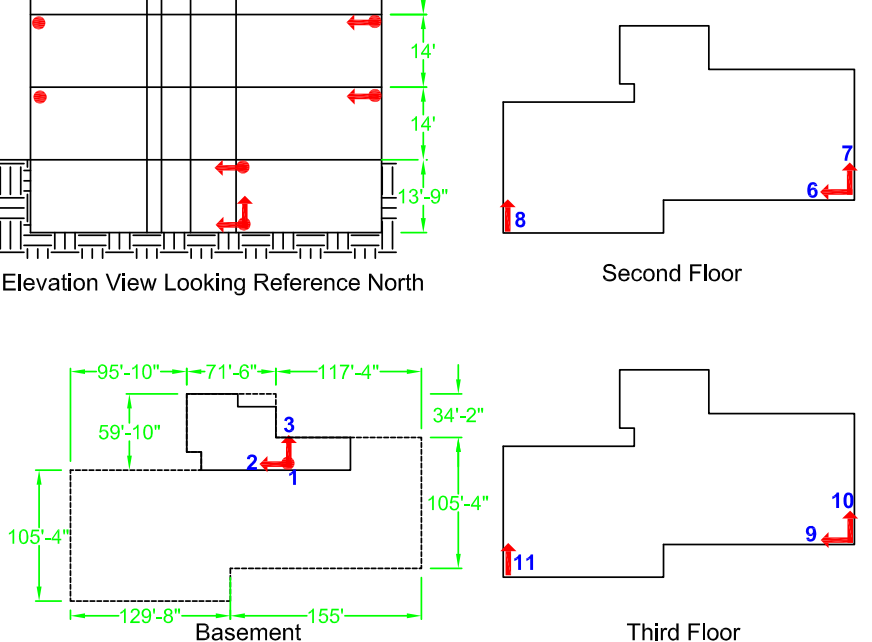

Third Floor
Revision Number: 3

Revised on $10 / 10 / 2012$
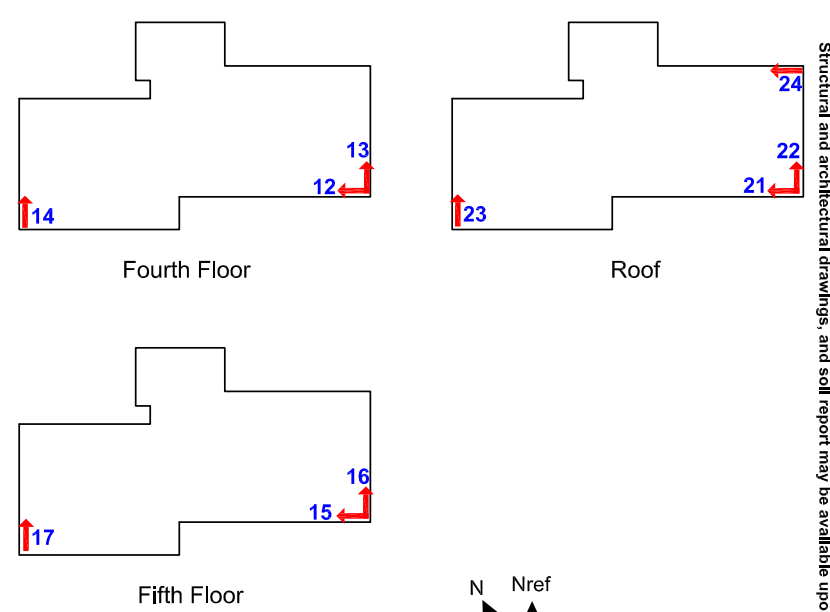

Orientation: $37^{\circ}$

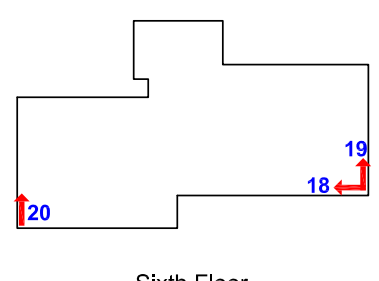

Sixth Floor

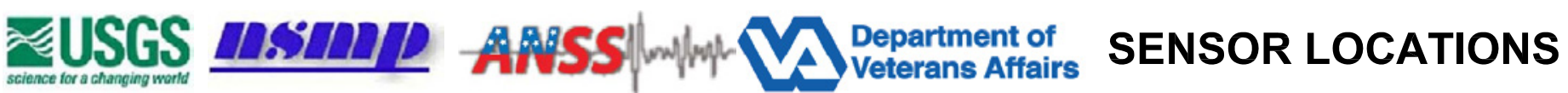

Figure 79. Diagram of sensor layout showing 24 sensors in Building B30 of the San Juan Caribbean Veterans Affairs Medical Center, Puerto Rico. 


\section{NSMP Station 7413-Oklahoma City, Oklahoma: Main Hospital, Building No. 1}

\section{Building Description}

Building 1, located in Oklahoma City, Oklahoma, is the main hospital building at the Oklahoma City VA Medical Center (http://www.oklahoma.va.gov/). This 12-story structure (fig. 80 through fig. 84) is about $854,780 \mathrm{ft}^{2}$. It was designed in 1950 and has an irregular shape with two different units- Unit A and Unit B. Unit A is south of Unit B. Unit A has a long main rectangular wing that has two smaller, symmetric rectangular wings in both the southeast and southwest directions from the center of Unit A. The main wing of Unit A has the approximate dimensions of 36 by $174 \mathrm{ft}$. The two rectangular protrusions have approximate dimensions of 37 by $59 \mathrm{ft}$. Unit B resembles a cross-like shape and has four wings in all four cardinal directions. The approximate dimensions for the north, south, east, and west wings are 78 by $36 \mathrm{ft}, 41$ by 38 $\mathrm{ft}, 37$ by $58 \mathrm{ft}$, and 43 by $117 \mathrm{ft}$, respectively. In the past, the building had several major retrofittings. Three seismic joints separate the two units into four major parts. This building is primarily constructed from reinforced concrete, although in many instances, steel beams are encased with concrete for added rigidity. Typical floor and roof construction consists of composite reinforced concrete slabs. The basement floor is a concrete slab on grade. Concrete walls and columns connect to the caisson caps of the pier foundation.

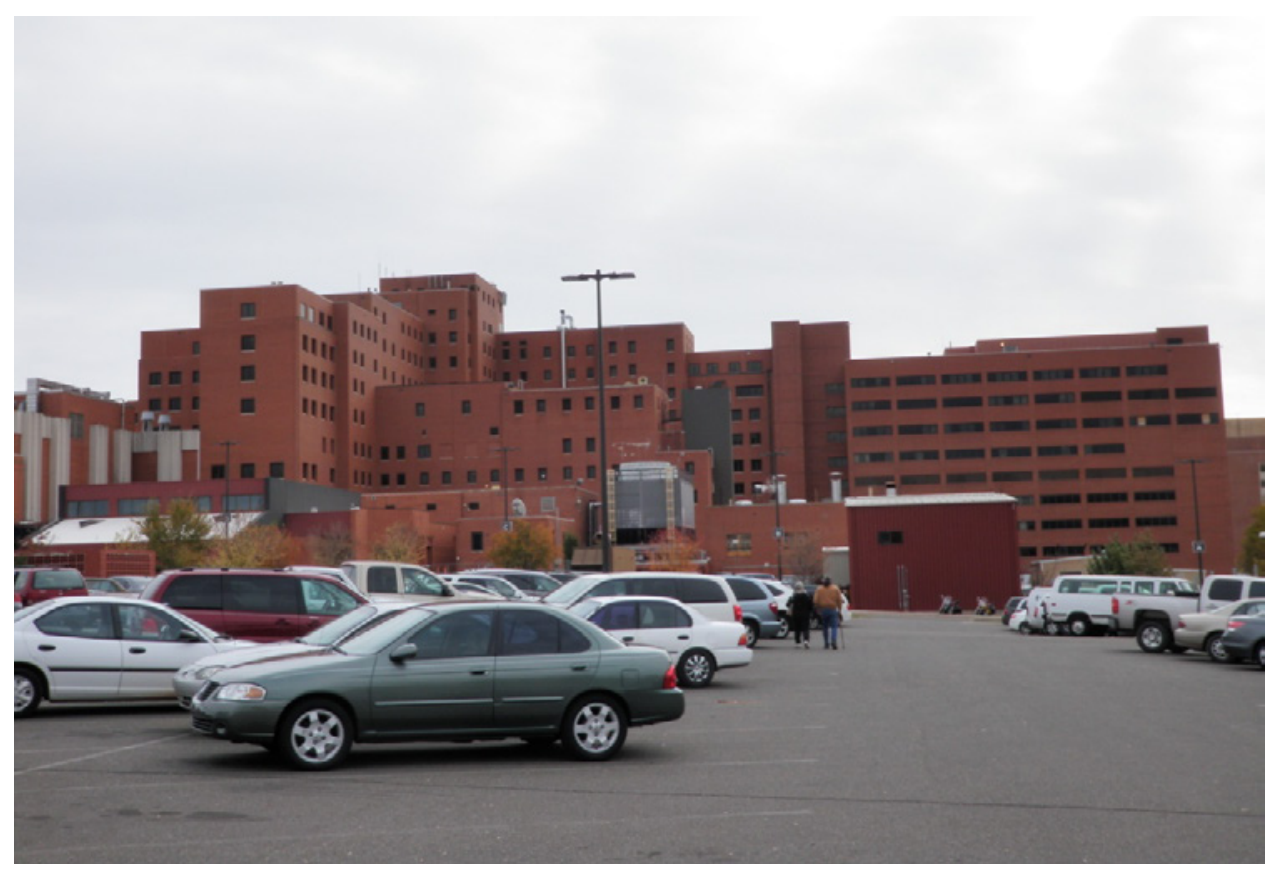

Figure 80. Photograph of the Building 1, Oklahoma City Veterans Affairs Medical Center, Oklahoma (back side view) (U.S. Geological Survey photograph). 


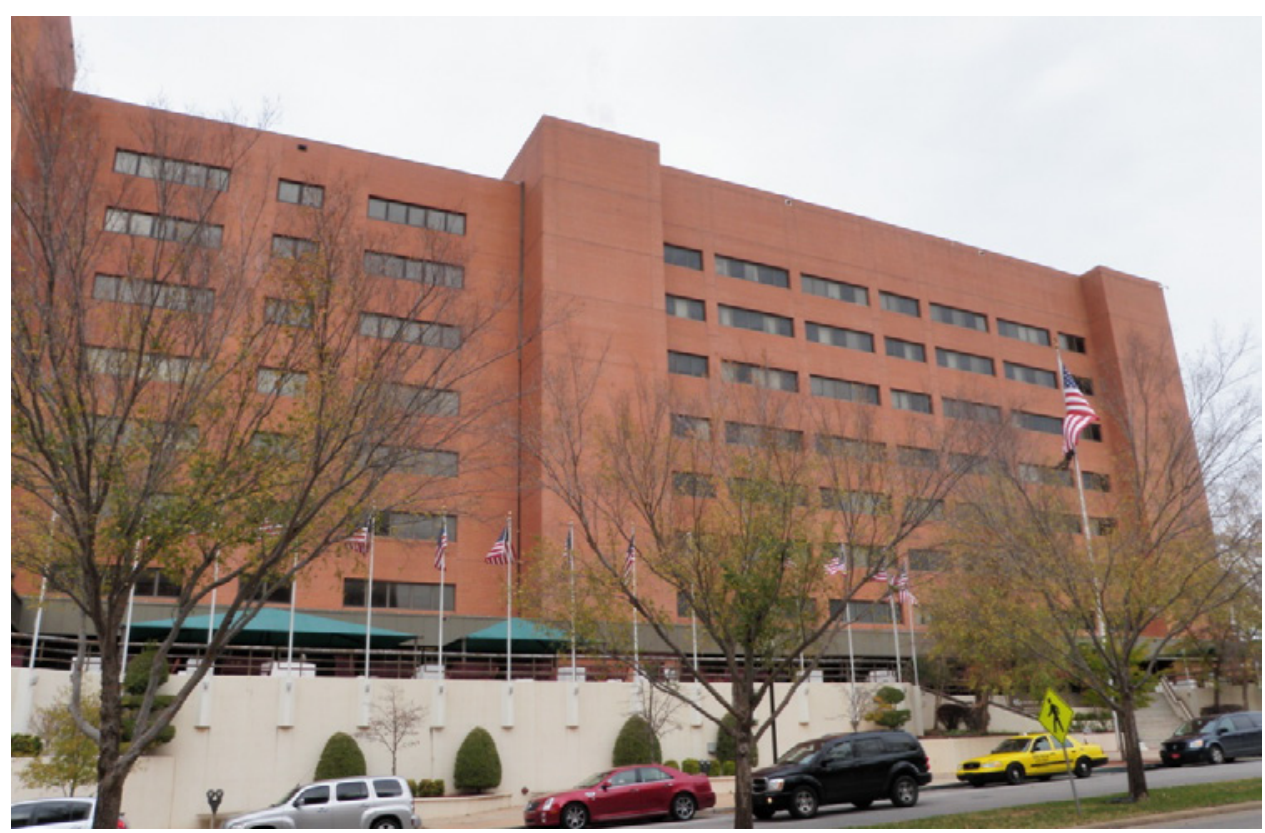

Figure 81. Photograph of the Building 1, Oklahoma City Veterans Affairs Medical Center, Oklahoma (front view) (U.S. Geological Survey photograph).

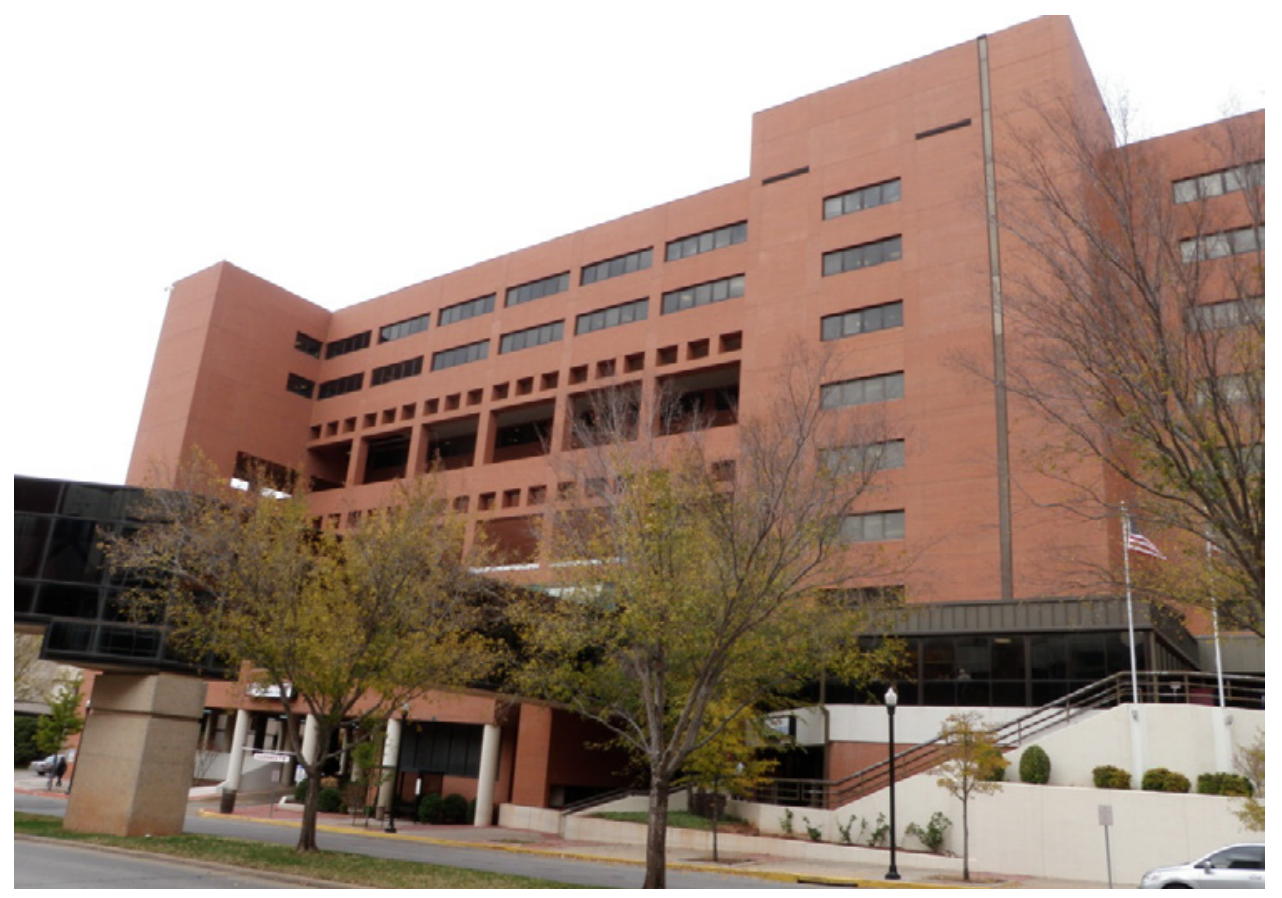

Figure 82. Photograph of the Building 1, Oklahoma City Veterans Affairs Medical Center, Oklahoma (entrance) (U.S. Geological Survey photograph). 


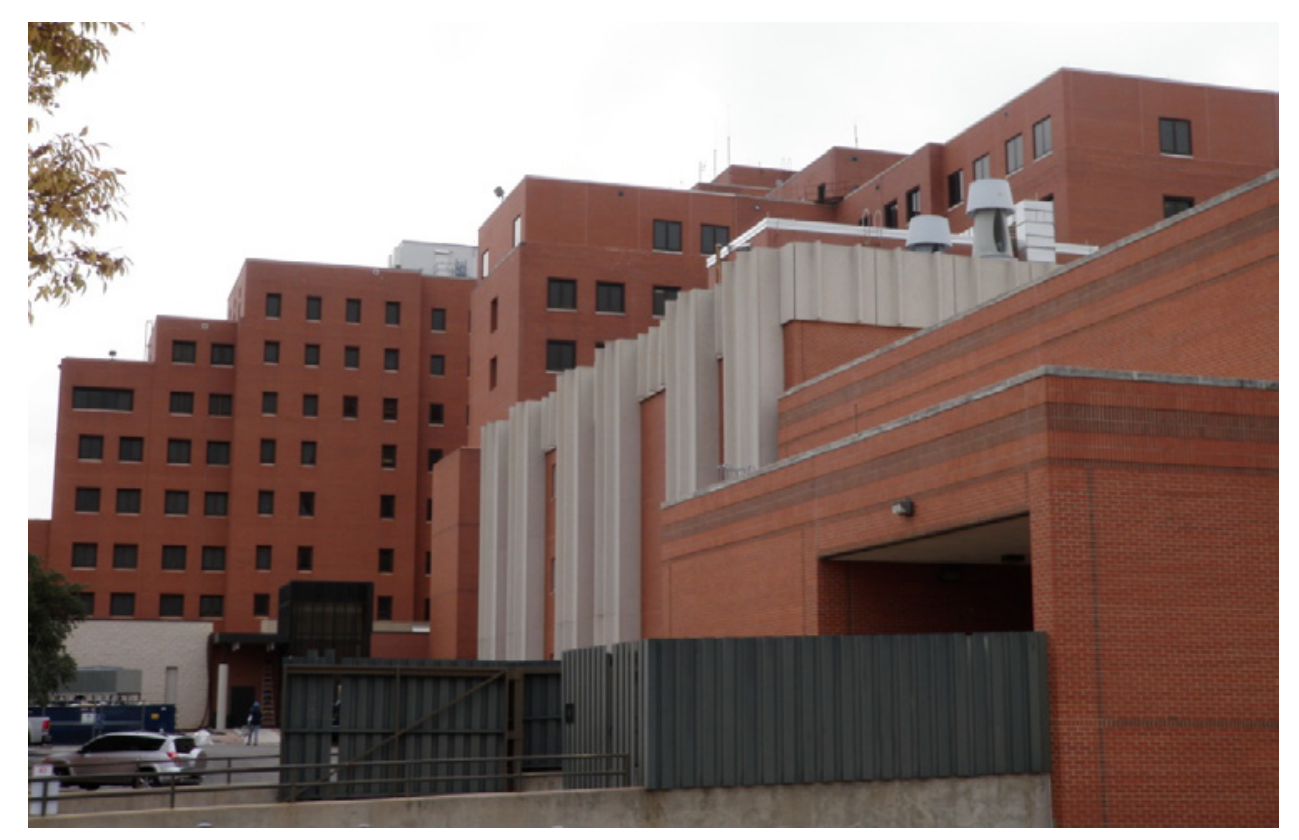

Figure 83. Photograph of the Building 1, Oklahoma City Veterans Affairs Medical Center, Oklahoma (east side view) (U.S. Geological Survey photograph).

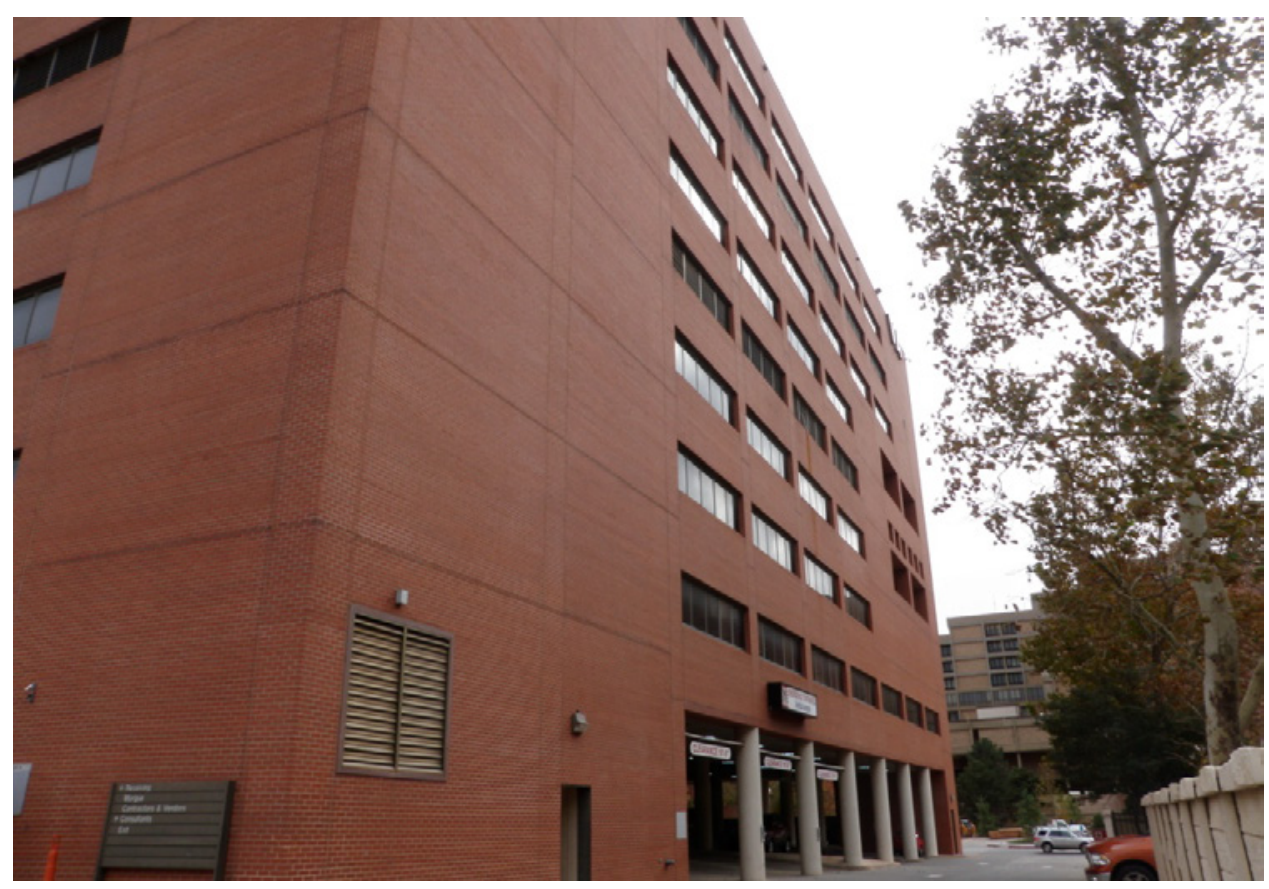

Figure 84. Photograph of the Building 1, Oklahoma City Veterans Affairs Medical Center, Oklahoma (west side view) (U.S. Geological Survey photograph).

\section{Seismic-Hazard Conditions}

The building is located in an area of moderate seismicity. The short-period spectral acceleration, $\mathrm{S}_{\mathrm{S}}$, using the current NEHRP recommended provisions for seismic regulations of new buildings and other structures, is $0.34 \mathrm{~g}$. The long-period spectral acceleration, $\mathrm{S}_{1}$, is $0.74 \mathrm{~g}$. 


\section{Instrumentation}

Building 1 consists of several major blocks separated by four major seismic joints. A total of 60 accelerometers are deployed in the building at each floor level to measure the significant response of the building during strong shaking (fig. 85 through fig. 87). The accelerometers are placed in the critical corners of each block so that both the lateral and torsional responses can be measured and computed. A triaxial accelerometer (channels 1 through 3 ) is placed on the basement slab to measure the three components of input ground motion. Every floor of each major block is instrumented by at least three accelerometers to monitor lateral movement of each major block.

The building accelerometers are complemented by a three-component seismic accelerometer located at a free-field site (NSMP Station No. 7414), approximately 1,030 ft away from the building, to monitor ground shaking without interference from the earthquake response of the building. 
U.S. Department of Veterans Affairs

Oklahoma City, OK - Steel Moment Frame, Twelve-Story Hospital Building

Building No: 1

NSMP Station No: 7413

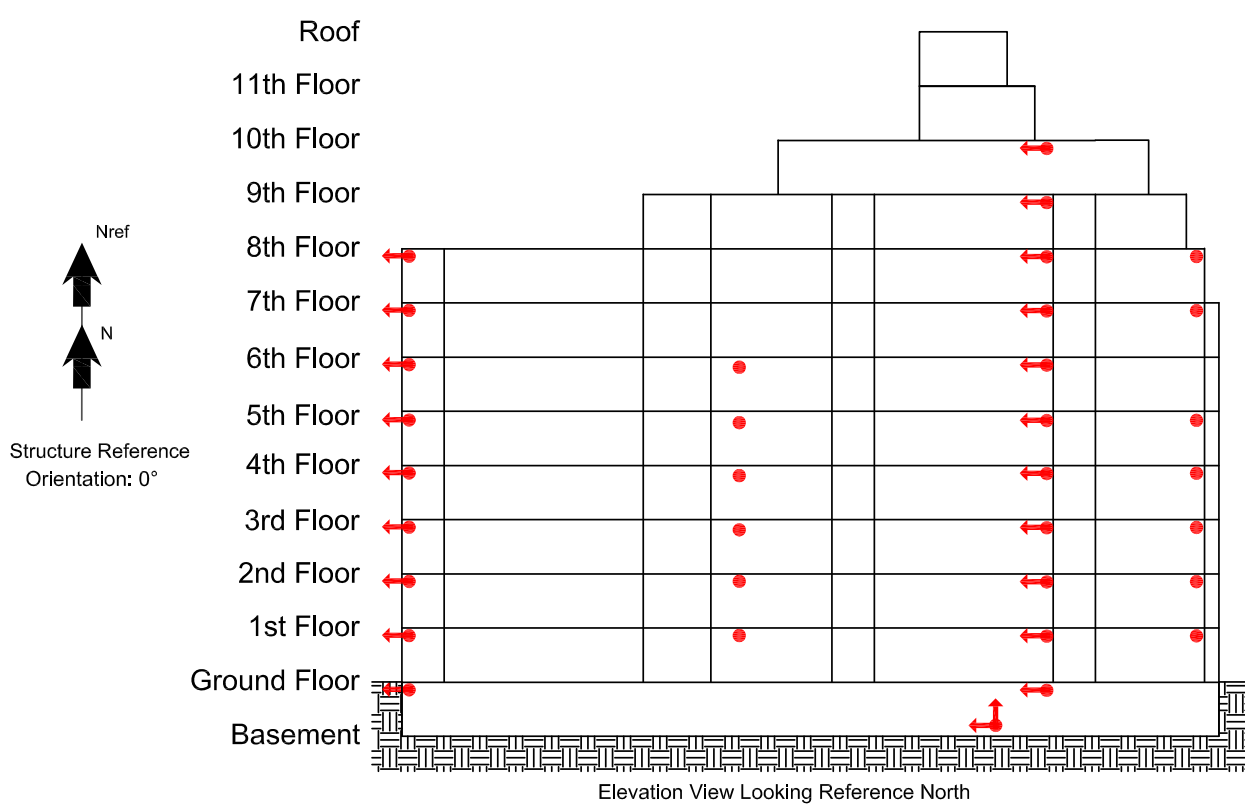

$\underset{1}{\longrightarrow}$

$\approx 1030 \mathrm{ft}$ NSMP Reference
Revision Number: 5

Revised on 10/24/2012

Page 1 of 3

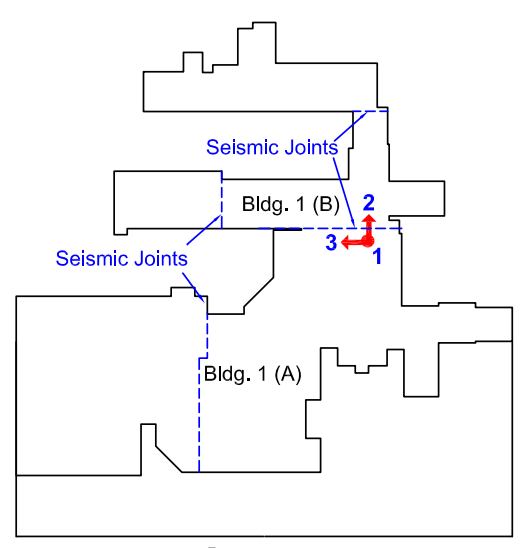

Basemen

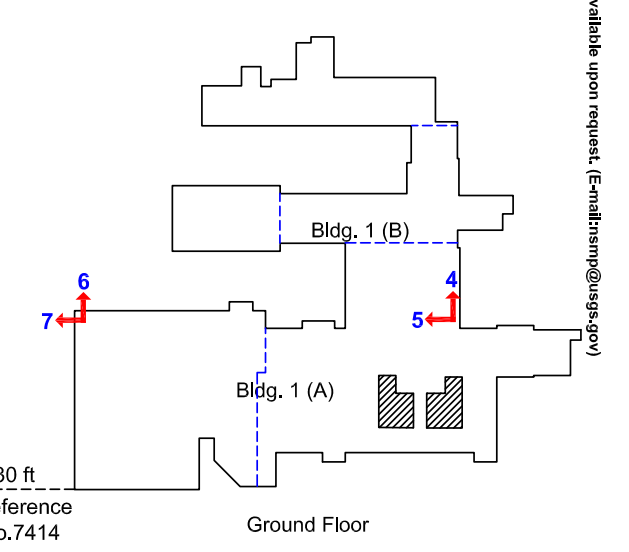

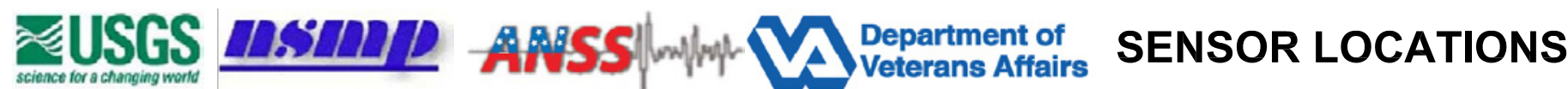

Figure 85. Diagrams of sensor layout showing 96 sensors in Building 1 of the Oklahoma City Veterans Affairs Medical Center, Oklahoma (page 1 of 3 ; see also figs. 86 and 87$)$. 
U.S. Department of Veterans Affairs

Oklahoma City, OK - Steel Moment Frame, Twelve-Story Hospital Building

Building No: 1

NSMP Station No: 7413

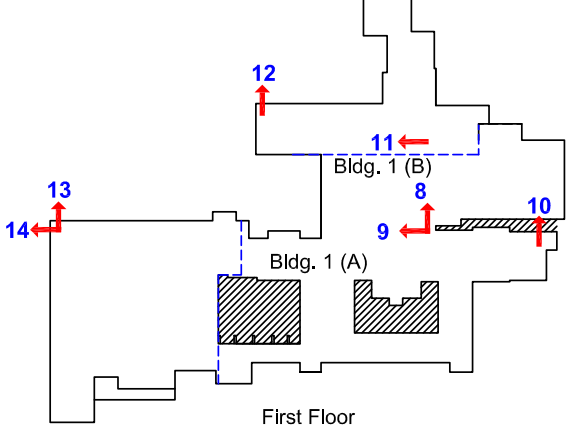

First Floor

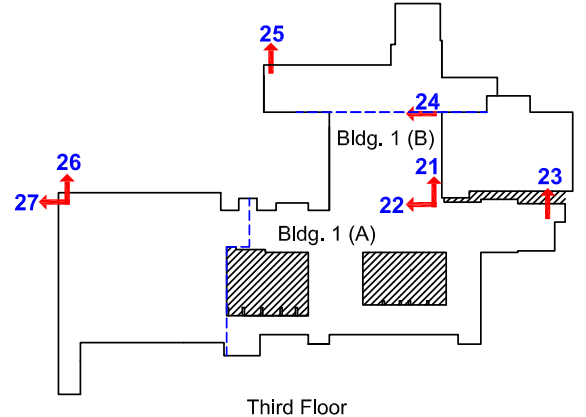

Third Floor
Revision Number: 5

Revised on $10 / 24 / 2012$

Page 2 of 3

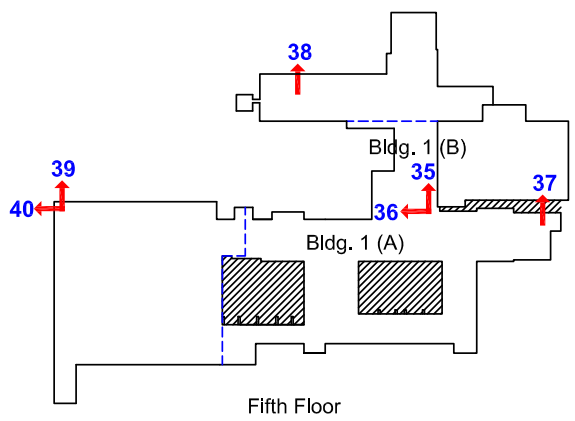

Fifth Floor
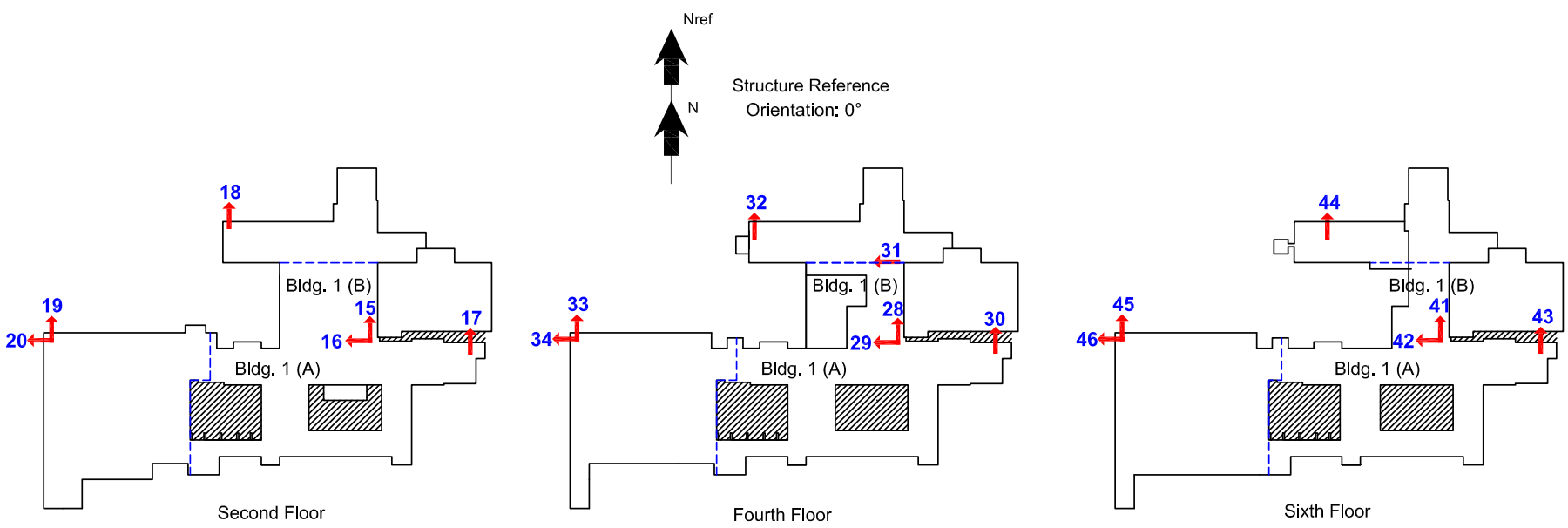

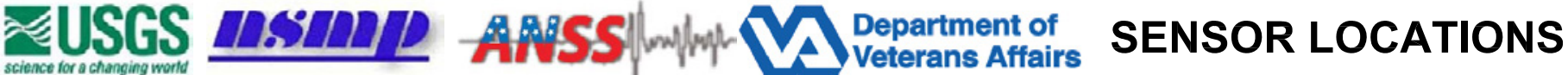

Figure 86. Diagrams of sensor layout showing 96 sensors in Building 1 of the Oklahoma City Veterans Affairs Medical Center, Oklahoma (page 2 of 3; see also figs. 86 and 87$)$. 
U.S. Department of Veterans Affairs

Oklahoma City, OK - Steel Moment Frame, Twelve-Story Hospital Building

Building No: 1

NSMP Station No: 7413

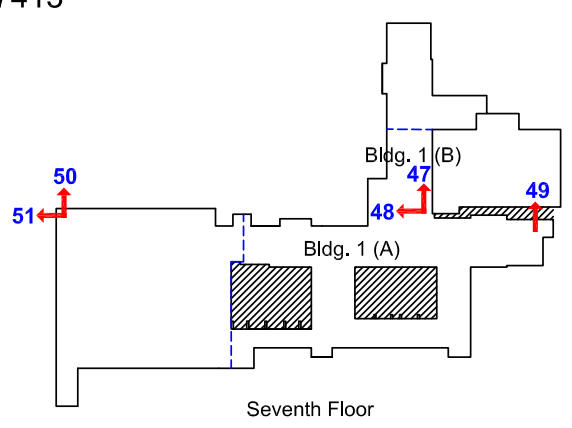

Orientalio
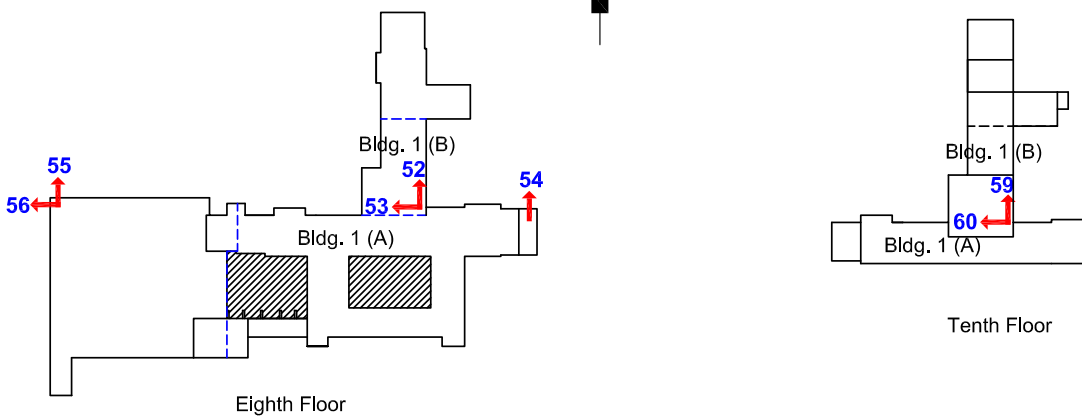

Tenth Floor

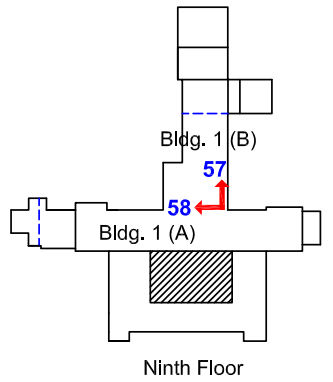

Revision Number: 5

Revised on $10 / 24 / 2012$

Page 3 of 3

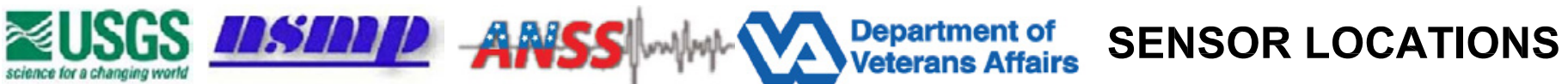

Figure 87. Diagrams of sensor layout showing 96 sensors in Building 1 of the Oklahoma City Veterans Affairs Medical Center, Oklahoma (page 3 of 3; see also figs. 85 and 86). 


\section{NSMP Station 7057-Roseburg, Oregon: Main Hospital, Building No. 1}

\section{Building Description}

Building 1 is located at the Department of Veterans Affairs medical center campus in Roseburg, Oregon, and is listed as a historic structure by the VA (fig. 88 and fig. 89). The structure was originally constructed in 1932 and was remodeled in 1974, 1981, and 1991. Building 1 is a five-story structure with a pipe basement of approximately $123,320 \mathrm{ft}^{2}$. It is used primarily as an inpatient hospital and has facilities for outpatient rehabilitation and therapy in the VA Roseburg Healthcare System (http://www.roseburg.va.gov/).

Building 1 is a reinforced concrete frame building with unreinforced masonry infill walls. The building is $\mathrm{T}$ shaped in plan for the first two stories and rectangular in plan for the remaining stories. The approximate overall dimensions are 278 by $213 \mathrm{ft}$. The story heights are $13 \mathrm{ft}, 12 \mathrm{ft}$, $12 \mathrm{ft}, 12.5 \mathrm{ft}$, and $12.5 \mathrm{ft}$ for the first, second, third, fourth, and fifth stories, respectively. There is an unfinished pipe basement approximately $6 \mathrm{ft}$ below the first floor. There are no structures immediately adjacent to Building 1 .

The floors consist of concrete pan joist slabs (fig. 90) that are supported by reinforcedconcrete beams and columns. The main roof and penthouse roof are wood framed (fig. 91), supported at the perimeter by concrete beams, and supported on the interior with structural steel beams and posts. The interior and exterior columns are founded on individual spread footings, and the masonry walls are founded on concrete strip footings. The ground floor consists of the unfinished basement.

The building's lateral-force resisting system consists of a nonductile reinforced concrete frame with 8-inch thick perimeter infill walls of unreinforced brick masonry (fig. 92). The perimeter masonry infill walls have many openings. The concrete walls below the ground floor around the perimeter transfer lateral loads to the foundation. The floor diaphragms are reinforced concrete slabs that typically span between the interior columns and exterior masonry walls. The roof diaphragm consists of one layer of straight sheathing and spans between the perimeter walls and interior lines of wood framing that are braced with wood posts.

The exterior face of the building consists of a layer of unreinforced brick. Many of the interior partitions consist of hollow clay tile, except in areas of remodeling. In these areas, hollow clay tile has been replaced with metal lath and plaster and metal studs.

\section{Seismic-Hazard and Soil Conditions}

The building sits on a level site with the ground floor at approximately $3 \mathrm{ft}$ above the level of the exterior grade. The building is founded on relatively stiff soils of varying depths. The susceptibility of the site to settlement due to earthquake-induced liquefaction is assumed to be low.

The building is located in an area of high seismic hazard. The short-period spectral acceleration, $\mathrm{S}_{\mathrm{S}}$, using the current NEHRP recommended provisions for seismic regulations of new buildings and other structures, is $0.83 \mathrm{~g}$. The long-period spectral acceleration, $\mathrm{S}_{1}$, is $0.42 \mathrm{~g}$.

\section{Instrumentation}

A total of 36 accelerometers are deployed in the building (fig. 94 and fig. 95). A triaxial accelerometer (channels 1 through 3 ) is placed on the first-floor ground level to measure the three components of input ground motion. The first- and second-floor ceilings are instrumented with five accelerometers each (channels 4 through 13) to measure floor lateral motion and 
compute floor and torsional motion. Eight accelerometers (channels 14 through 21) are placed on the third-floor ceiling to monitor forth floor diaphragm motion. The fifth floor ceiling is monitored by six accelerometers - three are oriented in the reference east-west direction and three sensors are oriented in the reference north-south direction. A triaxial accelerometer (channels 28 through 30) together with six other accelerometers (channels 31 through 36) is placed on the fourth-floor ceiling level to measure floor lateral and vertical motion at the roof level. This added vertical sensor will allow for studying vertical wave propagation in the building.

The building accelerometers are complemented by a three-component seismic accelerometer located at a reference site (NSMP Station No. 7058), approximately $1,410 \mathrm{ft}$ away from the building, to monitor ground shaking without interference from the earthquake response of the building (fig. 93).

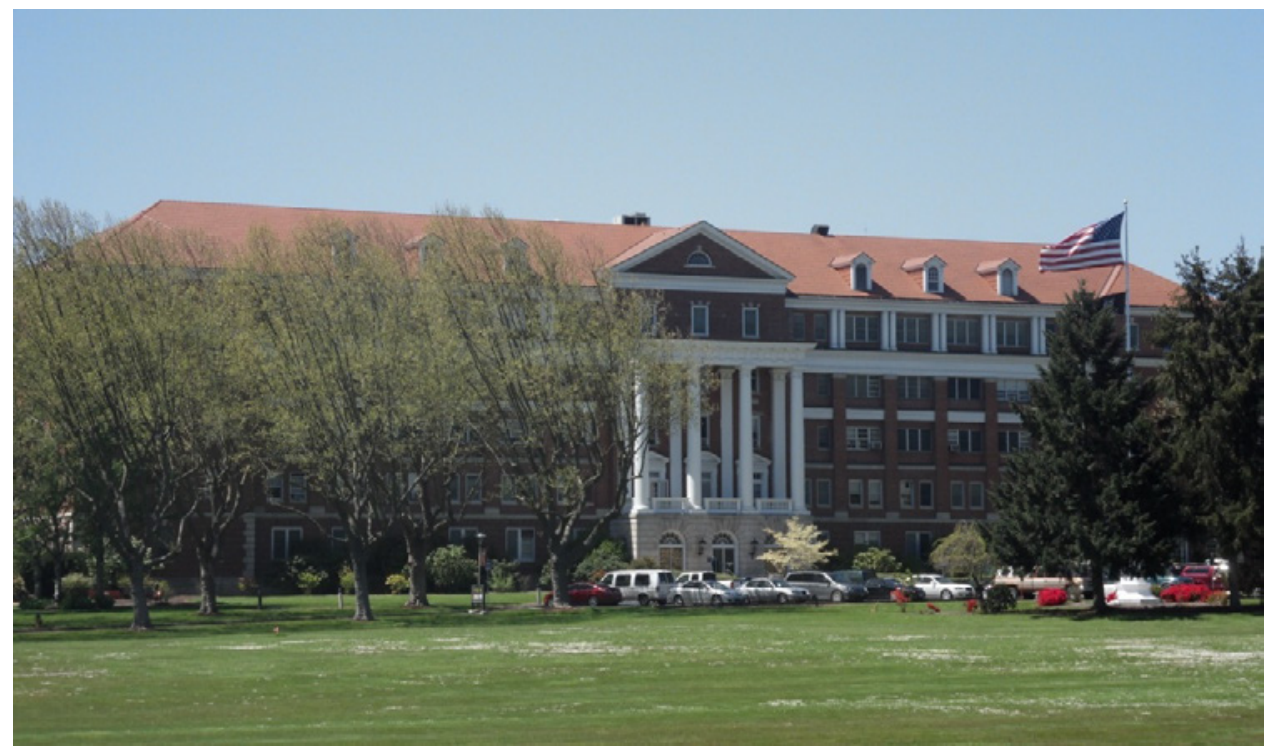

Figure 88. Photograph of Building 1, Roseburg Veterans Affairs Medical Center, Oregon (front view) (U.S. Geological Survey photograph). 


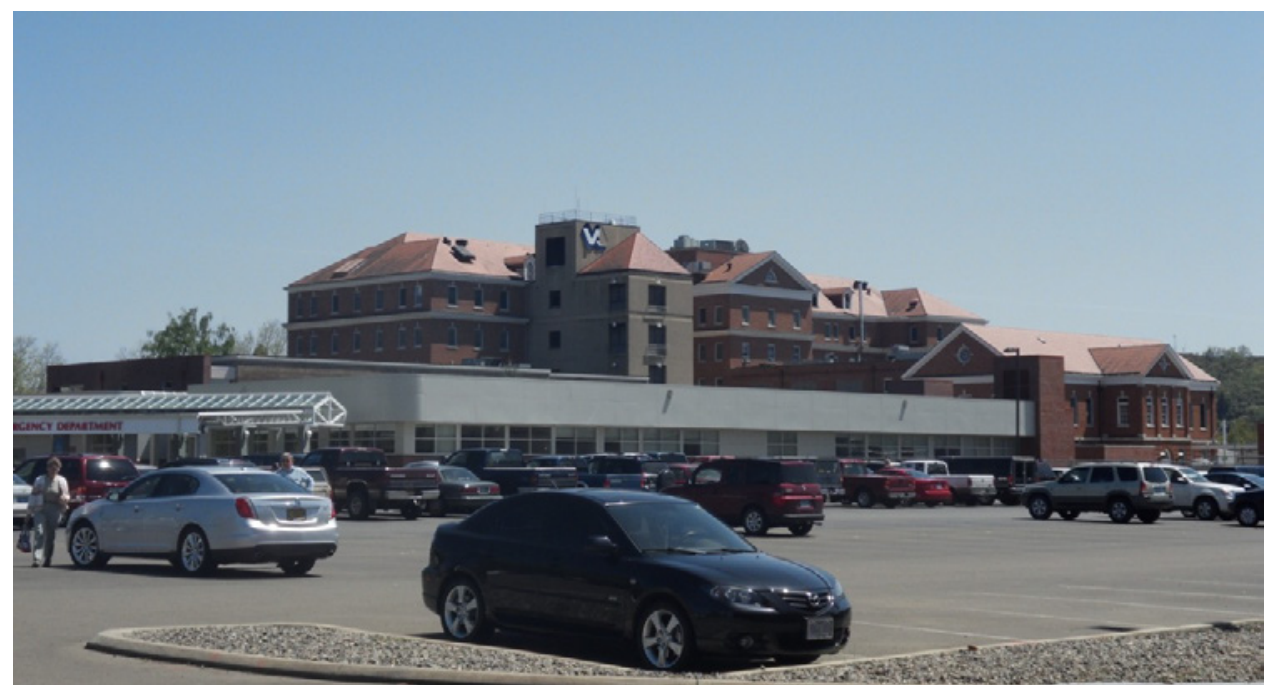

Figure 89. Photograph of Building 1, Roseburg Veterans Affairs Medical Center, Oregon (looking west) (U.S. Geological Survey photograph).

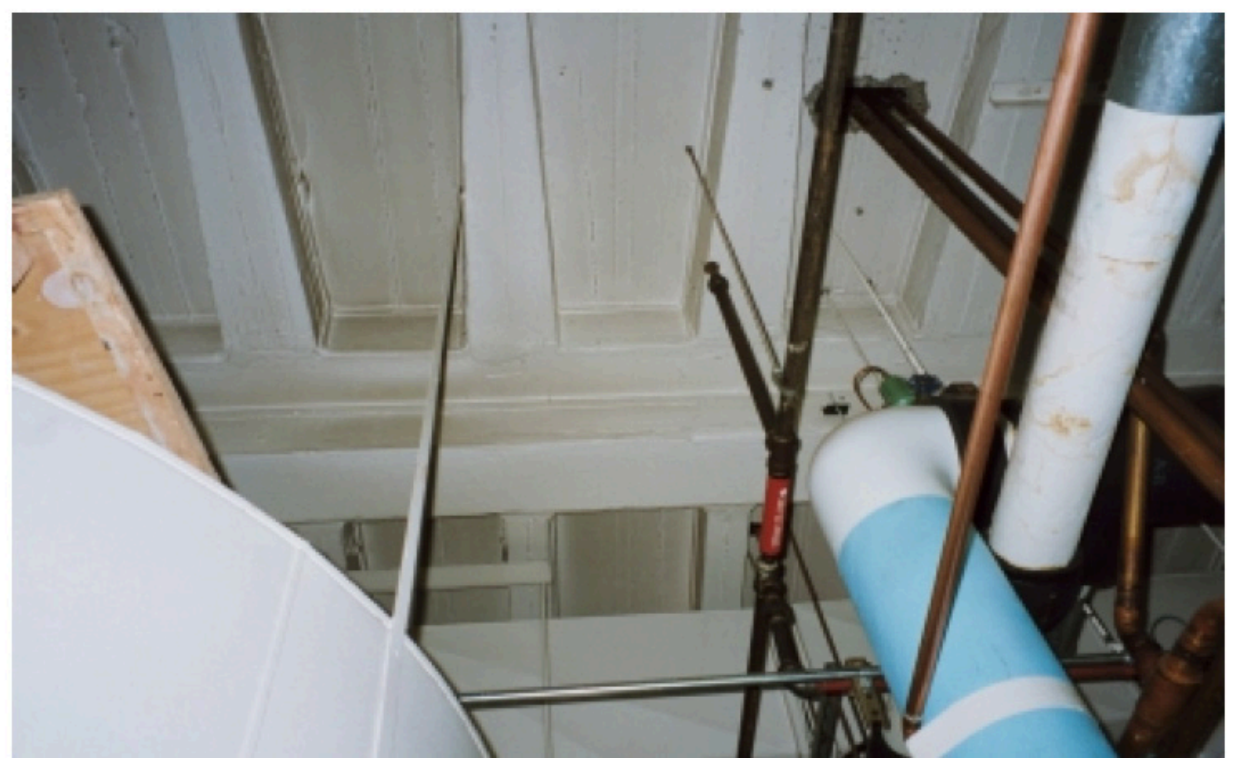

Figure 90. Photograph of typical floor slab, viewed from below, in Building 1, Roseburg Veterans Affairs Medical Center, Oregon (U.S. Department of Veterans Affairs photograph). 


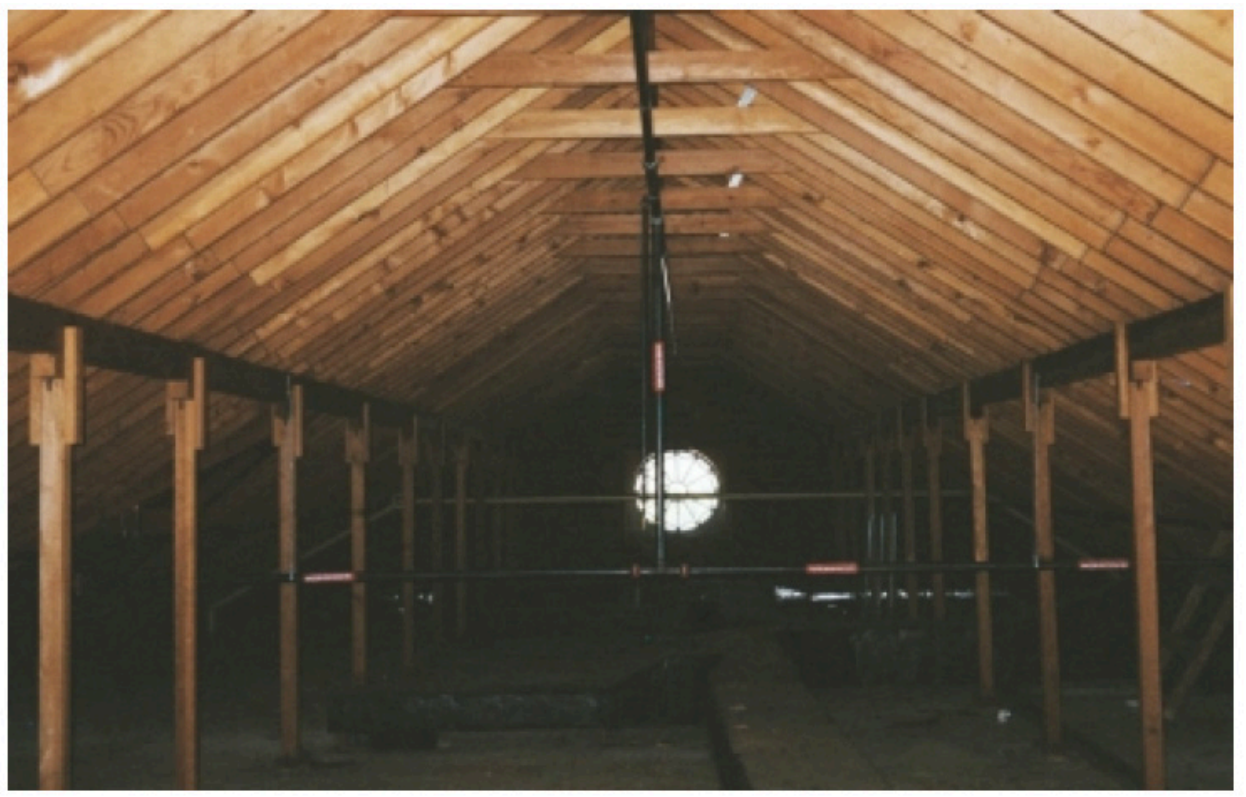

Figure 91. Photograph of roof framing in Building 1, Roseburg Veterans Affairs Medical Center, Oregon (U.S. Department of Veterans Affairs photograph).

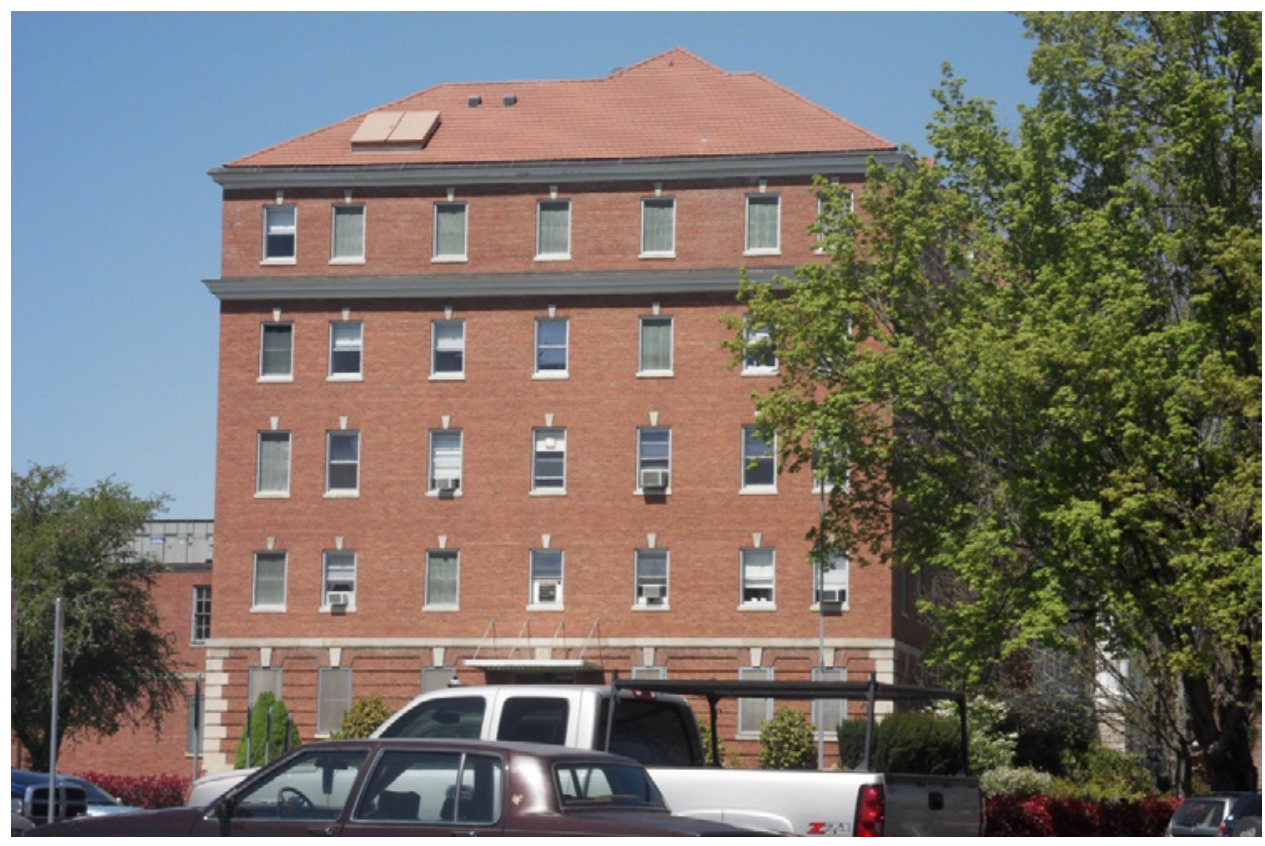

Figure 92. Photograph of Building 1, Roseburg Veterans Affairs Medical Center, Oregon (looking north) (U.S. Geological Survey photograph). 


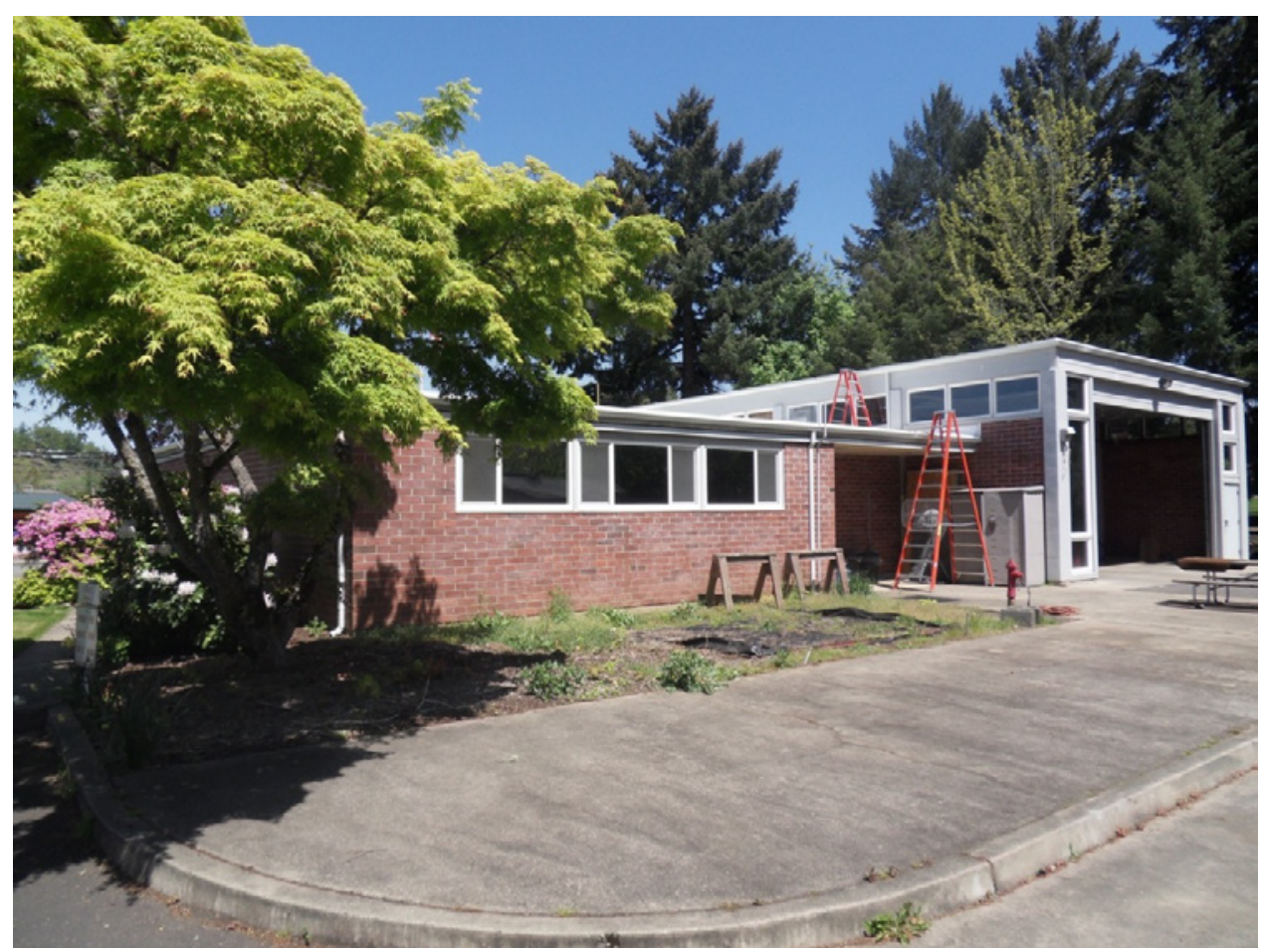

Figure 93. Photograph of reference station to measure ground shaking on Roseburg Veterans Affairs Medical Center, Oregon, away from Building 1 (U.S. Geological Survey photograph). 
U.S. Department of Veterans Affairs

Roseburg, OR - Reinforced Concrete/Masonry, Five-Story Hospital Building

Building No:1

NSMP Station No: 7057

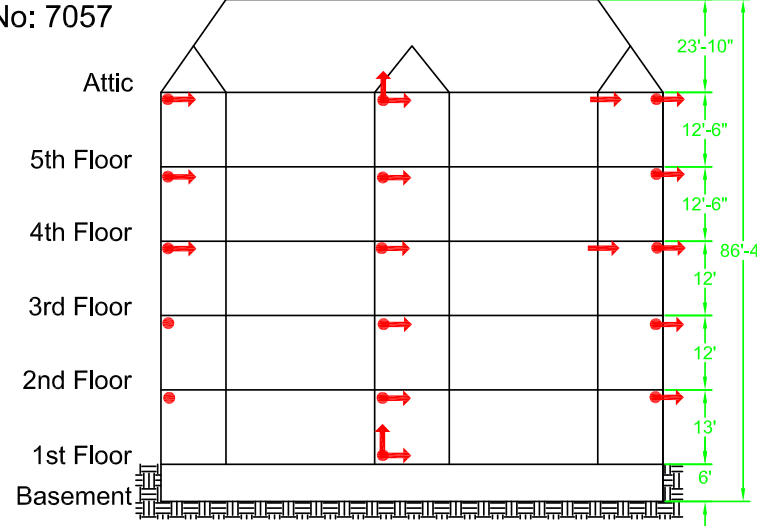

Elevation View Looking Reference West

First Floor

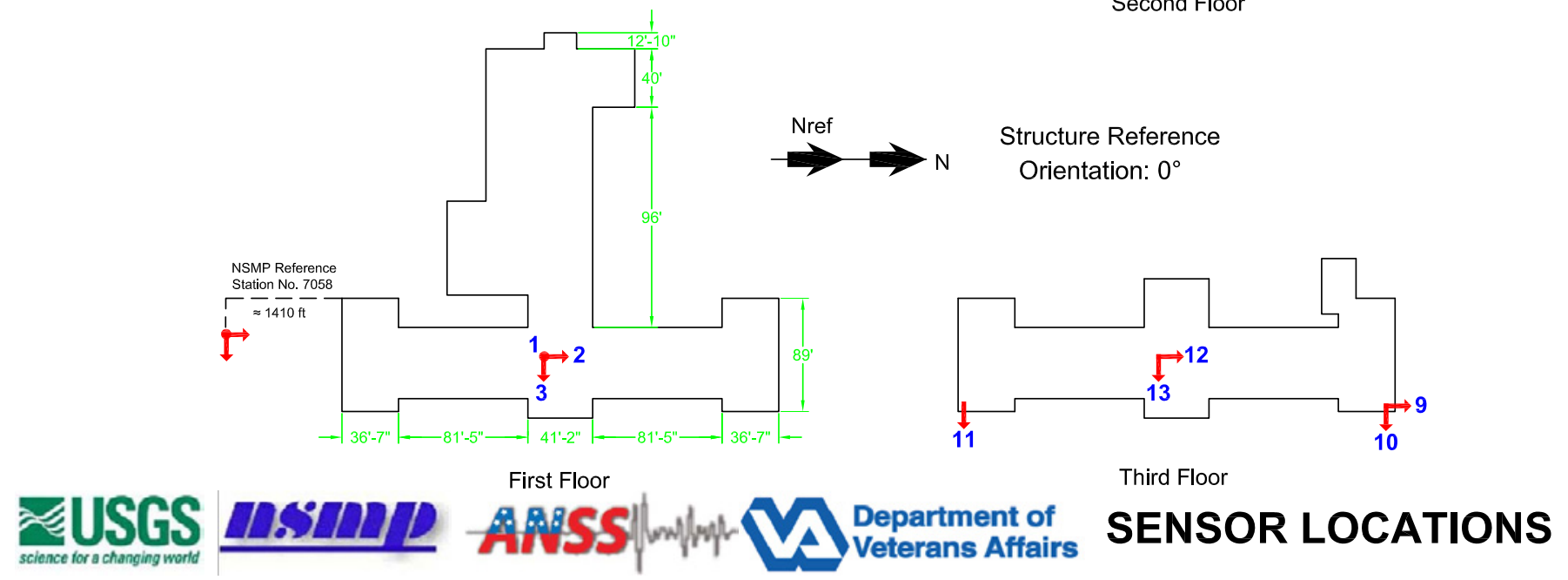

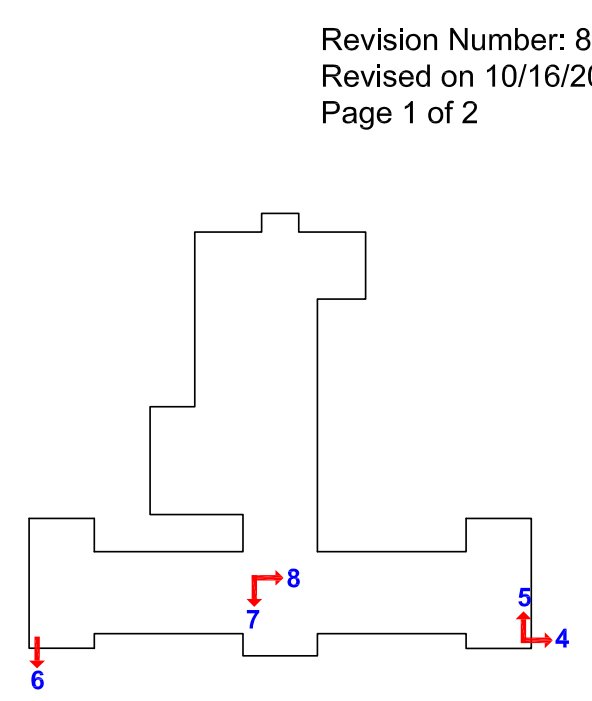

Second Floor

Figure 94. Diagrams of sensor layout showing 36 sensors in Building 1 of the Roseburg Veterans Affairs Medical Center, Oregon, (page 1 of 2; see also fig. 95). 
U.S. Department of Veterans Affairs

Roseburg, OR - Reinforced Concrete/Masonry, Five-Story Hospital Building

Building No:1

NSMP Station No: 7057

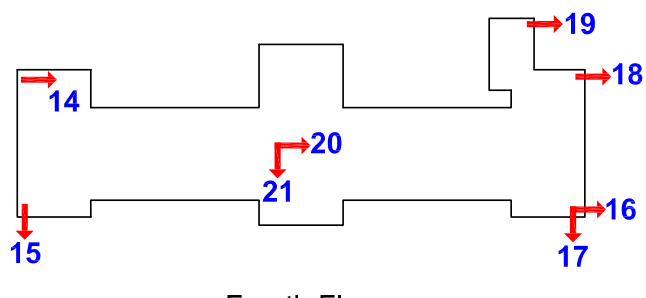

Fourth Floor

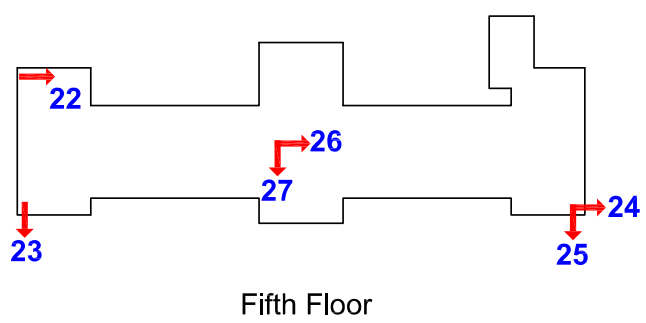

Revision Number: 8

Revised on 10/16/2012

Page 2 of 2
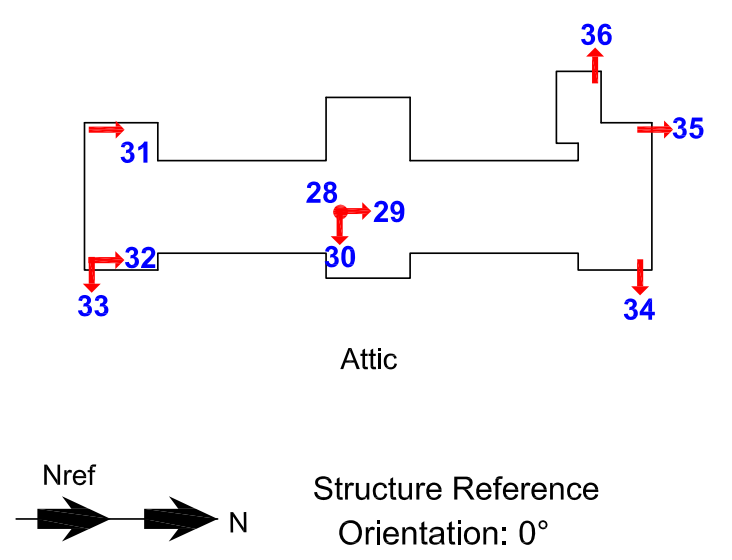

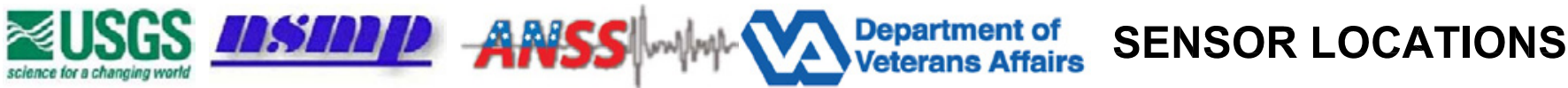

Figure 95. Diagrams of sensor layout showing 36 sensors in Building 1 of the Roseburg Veterans Affairs Medical Center, Oregon, (page 2 of 2; see also fig. 94). 


\section{NSMP Station 7059-White City, Oregon: Primary Care Clinic, Building No. 201}

\section{Building Description}

Building 201, of the VA Southern Oregon Rehabilitation Center (http://www.southernoregon.va.gov/), is a two-story concrete and masonry structure (fig. 96 through fig. 98), located in White City, Oregon. This building has an irregular floor plan resembling one large rectangle attached to a smaller one. The dimensions for the main part of the building are 60 by $225 \mathrm{ft}$. The smaller section that is attached to the northeast side of the main wing has dimensions of 45 by $85 \mathrm{ft}$. The building has an area of $27,069 \mathrm{ft}^{2}$.

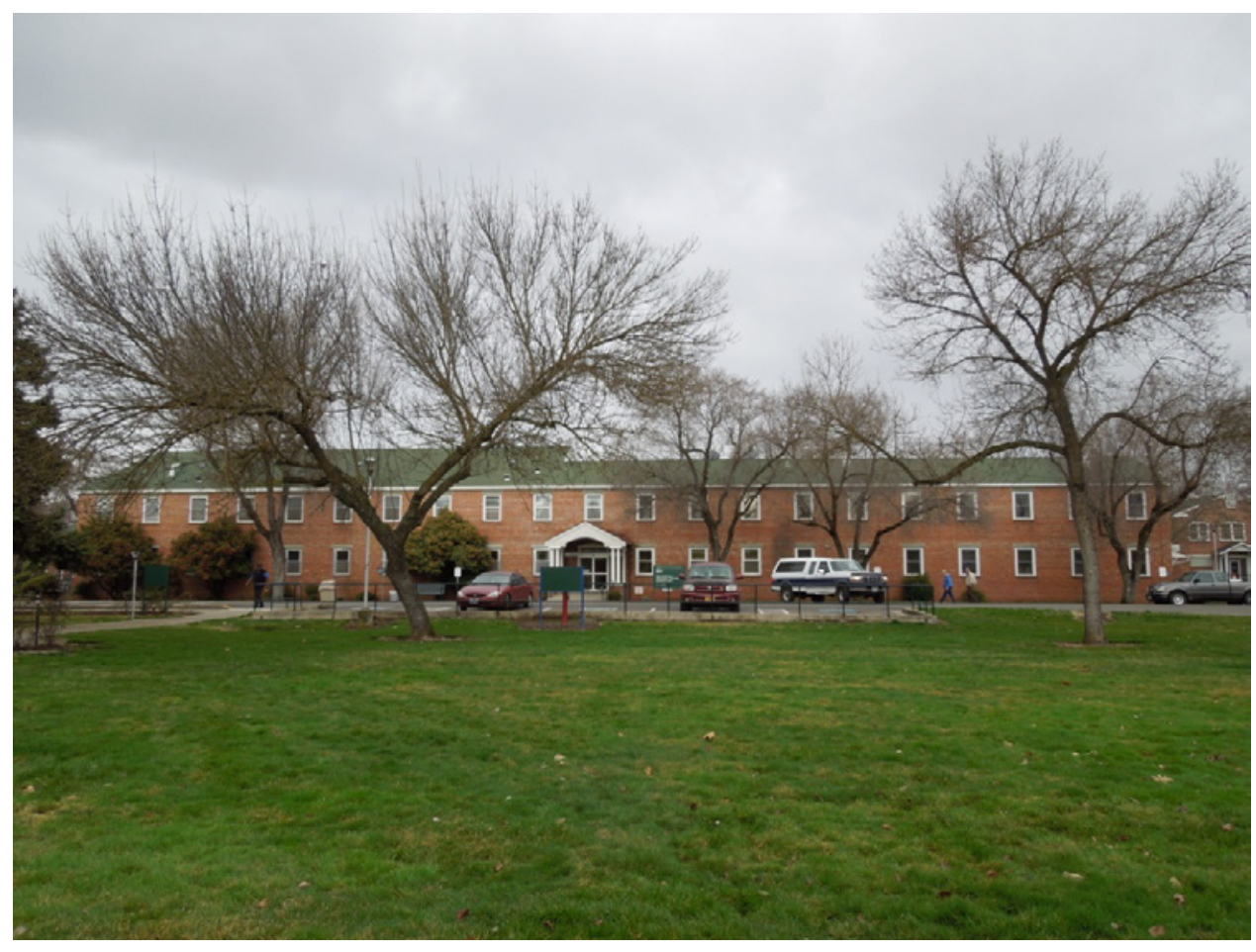

Figure 96. Photograph of Building 201, White City Veterans Affairs Medical Center, Oregon (front view)

(U.S. Geological Survey photograph). 


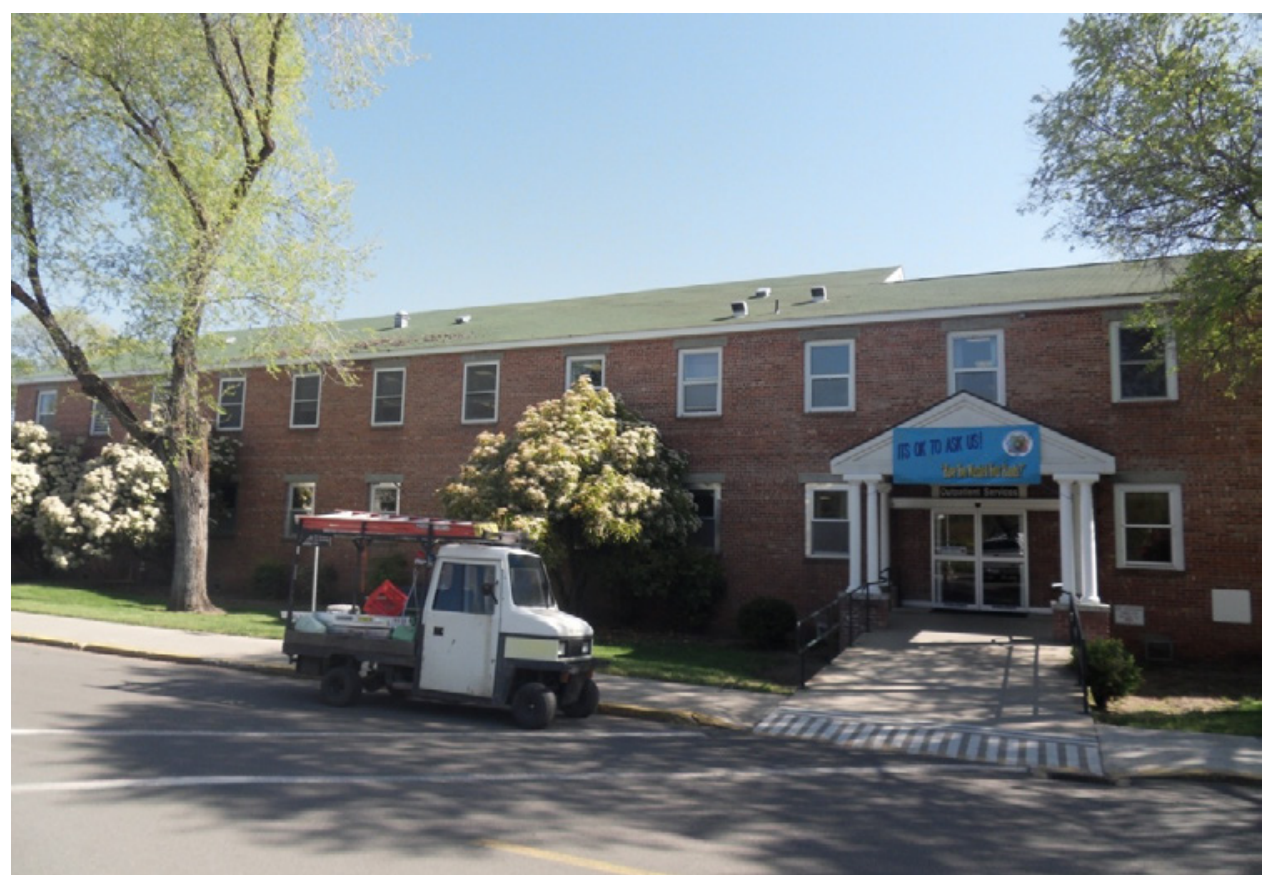

Figure 97. Photograph of Building 201, White City Veterans Affairs Medical Center, Oregon (looking northeast) (U.S. Geological Survey photograph).

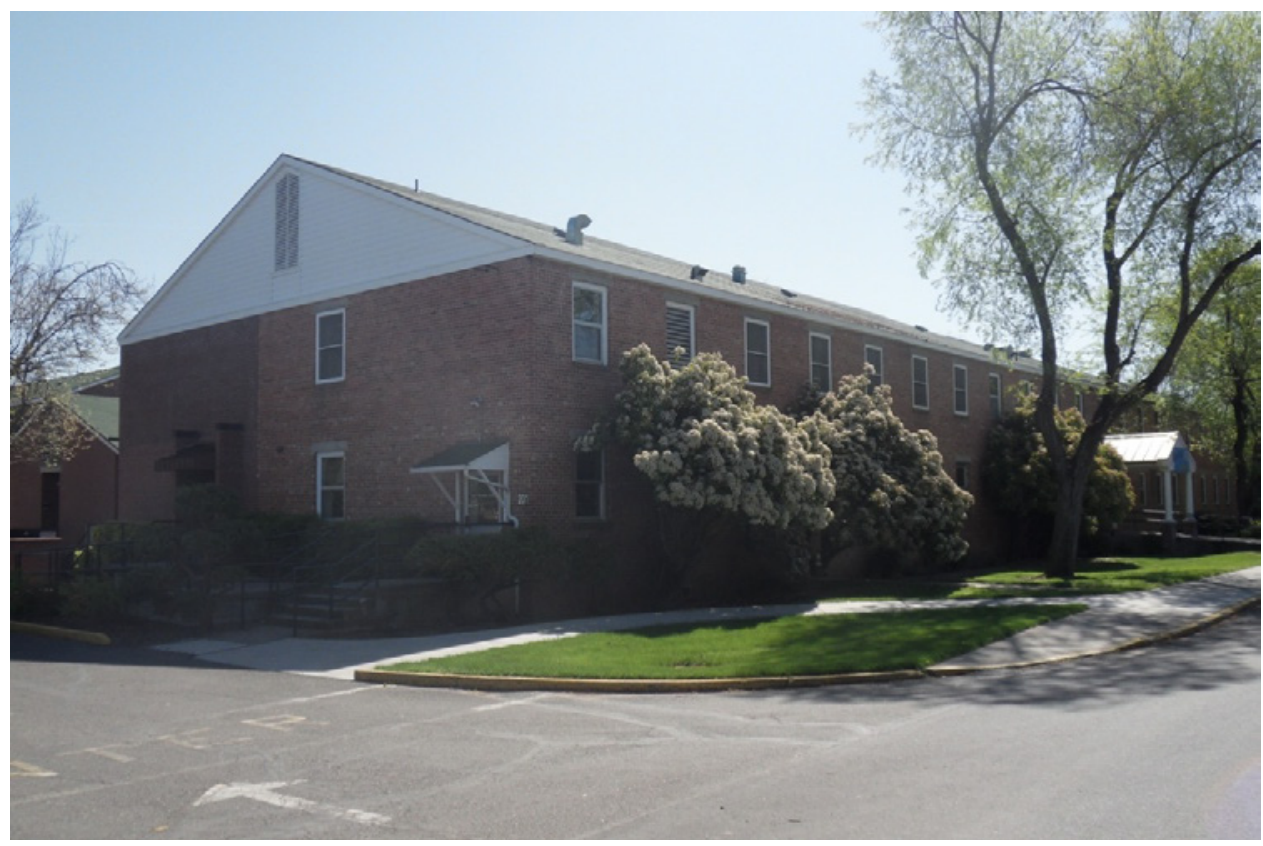

Figure 98. Photograph of Building 201, White City Veterans Affairs Medical Center, Oregon (looking east) (U.S. Geological Survey photograph).

\section{Seismic-Hazard Conditions}

The building is located in an area of moderate seismicity. The short-period spectral acceleration, $\mathrm{S}_{\mathrm{S}}$, using the current NEHRP recommended provisions for seismic regulations of new buildings and other structures, is $0.58 \mathrm{~g}$. The long-period spectral acceleration, $\mathrm{S}_{1}$, is $0.26 \mathrm{~g}$. 


\section{Instrumentation}

A total of 11 accelerometers are deployed in the building to measure its lateral motion (fig. 99). A triaxial accelerometer is placed on the first-floor ground level to measure the three components of input ground motion. Eight accelerometers are distributed at the corners of the building to measure floor translational motion and compute floor torsional response to input ground shaking. Five accelerometers (channels 4 through 8 ) are placed on the first-floor ceiling level to monitor the second floor. The second-floor ceiling is equipped with three accelerometers (channels 9 through 11) to measure roof-diaphragm motions. The floor relative displacement can be computed from the accelerometers located at the same corners of the building. Floor torsional motion can also be obtained from two likewise oriented accelerometers at the same level. 
U.S. Department of Veterans Affairs

White City, OR - Two-Story Hospital Building

Building No: 201

NSMP Station No: 7059

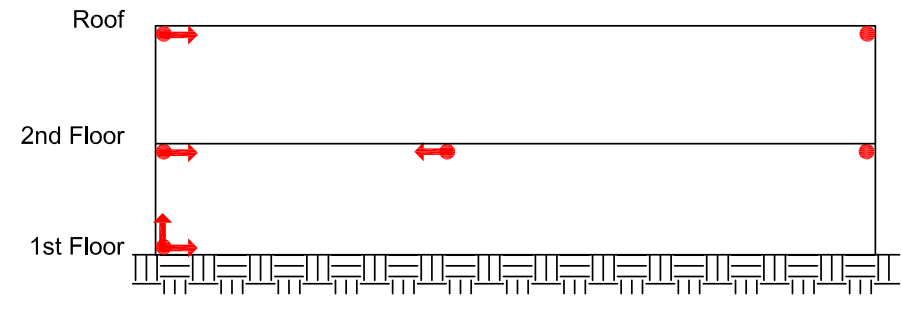

Elevation View Looking Reference West

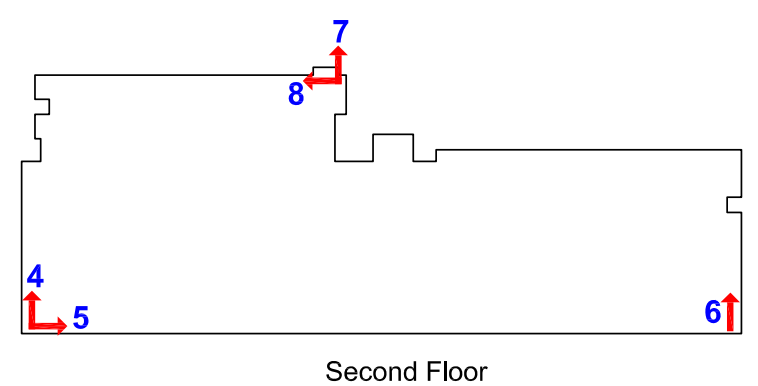

Structure Reference

Nre Orientation: $315^{\circ}$

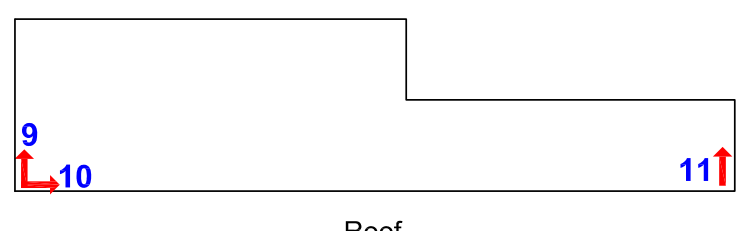

Roof

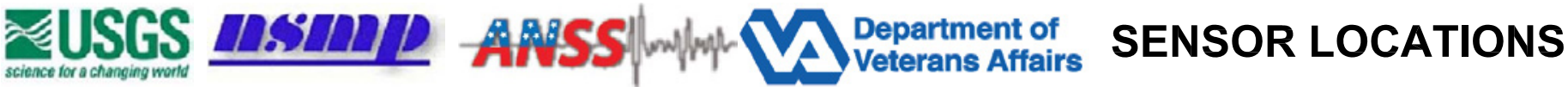

Figure 99. Diagram of sensor layout showing 11 sensors in Building 201 of the White City Veterans Affairs Medical Center, Oregon. 


\section{NSMP Station 2191-Portland, Oregon: Main Hospital, Building No. 100}

\section{Building Description}

Building 100 is located at the Portland VA Medical Center (http://www.portland.va.gov/) in Portland, Oregon (fig. 100 and fig. 101). It was designed in 1982 using the H-08-8 VA seismic-design standard specifications for essential facilities. Construction was completed in 1988 and the building has not been significantly modified since then.

The building serves as the facility's main hospital. It is a nine-story structure with a penthouse. There is an interstitial level between every main level and the two basement levels. Total square footage is approximately $684,985 \mathrm{ft}^{2}$.

The general building type is a steel-braced frame structure. It is roughly $\mathrm{H}$ shaped in plan with a central seismic joint bisecting the building into two discrete rectangular-shaped sections. Approximate overall dimensions are 410 by $300 \mathrm{ft}$. From the ground level upwards, floors are stepped back, creating a roughly tiered shape in section. Floor-to-ceiling heights at the main levels are generally $11 \mathrm{ft}$, and interstitial story heights are $8 \mathrm{ft}$. The penthouse story height is approximately $18 \mathrm{ft}$.

The gravity system consists of main floors and roof composed of concrete on metal decking supported by steel beams and columns. The interstitial floors are lightweight vermiculite concrete suspended from the main floors above and (or) connected to the columns at the interstitial level. In addition, the floors are connected to the braces themselves where braced frames pierce the interstitial floors. The foundation system is steel-pipe piles with reinforced concrete pile caps connected by reinforced concrete grade beams.

The building's lateral-force resisting system consists of steel-braced frames that transfer lateral loads to the pile foundations. The main floor and roof diaphragms are reinforced concrete on metal decking with 3/4-inch-diameter stud connections. The exterior face of the building consists of ceramic veneer wall panels and glass.

\section{Seismic-Hazard and Soil Conditions}

The building is located on a sloping site on the side of a hill, with the exterior grade approximately level with the first floor at the east and south sides, sloping down to the lower basement level at the north and west sides. Piles are founded in fractured and weathered basalt, which lies beneath relatively stiff soils.

The building is located in an area of high seismic hazard. The short-period spectral acceleration, $\mathrm{S}_{\mathrm{S}}$, using the current NEHRP recommended provisions for seismic regulations of new buildings and other structures, is $1.00 \mathrm{~g}$. The long-period spectral acceleration, $\mathrm{S}_{1}$, is $0.35 \mathrm{~g}$.

\section{Instrumentations}

A total of 39 accelerometers are deployed at 12 levels in the building (fig. 102). A triaxial accelerometer (channels 1 through 3 ) is placed on the basement level 2 to measure the input ground motion. Three accelerometers (channels 4 through 6 ) are placed on the ceiling of the basement level 2. Twelve accelerometers (channels 7 through 18) are similarly distributed on the ceilings of basement level 1 and the first and second floors to monitor slab motions. The accelerometers are located near the floor edges and oriented parallel to the building sides. The total area of the upper floors is smaller than the lower levels; therefore, upper floors are 
instrumented with three accelerometers each. Twenty-one accelerometers (channels 19 through 39) are evenly distributed on the ceilings of the third floor through the ninth floor. The recordings of these accelerometers provide measurements of lateral floor motion around the reference east-west and north-south directions, as well as the floor torsional motion around the vertical axis. The accelerometers at different floor levels are located at the same corner of the building so that the relative displacement, thus inter-story drift between floors, can be obtained.

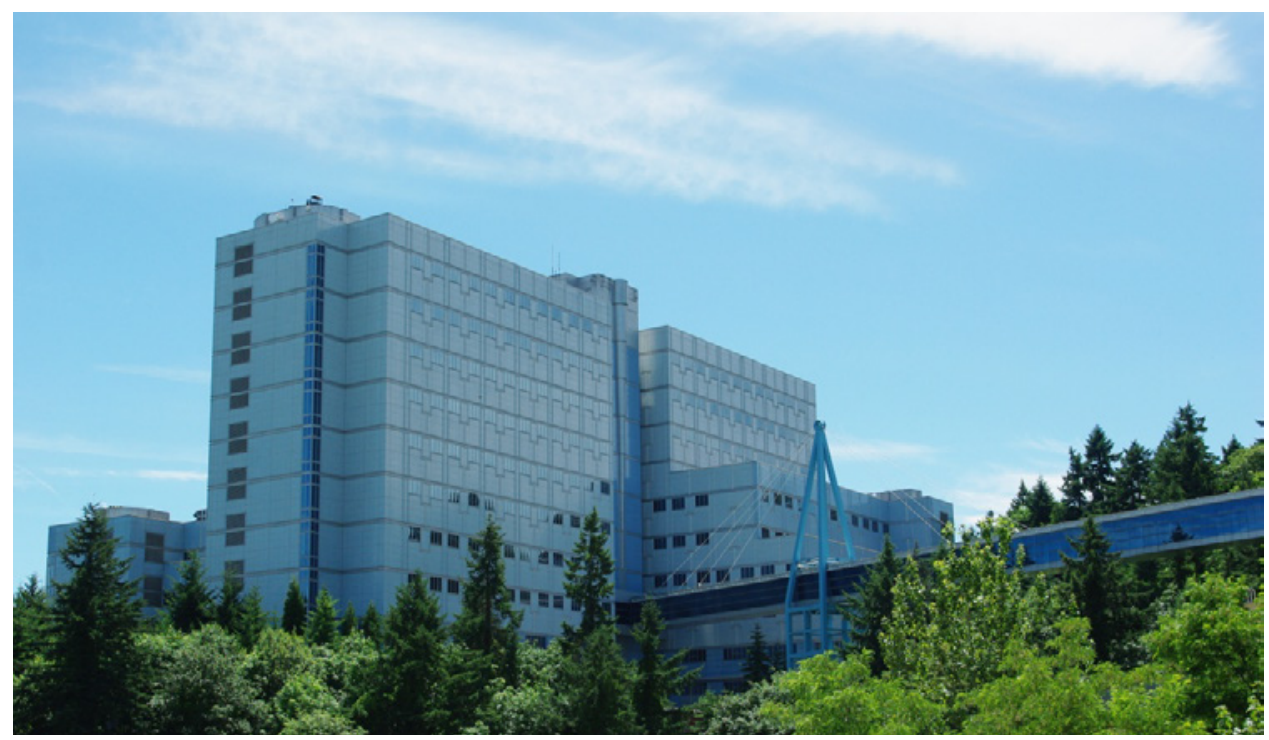

Figure 100. Photograph of Building 100, Portland Veterans Affairs Medical Center, Oregon (back side view) (U.S. Geological Survey photograph). 

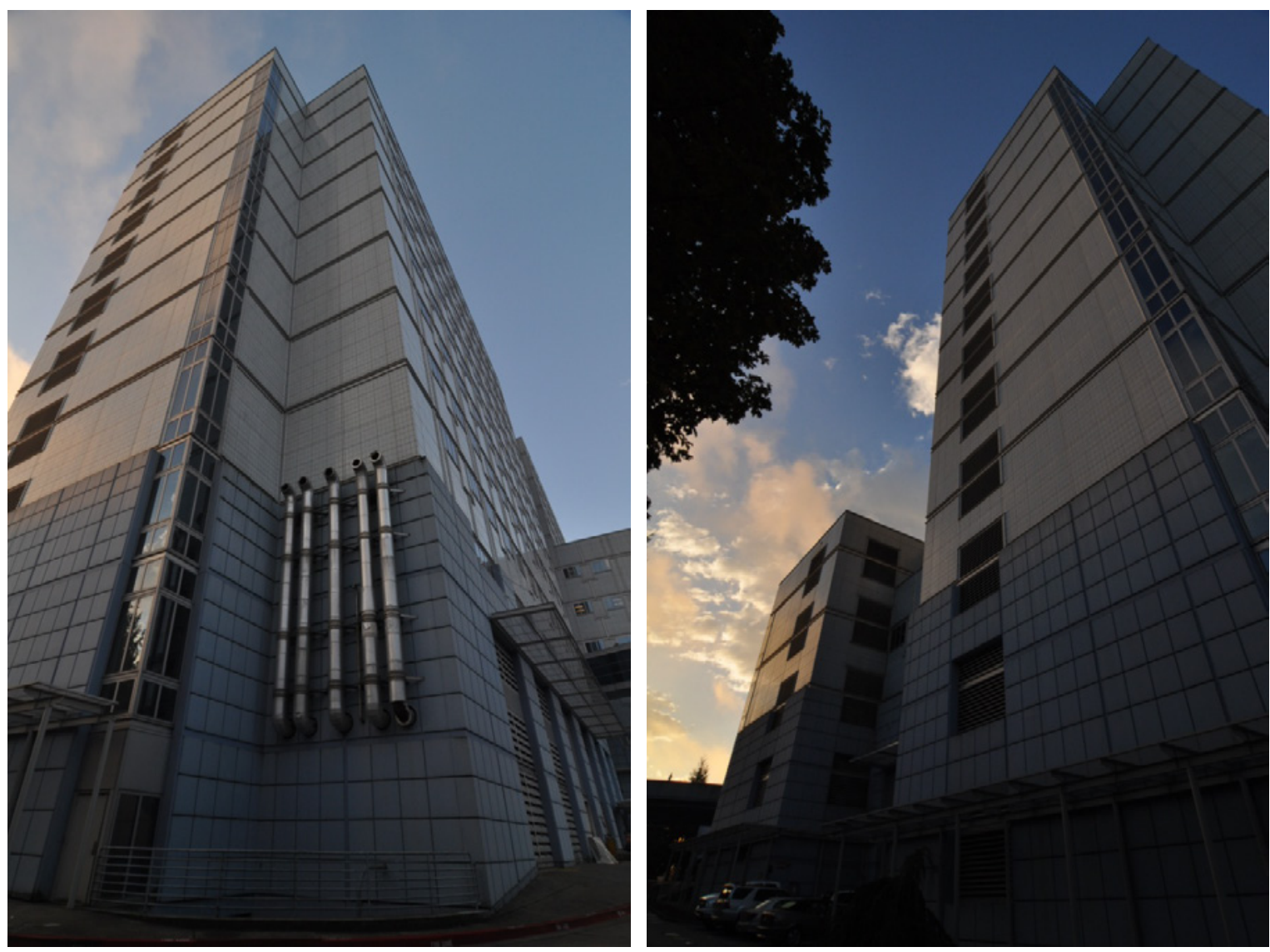

Figure 101. Photographs of Building 100, Portland Veterans Affairs Medical Center, Oregon (side views) (U.S. Geological Survey photograph). 
U.S. Department of Veterans Affairs

Portland, OR - Steel Moment Frame, Nine-Story Hospital Building

Building No: 100

NSMP Station No: 2191
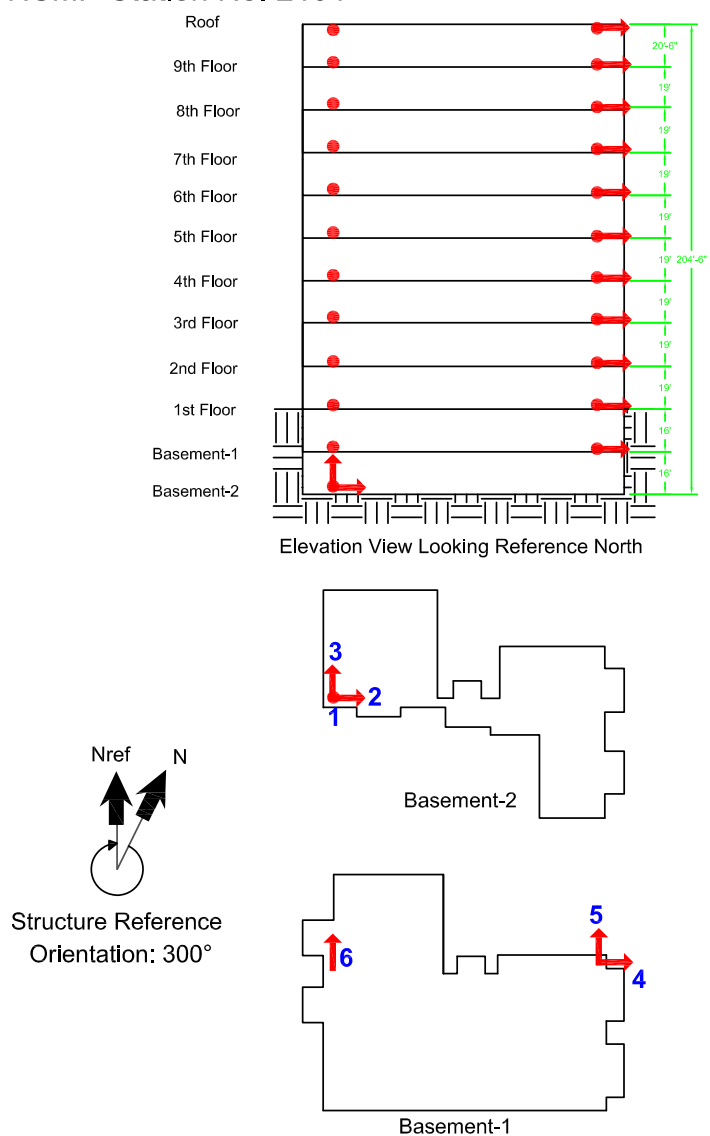

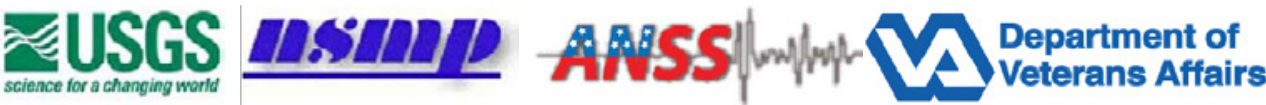
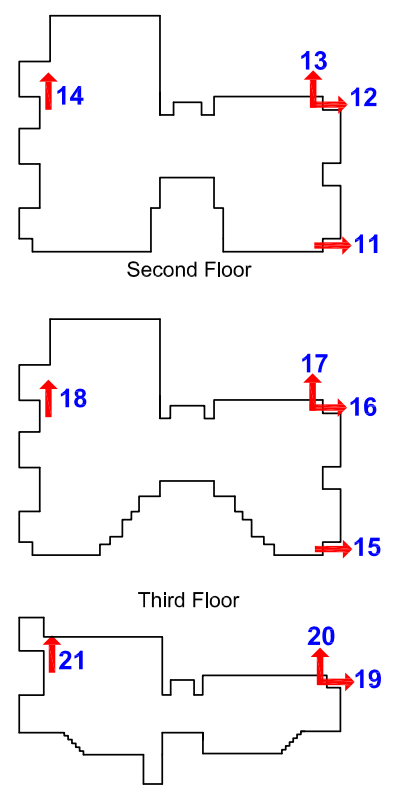

Fourth Floor

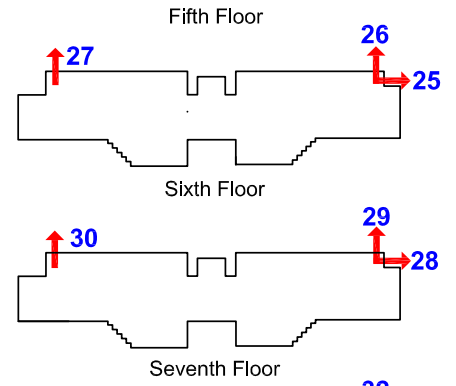

Revision Number: 7

Revised on 10/11/2012
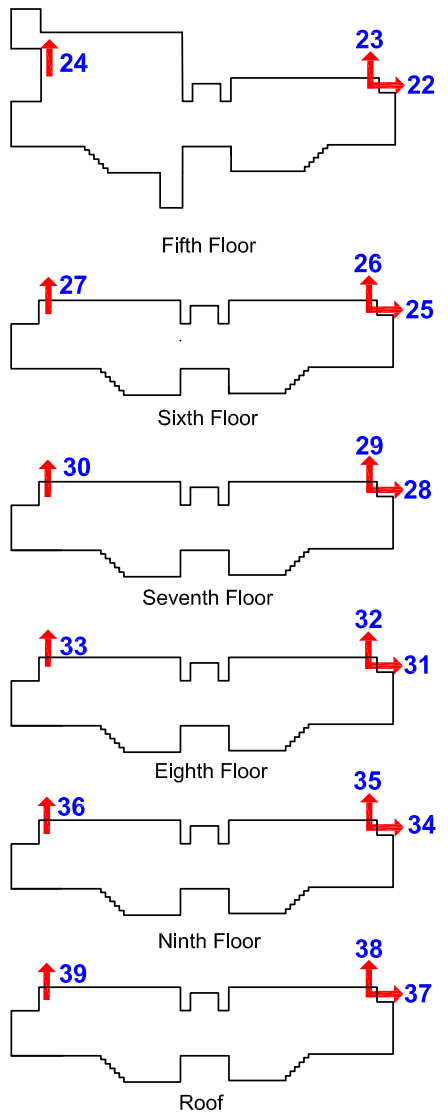

SENSOR LOCATIONS

Figure 102. Diagram of sensor layout showing 39 sensors in Building 100 of the Portland Veterans Affairs Medical Center, Oregon. 


\section{NSMP Station 2561-Charleston, South Carolina: Main Hospital, Building No. 1}

\section{Building Description}

Building 1 at the Ralph H. Johnson VA Medical Center (http://www.charleston.va.gov/) in Charleston, South Carolina, is approximately 453,616 $\mathrm{ft}^{2}$ (fig. 103 and fig. 105). This reinforced concrete building was initially designed in 1963 and underwent renovations to correct its seismic deficiencies in 1980. The building has an irregular shape that resembles a shape like a "T." The main wing of the structure is 71 by $263 \mathrm{ft}$. There are two different wings on both the east and west sides of the central wing. The east and west wings are separated by seismic joints from the central wing. Both the east and west wings are symmetrical and have the dimensions of 101.5 by $71.5 \mathrm{ft}$. The protrusion from the middle of the central wing is 97 by $62 \mathrm{ft}$. This structure is five stories tall and has a typical story height of $12 \mathrm{ft}$, with the only exception of the first floor, which is $14 \mathrm{ft}$ tall. Typical floor and the roof construction consist of composite reinforced concrete slabs supported by reinforced concrete columns. The concrete columns are supported by a foundation of piles and pile caps. The buildings lateral- and vertical-force resisting systems consist of shear walls in both directions and reinforced concrete frames.

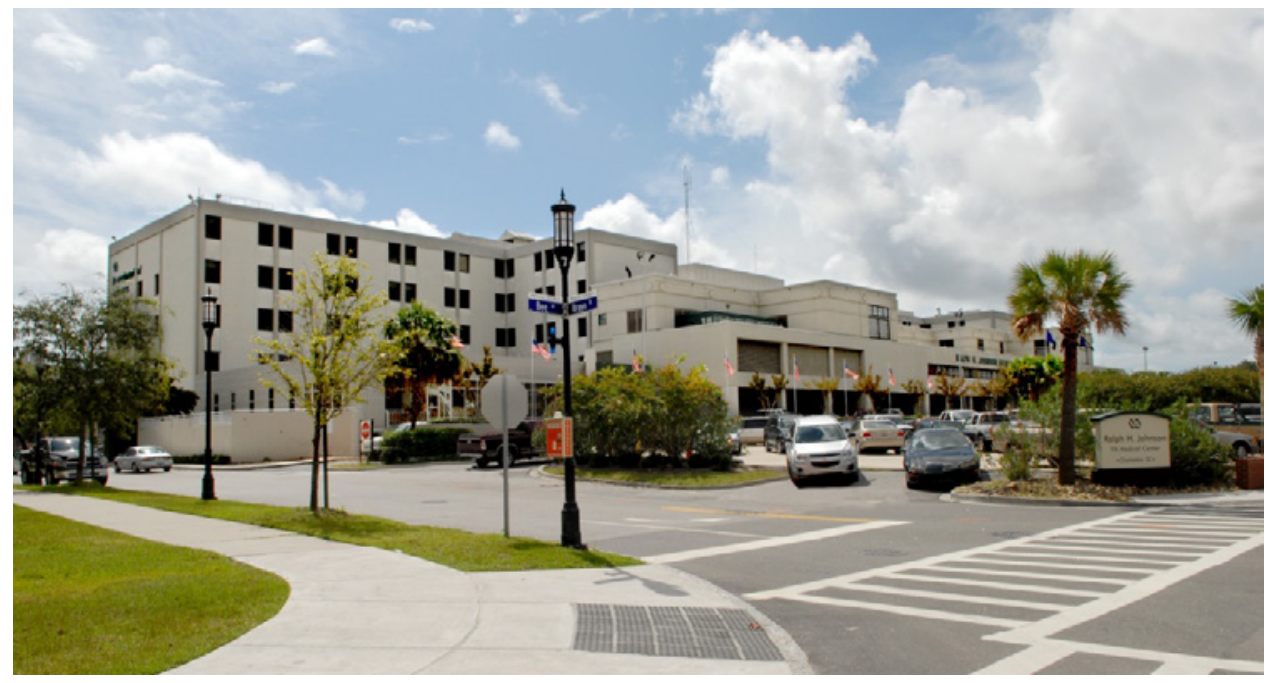

Figure 103. Photograph of Building 1, Charleston Veterans Affairs Medical Center, South Carolina (front view) (U.S. Department of Veterans Affairs photograph). 


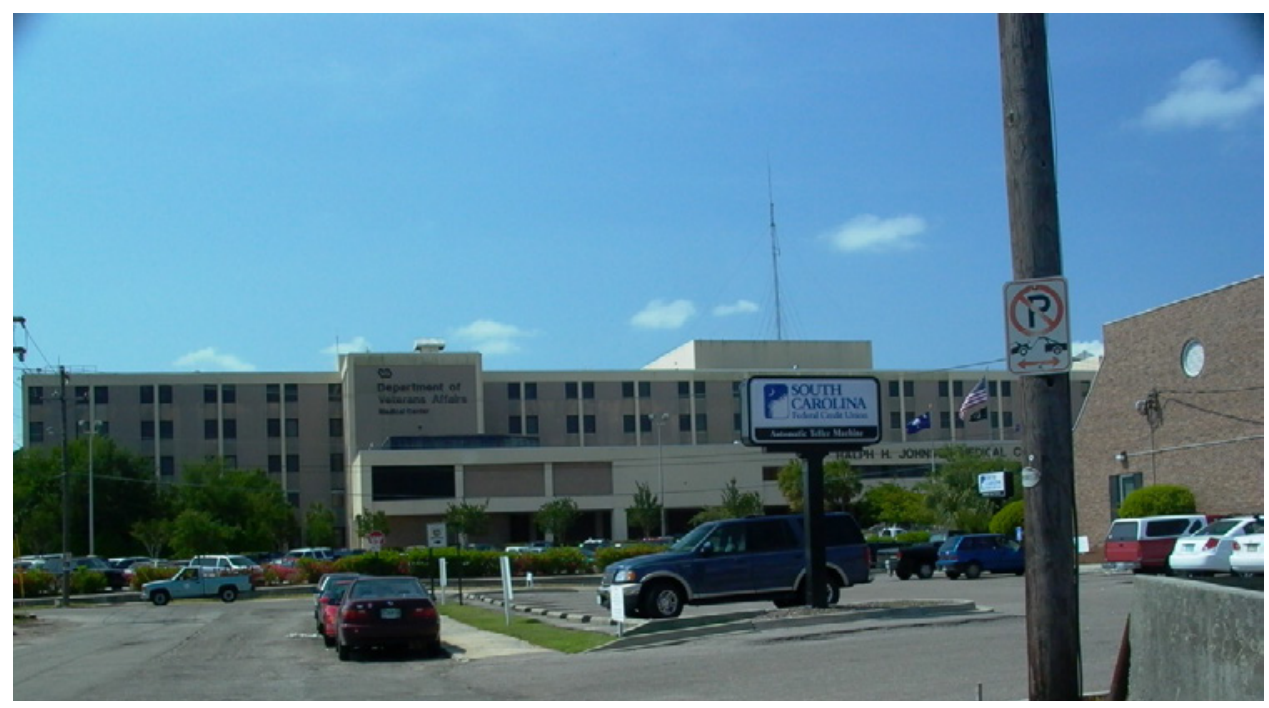

Figure 104. Photograph of Building 1, Charleston Veterans Affairs Medical Center, South Carolina (back side view) (U.S. Geological Survey photograph).

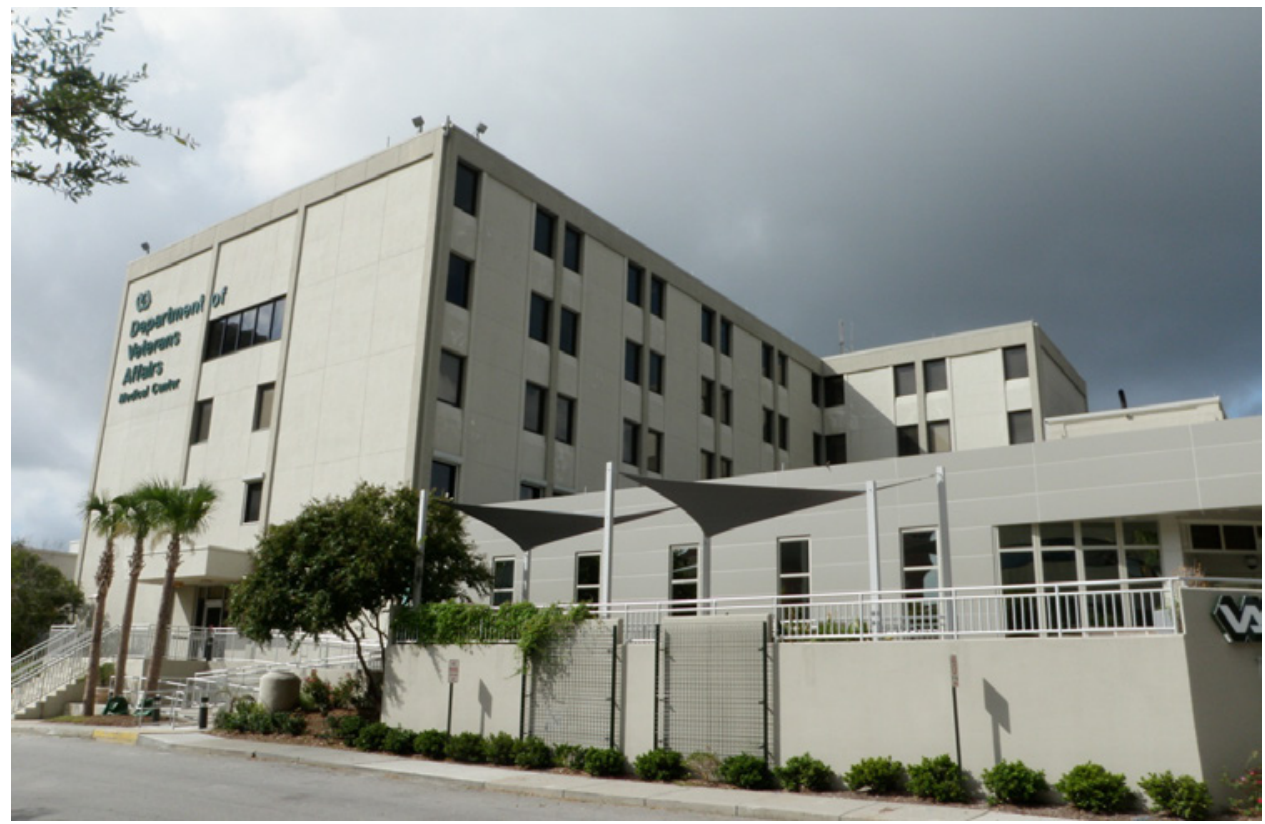

Figure 105. Photograph of Building 1, Charleston Veterans Affairs Medical Center, South Carolina (side view) (U.S. Geological Survey photograph).

\section{Seismic-Hazard Conditions}

The building is located in an area of very high seismic hazard. The short-period spectral acceleration, $\mathrm{S}_{\mathrm{S}}$, using the current NEHRP recommended provisions for seismic regulations of new buildings and other structures, is $1.49 \mathrm{~g}$. The long-period spectral acceleration, $\mathrm{S}_{1}$, is $0.36 \mathrm{~g}$.

\section{Instrumentation}

Building 1 consists of three blocks (A, B, C) separated by two seismic joints. Each block has a T-shape plan. A total of 48 accelerometers are deployed at six levels in the building to 
measure its response to ground shaking (fig. 106 and fig. 107). The accelerometers are strategically located at the corners of the building at each floor level to measure translational motion and compute torsional responses of each block and wing. A triaxial accelerometer (channels 1 through 3) is placed on the ground-floor level to measure the three components of input ground motion. Eight accelerometers (channels 4 through 11) are placed on the groundfloor ceiling level to monitor the first-floor slab. Thirty-seven accelerometers are similarly distributed on the ceilings of the first through the fifth floors to measure the translational motions of the slabs. At least three accelerometers are placed on the each floor so that floor torsional motion can be computed. For each block, the floor relative displacements, thus inter-story drifts, can be obtained at two different points along the same vertical axis.

The building accelerometers are complemented by a three-component seismic accelerometer located at a free-field site (NSMP Station No. 2553), approximately $165 \mathrm{ft}$ away from the building, to monitor ground shaking without interference from the earthquake response of the building. 
U.S. Department of Veterans Affairs

Charleston, SC - Reinforced Concrete, Five-Story Hospital Building

Building No: 1

NSMP Station No: 2561

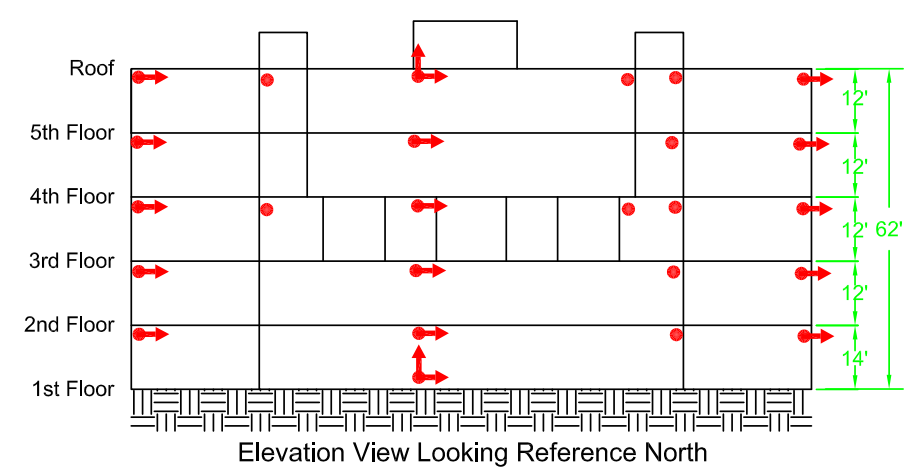

Elevation View Looking Reference North

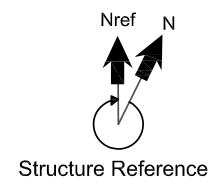

Structure Reference

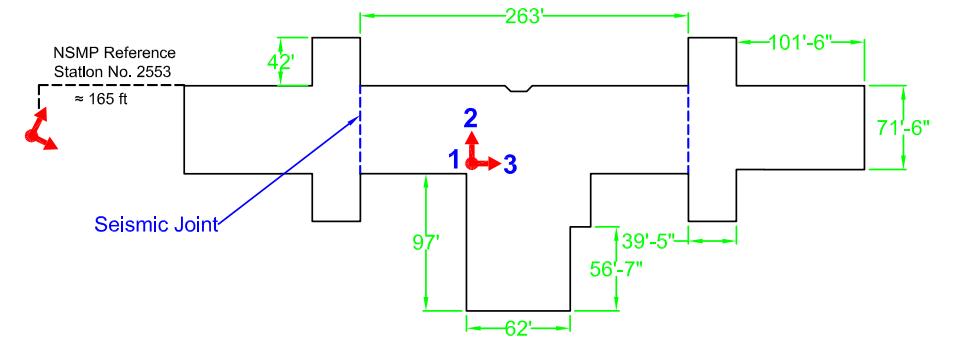

First Floor
Revision Number: 9

Revised on 10/10/2012

Page 1 of 2

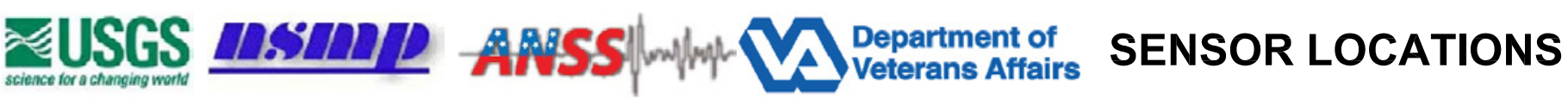

Figure 106. Diagrams of sensor layout showing 48 sensors in Building 1 of the Charleston Veterans Affairs Medical Center, South Carolina (page 1 of 2; see also fig. 107). 
U.S. Department of Veterans Affairs

Charleston, SC - Reinforced Concrete, Five-Story Hospital Building

Building No: 1

NSMP Station No: 2561

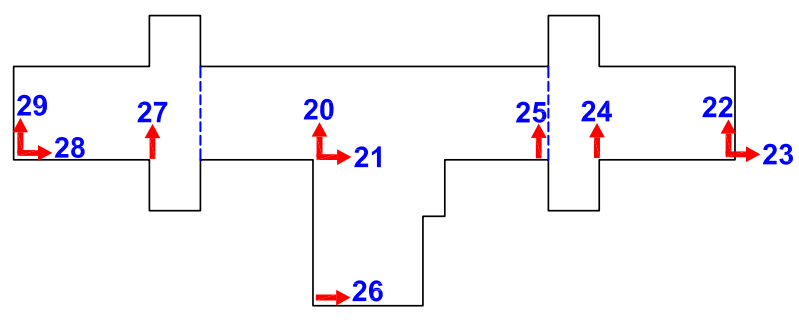

Fourth Floor

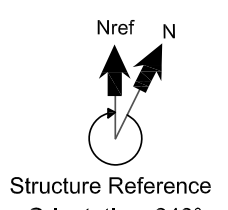

Orientation: $340^{\circ}$
Revision Number: 9

Revised on 10/10/2012

Page 2 of 2

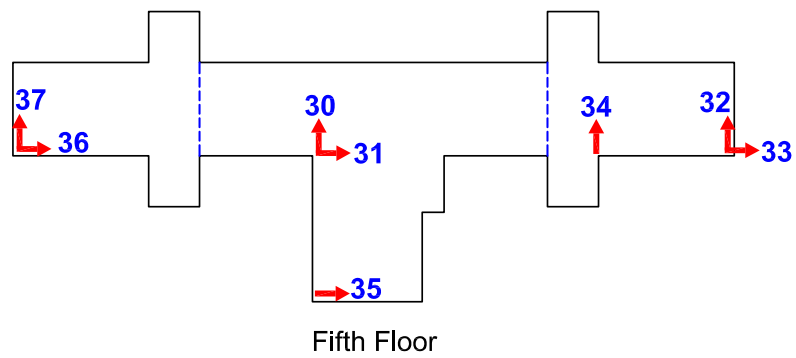

Fifth Floor

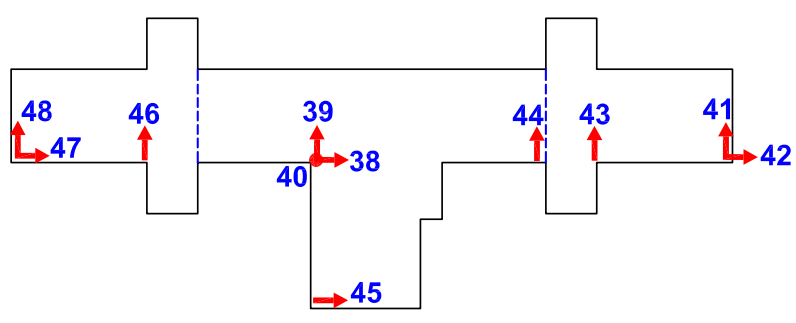

Roo

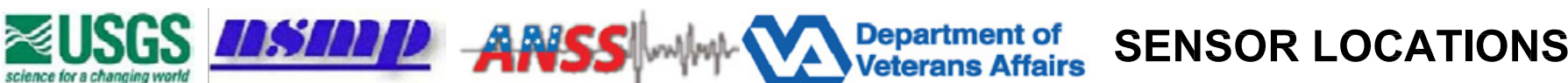

Figure 107. Diagrams of sensor layout showing 48 sensors in Building 1 of the Charleston Veterans Affairs Medical Center, South Carolina (page 2 of 2; see also fig. 106). 


\section{NSMP Station 7411—Memphis, Tennessee: Spinal-Chord Injury, Building No. 7}

\section{Building Description}

Building 7 at the Memphis VA Medical Center (http://www.memphis.va.gov/) in Memphis, Tennessee, is a three-story reinforced concrete structure that is approximately 314,903 $\mathrm{ft}^{2}$ (fig. 108 through fig. 110). This building is used primarily for treating spinal-cord injury patients. The building has an irregular plan with base dimensions of $151 \mathrm{ft} 10$ inches and $294 \mathrm{ft} 8$ inches. In the center of the building is a square courtyard. The basement has a height of $8 \mathrm{ft} 4$ inches. The first floor has a height of approximately $16 \mathrm{ft}$, and the second floor has a height of 13 $\mathrm{ft} 8$ inches. The buildings lateral- and vertical-force resisting systems consist of reinforced concrete frames. The floor and roof construction consists of composite reinforced concrete slabs. The basement floor is a concrete slab on grade.

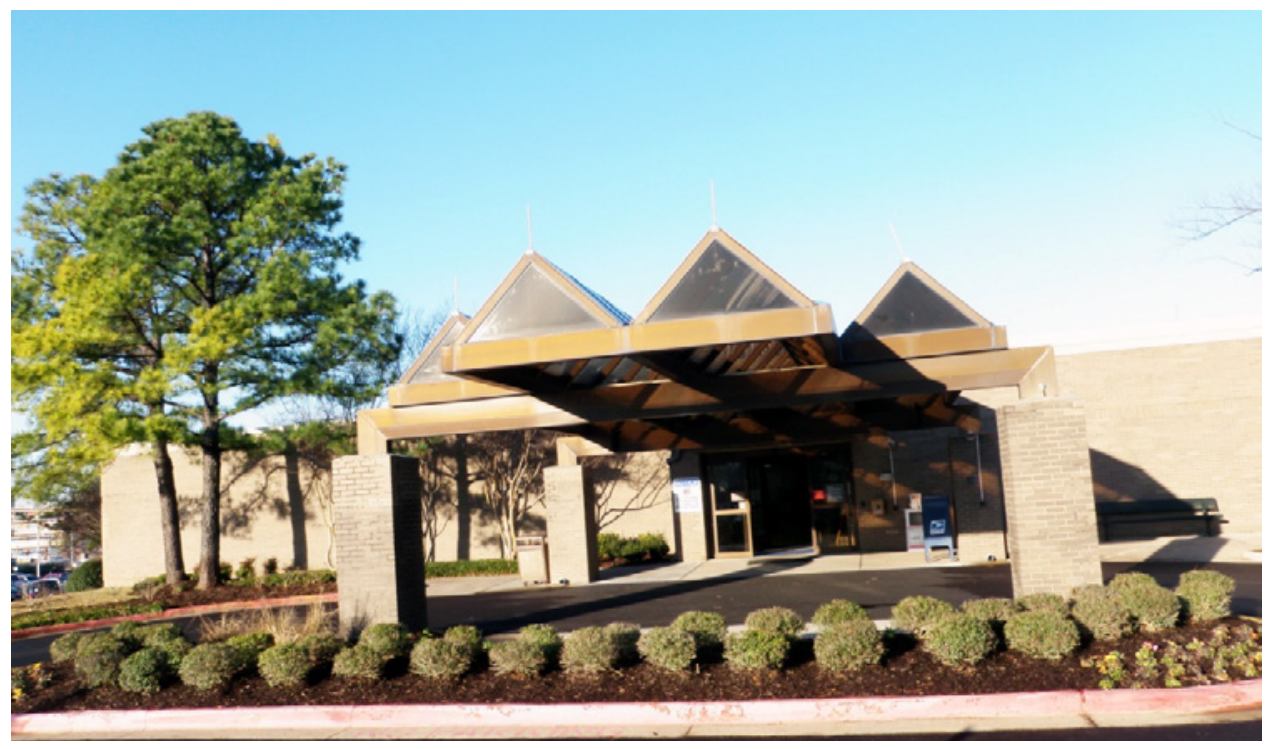

Figure 108. Photograph of Building 7, Memphis Veterans Affairs Medical Center, Tennessee (entrance)

(U.S. Geological Survey photograph). 


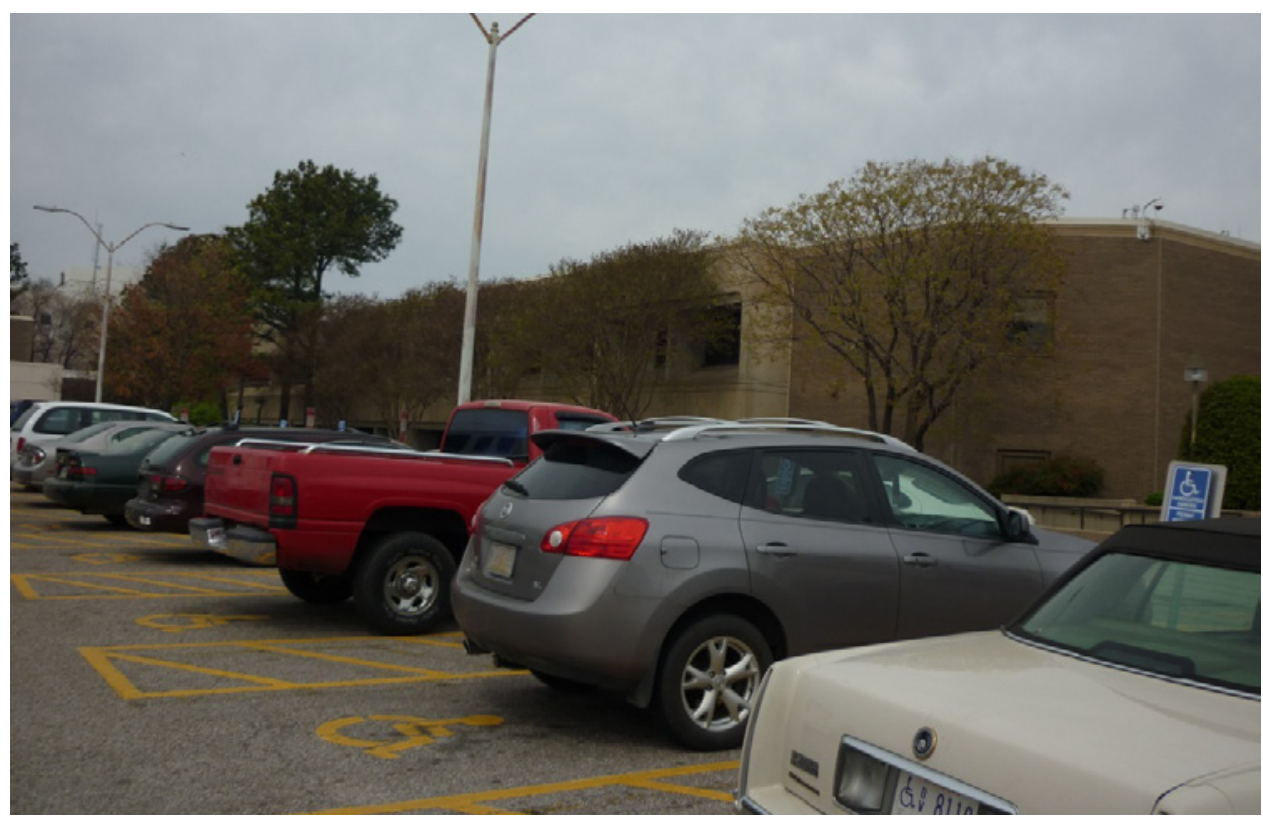

Figure 109. Photograph of Building 7, Memphis Veterans Affairs Medical Center, Tennessee (looking northwest) (U.S. Geological Survey photograph).

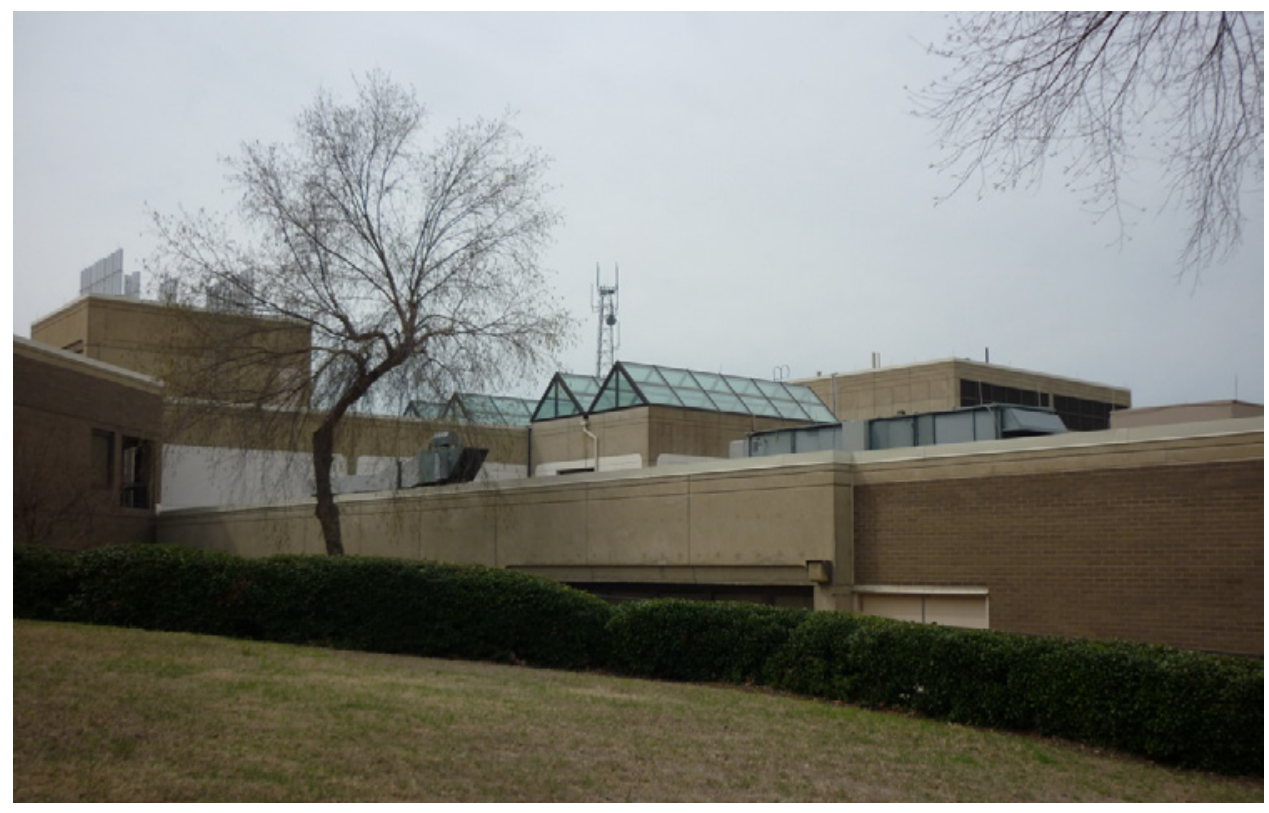

Figure 110. Photograph of Building 7, Memphis Veterans Affairs Medical Center, Tennessee (looking west) (U.S. Geological Survey photograph).

\section{Seismic-Hazard Conditions}

The building is located in an area of very high seismic hazard. The short-period spectral acceleration, $\mathrm{S}_{\mathrm{S}}$, using the current NEHRP recommended provisions for seismic regulations of new buildings and other structures, is $1.34 \mathrm{~g}$. The long-period spectral acceleration, $\mathrm{S}_{1}$, is $0.37 \mathrm{~g}$. 


\section{Instrumentation}

A total of 12 accelerometers are deployed in the building to measure its lateral motion in reference east-west and north-south directions (fig. 111 and fig. 112). A triaxial accelerometer (channels 1 through 3 ) is placed on the basement slab to measure the three components of input ground motion. Nine accelerometers (channels 4 through 12) are placed on the ceilings of the basement, first, and second floors to measure slab lateral motions. The reference southwest corner of the building has an accelerometer (channels 4, 7, and 10) oriented in the weak direction at each floor level. The relative floor displacement, thus inter-story drifts, at this corner can be computed from these accelerometers. Similarly, the reference southeast corner of the building has two accelerometers (channels 5, 6, 8, 9, 11, and 12) at each floor so that the floor relative displacement at this corner can be computed. The floor torsion can be obtained from two likewise oriented accelerometers on the same floor.

The building accelerometers are complemented by a three-component seismic accelerometer located at a reference site (NSMP Station No. 7412), approximately $590 \mathrm{ft}$ away from the building, to monitor ground shaking without interference from the earthquake response of the building. 
U.S. Department of Veterans Affairs

Memphis, TN - Reinforced Concrete, Three-Story Hospital Building

Building No: 7

NSMP Station No: 7411
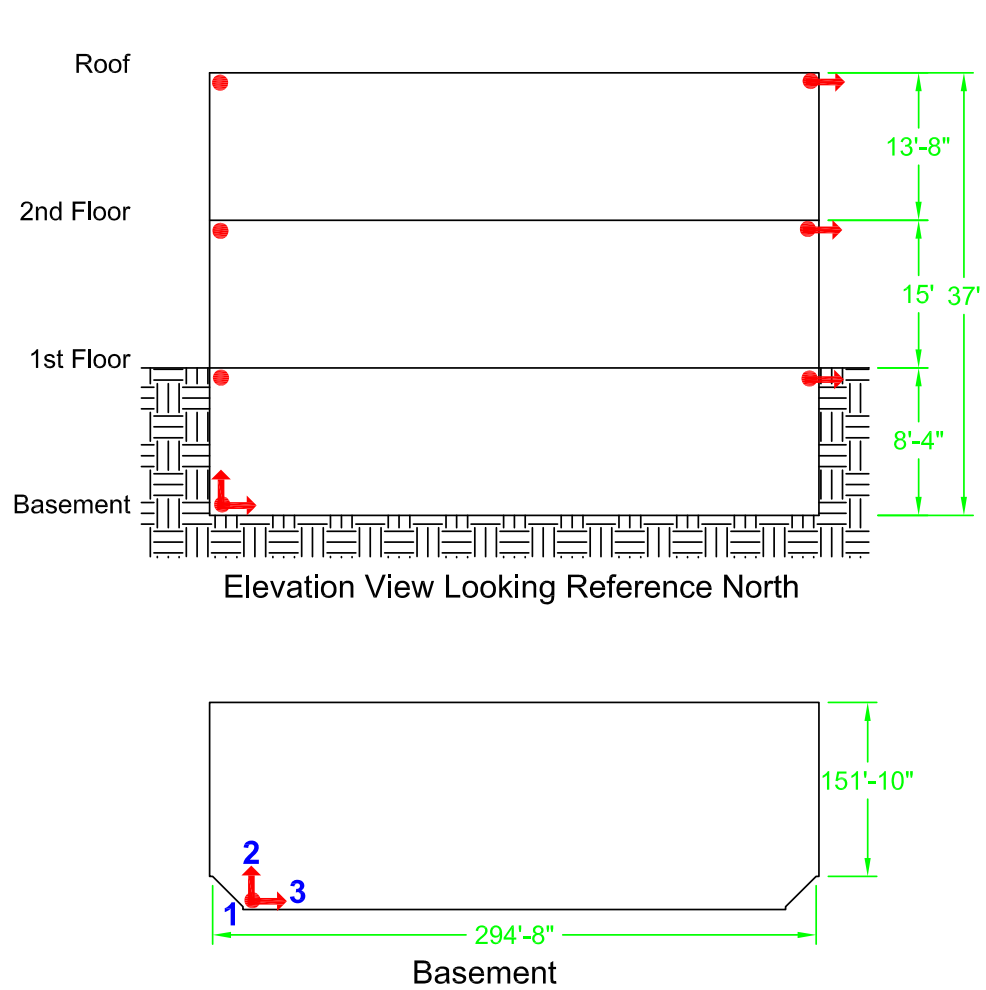

Revision Number: 7

Revised on $10 / 11 / 2012$

Page 1 of 2

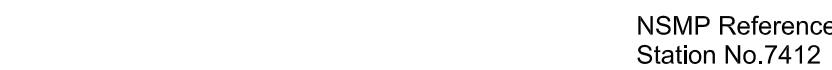

Station No.7412

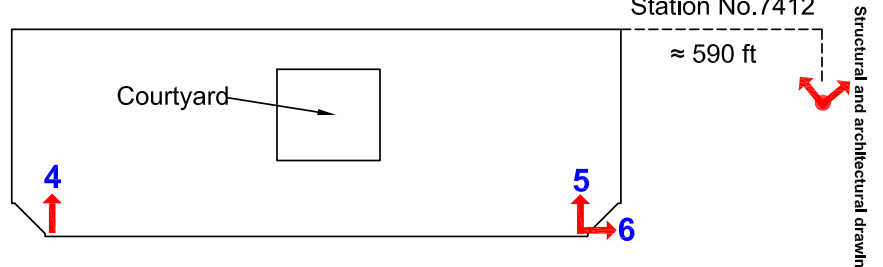

First Floor

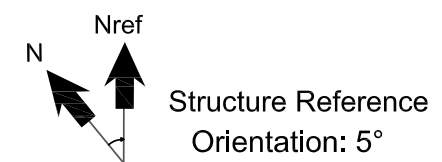

Orientation: $5^{\circ}$

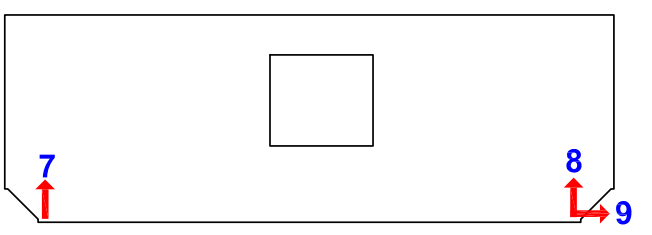

Second Floor

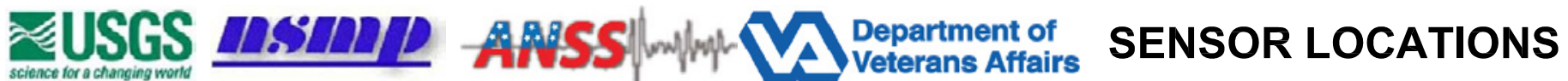

Figure 111. Diagrams of sensor layout showing 12 sensors in Building 7 of the Memphis Veterans Affairs Medical Center, Tennessee (page 1 of 2; see also fig. 112). 
U.S. Department of Veterans Affairs

Memphis, TN - Reinforced Concrete, Three-Story Hospital Building

Building No: 7

NSMP Station No: 7411
Revision Number: 7

Revised on 10/11/2012

Page 2 of 2
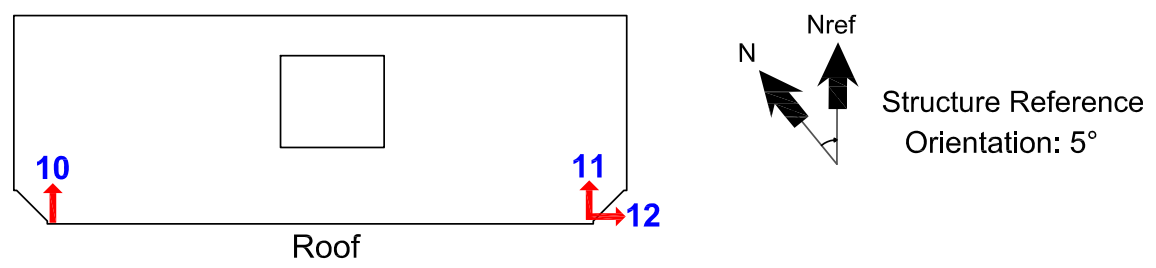

Orientation: $5^{\circ}$

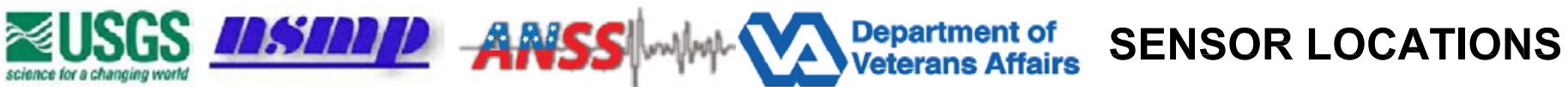

Figure 112. Diagrams of sensor layout showing 12 sensors in Building 7 of the Memphis Veterans Affairs Medical Center, Tennessee (page 2 of 2; see also fig. 111). 


\section{NSMP Station 7410-Memphis, Tennessee: Bed Tower, Building No. 1A}

\section{Building Description}

Building 1A at the Memphis VA Medical Center (http://www.memphis.va.gov/) in Memphis, Tennessee, is a bed tower with six stories covering $654,118 \mathrm{ft}^{2}$. This reinforced concrete structure, built in 2000, has a square plan with indentations pointing inwards at the corners (fig. 113 through fig. 115). There is also a courtyard in the northern center side of the building. Additionally, there is an L-shaped opening from starting on the second floor on the southern center side of the building, reaching to the top of the structure. The vertical- and lateralforce resisting systems are comprised of reinforced concrete moment resisting frames and shear walls.

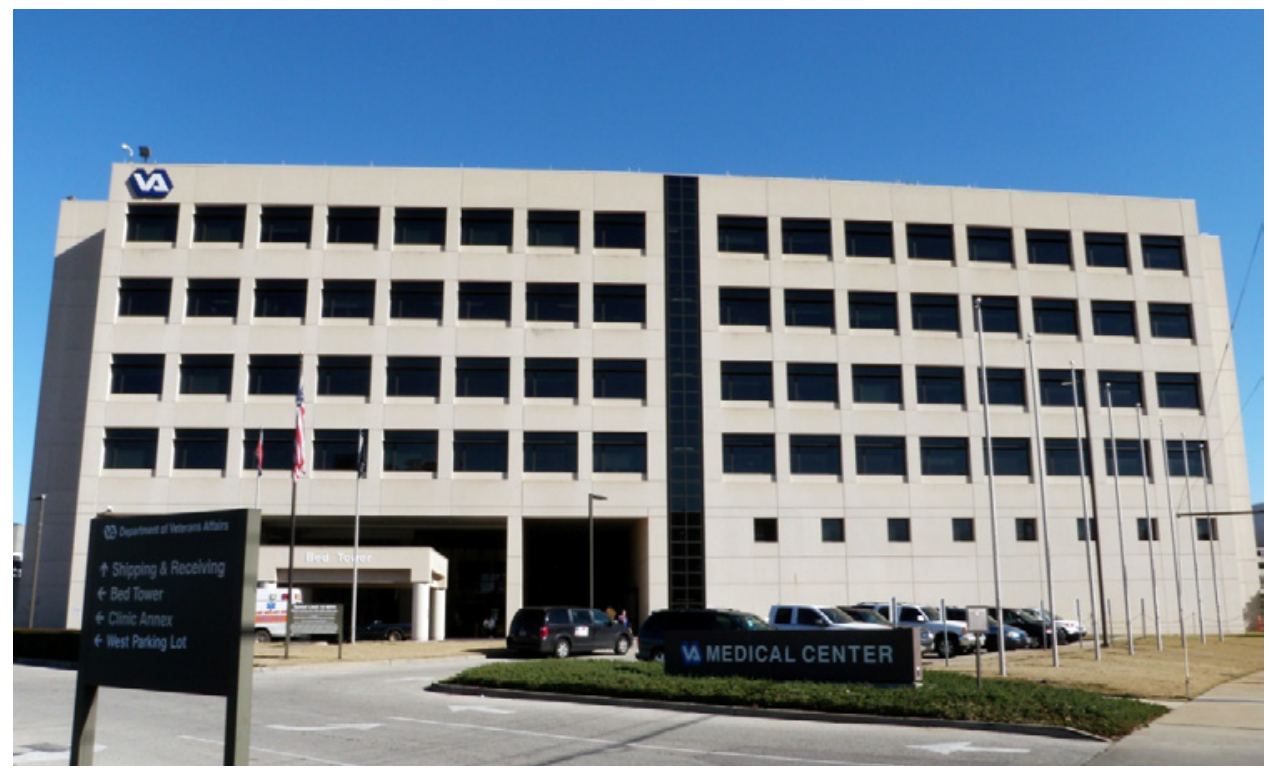

Figure 113. Photograph of Building 1A, Memphis Veterans Affairs Medical Center, Tennessee (U.S. Geological Survey photograph). 


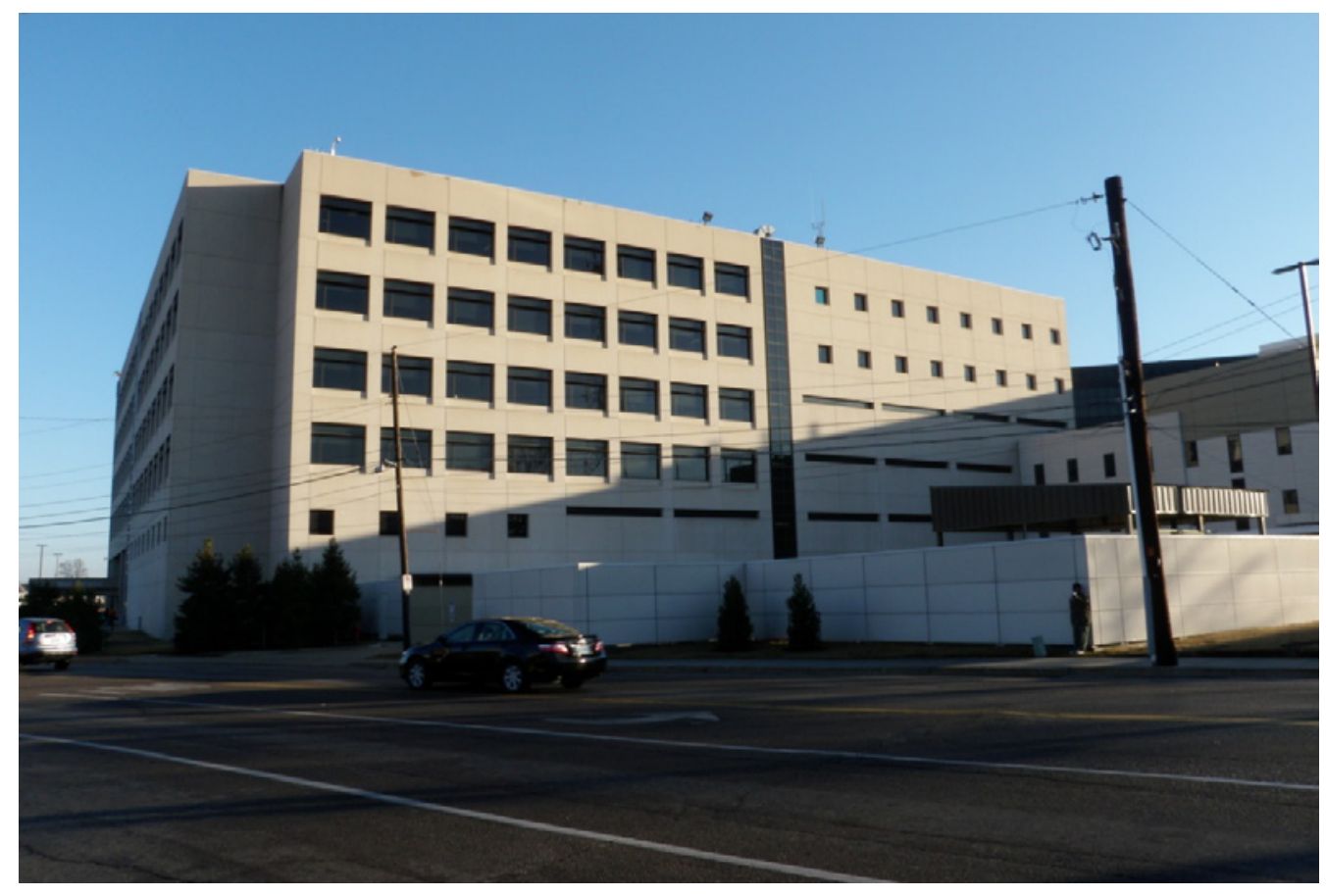

Figure 114. Photograph of Building 1A, Memphis Veterans Affairs Medical Center, Tennessee (looking north) (U.S. Geological Survey photograph).

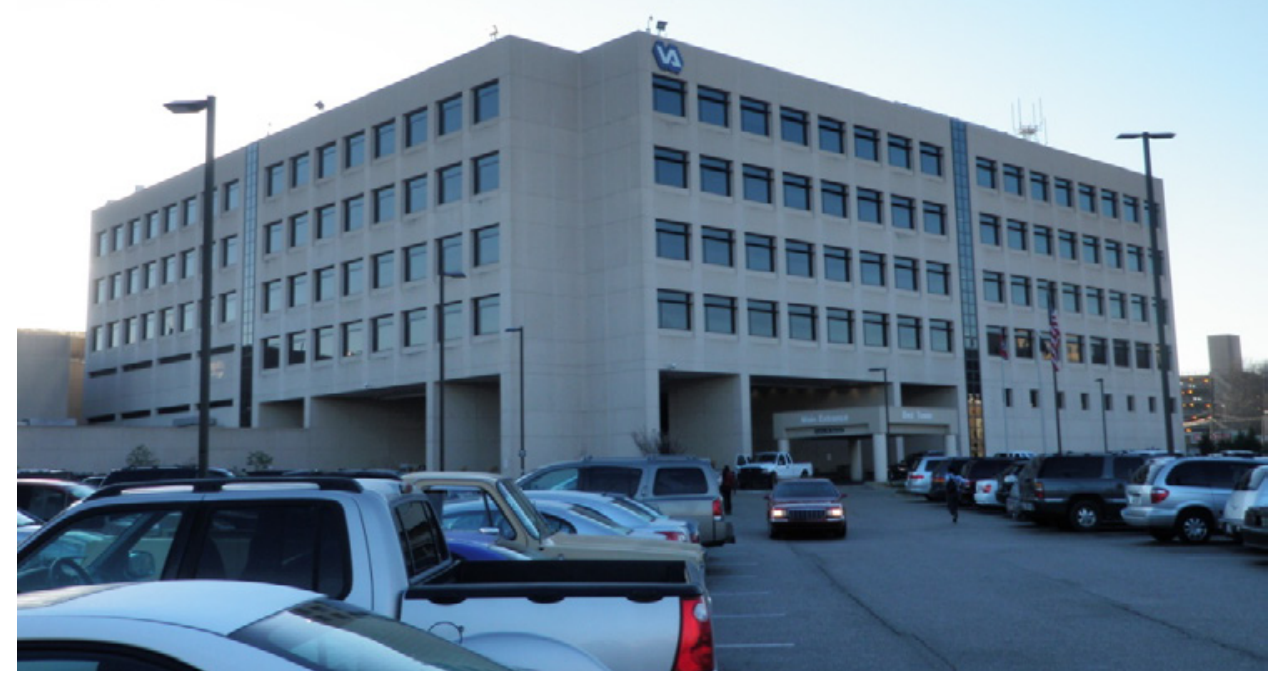

Figure 115. Photograph of Building 1A, Memphis Veterans Affairs Medical Center, Tennessee (looking southeast) (U.S. Geological Survey photograph). 


\section{Seismic-Hazard Conditions}

The building is located in an area of very high seismic hazard. The short-period spectral acceleration, $\mathrm{S}_{\mathrm{S}}$, using the current NEHRP recommended provisions for seismic regulations of new buildings and other structures, is $1.34 \mathrm{~g}$. The long-period spectral acceleration, $\mathrm{S}_{1}$, is $0.37 \mathrm{~g}$.

\section{Instrumentation}

A total of 24 accelerometers are deployed at seven levels in the building (fig. 116 through fig. 118). A triaxial accelerometer (channels 1 through 3 ) is placed on the ground floor to measure the three components of input ground motion. The accelerometers are placed at the corners of the building oriented parallel the building's sides. Four accelerometers (channels 4 through 7) are placed on the ceiling of the basement to measure the building response at three corners. The first-floor ceiling is instrumented with three accelerometers (channels 8 through 10). Four accelerometers (channels 11 through 14) are placed on the ceiling of the second floor at three corners to measure floor lateral response in the reference east-west and north-south directions. The ceilings of the third and fourth floor are similarly instrumented with three accelerometers each to monitor slab movement. Four accelerometers are placed on the fifth-floor ceiling level to measure roof lateral motion. The floor torsional motion can be obtained from two likewise oriented accelerometers on the same floor. The floor relative displacements and interstory drifts can be computed from the accelerometers located at the same corner of the building along the same vertical axis.

The building accelerometers are complemented by a three-component seismic accelerometer located at a reference site (NSMP Station No. 7412), approximately $330 \mathrm{ft}$ away from the building, to monitor ground shaking without interference from the earthquake response of the building. 
U.S. Department of Veterans Affairs

Memphis, TN - Reinforced Concrete, Six-Story Hospital Building

Building No: $1 \mathrm{~A}$

NSMP Station No: 7410

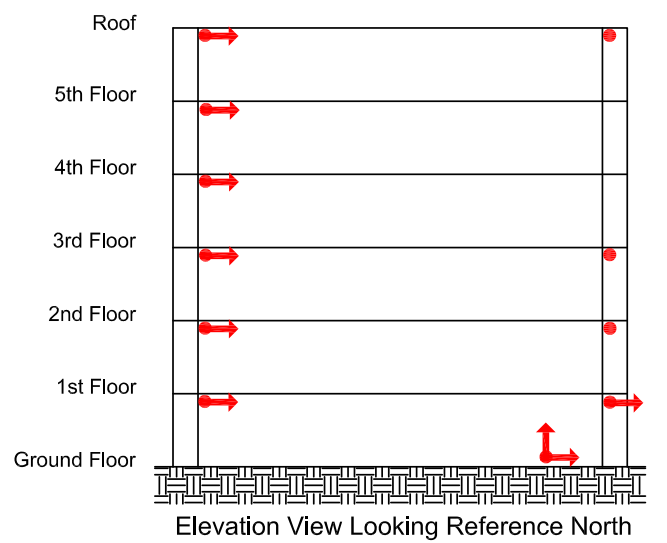

NSMP Reference

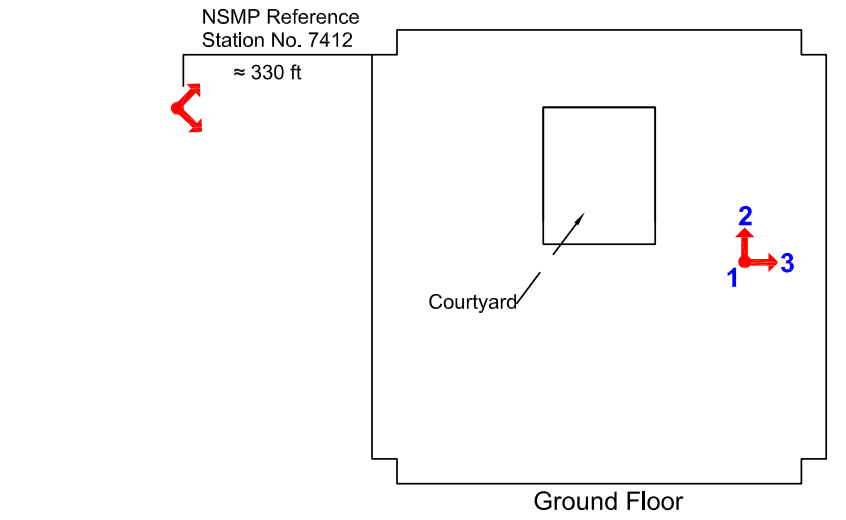

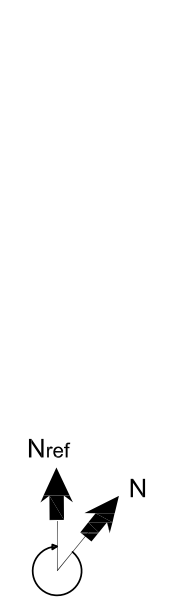

Structure Reference
Orientation: $355^{\circ}$

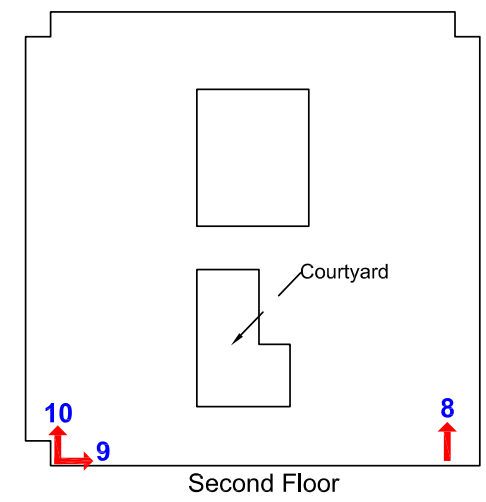

Department of

Veterans Affairs

SENSOR LOCATIONS

Figure 116. Diagrams of sensor layout showing 24 sensors in Building $1 \mathrm{~A}$ of the Memphis Veterans Affairs Medical Center, Tennessee (page 1 of 3 ; see also figs. 117 and 118). 
U.S. Department of Veterans Affairs

Memphis, TN - Reinforced Concrete, Six-Story Hospital Building

Building No: $1 \mathrm{~A}$

NSMP Station No: 7410

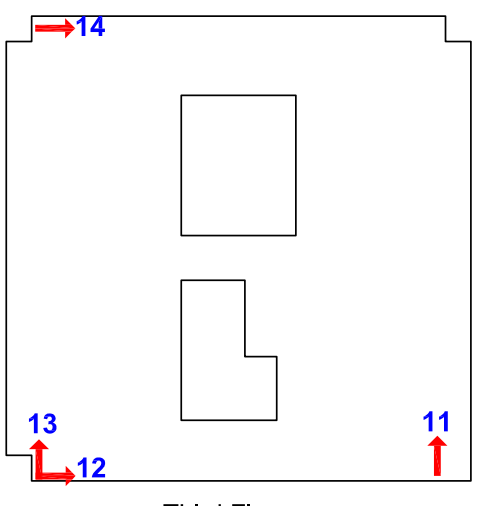

Third Floor

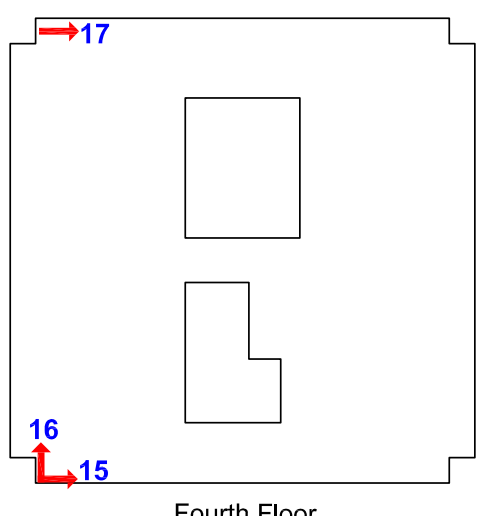

Fourth Floor
Revision Number: 7

Revised on $8 / 14 / 2012$

Page 2 of 3
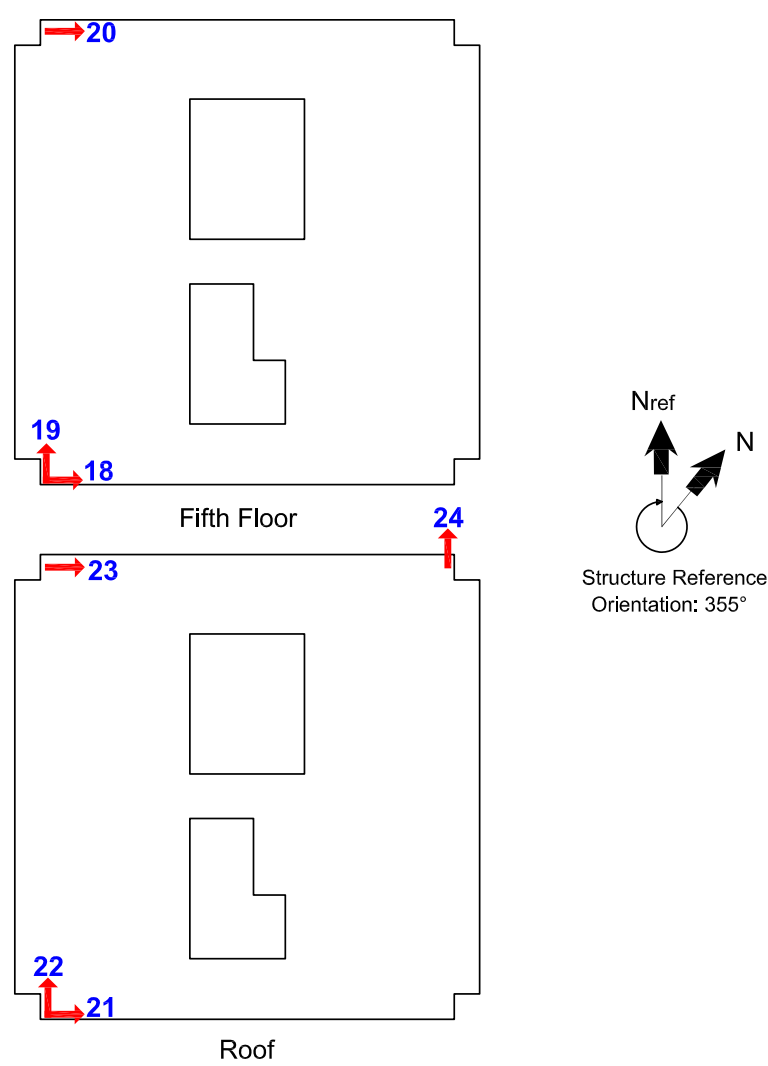

Structure Reference Orientation: $355^{\circ}$

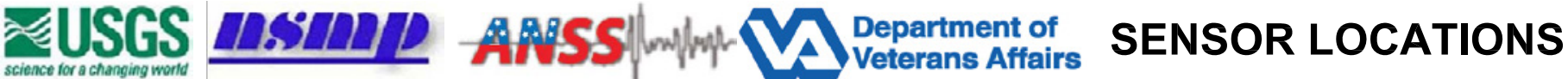

Figure 117. Diagrams of sensor layout showing 24 sensors in Building 1A of the Memphis Veterans Affairs Medical Center, Tennessee (page 2 of 3; see also figs. 116 and 118). 
U.S. Department of Veterans Affairs

Memphis, TN - Reinforced Concrete, Six-Story Hospital Building

Building No: $1 \mathrm{~A}$

NSMP Station No: 7410

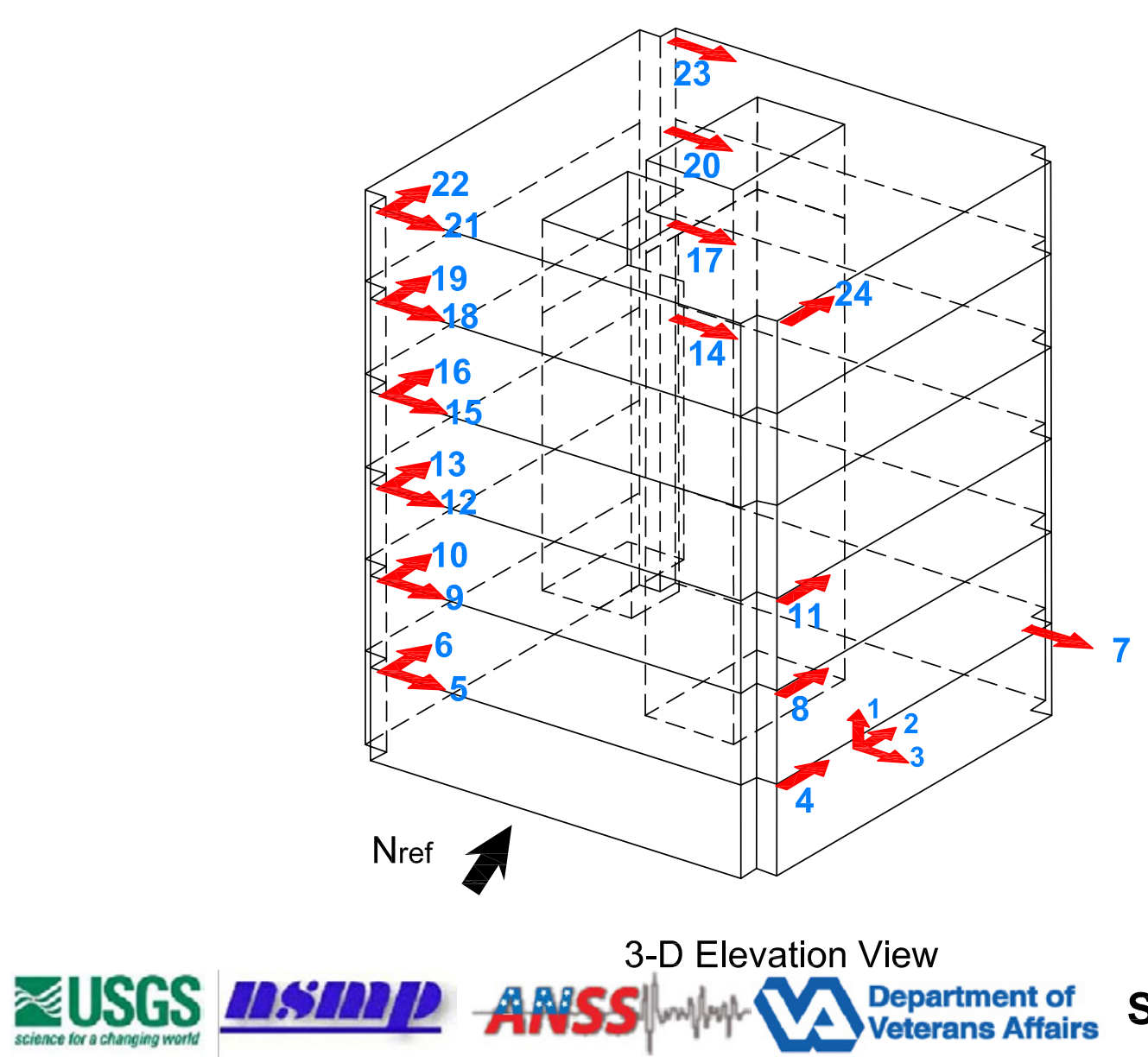

Revision Number: 7

Revised on 8/14/2012

Page 3 of 3

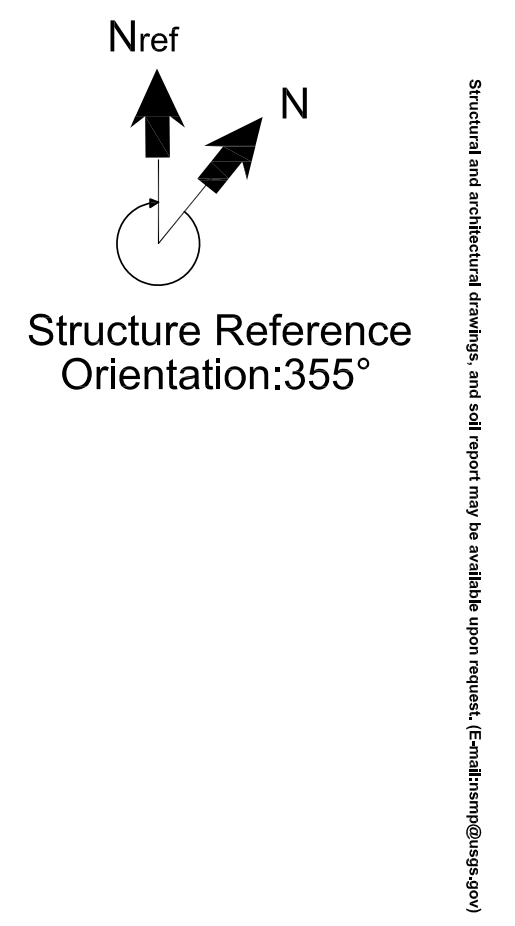

Figure 118. Diagrams of sensor layout showing 24 sensors in Building 1A of the Memphis Veterans Affairs Medical Center, Tennessee (page 3 of 3; see also figs. 116 and 117). 


\section{NSMP Station 7237-Salt Lake City, Utah: Main Hospital, Building No. 14}

\section{Building Description}

Building 14 of the VA Salt Lake City Health Care System

(http://www.saltlakecity.va.gov/) in Salt Lake City, Utah, is a four-story structure that is approximately 209,723 $\mathrm{ft}^{2}$ (fig. 119). The building resembles a rectangular shape with irregularities on its south and west sides. The building's floor and roof consists of composite reinforced concrete slabs. This building resists lateral and vertical forces through the use of reinforced concrete walls added to façade.

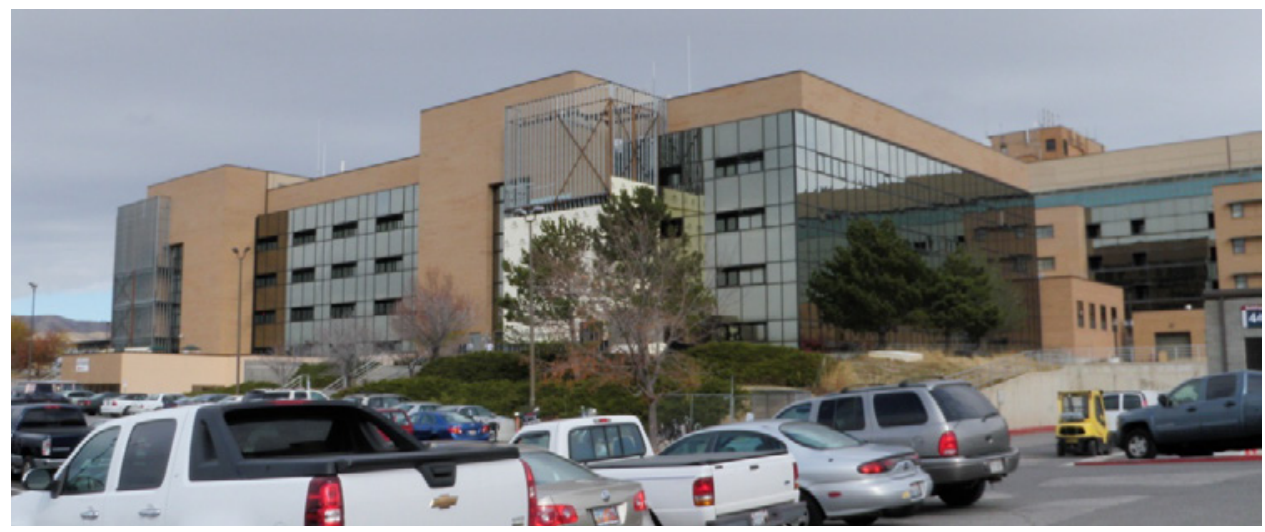

Figure 119. Photograph of Building 14, Salt Lake City Veterans Affairs Medical Center, Utah (U.S. Geological Survey photograph).

\section{Seismic-Hazard and Soil Conditions}

Geotechnical testing was performed in 2010 on the building site. The boreholes that were dug to $32 \mathrm{ft}$ deep on site showed that the surface of the site is asphalt underlain by $4.5 \mathrm{ft}$ of fill material. The fill material encountered consists of sands and gravels mixed with small amounts of silt and clay. Beneath the asphalt and fill material are alternating layers of silty clay and silty/clayey fine to coarse sand and fine coarse gravel. No ground water was discovered.

The building is located in an area of very high seismic hazard. The short-period spectral acceleration, $\mathrm{S}_{\mathrm{S}}$, using the current NEHRP recommended provisions for seismic regulations of new buildings and other structures, is $1.58 \mathrm{~g}$. The long-period spectral acceleration, $\mathrm{S}_{1}$, is $0.63 \mathrm{~g}$.

\section{Instrumentation}

A total of 24 accelerometers are deployed in the building to measure and compute its lateral and torsional motion (fig. 120 and fig. 121). A triaxial accelerometer (channels 1 through 3 ) is placed on the basement slab to measure the three components of input ground motion. Another two accelerometers oriented vertically (channels 4 and 5) are also placed on the basement slab near two corners of the building. The rocking motion of the building about the reference east-west and north-south directions can be obtained from vertically oriented accelerometers in the basement. The basement ceiling is instrumented with three accelerometers (channels 6 through 8) to monitor first-floor motions. Similarly, four accelerometers (channels 9 through 12) are placed on the first-floor ceiling level to measure lateral motions of the second floor. The floor lateral motions in reference east-west and north-south directions can be captured by a pair of accelerometers: Channels 10 and 11 will define the reference north-south lateral 
motion, and channels 9 and 12 will define the reference east-west lateral motion. The torsional motion of the floor can be obtained from either channels 10 and 11 or channels 9 and 12. Twelve accelerometers are placed on the ceilings of the second floor through the fourth floor in a similar manner to measure floor lateral and compute torsional motions. The floor relative displacements and inter-story drifts can also be computed from accelerometers located at same corner of the building at different elevations.

The building accelerometers are complemented by a three-component seismic accelerometer located at a free-field site (NSMP Station No. 7238), approximately $330 \mathrm{ft}$ away from the building, to monitor ground shaking without interference from the earthquake response of the building. 
U.S. Department of Veterans Affairs

Salt Lake City, UT - Reinforced Concrete, Four-Story Hospital Building

Building No: 14

NSMP Station No: 7237
Revision Number: 6

Revised on 10/11/2012

Page 1 of 2
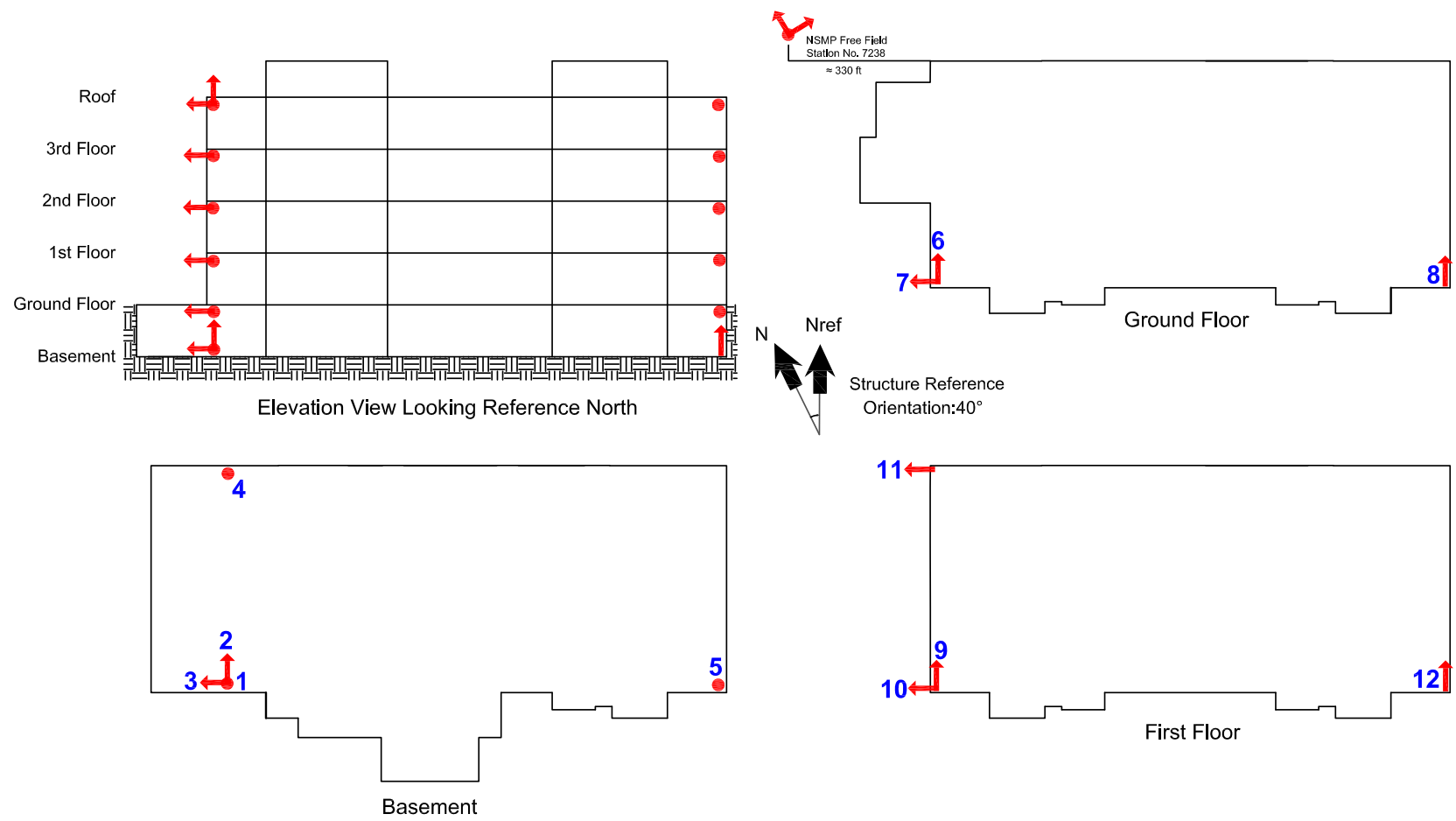

Structure Reference
Orientation: $40^{\circ}$

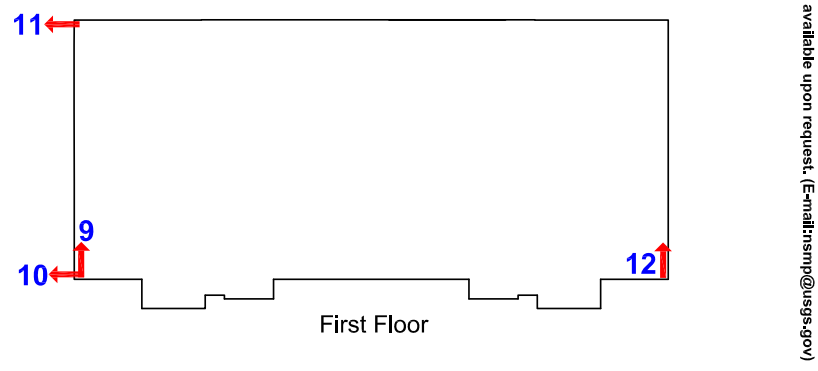

\section{₹USGS}

Figure 120. Diagrams of sensor layout showing 24 sensors in Building 14 of the Salt Lake City Veterans Affairs Medical Center, Utah (page 1 of 2; see also fig. 121). 
U.S. Department of Veterans Affairs

Salt Lake City, UT - Reinforced Concrete, Four-Story Hospital Building Building No: 14

NSMP Station No: 7237
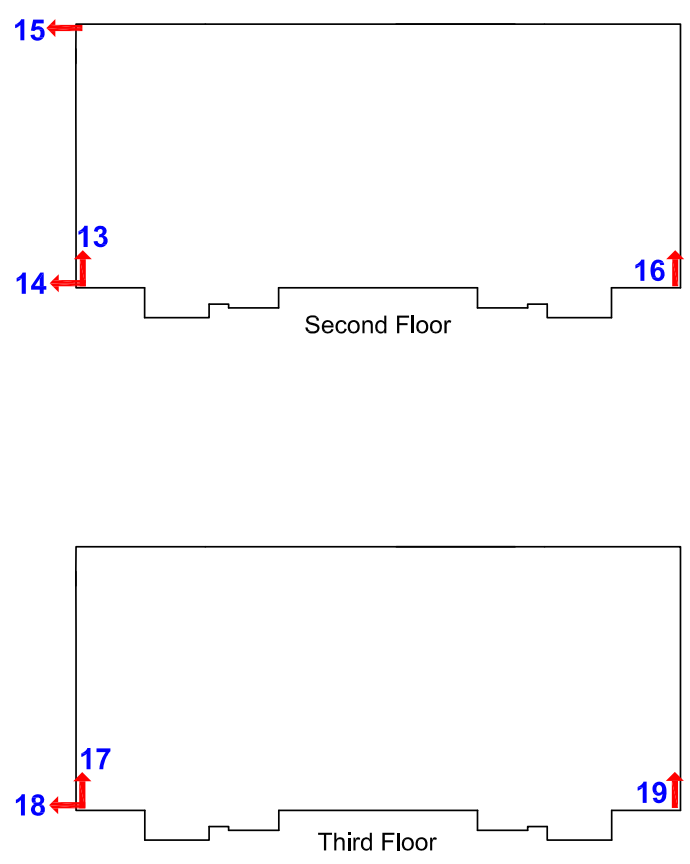

Revision Number: 6

Revised on $10 / 11 / 2012$

Page 2 of 2
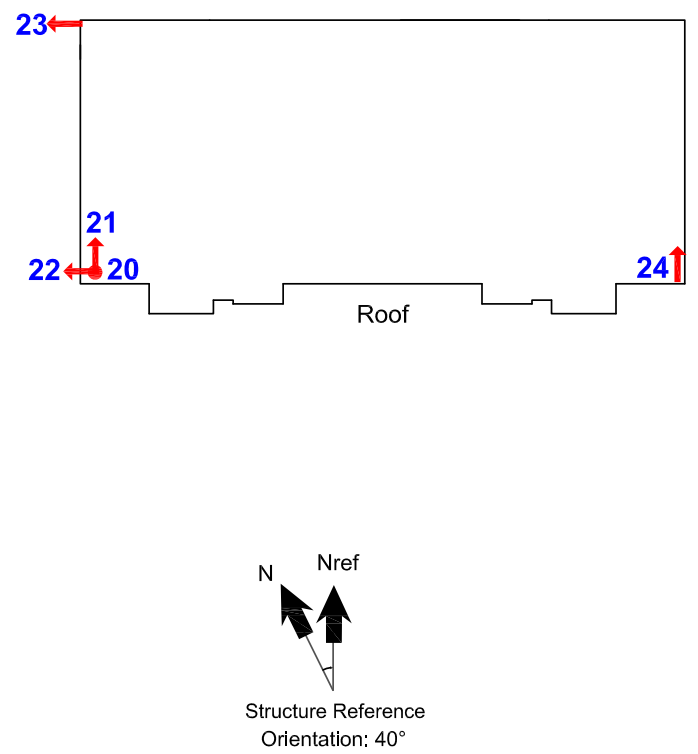

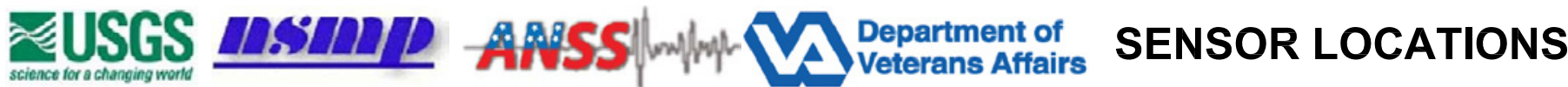

Figure 121. Diagrams of sensor layout showing 24 sensors in Building 14 of the Salt Lake City Veterans Affairs Medical Center, Utah (page 2 of 2; see also fig. 120). 


\section{NSMP Station 7600—Richmond, Virginia: Main Hospital, Building No. 500}

\section{Building Description}

Building 500, located in Richmond, Virginia, is part of the Hunter Holmes McGuire VA Medical Center (http://www.richmond.va.gov/). This $260,000-\mathrm{ft}^{2}$ building is a five-story steel structure (fig. 122). The original structure was designed in 1978 and has not been modified heavily since. The structure has an irregular plan shape with several vertical offsets. A system of three seismic joints is used in strategic parts of the building to isolate different sections. The plan for each level is different as the building narrows down near the roof. The typical story height is $18 \mathrm{ft}$. The vertical- and lateral-load resisting system is composed of steel frames. The foundation of the structure consists of isolated square footings.

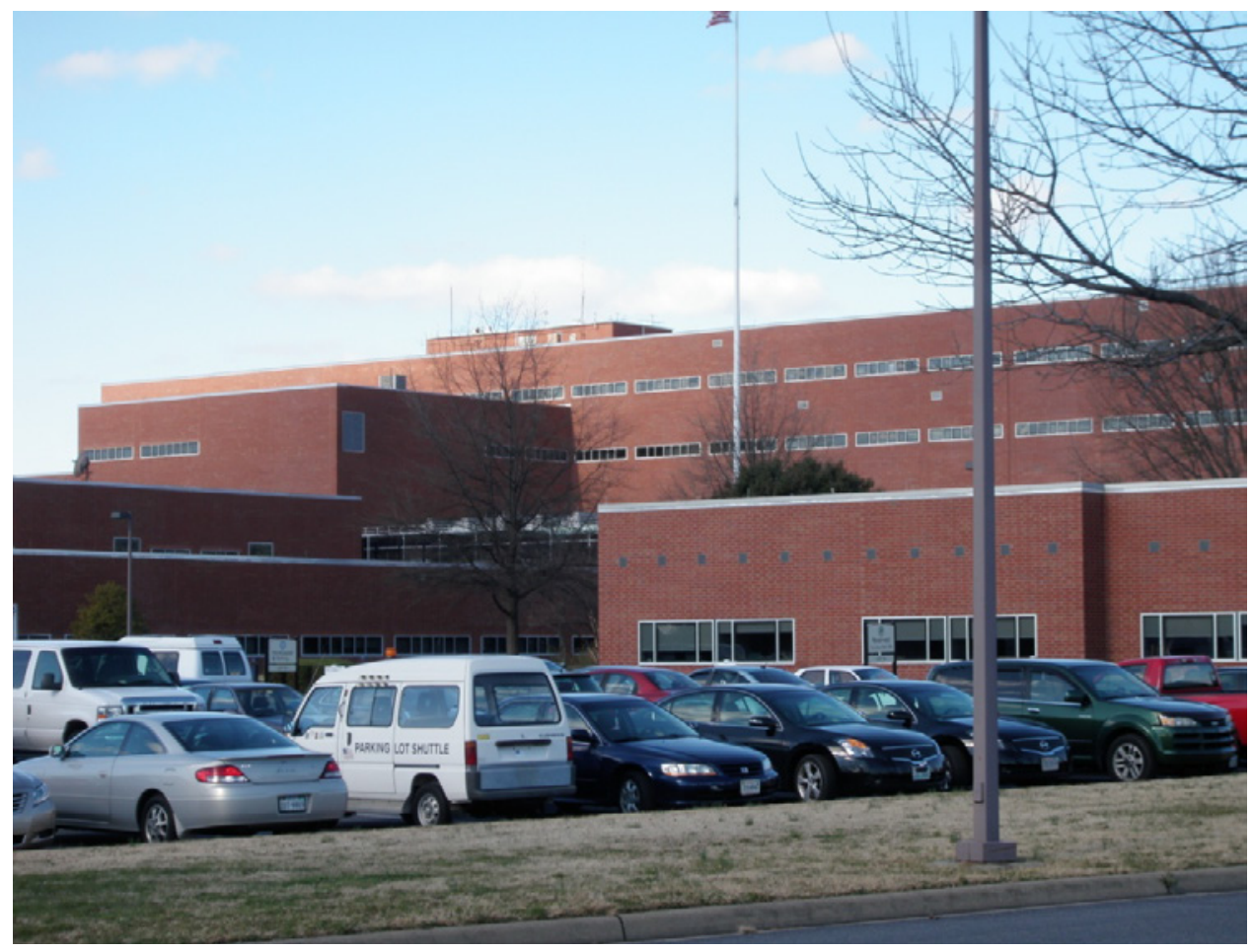

Figure 122. Photograph of Building 1, Richmond Veterans Affairs Medical Center, Virginia (U.S. Geological Survey photograph).

\section{Seismic-Hazard and Soil Conditions}

Geotechnical tests were conducted on site in 1977. The borehole data shows that the soil stratigraphy of the site consisted of clayey silt on top followed by dense coarse to fine sand with some gravel and silty clay matrix. Under that layer is coarse to medium sand and gravel with traces of clay. This layer is then followed by a loose to medium dense clayey fine sand and silt. Below this layer is a layer of stiff silty clay.

The building is located in an area of moderately low seismicity. The short-period spectral acceleration, $\mathrm{S}_{\mathrm{S}}$, using the current NEHRP recommended provisions for seismic regulations of new buildings and other structures, is $0.22 \mathrm{~g}$. The long-period spectral acceleration, $\mathrm{S}_{1}$, is $0.10 \mathrm{~g}$. 


\section{Instrumentation}

The building consists of several blocks separated by seismic joints. The two blocks in the middle have five stories, and other blocks rise up to the second-floor level. Therefore, a considerable number of accelerometers are deployed in the two middle blocks to capture overall response of the building during a possible earthquake. A total of 36 accelerometers (fig. 123 and fig. 124) are placed in the building. A triaxial accelerometer (channels 1 through 3 ) is placed on the basement slab level to measure the three components of the input ground motion. Three accelerometers (channels 4 through 6) are placed on basement-floor ceiling level to monitor firstfloor slab movement. Thirty accelerometers (channels 7 through 36) are evenly distributed on the ceilings of the first through the fifth floors to measure floor lateral motions and compute floor torsional motions. The floor relative displacements and inter-story drifts can be computed from accelerometers located at the same corner of the building along the same vertical axis.

The building accelerometers are complemented by a three-component seismic

accelerometer located at a free-field site (NSMP Station No. 7600), approximately 1,640 ft away from the building, to monitor ground shaking without interference from the earthquake response of the building. 
U.S. Department of Veterans Affairs

Richmond, VA - Steel Moment Frame, Five-Story Hospital Building

Building No: 500

NSMP Station No: 7600

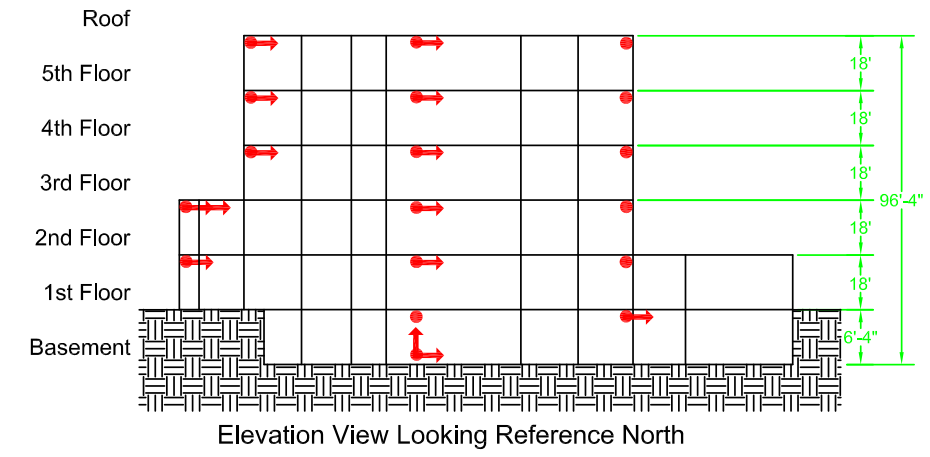

Elevation View Looking Reference North

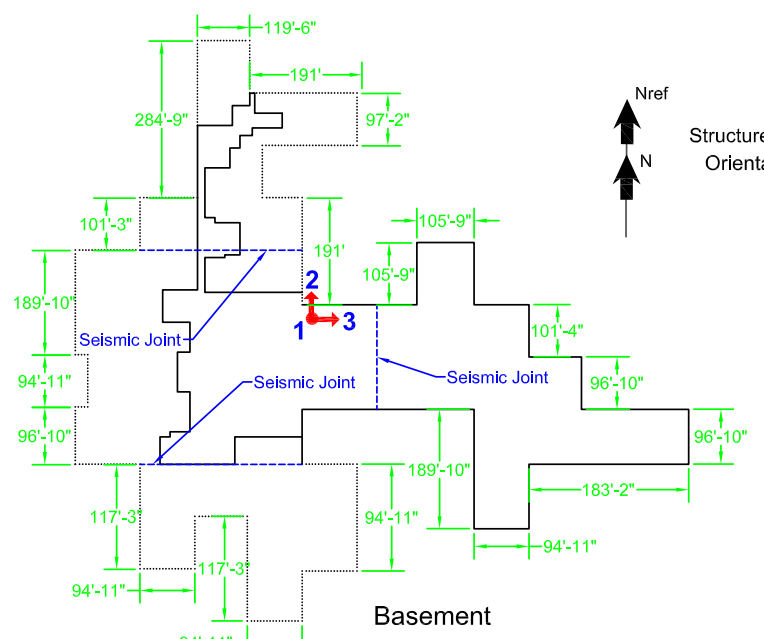

Revision Number: 3

Revised on 10/11/2012

Page 1 of 2

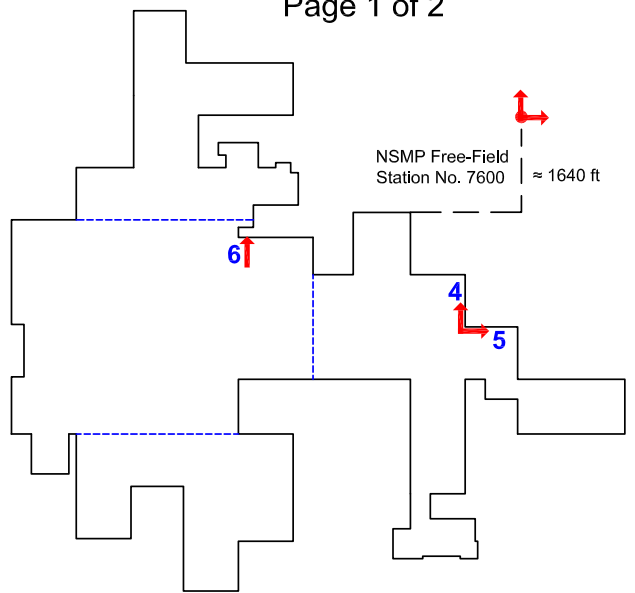

First Floor

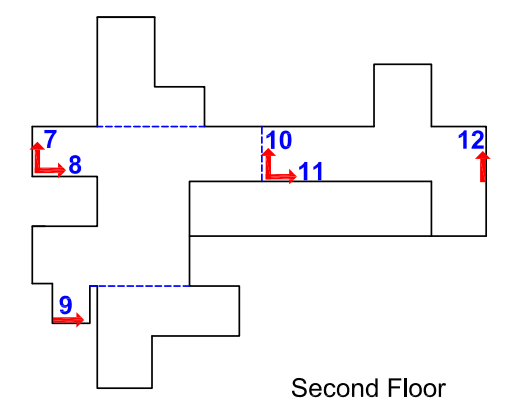

Department of

Veterans Affairs

SENSOR LOCATIONS

Figure 123. Diagram of the sensor layout showing 36 sensors in Building 500 of the Richmond Veterans Affairs Medical Center, Virginia (page 1 of 2; see also fig. 124). 
U.S. Department of Veterans Affairs

Richmond, VA - Steel Moment Frame, Five-Story Hospital Building

Building No: 500

NSMP Station No: 7600

Fourth Floor
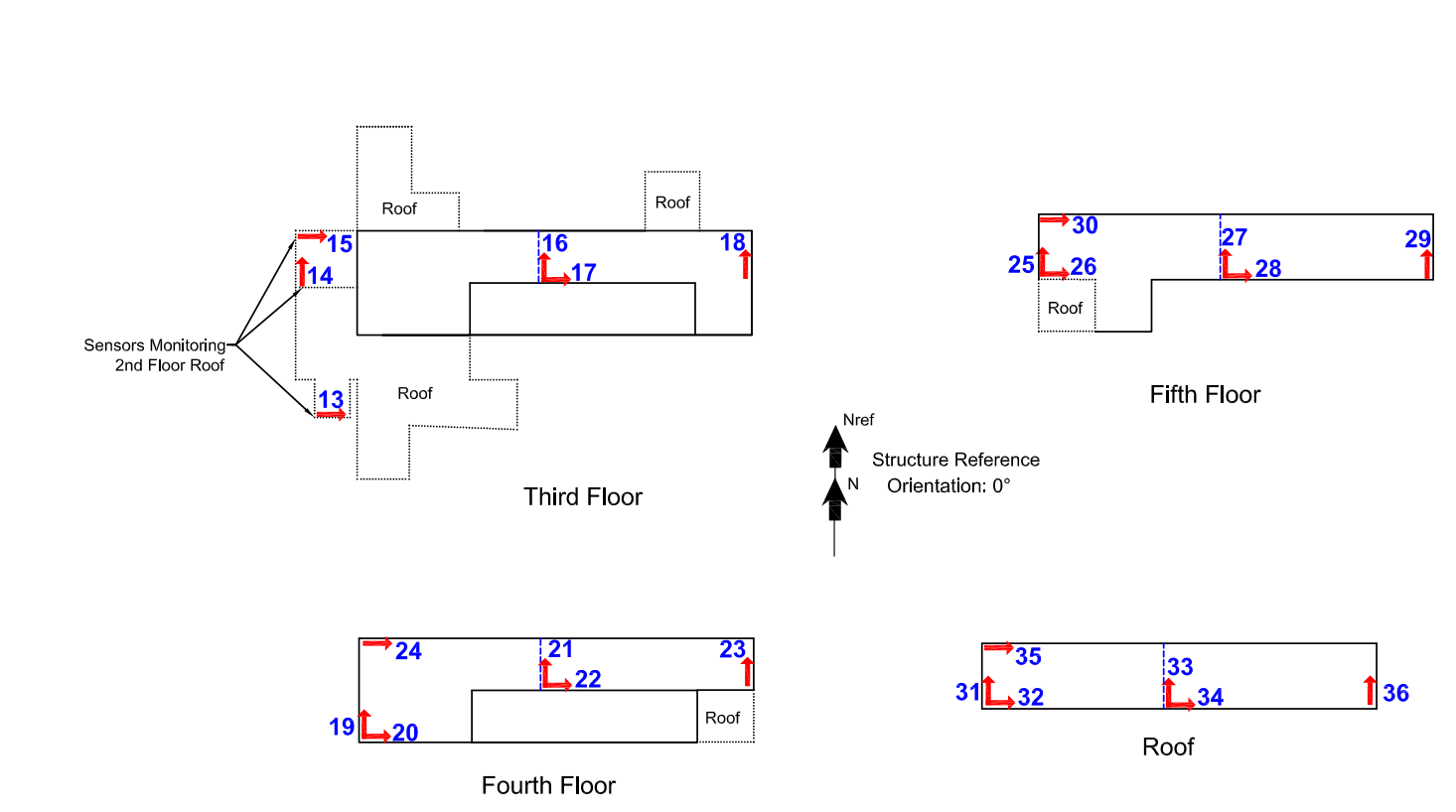

Revision Number: 3

Revised on $10 / 11 / 2012$

Page 2 of 2

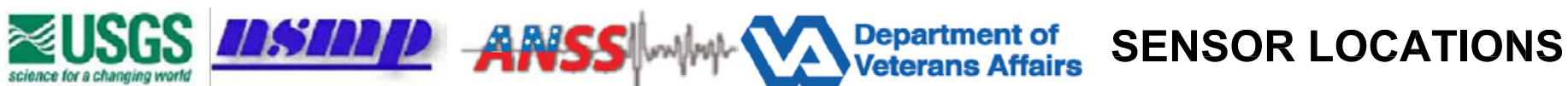

Figure 124. Diagram of the sensor layout showing 36 sensors in Building 500 of the Richmond Veterans Affairs Medical Center, Virginia (page 2 of 2; see also fig. 123). 


\section{NSMP Station 2129-Seattle, Washington: Main Hospital Diagnosis and Treatment Wing, Building No. 100}

\section{Building Description}

Building 100 is located at the VA Puget Sound Health Care System (http://www.pugetsound.va.gov/) in Seattle, Washington (fig. 125 and fig. 126). It was designed in 1980 using VA Handbook H-08-8, Earthquake Resistant Design Requirements for VA Hospital Facilities. Construction was completed in 1981, and later the structure was retrofitted. The building is a four-story structure with one basement level and an interstitial floor between each aboveground story. The total floor area of the building is approximately $250,000 \mathrm{ft}^{2}$. The gross area including interstitial floors is $665,319 \mathrm{ft}^{2}$.

The general building type is a combination of steel moment frames in the transverse direction and steel-braced frames in the longitudinal direction. The building is rectangular in plan with a stepped-back elevation, designed to accommodate a future expansion. The overall dimensions are 380 by $180 \mathrm{ft}$. Floor-to-floor heights are $18 \mathrm{ft}$, and floor-to-ceiling heights are approximately $10 \mathrm{ft}$. The building has adjacent buildings on three sides with a 3 inches seismic joint separating each adjacent building.

The gravity system consists of a 4.5 -inch concrete slab over a 2 -inch metal deck supported by W21 floor beams, W36 girders, and steel wide-flange columns. The interstitial floors are poured gypsum concrete decks suspended by steel hanger rods from the main floors above. It appears that the gypsum concrete floor is cast around the steel columns. The foundation system consists of spread footings and concrete basement walls with most interior columns supported on spread footings. The basement floor is a concrete slab on grade.

The building's lateral-force resisting system consists of 2 lines of steel-braced frames in the longitudinal direction and 11 lines of steel moment frames in the transverse direction. The main floor and roof diaphragms are a reinforced concrete-metal deck system with 3/4 inchdiameter shear-stud connectors on the steel floor beams.

The exterior curtain wall system is a metal panel system with glazing at each main floor level. The interior partitions are typically metal stud and drywall, and the ceiling consists of lightweight suspended acoustical tiles. 


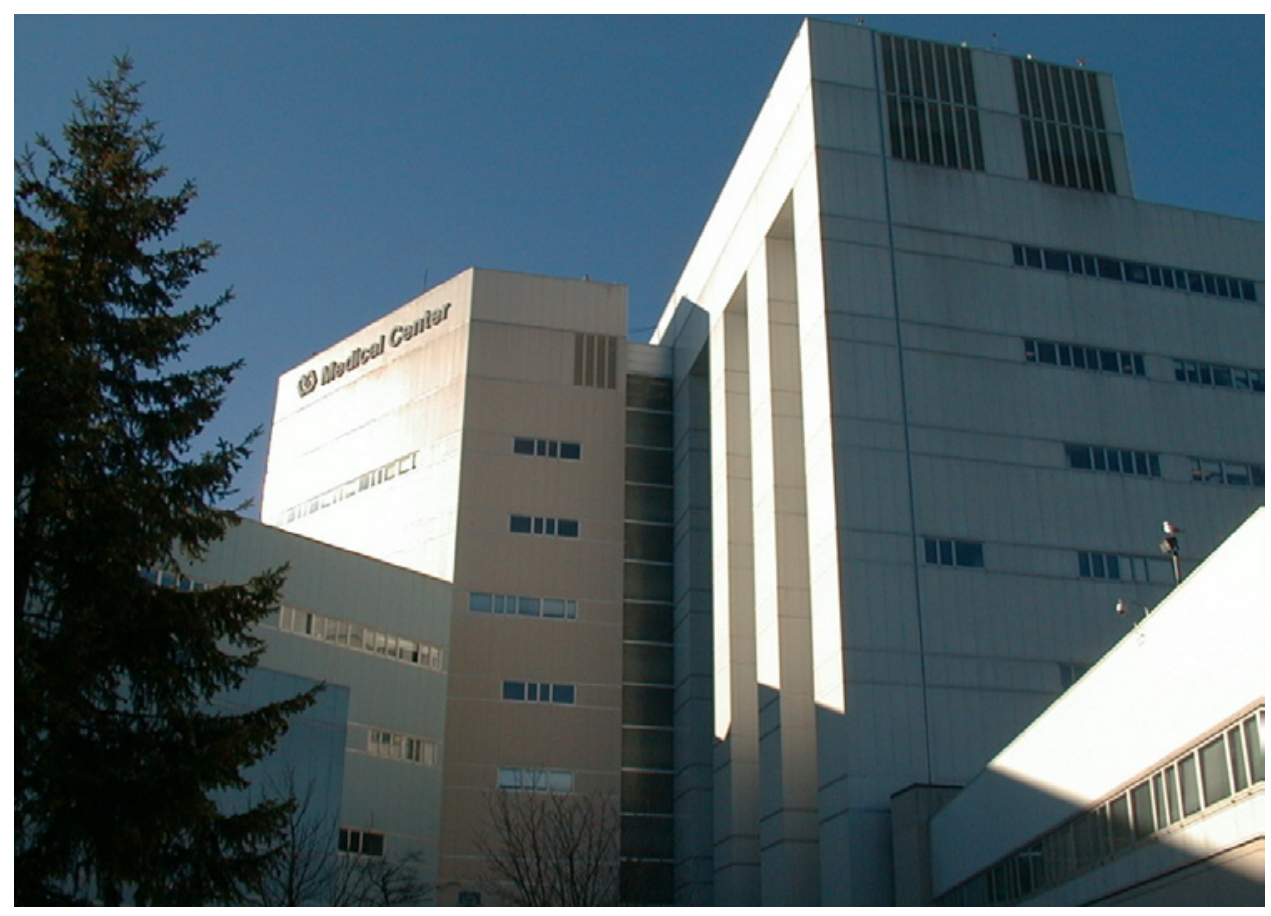

Figure 125. Photograph of Building 100, Seattle Veterans Affairs Medical Center, Washington (U.S. Geological Survey photograph).

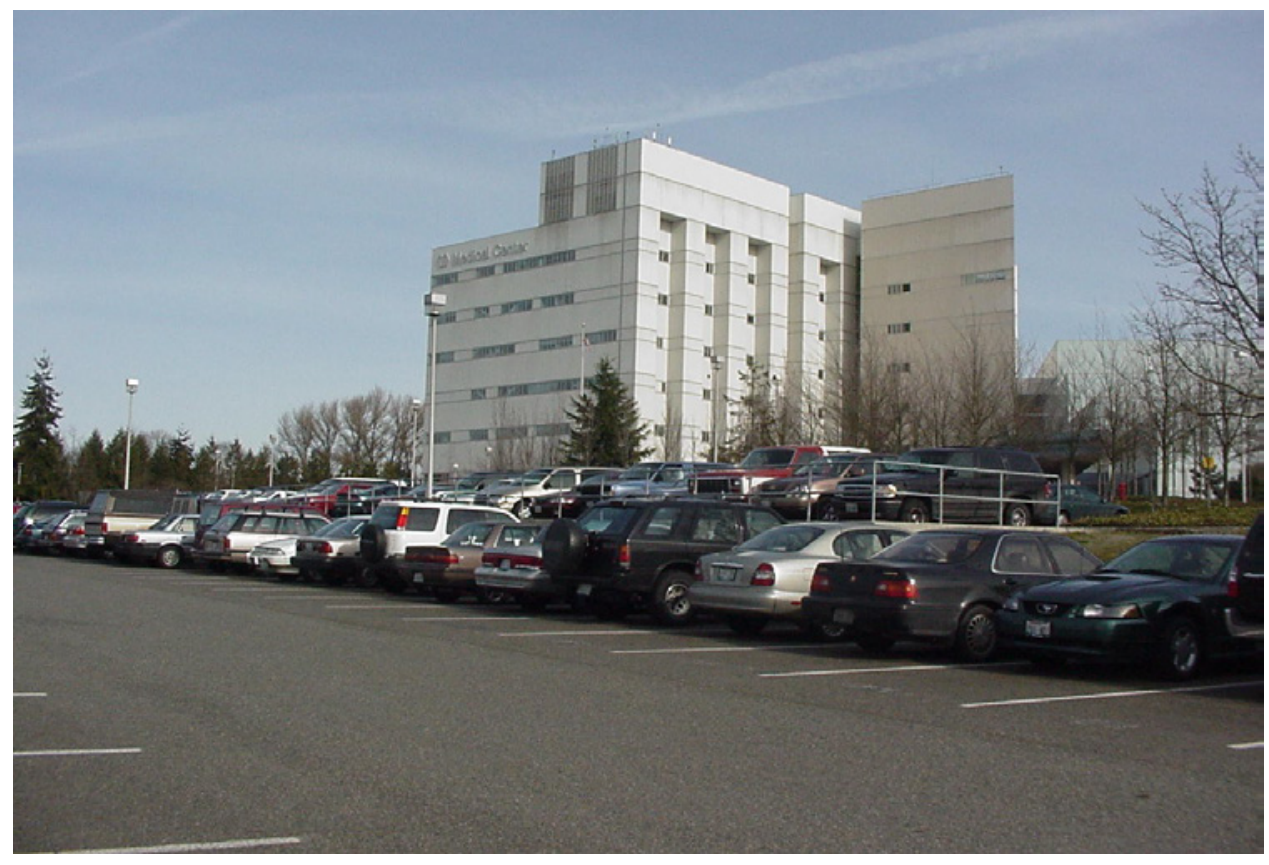

Figure 126. Photograph of Building 100, Seattle Veterans Affairs Medical Center, Washington (back side view) (U.S. Geological Survey photograph). 


\section{Seismic-Hazard and Soil Conditions}

The building is located on a relatively flat site with the ground floor at the level of the exterior grade. The soil conditions at the building site are not known.

The building is located in an area of very high seismic hazard. Using the 2003 NEHRP seismic maps, the short-period spectral acceleration, $\mathrm{S}_{\mathrm{S}}$, is $1.53 \mathrm{~g}$ and the long-period spectral acceleration, $\mathrm{S}_{1}$, is $0.53 \mathrm{~g}$.

\section{Instrumentation}

A total of 27 accelerometers are deployed at eight levels in the building (fig. 127). A triaxial accelerometer (channels 1 through 3 ) is placed on the basement to measure the three components of input ground motion. Twenty-one accelerometers (channels 7 through 27) are evenly distributed on the ceilings of the first through seventh floors to measure floor lateral motion in the reference east-west and north-south directions. Floor torsional motion can be obtained from likewise oriented accelerometers located on the same floor. The reference southwest corner of the building has two accelerometers oriented parallel to the building sides at each floor level. The relative floor displacements, thus inter-story drift, can be computed from the recordings of these accelerometers. The reference southeast corner of the building also has an accelerometer at each floor level. The relative floor displacements can be similarly computed at this corner of the building.

The building's accelerometers are complemented by a three-component seismic accelerometer located at a free-field site (NSMP Station No. 2130), approximately $330 \mathrm{ft}$ away from the building, to monitor ground shaking without interference from the earthquake response of the building. 
U.S. Department of Veterans Affairs

Seattle, WA - Steel Moment Frame, Seven-Story Hospital Building

Building No: 100

NSMP Station No: 2129

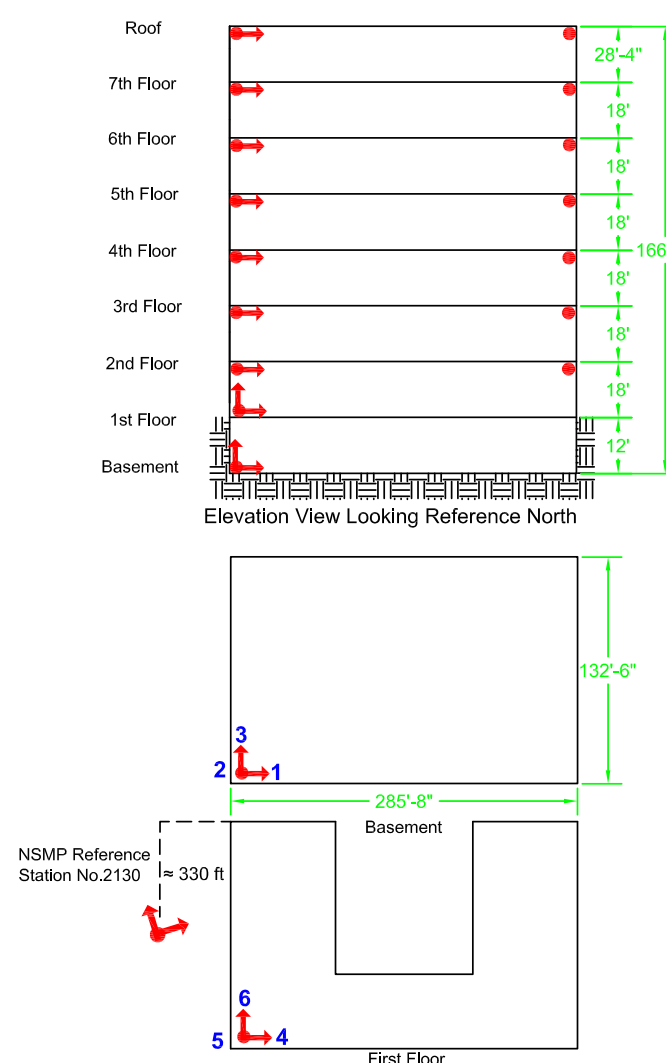

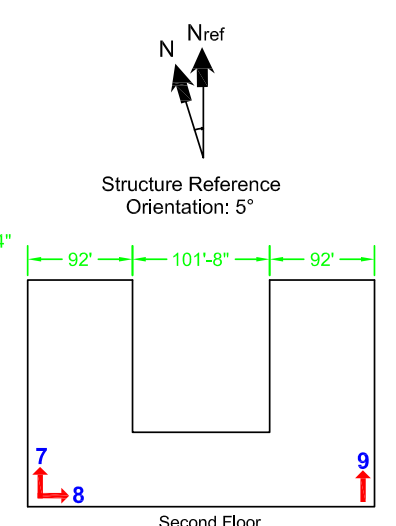
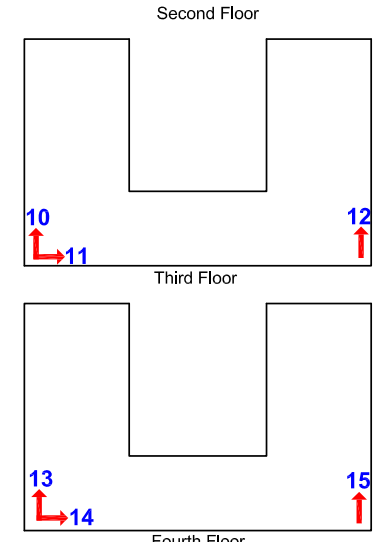

Revision Number: 8

Revised on 10/10/2012
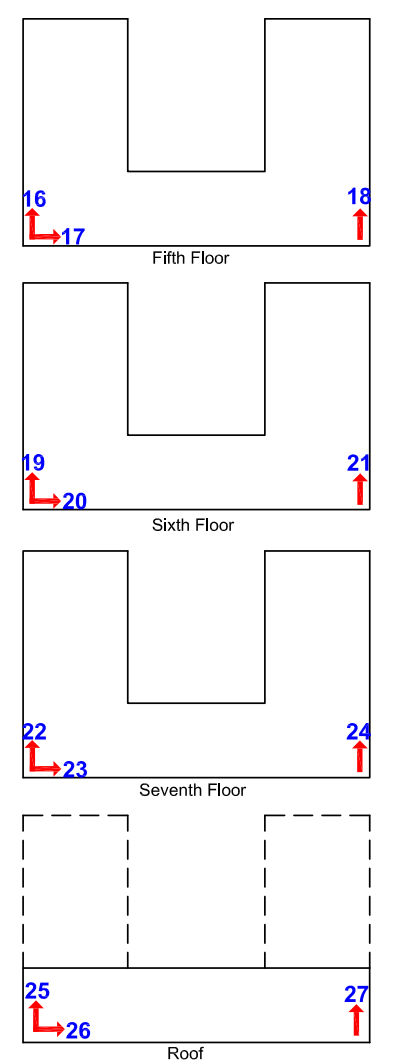

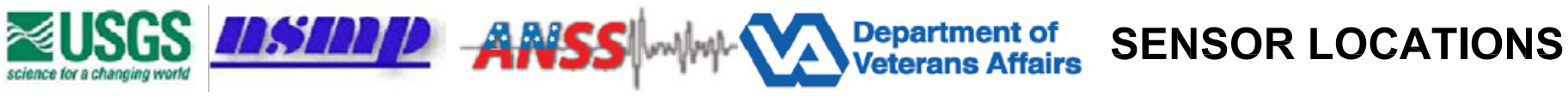

Figure 127. Diagram of sensor layout showing 27 sensors in Building 100 of the Seattle Veterans Affairs Medical Center, Washington. 


\section{NSMP Station 7061-Vancouver, Washington: Barnes Rehabilitation Building, Building No. 11}

\section{Building Description}

Building 11 at the Portland VA Medical Center (http://www.portland.va.gov/) in Vancouver, Washington, is a three-story steel braced frame structure that is approximately $133,263 \mathrm{ft}^{2}$ (fig. 128 through fig. 130). The building was initially designed in 1990 and has not been significantly modified since its conception. This building, serving as the main hospital building on the campus, consists of three wings that are separated by two seismic joints. Wing A has a somewhat rectangular floor plan with approximate dimensions of 125 by $145 \mathrm{ft}$. Wing A is located on the north side of the building. The two seismic joints that connect Wing B and Wing $\mathrm{C}$ to Wing A are located at the Wing's south side and at the northwest side. Wing B also carries a somewhat rectangular shape and has the approximate dimensions of 259 by $85 \mathrm{ft}$. Wing $\mathrm{C}$ is shaped like a Y. The dimensions of both the southwest and the northwest protrusions of Wing $\mathrm{C}$ are 120 by $69 \mathrm{ft}$ and $64 \mathrm{ft} 7$ inches by $149 \mathrm{ft} 4$ inches, respectively. These two protrusions are located a distance of $75 \mathrm{ft} 4$ inches away from the seismic joint southwest of Wing A. Wings B and $\mathrm{C}$ are only one story at $12 \mathrm{ft}$ high. Wing A goes up three stories; the first story is $10 \mathrm{ft} 10$ inches high, the second story is $11 \mathrm{ft} 2$ inches high, and the third story is $24 \mathrm{ft} 4$ inches high.

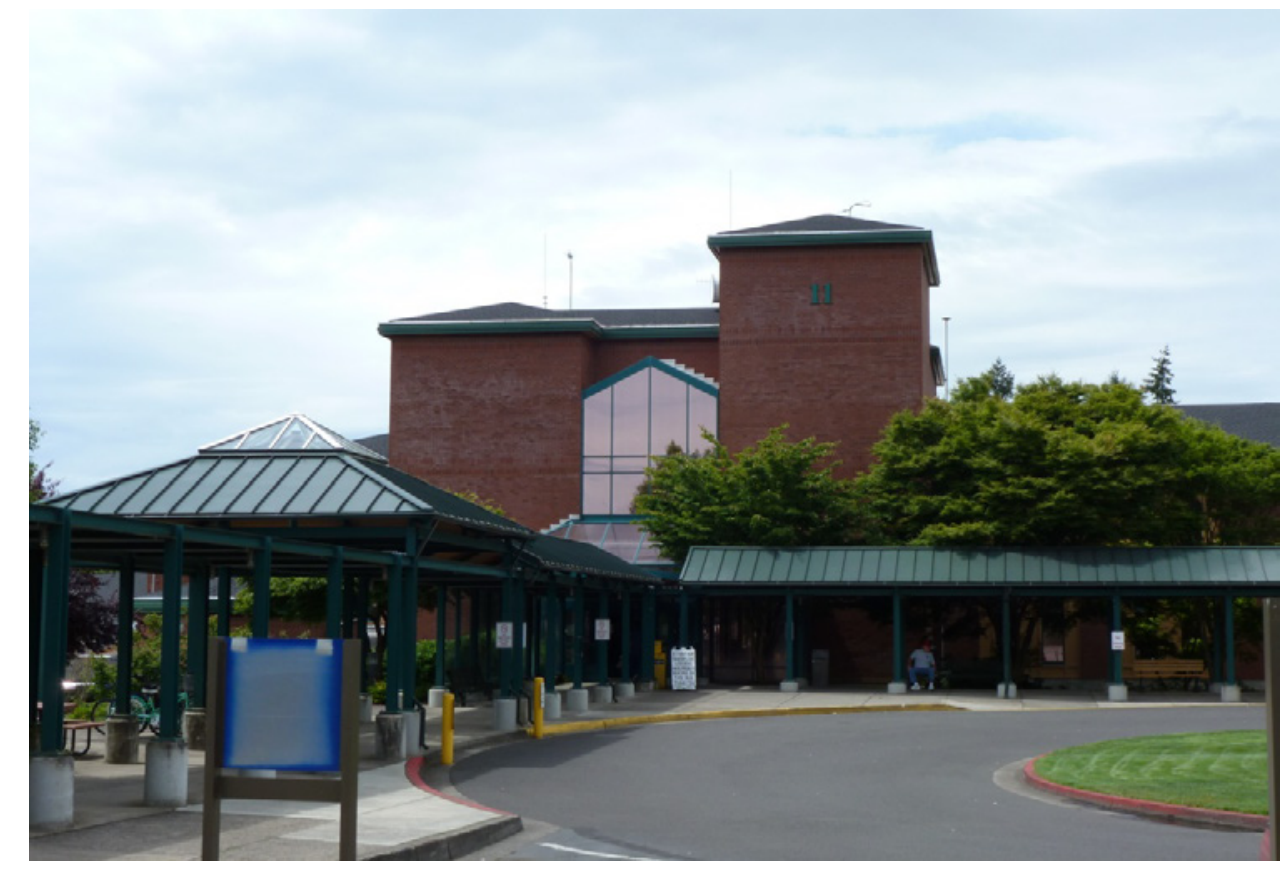

Figure 128. Photograph of Building 11, Vancouver Veterans Affairs Medical Center, Washington (entrance) (U.S. Geological Survey photograph). 


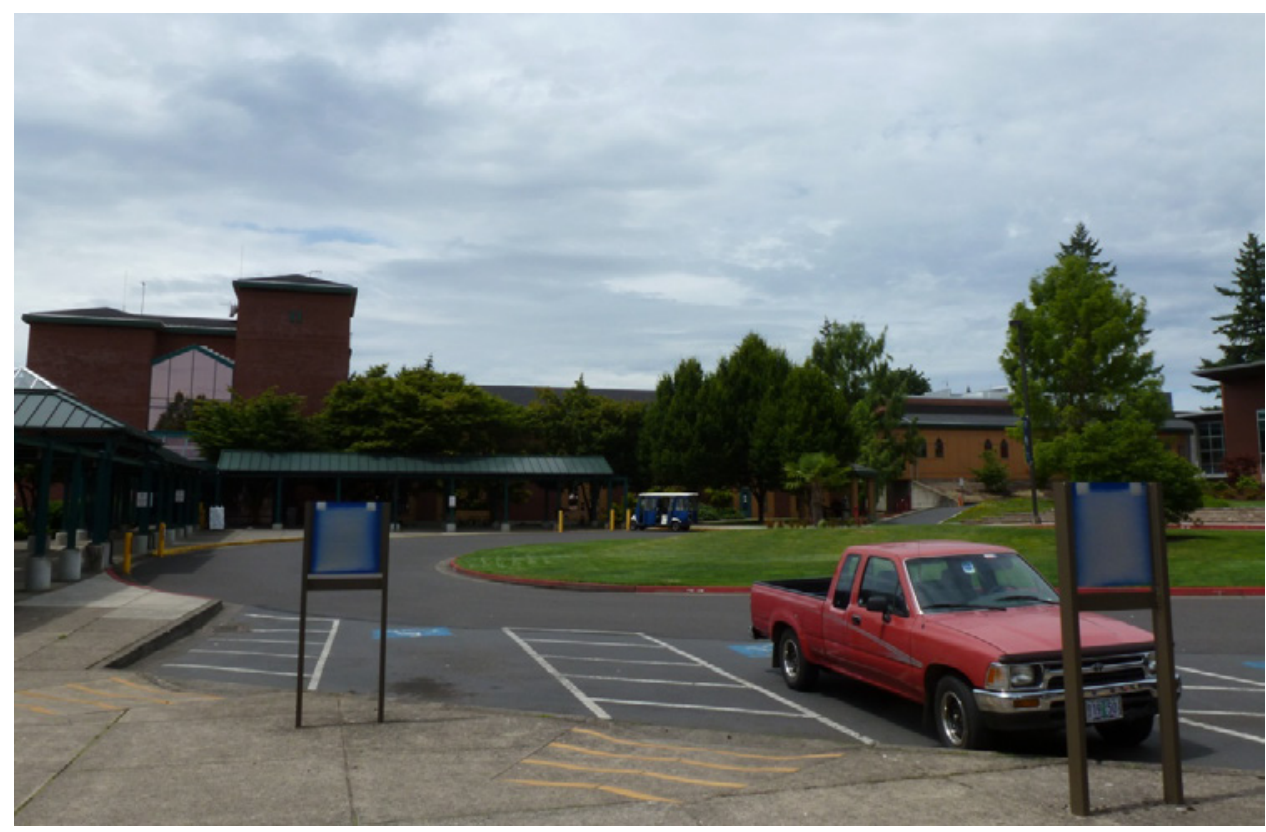

Figure 129. Photograph of Building 11, Vancouver Veterans Affairs Medical Center, Washington (looking west) (U.S. Geological Survey photograph).

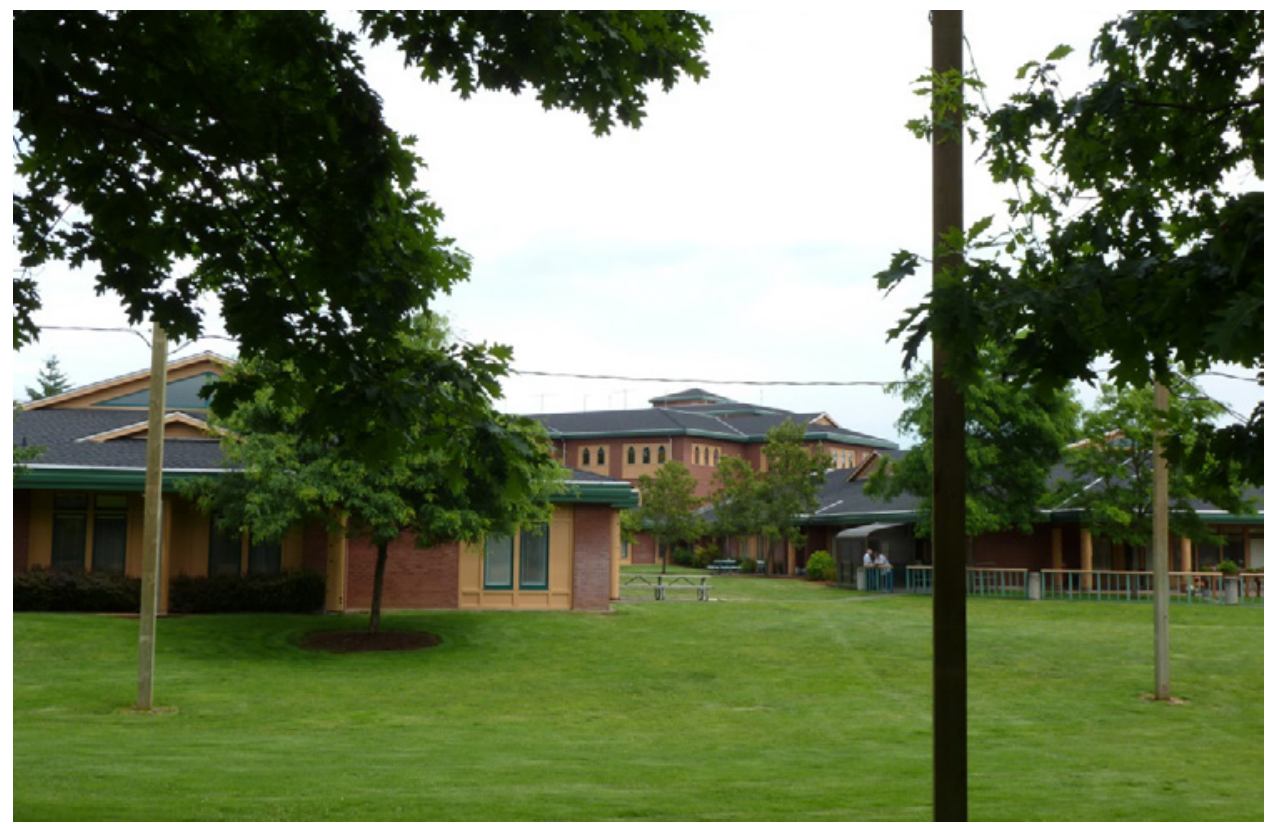

Figure 130. Photograph of Building 11, Vancouver Veterans Affairs Medical Center, Washington (looking east) (U.S. Geological Survey photograph).

This building's lateral- and vertical-force resisting systems consist of steel momentresisting frames. Typical roof and floor construction consists of reinforced concrete composite slabs. The foundation of this structure rests on isolated spread footings. 


\section{Seismic-Hazard Conditions}

The building is located in an area of high seismic hazard. The short-period spectral acceleration, $\mathrm{S}_{\mathrm{S}}$, using the current NEHRP recommended provisions for seismic regulations of new buildings and other structures, is $0.89 \mathrm{~g}$. The long-period spectral acceleration, $\mathrm{S}_{1}$, is $0.32 \mathrm{~g}$.

\section{Instrumentation}

Building 11 has an asymmetrical floor plan; therefore, some level of torsional response is expected to occur under strong ground shaking. To capture the building's earthquake response, and possible pounding during an earthquake by adjacent wings, which are separated by seismic joints, 24 accelerometers are distributed strategically between the three-story main building and two adjacent single-story wood-frame wings (fig. 131). At the first-floor level of the main building, a triaxial accelerometer (channels 1 through 3) is to record base-level input ground shaking in two horizontal and one vertical direction. Each floor of Wing A, B, and C has at least three accelerometers; therefore, the floor lateral and torsional motion can be obtained.

The building's accelerometers are complemented by a three-component seismic accelerometer located at a free-field site (NSMP Station No. 7062), approximately $330 \mathrm{ft}$ away from the building, to monitor ground shaking without interference from the earthquake response of the building. 
U.S. Department of Veterans Affairs

Vancouver, WA - Steel Moment Frame, Three-Story Hospital Building

Building No: 11

NSMP Station No: 7061
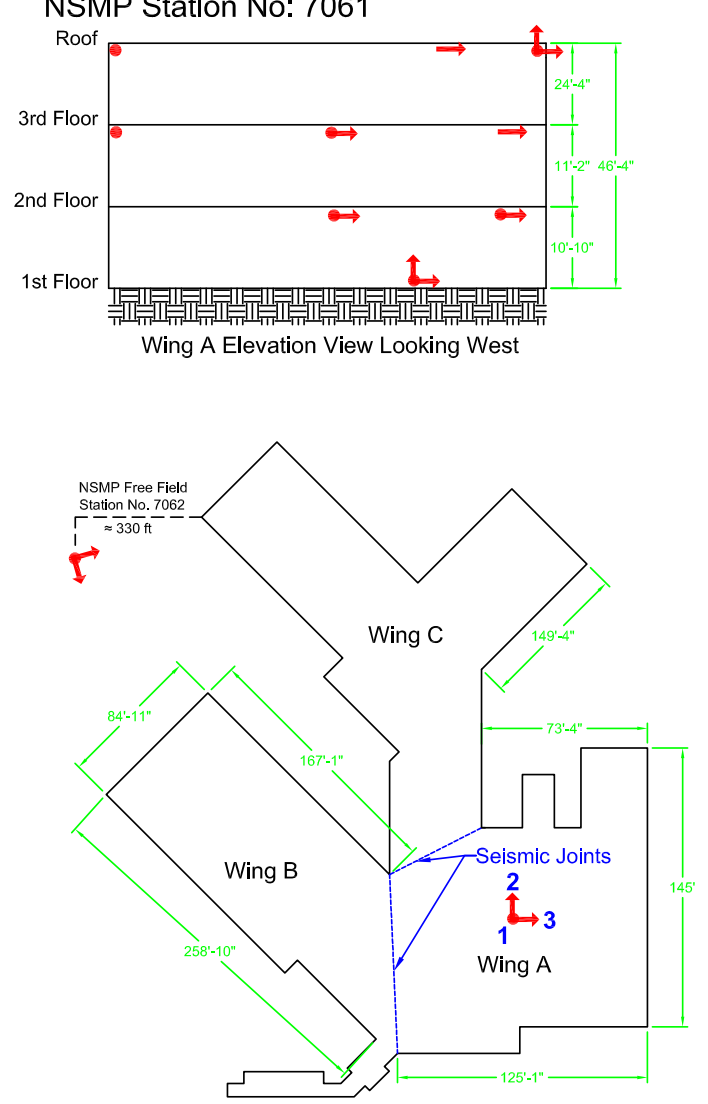

First Floor

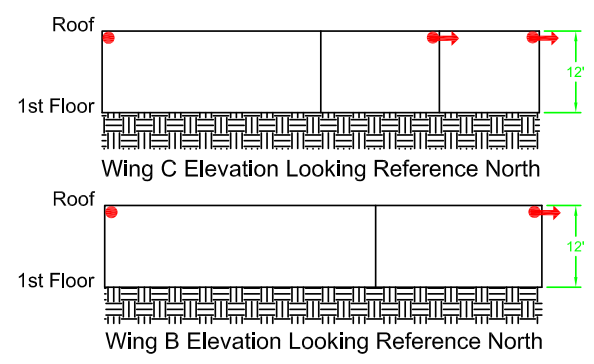

Revision Number: 10

Revised on 10/11/2012

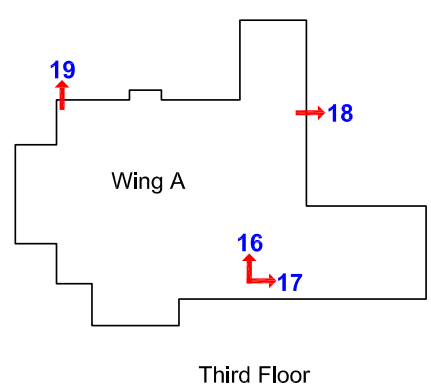

Structure Reference Orientation: $335^{\circ}$

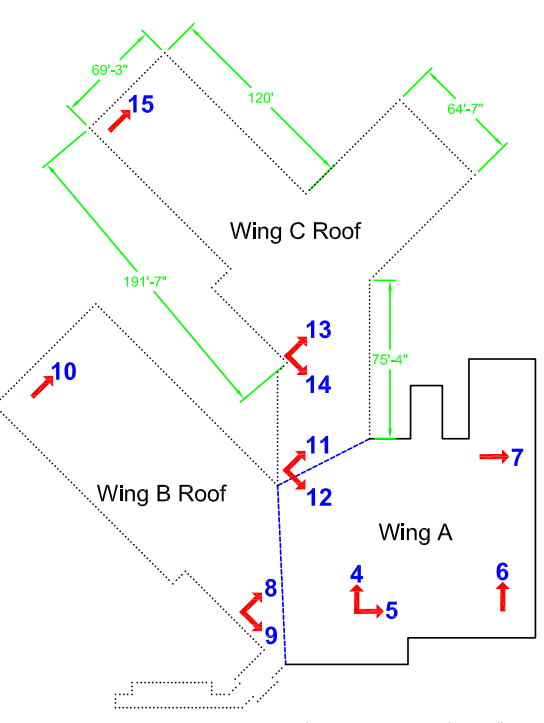

Second Floor (Roof)

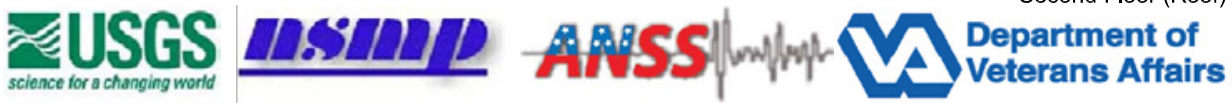

SENSOR LOCATIONS

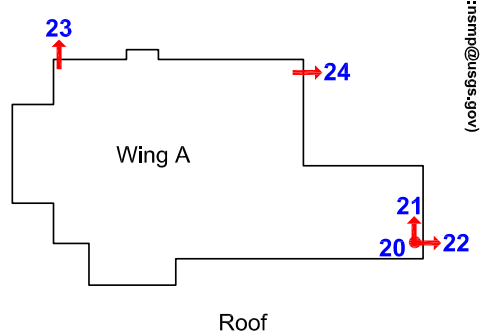

Figure 131. Diagram of sensor layout showing 24 sensors in Building 11 of the Vancouver Veterans Affairs Medical Center, Washington. 


\section{Acknowledgments}

We would like to thank USGS National Strong Motion Project staff, including James Smith, Arnie Acosta, Edna Anjal, Jonah Merrit, Walt Junglut, and Kent Fogleman, for their dedication and efforts at every step of the project. We also wish to thank James Blair for preparing the layout map, Scott Haefner for developing the project Website, Chris Stephens, Keith Knudsen, and Brad Aagard for reviewing this report and providing their constructive comments and suggestions. Finally, sincere thanks are extended to the VA engineering staff for their continuous support. Funding for this project was provided by the U.S. Department of Veterans Affairs.

\section{References Cited}

Boore, D.M., Joyner, W.B., and Fumal, T.E., 1997, Equations for estimating horizontal response spectra and peak acceleration from western North American earthquakes-A summary of recent work: Seismological Research Letters, v. 68, p. 128-153.

Kalkan, E., Fletcher, J.P.B., Leith, W.S., McCarthy, J., and Krishna, B., 2012a, Real-time seismic monitoring of instrumented hospital buildings: U.S. Geological Survey Fact Sheet 2012-3028, 2 p., available at http://pubs.usgs.gov/fs/2012/3028/.

Kalkan, E., Banga, K., Ulusoy, H.S., Fletcher, J.P.B., Leith, W.S., and Blair, J.L., 2012b, Helping safeguard Veterans Affairs' hospital buildings by advanced earthquake monitoring: U.S. Geological Survey Fact Sheet 2012-3094, 2 p. available at http://pubs.usgs.gov/fs/2012/3094/.

Ulusoy, H., Kalkan E., Fletcher, J.P.B., Leith, W.K. and Banga, K., 2012, Design and implementation of a structural health monitoring and alerting system for hospital buildings in the United States: Proceedings of the 15th World Conference on Earthquake Engineering, , Lisbon, Portugal, September 24-28, 2012, paper no. 4474. 


\section{Appendix A: Hardware for Earthquake Monitoring}

The following hardware is used for instrumenting hospital buildings. The details of each component are provided in the subsequent sections.

- Motion sensors

- Digital recorder with internal batteries and charger

- Cables (data, Global Positioning System (GPS), and telemetry)

- GPS antenna

- Cellular modem antenna (if needed)

\section{Motion Sensors}

The typical motion sensor used in free-field stations is a triaxial force-balance accelerometer (FBA); the same sensor is also used in medical buildings together with its uniaxial version (fig. 132). FBAs used are designed for measuring accelerations as large as $\pm 4 g$ and as low as the ambient noise level from $1 \mathrm{~Hz}$ to $200 \mathrm{~Hz}$. No micro-electro-mechanical-systems (MEMS)-based sensors were used because their noise level is currently too high for structuralhealth monitoring applications in hospitals.

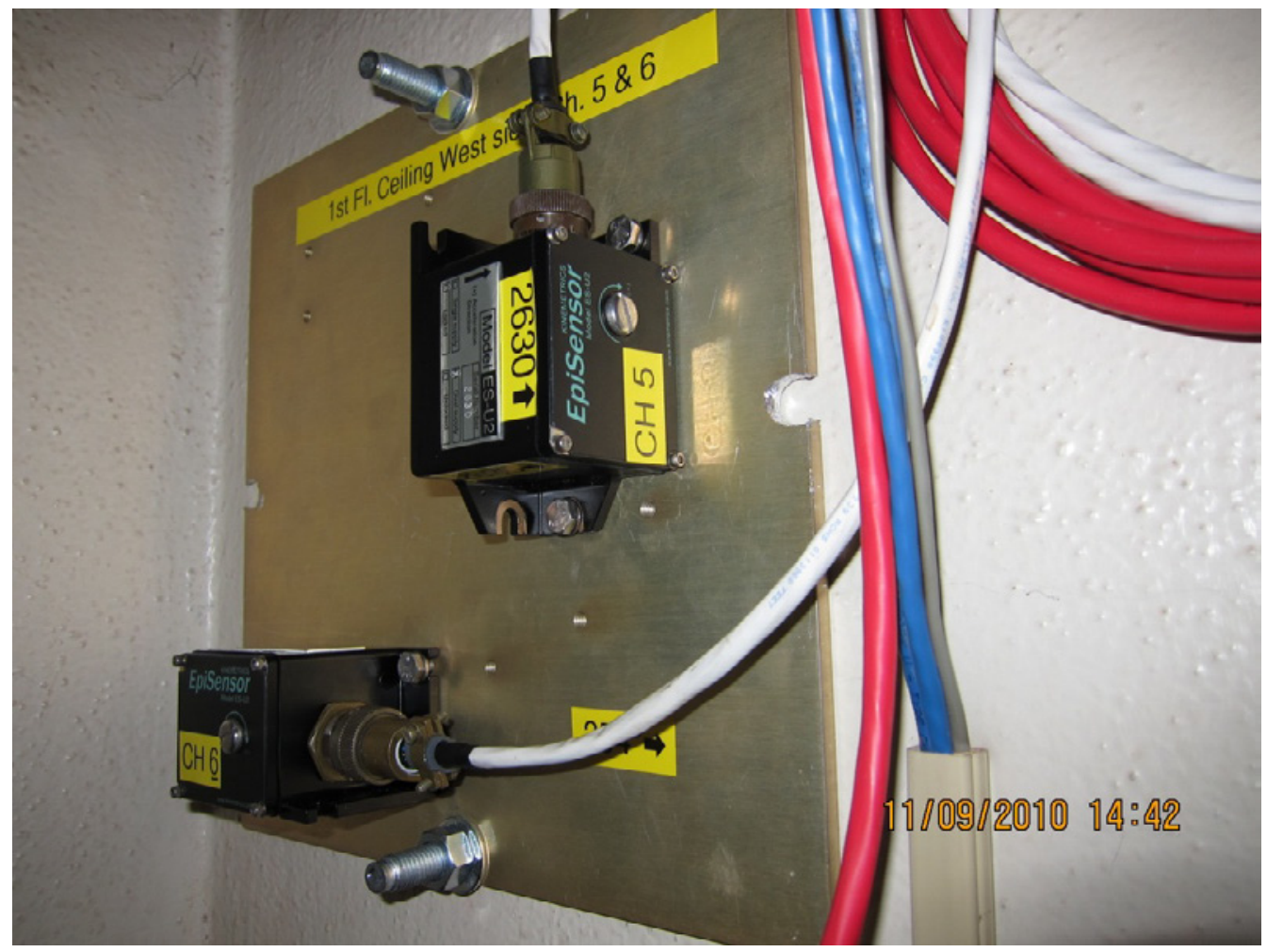

Figure 132. Photograph of uniaxial force-balance accelerometers installed on a mounting plate (U.S. Geological Survey photograph).

\section{Recorders}

To record accelerations measured by sensors, Internet Protocol (IP)-based 24-bit multichannel digital recorders (digitizers) are used (fig. 133). These recorders have high dynamic range on as many as 36 channels offering multiple real-time data streams. They also allow for 
remote access through a Web browser to change operational parameters, change recording and telemetry modes and formats, and to view or retrieve recorded files. Sampling rate in all recorders is set to 200 samples per second (sps). Recorders have internal batteries for back up power and use the Internet for telemetry.

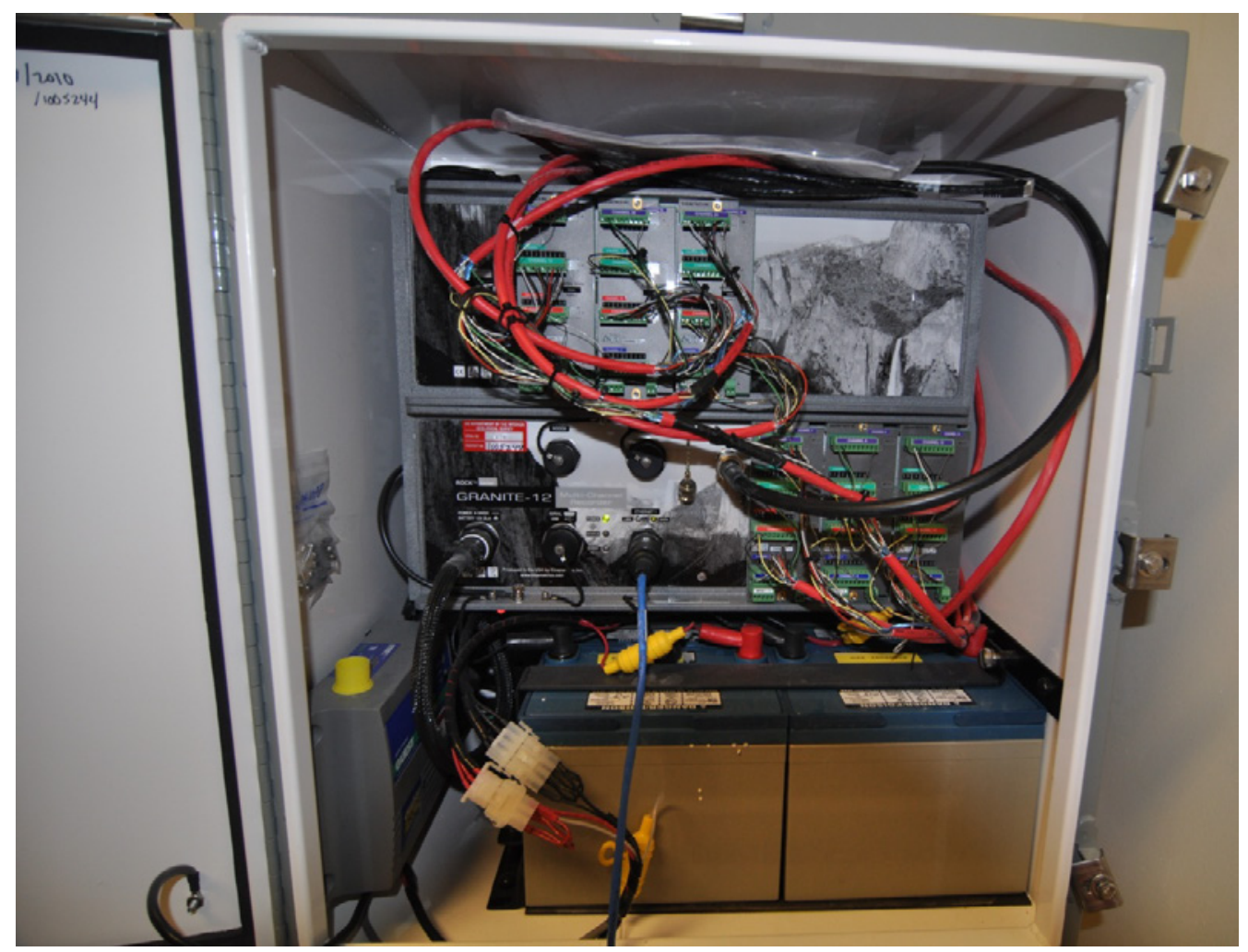

Figure 133. Photograph of 24-bit digital Internet Protocol (IP)-based recorder with batteries and charger installed within a National Electrical Manufacturers Association (NEMA) cabinet (U.S. Geological Survey photograph).

Within medical buildings, recorders are generally located at a level close to the roof or a outside wall for the shortest possible run to facilitate the installation of the GPS antenna for absolute timing for records (fig. 134). 


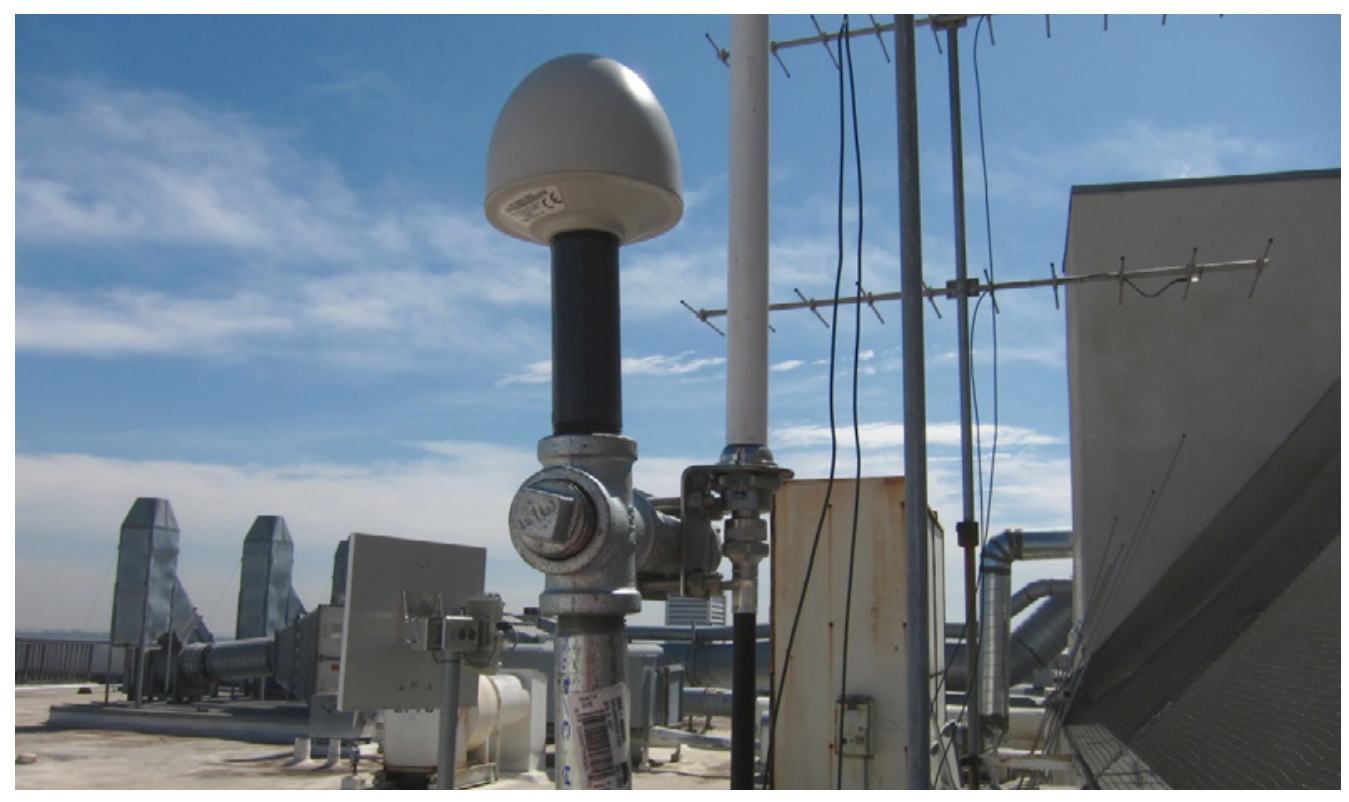

Figure 134. Photograph of Global Positioning System (GPS) antenna installed at the roof level of a medical building for absolute timing (U.S. Geological Survey photograph).

\section{Cables}

Custom made USGS cable is used to connect sensors to central recorders. This cable has four pairs of 22 AWG (American wire gauge) stranded $(7 \times 30)$ and tinned copper wires. Each pair of wires is individually shielded (fig. 135). In addition to the four pairs, there are three individual $20 \mathrm{AWG}$ stranded conductors $(7 \times 28)$, which are non-shielded tinned copper. The outer cable jacket is plenum rated and has an overall foil shield with a 20 AWG stranded drain wire. The outside jacket of the cable is red in color and has the following printed in addition to the standard National Electrical Code (NEC) plenum cable nomenclature, "(CAUTION! USGS Seismic monitoring cable, DO NOT CUT!)." Cable is manufactured as a spool of 1,000 ft, which is enough to connect a single sensor without splicing. No cable splicing is used in installations. Also for GPS antennas, low-loss coaxial communications cable (LMR 400) is used. 

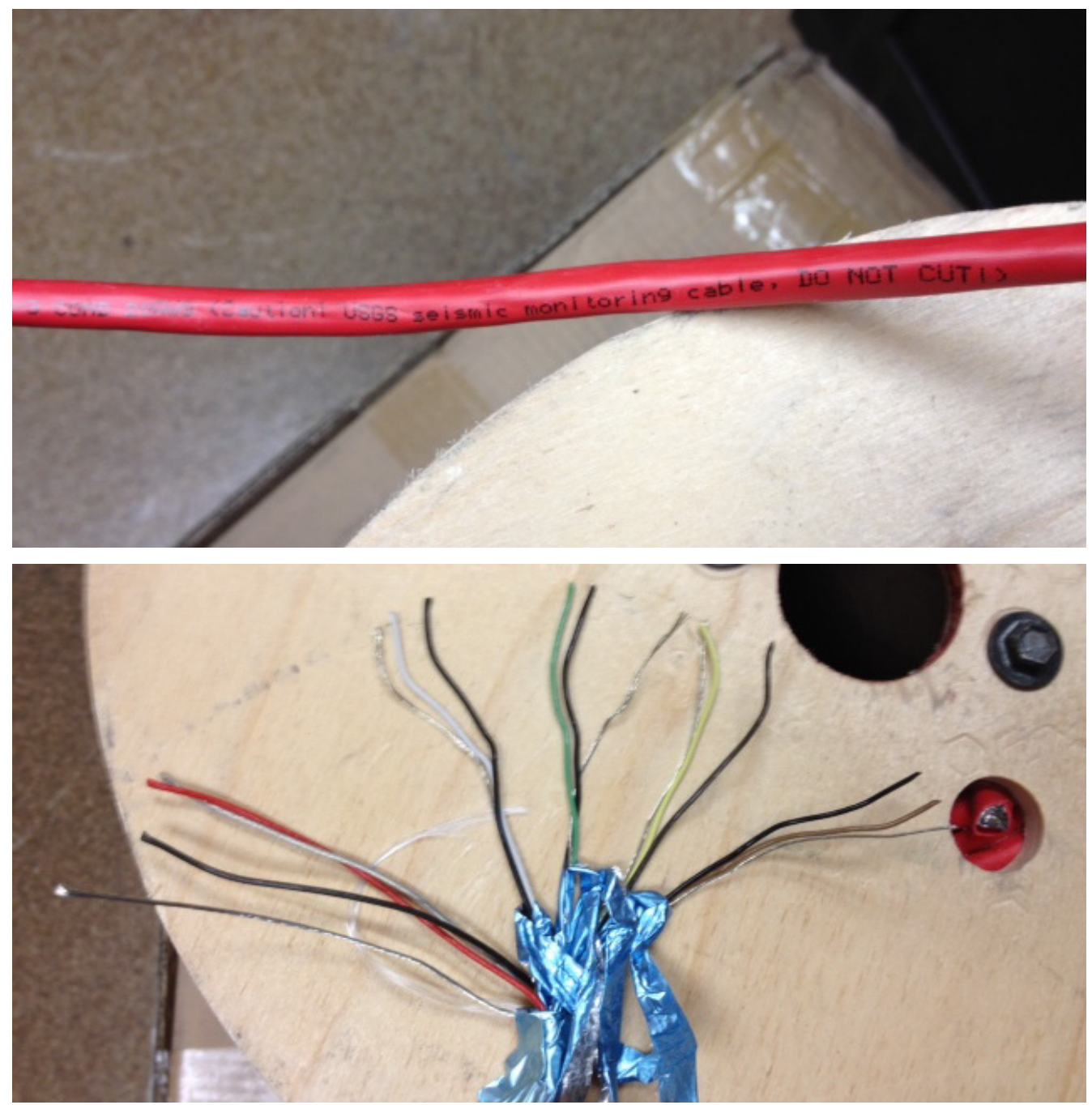

Figure 135. Photographs of custom-made U.S. Geological Survey (USGS) cable used for connecting accelerometers to recorders. Top, red-jacketed cable printed with the words "(CAUTION! USGS Seismic monitoring cable, DO NOT CUT!)." Bottom, cable with jacket removed showing four pairs of individually shielded 22 AWG (American wire gauge) stranded $(7 \times 30)$ and tinned copper wires, as well as three individual 20 AWG stranded conductors (7×28) that are non-shielded tinned copper (U.S. Geological Survey photograph).

\section{Appendix B: Free-Field and Reference Stations}

VA medical buildings have a dedicated free-field station (fig. 136) or a reference station, where a triaxial accelerometer and a recorder are installed to measure ground motion away from the structures. The reference station is a single story light-weight structure as shown in figure 137. Free-field stations use a "T-hut" mounted on a concrete foundation, details of which are shown in figure 138. 


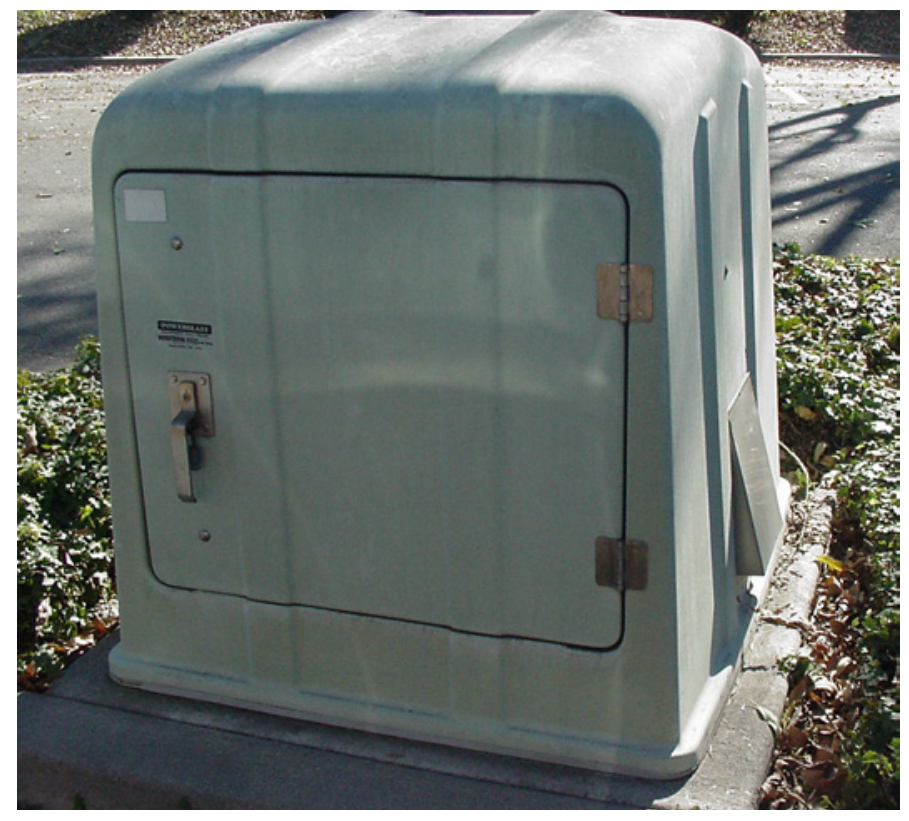

Figure 136. Photograph of a typical free-field station where a triaxial accelerometer and a recorder are installed to measure ground motion at Veterans Affairs medical centers away from structures that are being seismically monitored (U.S. Geological Survey photograph).

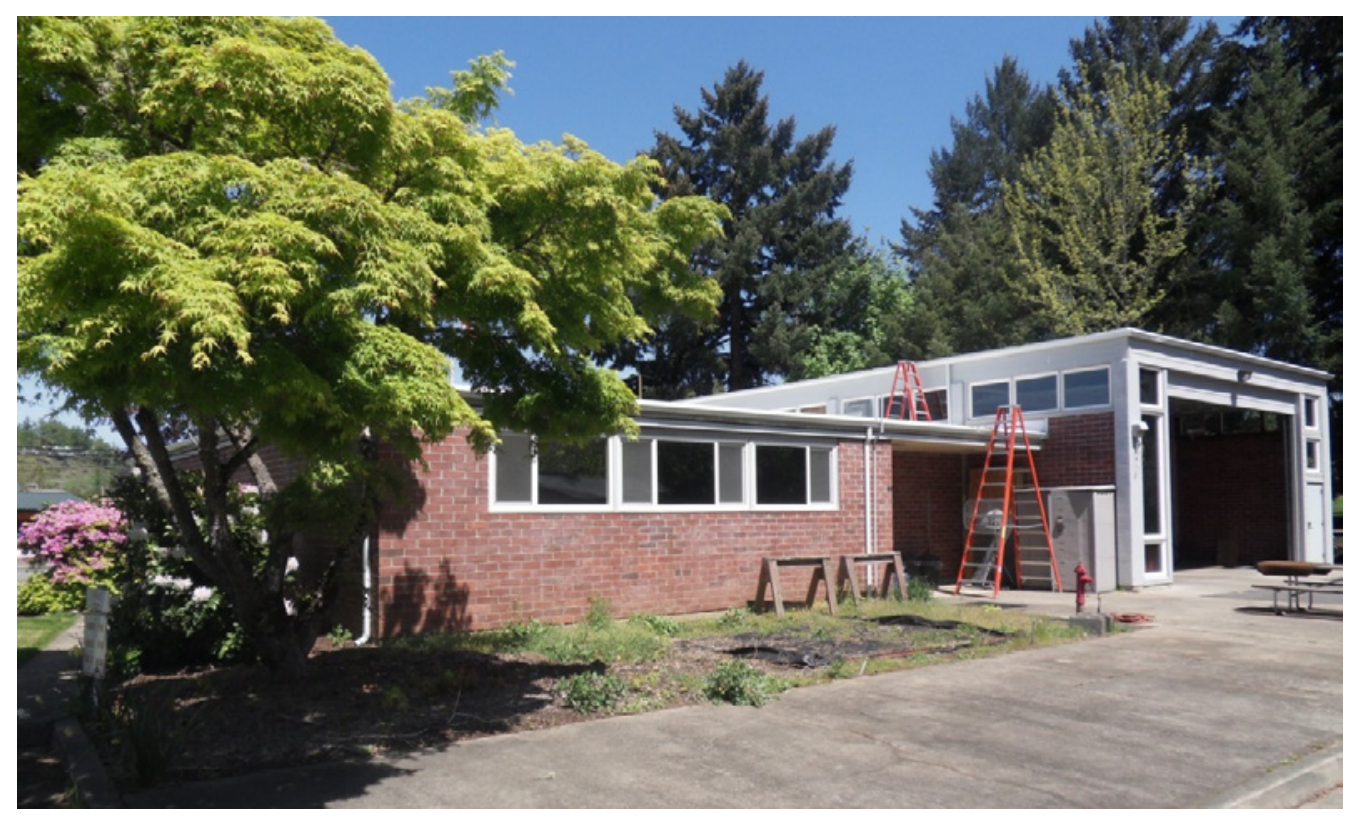

Figure 137. Photograph of a typical reference station where a triaxial accelerometer and a recorder are installed to measure ground motion at Veterans Affairs medical centers away from structures that are being seismically monitored (U.S. Geological Survey photograph). 
Foundation Design for Strong Motion Free-Field Station

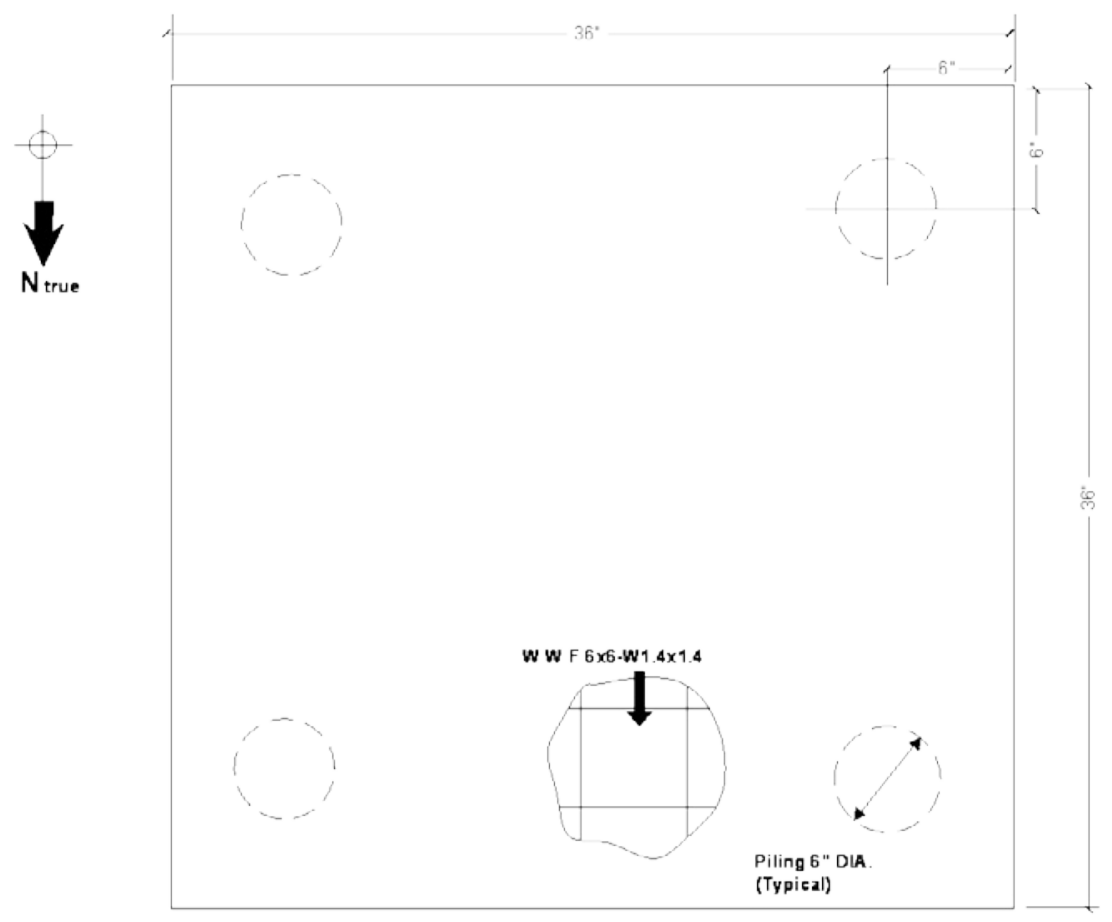

PLAN

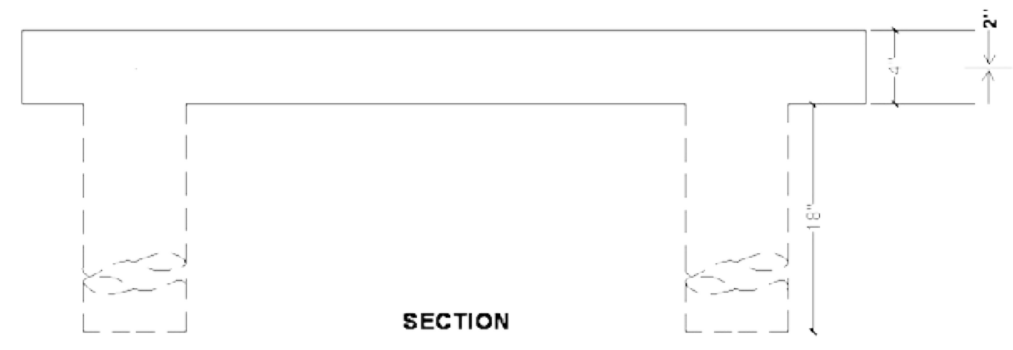

EUSGS MSSIIII)

Rev. 2/13/2012

\section{CONSTRUCTION NOTES:}

1 Approxirnately $1 / 2$ cubic yard of concrete is required for the siat

2 Concrete is six (6) sock mix, $3 / 4$ inch maximurn aggregatio

3 Wre mesh is 6" $\times 6^{\prime \prime}$ W $14 \times$ W 4 (10 gauge wire

4. All rebar is halt $(1 / 2)$ inch \{number 4 \}

5 Corner plings extend anproximately helow the slah and are 6 inches in

diameter (these are typically made with a post hole digqer)

6. Wre mesh and rebar are secured with wire ties

7. Slab to be level and concrete should be troweled to a smooth finish.

Figure 138. Foundation details for free-field ground-motion recording stations. 